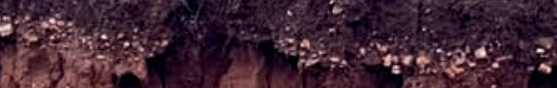

\title{
Providing support in relation to the implementation of soil and land related Sustainable Development Goals at EU level
}

Final report

Keesstra, S.D., Muro, M., Maring, L., Arellano Jaimerena, B., van Eupen, M., Elbersen, B., McNeill, A., Tugran, T.,

Markowska, A. 



\section{Providing support in relation to the implementation of soil and land related Sustainable Development Goals at EU level}

Final report

Keesstra, S.D., Muro, M., Maring, L., Arellano Jaimerena, B., van Eupen, M., Elbersen, B., McNeill, A., Tugran, T., Markowska, A.

The project was funded by the European Commission, DG Environment.

Service contract No - 07.0202/2018/792008/SER/ENV.D. 1

Wageningen Environmental Research

Wageningen, September 2020

Reviewed by:

dr. ir. M.J.D. (Mirjam) Hack-ten Broeke

Team leader Soil, Water and Land Use Team

Approved for publication:

dr. ir. M.J.D. (Mirjam) Hack-ten Broeke

Team leader Soil, Water and Land Use Team

Report 3032

ISSN 1566-7197 
Keesstra, S.D., Muro, M., Maring, L., Arellano Jaimerena, B., van Eupen, M., Elbersen, B., McNeill, A., Tugran, T., Markowska, A., 2020. Providing support in relation to the implementation of soil and land related Sustainable Development Goals at EU level; Final report. Wageningen, Wageningen Environmental Research, Report 3032. 196 pp.; 10 fig.; 13 tab.; 121 ref.

Increasing land take, soil sealing and loss of ecosystem functions due to soil and land degradation have been recognised as major environmental and socioeconomic challenges, both in the EU and worldwide. In 2015, the UN put forward the 2030 Agenda, with 17 interdependent Sustainable Development Goals (SDGs). Many of the SDGs reflect challenges related to land and soil. This report comprises of a review of the state of affairs in the EU related to the implementation of the land and soil related SDGs. Literature reviews, policy mapping, EU wide soil data analysis, combined with national surveys and targeted interviews were carried out. A set of recommendations for related to the way forward to more effective implementation and widespread uptake of sustainable land and soil management addressed to the following four stakeholder groups are given: (i) practitioners and endusers; (ii) scientist; (iii) policymakers and (iv) citizens.

Toenemend ruimtebeslag, bodemafdekking en verlies van ecosysteemfuncties als gevolg van bodemen landdegradatie worden zowel in de EU als wereldwijd gezien als grote ecologische en sociaaleconomische uitdagingen. In 2015 hebben de VN de Agenda 2030 voorgesteld, met 17 samenhangende duurzame ontwikkelingsdoelstellingen (SDG's). Veel van de SDG's hebben een relatie met opgaves die verband houden met land en bodem. Dit rapport bevat een overzicht van de stand van zaken in de EU met betrekking tot de implementatie van de land- en bodemgerelateerde SDG's. Dit overzicht werd tot stand gebracht door literatuuronderzoek, een beleidsanalyse, analyse van bodemgegevens in de hele EU, gecombineerd met nationale enquêtes en gerichte interviews. Er wordt een reeks aanbevelingen gedaan gericht op vier doelgroepen om de implementatie en acceptatie van duurzaam land- en bodembeheer in de EU te bevorderen: (i) eindgebruikers; (ii) wetenschappers; (iii) beleidsmakers en (iv) burgers.

Keywords: Soil threats, ecosystem functions, land degradation neutrality, policy mapping, fostering uptake of sustainable land and soil management

The pdf file is free of charge and can also be downloaded at https://doi.org/10.18174/531395 or via the website www.wur.nl/environmental-research (scroll down to Publications - Wageningen Environmental Research reports). Wageningen Environmental Research does not deliver printed versions of the Wageningen Environmental Research reports.

(C) 2020 Wageningen Environmental Research (an institute under the auspices of the Stichting Wageningen Research), P.O. Box 47,6700 AA Wageningen, The Netherlands, $\mathrm{T}+31(0) 3174807$ 00, www. wur. nl/environmental-research. Wageningen Environmental Research is part of Wageningen University \& Research.

- Acquisition, duplication and transmission of this publication is permitted with clear acknowledgement of the source.

- Acquisition, duplication and transmission is not permitted for commercial purposes and/or monetary gain.

- Acquisition, duplication and transmission is not permitted of any parts of this publication for which the copyrights clearly rest with other parties and/or are reserved.

Wageningen Environmental Research assumes no liability for any losses resulting from the use of the research results or recommendations in this report.

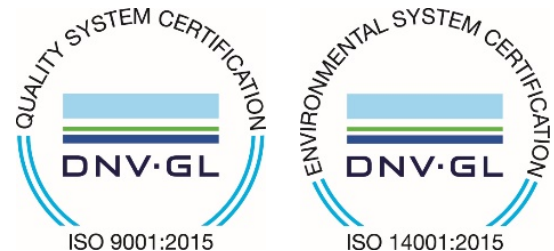

ISO 9001:2015

In 2003 Wageningen Environmental Research implemented the ISO 9001 certified quality management system. Since 2006 Wageningen Environmental Research has been working with the ISO 14001 certified environmental care system.

By implementing the ISO 26000 guideline, Wageningen Environmental Research can manage and deliver its social responsibility.

Wageningen Environmental Research report 3032 | ISSN 1566-7197

Photo cover: Soil profile under grazing land (photo taken by Saskia Keesstra) 


\section{Contents}

$\begin{array}{ll}\text { Verification } & 5\end{array}$

$\begin{array}{ll}\text { Abbreviations } & 7\end{array}$

$\begin{array}{ll}\text { Executive summary } & 9\end{array}$

$\begin{array}{llr}1 & \text { Introduction } & 13\end{array}$

2 Description of work and deliverables $\quad 16$

$2.1 \quad$ Research aims and questions $\quad 16$

2.2 Organisation of the work and methodology 16

2.2.1 Task 1 - Analysis of the state of play of the implementation of land and soil-related SDGs 16

2.2.2 Task 2 - Support the organisation of a conference 17

2.2.3 Task 3 - Compilation and communication of good practices and $\begin{array}{ll}\text { recommendations } & 17\end{array}$

3.1 Coordination and implementation of land and soil-related SDGs 18

3.1.1 EU policies enabling the implementation of land and soil-related SDGs 19

3.1.2 Member State actions and policies promoting land and soil-related SDGs 33

3.2 Soil and land degradation and land degradation neutrality 50

3.2.1 Land degradation $\quad 50$

3.2.2 Land Degradation Neutrality (LDN) 53

3.2.3 Priorities on land degradation/LDN at national level 54

3.2.4 Land and soil-related SDG indicators and sub-indicators 56

3.2.5 National approaches to LDN 56

$\begin{array}{lll}3.3 & \text { A new approach to assessing measures } & 57\end{array}$

3.3.1 Introduction $\quad 57$

3.3.2 Mapping soil threats $\quad 59$

3.3.3 Results of mapping soil threats 64

3.3.4 Lighthouse examples to serve as good practice advice 66

Stakeholder views on the role of communication and awareness and the limitations for implementing soil and land related SDGs

$\begin{array}{lll}5.1 & \text { Institutional coordination and implementation } & 80\end{array}$

5.2 Land degradation/land degradation neutrality definitions and indicators 83

5.3 Measures to prevent, reduce or reverse degradation $\quad 85$

$\begin{array}{ll}\text { References } & 87\end{array}$

$\begin{array}{lll}\text { Annex } 1 & \text { Overview of the project's research questions } & 94\end{array}$

Annex 2 Questionnaire sent to the Soil Expert Group 95

$\begin{array}{lll}\text { Annex } 3 & \begin{array}{l}\text { Soil and land related sustainable development goals and } \\ \text { indicators }\end{array}\end{array}$

Annex 4 Relevance of EU policies for implementing soil and land SDGs 97

$\begin{array}{lll}\text { Annex } 5 & \text { Member State fact sheets } & 108\end{array}$

Annex 6 Examples of good practices/initiatives to achieve soil and land-related SDGs 



\section{Verification}

Report: 3032

Project number: 5200044926

Wageningen Environmental Research (WENR) values the quality of our end products greatly. A review of the reports on scientific quality by a reviewer is a standard part of our quality policy.

Approved reviewer who stated the appraisal,

position: Team leader Soil, Water and Land Use Team

name: dr. ir. M.J.D. (Mirjam) Hack-ten Broeke

date: $\quad 30-8-2020$

Approved team leader responsible for the contents,

name: dr. ir. M.J.D. (Mirjam) Hack-ten Broeke

date: $\quad 30-8-2020$ 


\section{Abbreviations}

\begin{tabular}{|c|c|}
\hline AECMs & Agri-Environment-Climate Measures \\
\hline AEnZ & Agri-Environmental Zonation \\
\hline CAP & Common Agricultural Policy \\
\hline CCS & Carbon Capture and Storage \\
\hline DEM & Digital Elevation Model \\
\hline EAFRD & European Agricultural Fund for Rural Development \\
\hline EAGF & European Agricultural Guarantee Fund \\
\hline EAP & Environmental Action Programme \\
\hline EASAC & European Academies Science Advisory Council \\
\hline EEA & European Environment Agency \\
\hline EEB & The European Environmental Bureau \\
\hline EIA Directive & Environmental Impact Assessment Directive \\
\hline ELD & Environmental Liability Directive \\
\hline ELSUS & European Landslide Susceptibility Map \\
\hline EnS & Environmental Stratification \\
\hline EnZ & Environmental Zones \\
\hline EQS & Environmental Quality Standards \\
\hline ESR & Effort Sharing Regulation \\
\hline EU SEG & EU Soil Expert Group \\
\hline FAO & Food and Agriculture Organization of the United Nations \\
\hline FAS & Farm Advisory Service \\
\hline GAEC & Good Agricultural and Environmental Conditions \\
\hline GSP & Global Soil Partnership \\
\hline HLPF & UN High Level Political Forum \\
\hline IAEG-SDGs & Inter-Agency and Expert Group on SDG indicators \\
\hline IED Directive & Industrial Emissions Directive \\
\hline ILSWE & Index of Land Susceptibility to Wind Erosion \\
\hline INSPIRE Directive & Infrastructure for Spatial Information in the European Community \\
\hline IPBES & Intergovernmental Science-Policy Platform on Biodiversity and Ecosystem Services \\
\hline LDN & Land-Degradation-Neutrality \\
\hline LULUCF & Land use, land-use change, and forestry \\
\hline MFF & Multi-Annual Financial Framework \\
\hline MSFD & Marine Strategy Framework Directive \\
\hline NECD & National Emission Ceiling Directive \\
\hline PCA & Principal Component Analysis \\
\hline PPPR & Plant Protection Products Regulation \\
\hline RDPs & Rural Development Programmes \\
\hline RED & Renewable Energy Directive \\
\hline SDGs & United Nations Sustainable Development Goals \\
\hline SEA Directive & Strategic Environmental Assessment Directive \\
\hline SLM & Sustainable Land Management \\
\hline SMRs & Statutory Management Requirements \\
\hline SNAC & National Strategy for Adaptation to Climate Change \\
\hline SNBD & National Strategy for Biodiversity \\
\hline SNDD & National Strategy for Sustainable Development \\
\hline SOC & Soil Organic Carbon \\
\hline SOM & Soil organic matter \\
\hline SSD & Sewage Sludge Directive \\
\hline SUPD & Sustainable Use of Pesticides Directive \\
\hline SWD & EC Staff Working Document \\
\hline UBA & German Environment Agency \\
\hline
\end{tabular}


UN Convention to Combat Desertification

UNSC United Nations Statistical Commission

VGSSM Voluntary Guidelines for Sustainable Soil Management Water Framework Directive 


\section{Executive summary}

Increasing land take, soil sealing and loss of ecosystem functions due to soil and land degradation have been recognised as major environmental and socioeconomic challenges, both in the EU and worldwide. In 2015, the UN put forward the 2030 Agenda, with 17 interdependent Sustainable Development Goals (SDGs). Many of the SDGs reflect challenges related to land and soil, particularly SDG 15, concerning life on land. SDG 15 strives to achieve a land degradation-neutral world and is a key enabler for many other SDGs, including SDG 2 (zero hunger), 6 (clean water and sanitation), and 11 (sustainable cities and communities).

Since the adoption of the 2030 Agenda, the European Commission has published several strategic documents outlining the plans to implement the SDGs in the EU. In the Communication on 'Next Steps for a Sustainable European future' (2016), the Commission stressed its intention to mainstream the SDGs into EU policies. More recently, the reflection paper 'Towards a sustainable Europe 2030' (2019) presents the enabling factors and challenges to implementation of the SDGs in the EU. However, in 2006, EU initiatives on soil and land-related challenges started with the EU Soil Thematic Strategy, which was the first policy document at EU level uniquely dedicated to soil protection. The strategy aims to protect soil and its sustainable use, prevent further soil degradation, and restore degraded soils. The document highlights eight main threats to soils in the EU: erosion, organic matter decline, compaction, soil biodiversity loss, sealing, landslides, contamination and salinisation. Four key pillars were defined to achieve the goals of the strategy: 1) framework legislation; 2) integration of soil protection in other policies; 3) research; and 4) raising public awareness of soil-related challenges. In addition, soil and land related challenges have been integrated into a wider EU policy focusing on the sustainable use of resources.

The Roadmap to a Resource Efficient Europe adopted in 2011 aims for the achievement of sustainable resource management, including land and soil management, by 2050. It also sets a target of no net

land take by $\mathbf{2 0 5 0}$. This target has been repeated in the $7^{\text {th }}$ EU Environment Action Programme that came into force in 2014. Other targets established in the $7^{\text {th }}$ EAP aim to increase efforts to reduce soil erosion and to enhance soil organic matter as well as the integration of land use aspects in coordinated policies involving all relevant levels of government.

In December 2019 the European Green Deal ${ }^{\mathbf{6}}$ was launched as the new cornerstone that serves to transform the EU into a fair and prosperous society, with a modern, resource-efficient and competitive economy where there are no net emissions of greenhouse gases in 2050 and where economic growth is decoupled from resource use. Within the Green Deal elements such as the new EU Biodiversity Strategy for 2030 set targets and actions for nature protection and restauration, integrating as well as land degradation neutrality.

Despite these high-level initiatives, EU policies targeted at the prevention of land and soil degradation remain fragmented and rely on sectoral policies. Some of the sectoral policies can be very helpful in the implementation of soil and land related SDGs by establishing environmental standards and safeguards, promoting good practices and supporting sustainable approaches to natural resource management.

The policy mapping exercise in this study shows that few Member States have dedicated land or soil policies. Many of these policies set clear provisions for improving the condition of soil and land and have the potential to contribute significantly to the implementation of the land and soil-related SDGs. However, most policies at both EU and national level have been shaped before the adoption of the SDGs and therefore, they may not fully reflect the targets as formulated by the UN in 2015. Hence, there is a need to revise, update or reformulate the existing policies. New policy instruments need to be devised that can help to adjust the socioeconomic development to the limitations of our planet in line with the SDGs. 
In light of the COVID-19 crisis that started in 2020 in Europe, it has become even more evident that resilience is key to sustainability. Resilience is needed on all three main levels of the SDGs: the Biosphere, Society and Economy. The recovery from this crisis places a strong focus on increasing the resilience in society and economy, but it is important to keep in mind that many of the SDGs rely on sustainably managed soil and land. Therefore, action towards the long-term sustainable use of land and soil is essential to reach all SDGs; without that, there is no basis for the rest.

Measuring progress towards the achievement of the SDGs poses numerous challenges. The target accepted for SGD 15.3 (Land Degradation Neutrality (LDN)) has three sub-indicators focusing on land cover, land productivity and carbon stocks) may be a useful tool for tracking progress in achieving LDN in the different countries and environmental zones. At EU level, the Commission is currently developing a methodology and guidance to monitor the progress towards LDN. The adoption of quantitative targets (such as LDN and zero net land take) at Member State level would be a good step to making land and soil-related SDGs more operational.

Also, for other soil degradation processes, the methodology in Europe for monitoring and assessing the land and soil SDGs should be more clearly defined and elaborated. Although many countries have started to measure and monitor the land and soil SDGs, there is little coordination and no standard approach yet. Moreover, important soil degradation processes are not taken into account in comprehensive monitoring schemes for all ecosystems; while soil is part of all terrestrial ecosystems and therefore needs well-defined targets that can be assessed with a good set of indicators to assess the impact of measures taken for protection and restoration.

Essential for the success of the achievement of land and soil related SDGs is raising awareness for sustainable land and soil management. Better awareness of the importance of land and soils will promote region-specific but interdisciplinary land use planning at Member State level, in which the soil and landscape should play an important role. Moreover, it is important to assess the impact of new projects on the surrounding area, including off-site and on-site effects. In addition to a land-use plan, there should be a long-term vision, i.e. how will the implementation of the plan affect the area itself and its surroundings in 20 years?

For this, awareness needs to be raised on different levels and targeted for each specific stakeholder group to give all stakeholders an action perspective by showing good, real-life examples that are connected to them and which they could implement themselves:

- For practitioners and end-users: show and tell how land restoration is the best contribution to achieve the SDGs. Exchanging region-specific solutions (such as the lighthouse example approach in this report) will enhance local people's awareness of the importance of land and soil. They know their area and are emotionally attached to it. Seeing sustainable solutions implemented in their own region will raise the awareness of the potential and possibility of sustainable land and soil management. This can be helpful to make the transition to a truly new system which can replace an 'old and unsustainable' system of soil and land management.

- For science: the science community has to step out of its comfort zone and show what soil can bring to society. Scientists need to learn to communicate about soil: attract, interest, desire, action, as scientific evidence alone will not move policy.

- For policymakers: political leadership is needed to promote soil and land-related SDGs if we are to make real progress. Assisting countries to achieve their LDN target by showing good examples of countries where successful policies have already been implemented.

- Education: at all levels of education, starting at a young age, soil and land should be brought to their attention to show the importance of this for society in terms of food security, water resources, climate change and human health. The climate change action has a head start and can also serve the soil awareness by showing how system Earth works and how a healthy soil forms an important basis for this. 


\section{Recommendations: Create an enabling environment for transitional change}

\section{Institutional coordination and implementation}

The European Green Deal and its associated actions, as well as other overarching strategic documents, need to provide the framework driving the implementation and operationalisation of the soil and land SDGs

Whilst broad ambitions provide a high-level framework for soil and land protection, they clearly need to be translated into measurable, action-oriented policy targets, specifying incremental steps to be taken to ensure their realisation. A starting point for formulating targets is a robust understanding of the pressures impacting the state of land and soil and thus the SDGs. On this basis, sector or land use-specific targets could be formulated. The update of key strategic policy documents, including the Soil Thematic Strategy and the $8^{\text {th }}$ Environmental Action Programme, as well as actions planned under the Green Deal (e.g. the Zero Pollution Action Plan, the Strategy for a Sustainable Built Environment) offer opportunities to define SMART ${ }^{1}$ targets for specific sectors or types of land use.

Existing policies targeting the prevention of land and soil degradation remain fragmented and rely on sectoral interventions

- While environmental mainstreaming that incorporates soil and land aspects is important and can be effective, its results are dependent on the extent to which clear objectives and targets relating to land and soil can be incorporated in other policies, and on the effectiveness of their implementation. Ongoing and upcoming policy reviews, including for example the Sewage Sludge Directive, Industrial Emissions Directive and the Sustainable Use of Pesticides Directive, need to integrate the ambitions and targets formulated by the high-level strategic documents identified above.

- At Member State level, the adoption of quantitative targets (such as LDN and zero net land take) would be a good step to making land and soil-related SDGs more operational. It would be useful to share Italy's experience with the UNCCD's LDN Target Setting Programme with the other Member States.

- National sustainable development plans or strategies need to be updated to integrate the SDGs and should include explicit targets and actions for sustainable land and soil management.

Member States have adopted national sustainable development plans or strategies but not all address the SDGs as adopted in 2015

Member States that have not yet updated their national strategic documents following the adoption of the Sustainable Development Goals adopted in 2015, are encouraged to initiate a strategy review to ensure that their national frameworks guiding their activities serve the ambitions of the UN's Agenda 2030, but also contribute to the achievement of EU objectives such as no net land take or climate neutrality by 2050 and the zero pollution ambition.

Member States have adopted coordinated and participatory approaches to implement the SDGs but focus on the involvement of organised interests

- Information about the SDGs, their relevance to society as well as the individual, and the important role land and soil play in realising these ambitions, need to be widely communicated. To engage people, we should use the current momentum on climate and biodiversity to put soil and land on the agenda by showing how they link to food security and the mitigation and adaptation of climate change impacts.

- The update of the STS (planned in 2021) offers an opportunity to build on its positive experiences with raising awareness for soil. Mirroring recent initiatives in other policy fields ${ }^{2}$, 'soil literacy' ${ }^{3}$ may be a concept which could be developed and promoted at EU level as a way of delivering a more coordinated approach to soil awareness activities in Europe. Such an initiative could involve the setting up (and financing) of a new platform connecting relevant organisations and projects or may

1 Specific, Measurable, Achievable, Realistic, and Timely

2 See for example the EU4Ocean Coalition for Ocean Literacy which aims to bring together organisations, projects and people that contribute to ocean literacy in order to create awareness and trigger action for sustainable ocean management, build capacity and put ocean literacy on the policy agenda. Information available at: https://webgate.ec.europa.eu/maritimeforum/en/frontpage/1482

3 The Global Soil Biodiversity Initiative notes that "The world needs more citizens who are soil literate-who understand how soils and humanity depend on each other for their mutual long-term existence. The insufficiency of such understanding (at societal levels) is due, in part, to the world's "soil education gap"-the shortage of soil education efforts relative to the scale of the societal need for them." (https://www.globalsoilbiodiversity.org/blog-beneath-our- 
build on the work of existing groups such as the European Network for Soil Awareness ${ }^{4}$ and the European Soil Bureau Network ${ }^{5}$.

- The increased emphasis on communication and dissemination introduced with the Commission's Research Framework Programme Horizon 2020 needs to be maintained, expanded, and refined to ensure widely supported outcomes that will improve uptake or research results in practice.

\section{Land degradation/land degradation neutrality definitions and indicators}

The SDGs and their associated targets for land and soil should be elaborated at EU level in order to develop a clear framework for data collection, monitoring, analysis and target setting.

- The methodology in Europe for monitoring and assessing the land and soil SDGs should be more clearly defined and elaborated for all soil degradation processes. Although many countries have started to measure and monitor the land and soil SDGs, there is little coordination and no standard approach yet.

- An LDN indicator based on the three UNCCD sub-indicators (land cover, land productivity, and carbon stocks) provides a good starting point for measuring progress in relation to the land and soil-related SDGs but further guidelines and coordination, as the Commission is currently working on, is necessary for this indicator to become fully operational. The standard indicators as defined by the UNCCD are not sufficient for the European context as they do not take into account several important issues:

- For most of the UNCCD sub-indicators there is more detailed information available in Europe than the generally used Tier 1 data.

- The mosaic landscape in most European countries is not represented in the large pixels that are used in the UNCCD indicator set.

- Important soil degradation processes are not taken into account in the UNCCD methodology, such as biodiversity decline (e.g. afforestation with single species); soil erosion (from terraced landscapes to large fields on sloping areas) or contamination.

- Design and implement a comprehensive monitoring scheme for all ecosystems; soil is part of all terrestrial ecosystems and therefore needs well-defined targets that can be assessed with a good set of indicators to assess the impact of measures taken for protection and restoration.

\section{Measures to prevent, reduce or reverse degradation}

Availability of examples:

- Exchange region-specific solutions to enhance awareness of the importance of land and soil for local people, who know their area and are emotionally attached to it. Seeing sustainable solutions implemented in their own region will raise the awareness of the potential and possibility of sustainable land and soil management. For example:

- Land and soil degradation and restoration measures as contributions for achieving sustainable development and with that, the SDGs

- Nature-based solutions and agro-ecology principles contribute significantly to climate mitigation and adaptation, at the same time addressing biodiversity loss and land degradation

- Measures to maximise resource efficiency: reusing and recycling soil and land resources

- Make new examples of region-specific solutions available via databases like WOCAT6 and/or the new EU Soil observatory of JRC (in line with the activities of the Horizon Europe Mission 5 Soil Health and Food $^{7}$ ). The development and exchange of good examples should be promoted on natural, urban and industrial land as well as for agricultural soils.

Shared methodologies:

- Develop tailored good practices for specific regions. This can be helpful to make the transition to a truly new system which can replace an 'old and unsustainable' system of soil and land management.

- Use a concrete methodology (for instance the lighthouse methodology proposed in this report) to assess the impact of the specific land management measures on soil and land-related SDGs, to demonstrate the trade-offs and synergies between the different SDGs impacted by those measures.

- Design a methodology for evaluating the costs and benefits for specific measures for the realisation of the SDGs.

\footnotetext{
4 http://www.bodenbuendnis.org/en/

5 https://ec.europa.eu/jrc/en/network-bureau/european-soil-bureau-network

6 WOCAT is a global network on Sustainable Land Management (SLM) that promotes the documentation, sharing and use of knowledge to support adaptation, innovation and decision-making in SLM. Available via https://www.wocat. net/en/.

7 https://ec.europa.eu/info/horizon-europe-next-research-and-innovation-framework-programme/mission-area-soil-healthand-food_en
} 


\section{Introduction}

Land and soil are essential for several ecosystem services and functions. This is reflected in the UN Sustainable Development Goals (SDGs), where land and soil play an important role in achieving half of the SDGs, specifically SDGs $2,3,6,11$, and 13-15, which relate to food security, human health, land management, water security, urban development, climate change and sustainable ecosystem services (EASAC, 2018; Keesstra et al, 2016).

Land and soil are limited and unrenewable natural resources and yet, according to the EEA Dashboard on land take, the area's agricultural, forest and other semi-natural and natural land taken into urban and other artificial land development ('land take') exceeds $500 \mathrm{~km}^{2}$ per year in the $\mathrm{EU}^{8}$ for the period 2012-2018 (EU28 countries only). Increasing land take, loss of soil function and ecosystem services have been recognised as some of the major environmental and socioeconomic challenges in Europe. In 2006, the EU adopted a Soil Thematic Strategy, aiming to protect soil and ensure its sustainable use (European Commission, 2006), while the 2011 Roadmap to a Resource Efficient Europe (European Commission, 2011) included the goal of achieving no net land take by 2050. This was echoed by the 7th EU Environment Action Programme as adopted by the European Parliament and the Council in 2013, which called on Member States to put policies in place by 2020 to achieve 'no net land take' by 2050 and to reduce soil erosion and the loss of soil organic matter (EC 2011a).

A recent comprehensive review of the state of the world's soils observed that most of these resources are in fair, poor or very poor condition, with 33\% of land 'moderately to highly degraded'. The chief threats to the integrity and quality of Europe's soil resources have been identified as climate change, soil sealing, salinisation, compaction, acidification, chemical pollution, loss of organic carbon and soil biodiversity erosion (FAO and ITPS, 2015). The Intergovernmental Science-Policy Platform on Biodiversity and Ecosystem Services (IPBES) states that 'avoiding, reducing and reversing land degradation is essential for reaching the majority of the Sustainable Development Goals and would deliver co-benefits for nearly all of them' (IPBES, 2018). Figure 1.1 shows expert judgement of how efforts to address land degradation impact on the SDGs.

\footnotetext{
8 Land take 2000-2018, average annual data for the period 2012-2018, https://www.eea.europa.eu/data-andmaps/dashboards/land-take-statistics.
} 

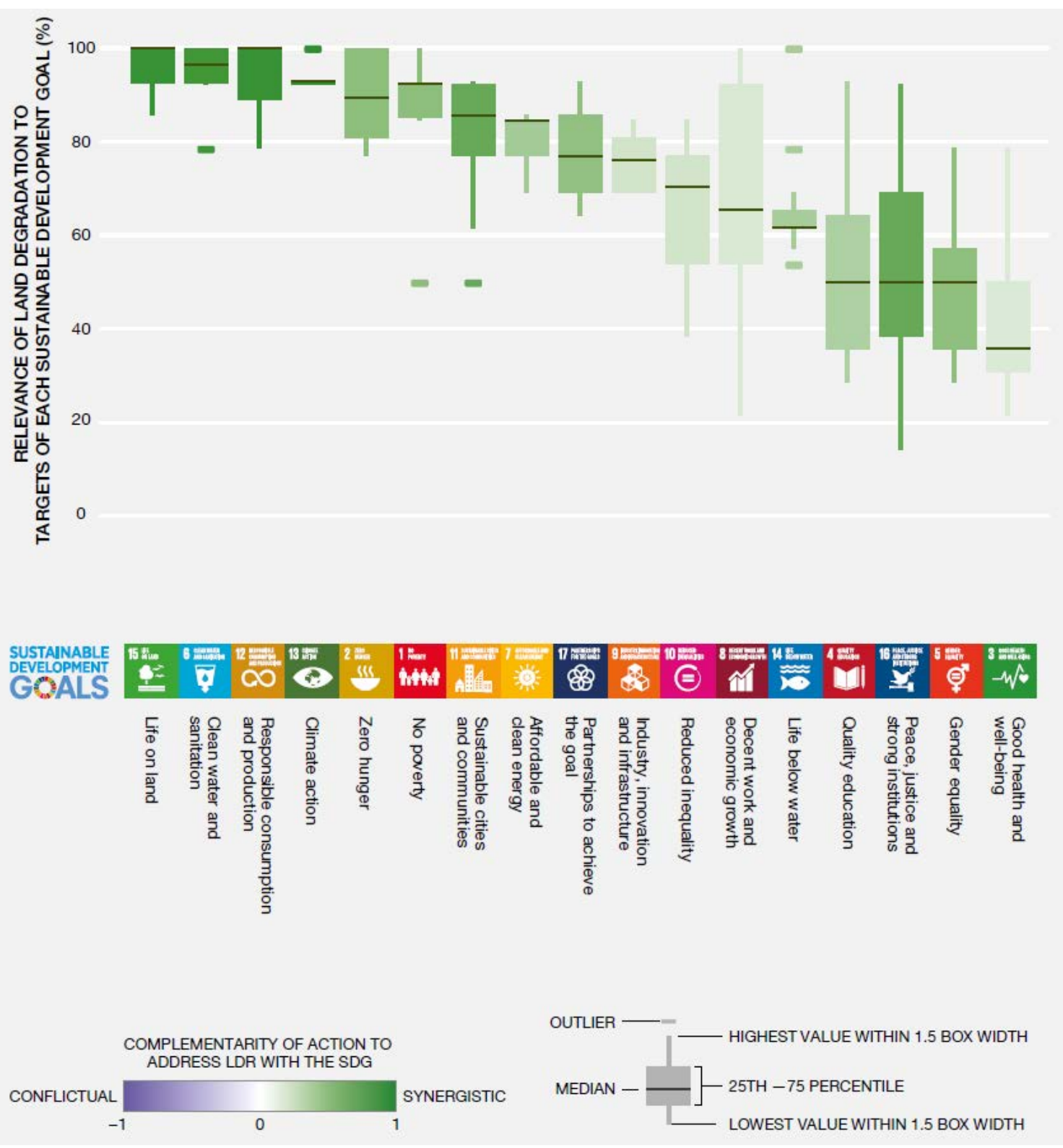

Figure 1.1 Relevance of land degradation to targets of each SDG

Vertical axis: \% of experts indicating that halting land degradation and restoration is relevant to achieving that goal. Green colours: indicate the degree to which the targets are synergistic with progress to address land degradation: dark green = all targets are aligned, lighter green boxes = potential trade-offs between targets and efforts to address land degradation and restoration. Nowhere was the relationship between efforts to address land degradation and meeting the SDGs judged to be more conflicting than synergistic.

With the adoption of the SDGs by the UN General Assembly in September 2015, the EU and the Member States committed to achieving land degradation neutrality (LDN) in the EU by 2030.

However, the most recent assessment of land take (i.e. the loss of agricultural land, forests and other semi-natural and natural areas to the development of buildings and other artificial surfaces) in the EU indicates that meeting the aim of no net land take by 2050 is unlikely to be achieved (EEA, 2018). It will be similarly difficult to achieve the EU's LDN objective by 2030 (European Court of Auditors, 2018). However, many organisations and Member States are developing activities towards avoiding land and soil degradation and achieving the SDGs.

This final report was drafted as part of the DG Environment (DG ENV) funded project Providing support in relation to the implementation of soil and land related Sustainable Development Goals at EU level (Service contract No. 07.0202/2018/792008/SER/ENV.D.1). 


\section{Guide to the Final Report}

Section 2 briefly describes the project's work programme and details the methodology adopted for each task. Section 3 presents the findings of the analysis of the implementation of land and soilrelated SDGs. The report concludes with a conclusion and recommendations (Section 4).

The following Annexes are submitted with this Final Report:

1. Overview of the project's research questions;

2. Questionnaire sent to the Soil Expert Group and selected experts;

3. Soil and land-related SDGs and indicators;

4. Relevance of EU policies for implementing land and soil-related SDGs;

5. Member State fact sheets; and

6. Examples of good practices/initiatives to achieve soil and land-related SDGs. 


\section{Description of work and deliverables}

This section will briefly describe the aims and objectives of the study as well as the methodology adopted to meet the objectives.

\section{$2.1 \quad$ Research aims and questions}

The aim of this study is to analyse progress on the implementation of land and soil-related SDG targets in the EU, taking due consideration of the 2030 Agenda commitments, and to provide a platform for exchanges on best practices between Member States on the implementation of land and soil-related SDGs.

The specific objectives of the study are to:

- Analyse the state of play of the implementation of land and soil-related SDGs in the EU, in particular on the LDN target (15.3).

- Support the organisation of a conference on the implementation of land and soil-related SDGs in the EU to discuss the findings of Task 1.

- Compile and communicate good practices and provide recommendations for the implementation of land and soil-related SDGs in the EU.

Project outputs will support the Commission in identifying opportunities for action at EU level to facilitate and promote the implementation of land and soil-related SDGs in the Member States.

\subsection{Organisation of the work and methodology}

The work for this project is organised into three main tasks. This section presents the methodology. The sub-sections below briefly recap the objectives of each task and detail the steps to deliver the expected outcomes.

2.2.1 Task 1 - Analysis of the state of play of the implementation of land and soilrelated SDGs

Task 1 aimed to analyse the state of play of the implementation of land and soil-related SDGs in the EU, in particular on the LDN target (15.3). Key areas of analysis included:

- Coordination on SDGs and leverage at EU and national level;

- Implementation of land and soil-related SDGs at EU and national level;

- Land and soil degradation target-setting at EU and national level;

- Measures to prevent, reduce or reverse degradation at EU and national level.

The data collection and analysis were guided by a set of research questions which are listed in Annex 1.

The analysis drew from a wide range of information sources, including scientific literature, national plans on sustainable development, policy documents and assessment studies, as well as previous surveys carried out by the Commission, the United Nations Convention to Combat Desertification (UNCCD) or other organisations and projects. Primary data were collected through a questionnaire circulated to the members of the EU Soil Expert Group (EU SEG) and national experts who were contacted to strengthen the response rate. The questionnaire (see Annex 2) included ten open-ended questions that reflected the main research questions, plus one question to elicit information on respondents' Member State and institutional affiliation. Overall, 18 questionnaires were returned, of which 1 of them only filled in the first question, so it was not further used in the analysis. The 
questionnaires are, covering 15 countries. Several countries submitted two replies (Italy - two from EU SEG; Slovakia - two national experts (one of which sent in the incomplete response); Denmark - one EU SEG, one national expert). Of the 18 questionnaires, 13 were completed by representatives of national authorities and agencies, with the remaining five returned by the national experts.

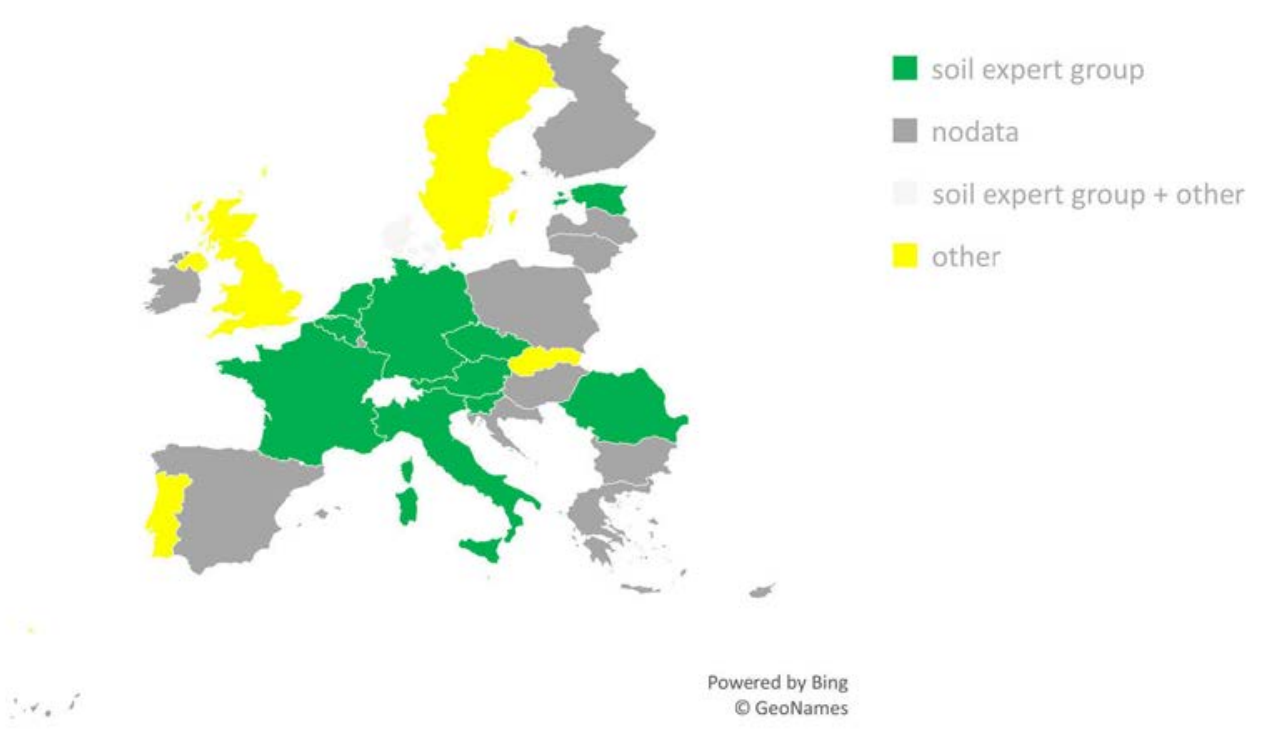

Figure 2.1 Geographical coverage of questionnaire responses

\subsubsection{Task 2 - Support the organisation of a conference}

A conference on the implementation of land and soil-related SDGs was organised on 25 November 2019 in Brussels. The conference pursued the following objectives:

- Provide an opportunity for stakeholder exchanges;

- Validate and complement the findings from Task 1 in order to identify and share good practices;

- Provide an opportunity for stakeholders to exchange their experiences, ideas and prospects for the implementation of land and soil-related SDGs.

The conference brought together 250 participants from a variety of backgrounds, including EU and national decision makers, researchers, managing authorities, industry, and representatives of civil society organisations. The agenda, as well as summaries of presentations, panel discussions and interactions, were documented in the conference proceedings. The proceedings can be accessed at https://www.soil-conference. $\operatorname{org}^{10}$.

\subsubsection{Task 3 - Compilation and communication of good practices and recommendations}

Task 3 extracted and formulated the key findings of the Task 1 analysis, together with the main learning points from the Task 2 conference. These were gathered in a brochure on the implementation of land and soil-related SDGs in the EU, together with examples of good practices. The brochure illustrates how land and soil-related targets and indicators are implemented in various Member States. The examples were gathered from literature, the conference presenters and attendees, and completed with targeted requests to organisations and networks such as the Soil Expert Group. Lessons learned and recommendations are tailored to the policy, research and practice communities and citizens. The brochure is available in English, Spanish, French and German and shared widely, through several channels of communication ${ }^{11}$.

\footnotetext{
9 The conference proceedings were submitted to the Commission and disseminated to all conference participants in January 2020.

${ }^{10}$ The conference proceedings were submitted to the Commission and disseminated to all conference participants in January 2020.

${ }^{11}$ Online at https://ec.europa.eu/environment/soil/index_en.htm
} 


\section{State of play of the implementation of land and soil-related SDGs in the EU}

This section presents an analysis of the state of play of implementation of land and soil-related SDGs at EU and national level. The data collection and analysis focused on information related to the SDGs on food security (SDGs 2 and 6), human health (SDG 3), sustainable cities (SDG 11), climate change (SDG 13), land-based nutrient pollution of the seas (SDG 14), and sustainability of terrestrial ecosystem services (SDG 15) (see Annex 3). Other SDGs rely on the availability of land and healthy soil resources, but the links between these SDGs and soil are somewhat weaker (Bouma, 2019).

Findings are organised along the following themes:

- Coordination and implementation of land and soil-related SDGS at EU and national level (Section 3.1);

- Soil and land degradation target-setting at EU and national level (Section 3.2);

- Measures to prevent, reduce or reverse degradation (Section 3.3).

Preliminary findings of the analysis were discussed with stakeholders at the conference on 25 November 2019 and subsequently updated for this Final Report.

\subsection{Coordination and implementation of land and soil- related SDGs}

The EU is a permanent observer at the UN General Assembly and played an active role in the development of the SDGs (European Commission a, no date). Since the Adoption of the 2030 Agenda, the European Commission has published a series of documents outlining how it envisages implementing the SDGs. Key among these are the Communication on 'Next Steps for a Sustainable European future' (European Commission, 2016 a), and an accompanying Staff Working Document on 'European actions supporting the 2030 Agenda and the SDGs' (European Commission, 2016 b) (see Box 3.1). 


\section{Implementation of the SDGs at EU level}

In November 2016, the European Commission issued a Communication on 'Next steps for a sustainable European future. European action for sustainability' (European Commission, 2016a), in which it states the Commission's intention to mainstream the SDGs 'into EU policies and initiatives, with sustainable development as an essential guiding principle for all its policies', to report regularly on the EU's progress towards the implementation of the 2030 Agenda from 2017, and to launch a 'reflection work on developing further a longer-term vision in a post-2020 perspective' (European Commission, 2016a). The Commission also emphasised the importance of including the SDGs as guidance in the actions taken within the European Semester (European Commission, 2017a) and the intention that the next MultiAnnual Financial Framework (MFF) (2018) will be in the context of sustainable development.

In 2017, the Commission established the Multi-stakeholder Platform, which saw a collaborative process to prepare a joint contribution to the Commission's reflection paper 'Towards a sustainable Europe by 2030' announced in the Commission Work Programme for 2018 (European Commission, 2018a). The platform also proposed the development of an overarching Sustainable Europe 2030 Strategy to guide all EU policies and programmes. The Commission Work Programme for 2019 confirmed the planned adoption of this reflection paper, published in January 2019 (European Commission, 2019a). The paper 'presents the challenges faced by the EU, the key enablers of an effective transition towards sustainability, and three possible scenarios for integrating SDGs within EU policies' (IEEP, 2019).

Since 2016, Eurostat has published reports providing an overview of progress towards the SDGs in the EU. The 2019 report (Eurostat, 2019) was at the core of the EU's reporting to the UN High Level Political Forum (HLPF) in July of that year. 'The report uses the EU SDG indicator set, which was developed to monitor SDG progress in the EU context and adopted in May 2017 by the European Statistical System Committee' (IEEP, 2019). In particular, the EU reported that it was making progress on most of the SDGs. The Eurostat website offers interactive tools where data can be compared (Eurostat, no date).

The Commission also presented the HLPF with 'the 2019 Joint Synthesis Report on the European Consensus on Development' (European Commission, 2019b), which provides an overview of the EU and Member State actions for the implementation of the 2030 Agenda in developing countries through development cooperation; and the '2019 report on Policy Coherence for Development (PCD)' (European Commission, 2019 c), which 'illustrates contributions by the EU and its Member States to support achievement of the SDGs in partner countries over the period 2015-2018. The report stems from the new European Consensus on Development (2017), which foresees that PCD is applied across all policies and all areas covered by the 2030 Agenda' (IEEP, 2019).

At the end of 2019, the European Commission published its Communication on the European Green Deal which sets out the roadmap for making the EU's economy sustainable. It is considered an integral part of this Commission's strategy to implement the United Nation's 2030 Agenda and the SDGs. The Roadmap annexed to the Communication identifies key actions to be implemented under the Green Deal, of which the Biodiversity Strategy for 2030, the Zero Pollution Action Plan, as well as the Soil Sealing Action and Brownfield Action will be crucial in advancing land and soil protection in Europe.

This section presents a cutting-edge review of the implementation of land and soil-related SDGs in the EU Member States. Section 3.1.1 will present EU actions and policies enabling the implementation of land and soil-related SDGs at EU level. This will be followed by an overview of the Member States' institutional arrangements for implementing and coordinating land and soil-related SDGs, as well as the most relevant policies and strategies at national level (Section 3.1.2). Member State fact sheets are annexed to this report (Annex 5) and detail each country's progress towards SGD implementation.

\subsubsection{EU policies enabling the implementation of land and soil-related SDGs}

Land and soil degradation have long been recognised as a problem, both at EU and international level (see Box 3.2), yet policy responses remain fragmented, with more emphasis on awareness-raising than on targeted and comprehensive policies to change management practices. The protection, maintenance and improvement of land and soil at EU level relies heavily on sectoral and environmental policies. In addition, not all soil threats are equally well targeted by existing instruments. A recent European Court of Auditors' report notes that there is no EU-level strategy on desertification, and land degradation in general. The report emphasises that there are "a range of strategies, action plans and spending programmes at EU level [...], which are relevant for combating desertification, but which do not focus on it". The Court of Auditors subsequently calls on the 
Commission to "assess the appropriateness of the current legal framework for the sustainable use of soil across the EU, including addressing desertification and land degradation" (ECA 2018, p. 44).

\section{Box 3.2 Overview of the international soil and land policy framework}

\section{The International soil and land policy framework}

The UNCCD, adopted in 1994, was the first legally binding UN international agreement relevant to soil (UNCCD a, no date). The aim of the UNCCD is to prevent or reverse issues of drought, soil productivity and living conditions in the world's drylands (UNCCD b, no date). Parties to the Convention can declare themselves 'affected' countries, which then requires them to implement national, regional and subregional action programmes to reverse land degradation (UNCCD a, no date). The EU is a party to the UNCCD (since 1998) and all EU Member States are also individually either accession countries or ratified parties (UNCCD c, no date). Thirteen EU Member States, all located in Central and Eastern Europe, currently have 'affected country' status ${ }^{12}$, and must therefore prepare Regional and National Action programmes identifying contributing factors and measures to combat desertification.

Progress on the UNCCD was reviewed at the 2012 UN Conference on Sustainable Development. The outcome document, 'The Future We Want' (United Nations, 2012), included a section on 'Desertification, land degradation and drought'. It recognised the global problem of land degradation, the importance of soil management to sustainable development, and the need to take urgent action to reverse land degradation. It set a target of achieving a land-degradation-neutral world and called for the development of scientific indicators, scientific research and sharing of information relevant to land degradation. The target of land-degradation-neutrality (LDN) was taken up as one of the UN Sustainable Development Goals in 2015, making this target legally binding for all signatories.

In 2012, the Food and Agriculture Organization of the United Nations (FAO) Global Soil Partnership (GSP) was established, a voluntary, non-legally binding partnership that functions as a global platform for stakeholders to discuss and address global soil issues, mandated to improve governance and promote sustainable management of soils, including through awareness-raising (FAO, 2012). In 2013, the Intergovernmental Technical Panel on Soils was established as the scientific advisory body of the GSP. It is also responsible for producing the Status of World Soil Resources, a report delivered in December 2014 to mark the beginning of the International Year of Soils, looking at the threats to soils and ways to combat soil degradation.

In 2013, the European Soil Partnership was established by the GSP as the Regional Soil Partnership for Europe. Its Secretariat is hosted by the European Commission's Joint Research Centre (JRC). Its aim is to coordinate soil-related networks and activities and to contribute to the European chapter of the Status of World Soil Resources report (FAO, no date). It aims to bring together all of the stakeholders and institutions in Europe willing to adopt the principles of the World Soil Charter (see below), to give guidance on goals and priorities tailored to specific regions, and to develop relevant activities in those regions (ESDAC, no date).

The original World Soil Charter was adopted by the FAO in 1982 and revised in 2015. It sets out key principles relating to soil functions, threats, and sustainable management, as well as guidance for action towards sustainable soil management. It aims to ensure that soils are managed sustainably and that degraded soils are rehabilitated or restored. It also states that governments should support and develop initiatives to aid the adoption of sustainable soil management, support research programmes, contribute to national and global soil information, monitor sustainable soil management, and 'explicitly consider the role of soil management practices in planning for adaptation to and mitigation of climate change and maintaining biodiversity' (FAO, 2015). The World Soil Charter is complemented by the Voluntary Guidelines for Sustainable Soil Management, published by the FAO in 2017, which translate its principles into practice for policy makers, farmers, and other stakeholders (FAO, 2017).

\footnotetext{
${ }^{12}$ Bulgaria, Croatia, Cyprus, Hungary, Italy, Greece, Latvia, Malta, Portugal, Romania, Slovakia, Slovenia, and Spain. The EU has not declared itself as a party affected by desertification.
} 


\subsubsection{Analytical framework and policy mapping}

In order to identify the main EU policies enabling the implementation of LDN target and other soil and land related SDGs, we analysed the existing EU policy framework. In the absence of a clear definition of land degradation and operationalisation of the SDGs at EU level, we mapped the relevance of different soil threats and functions for the SDGs as the focus of this study. We then reviewed how different policies contribute to reducing soil threats and improving soil functions respectively as a means of gauging the extent to which current policies enable progress towards meeting the SDGs. Linking the soil functions and threats to the land and soil-related SDGs highlights the potential opportunities and shortcomings of existing policies to enable progress towards meeting the SDG (see Figure 3.1).

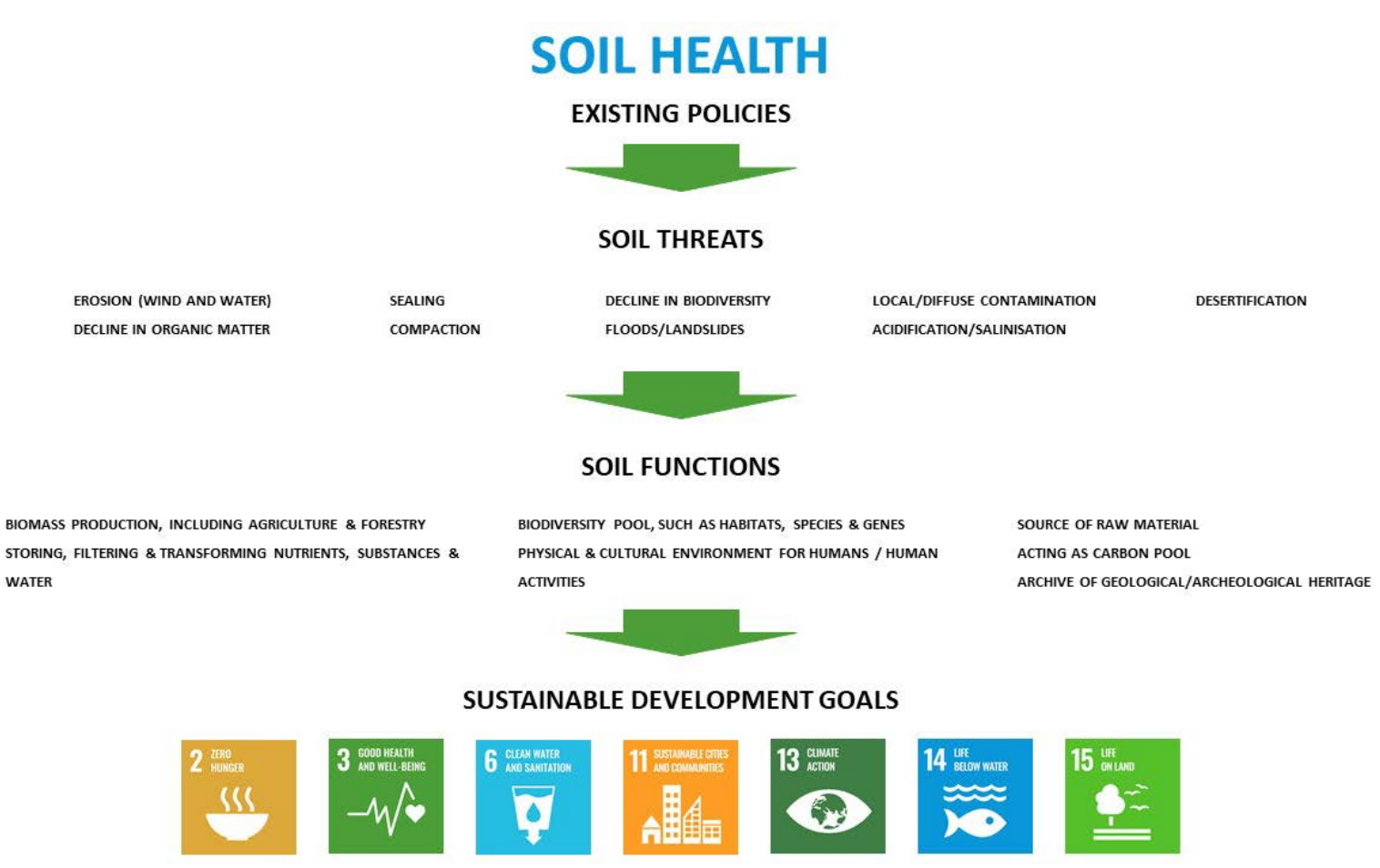

Figure 3.1 Analytical framework adopted for the EU-level policy analysis 


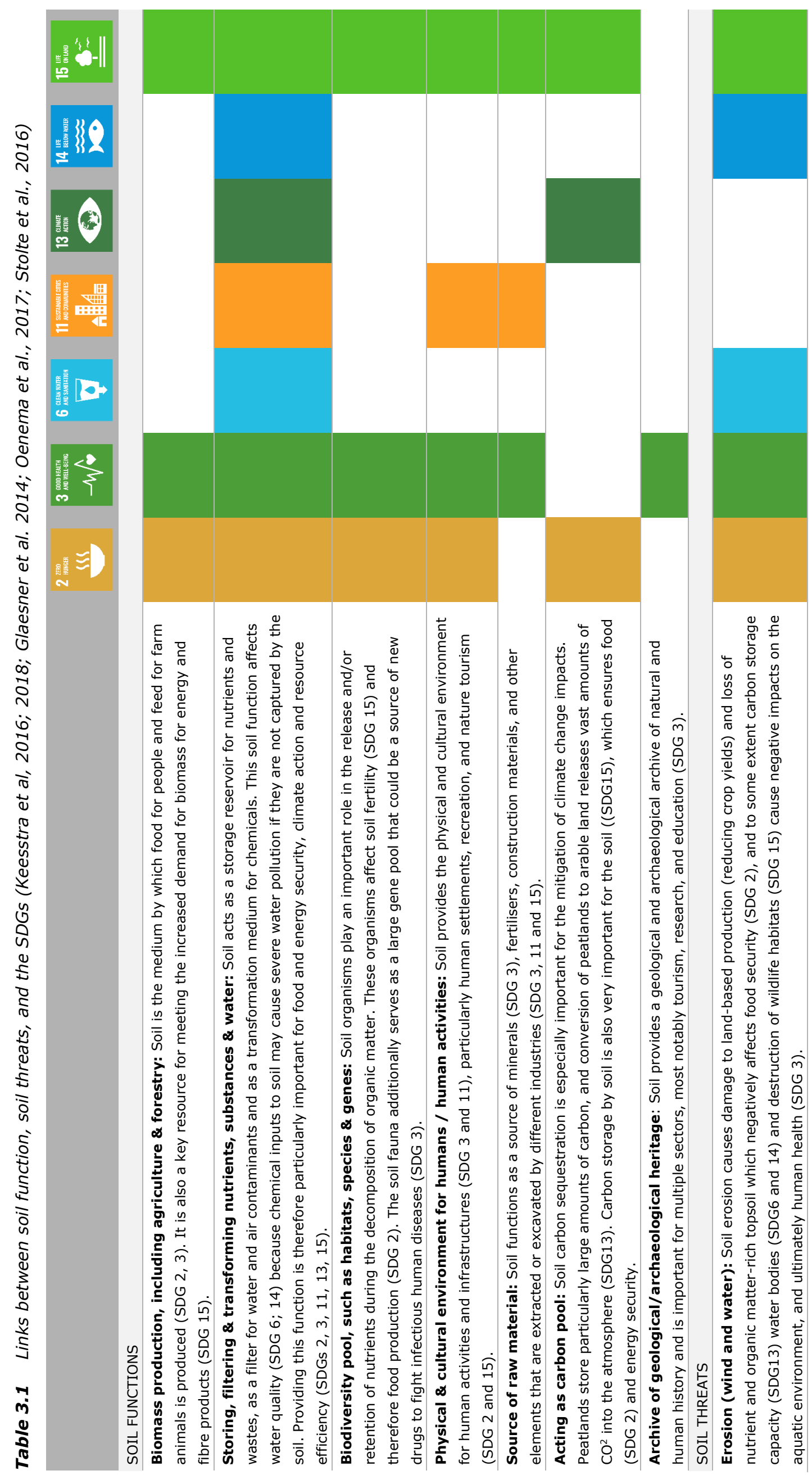




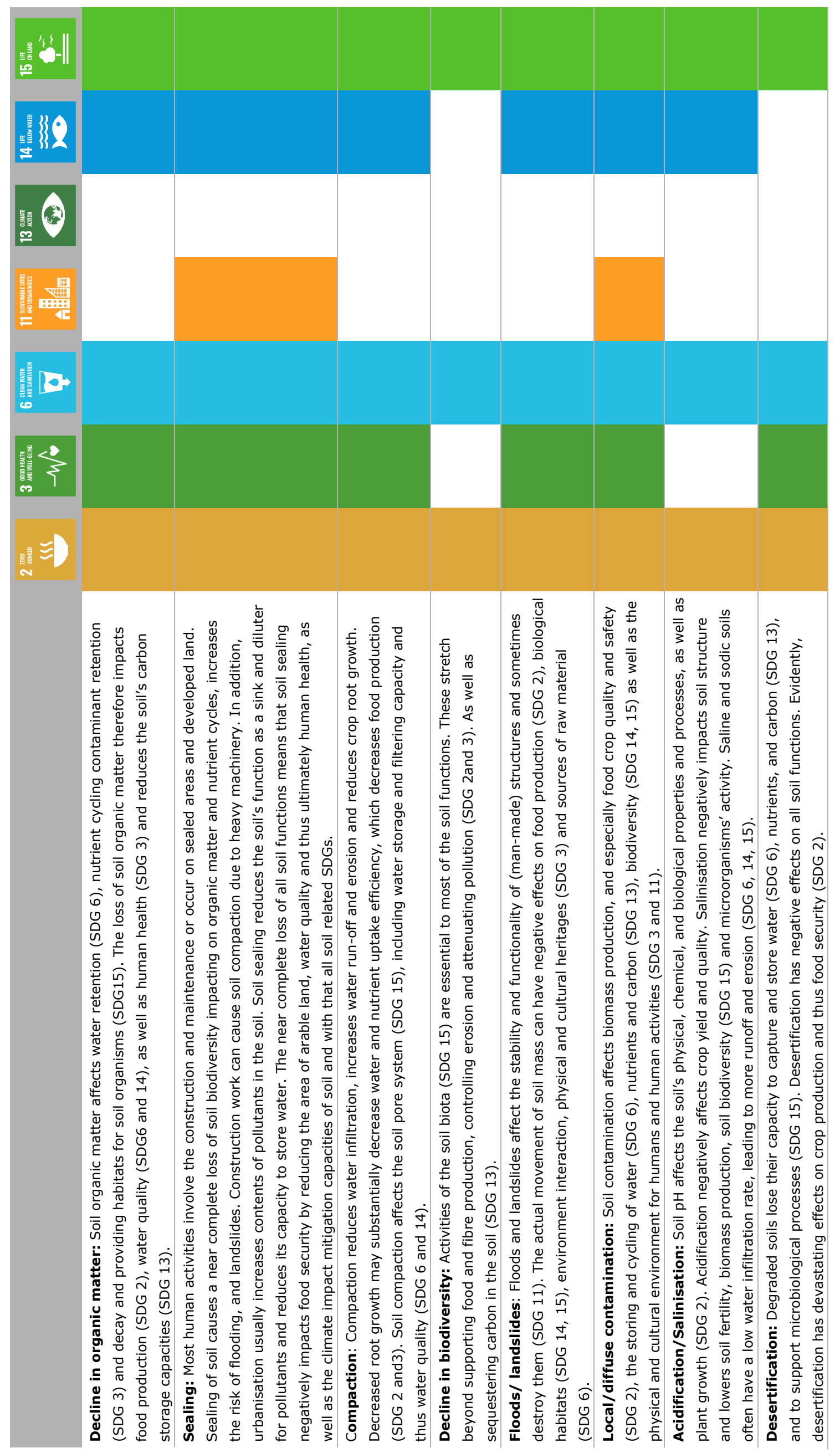


The policy selection was limited to strategies, policies and instruments with at least an indirect link to soil and land. Since most EU policies predate the adoption of the SDGs, the mapping exercise first drew from recent studies which broadly investigated the extent to which current EU policies promote the protection, maintenance and restoration of various soil and land functions or the reduction of soil degradation in general (Frelih-Larson et al., 2016; Vrebos et al., 2017; McNeill et al., 2018; Paleari, 2017; Frelih-Larson et al., 2016; Glæsner et al., 2014). This initial list was then evaluated and complemented by a quick review of those policy documents referenced by the policies already identified under the previous step. In addition, we explored information collected through a 2018 survey of the members of the Soil Expert Group ${ }^{13}$. Finally, we closely monitored new policy developments to capture any policy initiatives that could potentially increase soil and land protection as a basis for meeting the SDGs. There are several actions planned under the new Green Deal and which are to be further developed. These are not included in the analysis presented here (see Box 3.3).

Box 3.3 New EU-level policy initiatives relevant to soil and land

\section{The Soil Thematic Strategy}

To fulfil EU and international commitments on land-degradation neutrality, the Commission will update the EU Soil Thematic Strategy ${ }^{14}$ in 2021.

\section{The $8^{\text {th }}$ Environmental Action Programme (EAP)}

The 7th EAP, 'Living well, within the limits of our planet' came into force in 2014 and runs until the end of 2020.The 7th EAP formulated the objective that "Land is managed sustainably in the Union, soil is adequately protected and the remediation of contaminated sites is well underway" and called for actions to increase efforts to reduce soil erosion, enhance soil organic matter, remediate contaminated sites as well as to integrate land use aspects in coordinated policies at all levels of government. The EAP called on Member States to put policies in place to achieve no net land take by $2050^{15}$. The evaluation concluded that some progress towards achieving the objectives on land management and soil set out in the $7^{\text {th }}$ EAP have been made, citing the lack of a comprehensive instrument protecting soil, common definitions, targets, priorities, and harmonised monitoring methodologies.as the key challenges to fully achieving the formulated soil objectives ${ }^{16}$.

In October 2019, the Council of the European Union presented its conclusions of a meeting on the $8^{\text {th }}$ $\mathrm{EAP}^{17}$ and called upon the Commission "to present at the latest by early 2020 an ambitious and focused proposal for the 8th EAP for the period 2021-2030 [...] and stresses that the 8th EAP should build on the findings of the evaluation report of the 7th EAP, as well as the latest available science and knowledge, including the European environment - State and outlook 2020 report (SOER 2020)" (p.5). In its conclusions, the Council "underlines the need to take urgent additional action to protect and restore terrestrial, fresh water and marine biodiversity and ecosystem services, to promote nature-based solutions and to continue to promote sustainable management of soil" (p.8). In January 2020, the Commission published its new work programme which announced the upcoming launch of a legislative proposal for an 8th Environmental Action Programme (EAP).

\footnotetext{
13 In March 2018, the Commission administered a survey to the members of the EU Soil Expert Group which included the following two questions on the SDGs related to land and soil: (1) Do you agree that the objective of SDGs related to land and soil should be reflected in EU policies, in particular the 'Land Degradation Neutrality' target? If so, do you have any suggestions on how to do so? (2) Do you consider that there should be a coordinated approach at EU level to develop and implement Land Degradation Neutrality objective? Do you have any suggestions on how to do so?

${ }^{14}$ COM (2006) 231. Thematic Strategy for Soil Protection. Available at https://eur-lex.europa.eu/legalcontent/EN/TXT/?uri=CELEX:52006DC0231

${ }^{15}$ Decision No 1386/2013/EU of the European Parliament and of the Council of 20 November 2013 on a General Union Environment Action Programme to 2020 'Living well, within the limits of our planet'. Available at: https://eurlex.europa.eu/legal-content/EN/TXT/?qid=1597142785391\&uri=CELEX:32013D1386.

${ }^{16}$ SWD(2019) 181 final COM(2019) 233 final. Evaluation of the 7th Environment Action Programme to 2020 "Living well, within the limits of our planet" Accompanying the document Report from the Commission to the European Parliament, the Council, the European Economic and Social Committee and the Committee of the Regions on the evaluation of the $7^{\text {th }}$ Environment Action Programme COM(2019) 233 final. Available at: https://ec.europa.eu/environment/actionprogramme/pdf/SWD_2019_181_F1_OTHER_STAFF_WORKING_PAPER_EN_V3_P2_1022341.pdf.

17 Council of the European Union. 2019. The 8th Environment Action Programme: Turning the Trends Together - Council conclusions. Available at: https://www.consilium.europa.eu/media/40927/st12795-2019.pdf.
} 


\section{The European Green Deal ${ }^{18}$}

The European Green Deal sets out the roadmap for making the EU's economy sustainable and sets out several key actions which will be crucial in advancing land and soil protection in Europe. The Zero Pollution Action Plan for Air, Water and Soil that the Commission will adopt in 2021 will address pollution of soil and land. Soil sealing, the re-use of excavated soil and rehabilitation of contaminated brownfields will also be addressed in the upcoming Strategy for a Sustainable Built Environment. As part of the Commission's Zero Pollution Ambition for a toxic-free environment, a new EU Chemicals Strategy for Sustainability will be put forward.

The recently published Farm to Fork ${ }^{19}$ and the Biodiversity Strategy ${ }^{20}$ set out the following targets and commitments:

- to promote the objective of zero pollution from nitrogen and phosphorus flows from fertilisers by at least $50 \%$ and fertiliser use by at least $20 \%$. This should be achieved by strengthening the full implementation and enforcement of relevant environmental and climate legislation, and an action plan for integrated nutrient management (by 2022) \%;

- to reduce the overall use of and risk of chemical pesticides by $50 \%$ and the use of more hazardous pesticides by $50 \%$ by 2030 ;

- to recognise at least $10 \%$ of agricultural land as high-diversity landscape features;

- at least $25 \%$ of the EU's agricultural land must be organically farmed by 2030 ;

- commitment to significant progress in the remediation of contaminated soils.

\section{Horizon Europe: Mission on soil health and food}

The new European Research and Innovation Framework Programme, Horizon Europe, will commence in 2021. The European research and innovation missions, which are an integral part of the Horizon Europe framework programme, aim to deliver solutions to some of the greatest challenges facing our world, including one on soil health and food. The mission is still under development. Currently the aims of this mission are: (i) become the key tool to raise society's awareness of the importance of soils, engage with citizens, (ii) put Europe on a path towards sustainable land and soil management, (iii) create and combine knowledge and develop solutions for restoring soil health and soil functions. This is aimed to allow full use of the potential of soils to mitigate the effects of climate change and have wide-reaching impacts on food, people, and the planet. The results of the mission will directly feed into the new European Green Deal and contribute to the implementation of the SDGs.

Policies were organised into different policy clusters ${ }^{21}$ and then further categorised by type of policy instrument $^{22}$. In total, this scoping exercise generated a list of 28 policies (see Table 3.2). We acknowledge that this is not an exhaustive list of all policies at EU level which directly or indirectly impact on land and soil quality. They represent those policies most frequently cited by existing assessments reviewed for this analysis and found to be most relevant by the authors of this report.

\footnotetext{
${ }^{18} \operatorname{COM}(2019) 640$ final. The European Green Deal. Available at: https://ec.europa.eu/info/sites/info/files/european-greendeal-communication_en.pdf.

${ }^{19} \operatorname{COM}(2020)$ 381. final A Farm to Fork Strategy for a fair, healthy and environmentally-friendly food system. Available at https://eur-lex.europa.eu/legal-content/EN/TXT/?uri=CELEX:52020DC0381.

${ }^{20} \mathrm{COM}(2020) 380$ final. Biodiversity Strategy for 2030 Bringing nature back into our lives. Available at: https://eurlex.europa.eu/legal-content/EN/TXT/?qid=1590574123338\&uri=CELEX:52020DC0380.

${ }^{21}$ The organisation of the policies identified into different policy clusters is based on the author's judgement and does not necessarily align with other classifications.

${ }^{22}$ Regulatory instruments (European legislative acts, including direct regulations, directives and decisions, targets, standards, bans, permits/quotas, planning/zoning) impose obligations, prohibitions or restrictions, introduce standards; Planning instruments (Action programmes, strategies, communications (e.g. green papers, white papers, roadmaps) provide orientation for policy-making; Economic instruments (Pricing, such as tariffs, taxes and charges and tradable allowances, subsidies, risk liability schemes, green public procurement, voluntary agreements) sanction or reward behaviour through market mechanisms; and Information instruments (Information campaigns, labelling, stakeholder and public participation, training, advisory services) aim to stimulate changes in public preferences and behaviour; generate information for policy formulation and evaluation.
} 
Table 3.2 Policies selected for analysis

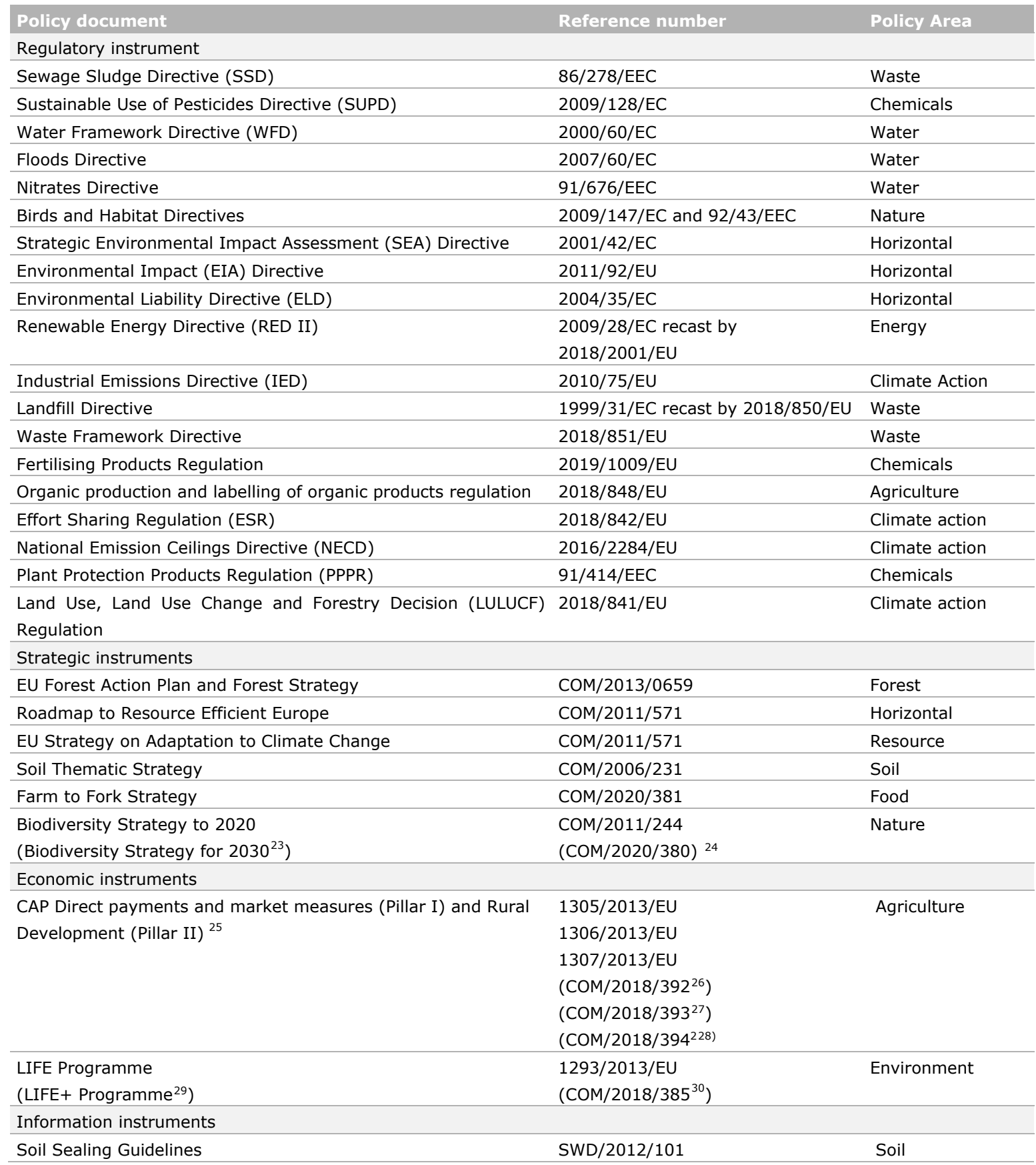

\footnotetext{
${ }^{23}$ The analysis presented in this document covers both the Biodiversity Strategy to 2020 and the new EU Biodiversity Strategy for 2030 which was published in May 2020.

${ }^{24}$ COM(2020) 380 final Biodiversity Strategy for 2030 Bringing nature back into our lives. Available at: https://eurlex.europa.eu/legal-content/EN/TXT/?qid=1590574123338\&uri=CELEX:52020DC0380.

25 In June 2018, the proposal for the post-2020 CAP was tabled; the analysis presented in this document covers both the existing and proposed regulations (as they were published in June 2018).

${ }^{26}$ Proposal for a Regulation establishing rules on support for strategic plans to be drawn up by Member States under the Common agricultural policy (CAP Strategic Plans) COM/2018/392 final.

${ }^{27}$ Proposal for a Regulation on the financing, management and monitoring of the common agricultural policy and repealing Regulation (EU) No 1306/2013. COM/2018/393 final.

${ }^{28}$ Proposal for a Regulation amending Regulations (EU) No 1308/2013 establishing a common organisation of the markets in agricultural products, (EU) No 1151/2012 on quality schemes for agricultural products and foodstuffs, (EU) No $251 / 2014$ on the definition, description, presentation, labelling and the protection of geographical indications of aromatised wine products, (EU) No 228/2013 laying down specific measures for agriculture in the outermost regions of the Union and (EU) No 229/2013 laying down specific measures for agriculture in favour of the smaller Aegean islands COM/2018/394 final/2.

${ }^{29}$ The analysis presented in this document covers both the current legislation as well as the proposal for a new regulation which was tabled in June 2018 and provides for a date of application as of 1 January 2021.

${ }^{30}$ Proposal for a Regulation establishing a Programme for the Environment and Climate Action (LIFE) and repealing Regulation (EU) No 1293/2013 final. COM/2018/385 final.
} 
Having identified the policies potentially relevant for implementing land and soil-related SDGs, the next step was to examine the extent to which the selected policies address - directly or indirectly different soil functions or threats. The analysis was recorded in a policy inventory, and included:

- Name of policy and official number

- Policy area (Nature, Water, Soil etc.)

- Type of interventions/measures

- General description

- Objectives/targets/priorities that are directly or indirectly relevant for soil/land

- Interventions/measures that are directly or indirectly relevant for soil/land

- Soil threats and functions that the policy may directly or indirectly improve/maintain (soil function) or reduce/prevent (soil threats)

- Relevance of policy for ensuring progress towards meeting SDGs

The review and description of these policies mainly drew from the original policy text as well as

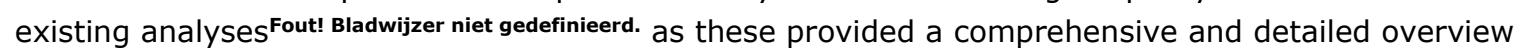
of relevant EU policies, links to soil threats and function, opportunities, and weaknesses.

\subsubsection{Relevance of EU policies for meeting the SDGs}

This section presents a summary of the potential contributions of EU policies to improving soil and land protection and management as a basis for meeting selected SDGs. A detailed analysis of how the different policies analysed here might contribute to meeting the SDGs by preventing and reducing soil threats as well as maintaining and improving soil functions can be found in Annex 4. It is important to note here that our assessment of the relevance of a given policy does not consider its actual effectiveness in the implementation of soil and land related SDGs. Many of the existing policies were created before the adoption of the SDGs and therefore do not explicitly reference the SDGs. An assessment of policy effectiveness is beyond the scope of this project.

The table below illustrates the large number of policy instruments that enable the implementation of SDGs, either through defining objectives and targets that - directly or indirectly - promote the protection or restoration of soil and land, or the provision of specific instruments and measures that could contribute to meeting the SDGs. Out of the 28 policy instruments reviewed, 14 contribute directly (in bold) to meeting at least three of the seven SDGs covered by this analysis. 
Table 3.3 Extent to which existing EU-level policy instruments for contributing to the achievement of the SDGs

\begin{tabular}{|c|c|c|c|c|c|c|c|c|c|c|}
\hline \multirow[b]{2}{*}{ Policy } & \multicolumn{7}{|c|}{ Relevance for progress towards meeting SDGs } & \multicolumn{3}{|c|}{ Total } \\
\hline & 2 & $-\sqrt{6}$ & 6 & 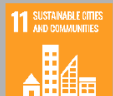 & POS & 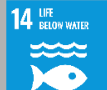 & 15 & ++ & + & $+/-$ \\
\hline \multicolumn{11}{|l|}{ Regulatory instruments } \\
\hline SSD & + & ++ & $+/-$ & & + & $+/-$ & ++ & 2 & 2 & 2 \\
\hline SUPD & + & ++ & ++ & & + & ++ & ++ & 4 & 2 & \\
\hline WFD & + & ++ & ++ & + & + & ++ & + & 3 & 4 & \\
\hline Floods Directive & + & + & + & + & + & ++ & ++ & 2 & 6 & \\
\hline Nitrates Directive & + & ++ & ++ & & + & ++ & + & 3 & 3 & \\
\hline Birds and Habitat Directive & & + & + & & + & + & ++ & 1 & 5 & \\
\hline SEA Directive & + & + & + & + & + & + & + & & 7 & \\
\hline EIA Directive & + & + & + & + & + & + & + & & 7 & \\
\hline ELD & ++ & ++ & + & ++ & & + & ++ & 4 & 2 & \\
\hline RED II & + & + & + & + & $+/-$ & + & $+/-$ & & 5 & 2 \\
\hline IED & ++ & ++ & ++ & ++ & + & ++ & ++ & 6 & 1 & \\
\hline Landfill Directive & & ++ & ++ & ++ & & ++ & ++ & 5 & & \\
\hline Waste Framework Directive & + & ++ & ++ & ++ & & + & ++ & 4 & 2 & \\
\hline Fertilising Products Regulation & + & + & + & + & + & + & + & & 7 & \\
\hline Organic Regulation & + & + & + & & + & + & + & & 7 & \\
\hline ESR & + & + & + & & ++ & + & ++ & 2 & 4 & \\
\hline NECD & ++ & ++ & + & & + & + & ++ & 3 & 3 & \\
\hline PPPR & & ++ & + & ++ & 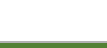 & + & ++ & 3 & 2 & \\
\hline LULUCF Regulation & + & + & + & & ++ & + & ++ & 2 & 4 & \\
\hline \multicolumn{11}{|l|}{ Planning instruments } \\
\hline $\begin{array}{l}\text { EU Forest Action Plan and } \\
\text { Forest Strategy }\end{array}$ & & & & & ++ & & ++ & 2 & & \\
\hline $\begin{array}{l}\text { Roadmap to Resource } \\
\text { Efficient Europe }\end{array}$ & ++ & + & ++ & ++ & ++ & ++ & ++ & 6 & 1 & \\
\hline $\begin{array}{l}\text { EU Strategy on Adaptation to } \\
\text { Climate Change }\end{array}$ & + & + & + & + & + & + & + & & 7 & \\
\hline Soil Thematic Strategy & ++ & ++ & ++ & ++ & ++ & ++ & ++ & 7 & 1 & \\
\hline Farm to Fork Strategy & ++ & ++ & + & + & ++ & + & ++ & 6 & 1 & \\
\hline Biodiversity Strategy & ++ & ++ & ++ & ++ & ++ & ++ & ++ & 7 & & \\
\hline \multicolumn{11}{|l|}{ Economic instruments } \\
\hline $\begin{array}{l}\text { CAP Direct payments and } \\
\text { market measures (Pillar I) } \\
\text { and Pillar II (Rural } \\
\text { Development) }\end{array}$ & ++ & + & + & + & ++ & + & ++ & 3 & 4 & \\
\hline LIFE Programme & + & + & + & + & + & + & + & & 7 & \\
\hline \multicolumn{11}{|l|}{ Information instruments } \\
\hline Soil Sealing Guidelines & + & + & + & + & + & + & ++ & 1 & 6 & \\
\hline
\end{tabular}

\section{Key to table}
$++$
A policy is highly relevant for a specific SDG, meaning that that its objectives and measures may directly contribute to meeting the respective SDG.
$+\quad$ A policy has an indirect and somewhat weaker link to a specific SDG.
$+/-\quad$ A policy might both facilitate and hinder meeting a specific SDG

Many of the policies assessed to have the strongest direct links to land and soil, and to most of the relevant SDGs, are mainly of a strategic nature, meaning that whilst they might explicitly address land and soil, they serve as a framework for other policies. This includes the Soil Thematic Strategy from 2006 that continues to form the cornerstone of EU-level policy on soil, the Roadmap to Resource Efficient Europe as well as the recently published Farm to Fork and Biodiversity Strategies. With the adoption of the last two Strategies, there is now a set of quantitative targets at EU level which take the form of broad ambitions (see table below). Whilst broad ambitions provide a high-level framework 
for soil and land protection, they clearly need to be translated in measurable, action-oriented policy targets, specifying incremental steps to be taken to ensure their realisation.

Table 3.4 Overarching quantitative soil and land targets at EU level

\begin{tabular}{|c|c|}
\hline Policy & Targets \\
\hline $\begin{array}{l}\text { Roadmap to a Resource Efficient } \\
\text { Europe }^{31}\end{array}$ & $\begin{array}{l}\text { By } 2050 \text {, all resources are sustainably managed, including land and soil: } \\
\text { - By } 2020 \text {, the area of land in the EU that is subject to soil erosion of more than } \\
10 \text { tonnes per hectare per year should be reduced by at least } 25 \% \text {, and } \\
\text { - By } 2020 \text {, SOM levels do not decrease overall and increase for soils currently with } \\
\text { less than } 3.5 \% \text { organic matter. }\end{array}$ \\
\hline
\end{tabular}

Despite the lack of any legislative instruments specifically targeting the protection, maintenance and improvement of land and soil at EU-level, there is an array of sectoral and environmental policies that directly or indirectly address different aspects of land and soil management, thus providing opportunities to enable the implementation of the land and soil-related SDGs. In a 2018 Commission survey on soil policy development (EEA, 2016), half of the responding Member States acknowledged the comprehensive policy framework at EU level and highlighted the need to integrate land and soilrelated SDGs into existing instruments.

Our assessment identifies the following regulatory, planning, and economic instruments as highly relevant for meeting the soil and land-related SDGs ${ }^{34}$ :

- The Sustainable Use of Pesticides Directive: the Directive contributes directly to SDGs 3, 6 and $\mathbf{1 4}$ by reducing the amount of harmful chemicals entering the soil, the aquatic and marine environment and agricultural products. Integrated pest management and other practices promoted by the Directive support SDG 15. Pesticides reduce soil microorganisms, resulting in reduced soil biodiversity and soil organic matter content. Low organic matter content results in lower water retention and reduced yields especially during drought and reduces the soil's carbon storage capacity. Thus, the SUPD is also likely to contribute to SDGs $\mathbf{2}$ and $\mathbf{1 3}$ to some extent.

- The Water Framework Directive: the WFD does not explicitly address soil protection; however, its objectives will indirectly deliver several co-benefits for soil health and is likely to contribute towards meeting all SDGs to some extent: reducing soil contamination (SDG 3 and SDG 11), as less pollution means a lower risk of contamination for agricultural and urban areas; lower pollution levels along with erosion control also means lower harmful inputs into the marine environment (SDG 14), and minimisation of landslides/floods reduces land and soil degradations (SDG 15). The WFD's impacts on soil health in general will ultimately also benefit food production (SDG 2) and mitigating climate change impacts (SDG 13).

- The Nitrates Directive aims to protect surface waters and groundwater against pollution by nitrates from agricultural sources by establishing limit values and promoting good farming practices. Measures contained in the Codes of Good Agricultural Practice, albeit voluntary outside designated Nitrate Vulnerable Zones, may halt land degradation (SDG 15) and mitigate climate change impacts (SDG 13). Reduced runoff and leaching should decrease input into the aquatic and marine

\footnotetext{
${ }^{31}$ Qualitative targets were first established by the 7th EAP which states that, by 2020, land is managed sustainably and soi is adequately protected, requiring in particular 'increasing efforts to reduce soil erosion and increase soil organic matter,' and enhancing 'the integration of land use aspects into coordinated decision-making involving all relevant levels of government, supported by the adoption of targets on soil and on land as a resource, and land planning objectives'.

$32 \operatorname{COM}(2020) 381$. final A Farm to Fork Strategy for a fair, healthy and environmentally-friendly food system. Available at https://eur-lex.europa.eu/legal-content/EN/TXT/?uri=CELEX:52020DC0381.

${ }^{33} \operatorname{COM}(2020) 380$ final. Biodiversity Strategy for 2030 Bringing nature back into our lives. Available at: https://eurlex.europa.eu/legal-content/EN/TXT/?qid=1590574123338\&uri=CELEX:52020DC0380.

${ }^{34}$ An analysis of all policies reviewed in this study can be found in Annex 4 .
} 
environment, thus benefitting SDGs 6 and 14. Better soil health will ultimately ensure sustained food production and thus contribute to SDG 2.

- The Environmental Liability Directive: the Directive establishes a framework of environmental liability based on the 'polluter-pays' principle, to prevent and remedy environmental damage. The Directive covers damage to land, water, and biodiversity with (or under) land. It directly contributes to reducing soil contamination, and the loss of soil biodiversity. Reducing soil contamination ensures that soil can be safely used for human activities and biomass production. The Directive therefore contributes to SDGs $\mathbf{2}, \mathbf{3}, \mathbf{1 1}$, and 15 . Decreased soil pollution can indirectly lower levels of contaminants entering the aquatic and marine environment (SDG 6 and 14).

- The Industrial Emissions Directive: the Directive aims to reduce and prevent emissions to air, water and land and reduce environmental impacts from industrial activities through a system of integrated permitting. The Directive covers both diffuse as well as point source pollutants from industry/combustion plant/waste installations and explicitly covers impacts on soils. Reduced soil contamination ensures that soil can be used safely for human activities and the production of biomass. The policy therefore contributes to SDGs $\mathbf{2}, \mathbf{3}, \mathbf{1 1}$, and $\mathbf{1 5}$. Reducing contamination to land and water will also indirectly contribute to fewer contaminants entering the aquatic and marine environment (SDGs 6 and 14).

- The Landfill Directive: the Directive aims to reduce and prevent emissions to air, water and land and reduce environmental impacts from industrial activities through a system of integrated permitting. The Directive covers both diffuse as well as point source pollutants from industry/combustion plant/waste installations and explicitly covers impacts on soils. Reduced soil contamination ensures that soil can be used safely for human activities and the production of biomass. The policy therefore contributes to SDGs 2, 3, 11, and 15. Reducing contamination to land and water will also indirectly contribute to fewer contaminants entering the aquatic and marine environment (SDGs 6 and 14).

- The Waste Framework Directive: the Directive aims to reduce the negative impact of waste generation and management on the environment and to increase the efficiency of resource use. Member States must take measures to ensure that waste management is carried out without endangering human health or the environment, including water, air, soil, plants, or animals. Measures are likely to reduce both local and diffuse contamination through deposition from water courses, run-off etc. Reducing soil contamination will ensure land can be used safely for human activities, and contribute directly to SDGs 311 , and 15 and to at least some extent, SDGs 6 and 14. The Directive promotes using biowaste for composting or anaerobic digestions, which could potentially contribute to improving soil organic matter, especially on agricultural land (SDG 2).

- The National Emissions Ceiling Directive: the NECD sets emission reduction commitments for 2020 and 2030 for five major air pollutants. It does not establish any soil-specific targets; however, Member States must draw up National Air Pollution Control Programmes containing an assessment of the likely impact of national emissions on air quality and identify mitigation measures. By limiting emissions, the carbon storage capacity of soil may be improved, and healthy fertile soils maintained for food production (SDG 2 and 15). Reducing emissions to soil will also contribute to SDG 3, and maintaining and protecting the carbon storage function of soils will contribute to SDG 13. Additional benefits will include a reduction of pollution in marine and aquatic environments.

- The Plant Protection Products Regulations: the PPPR requires that plant protection products have no unacceptable effects on the environment, specifically mentioning the contamination of soil and establishes procedures and criteria for the approval of active substances, safeners and synergists. The Regulation aims to protect human and animal health and the environment and prevent soil pollution from pesticides. It thus directly contributes to SDGs $\mathbf{3 , 1 1}$, and 15. Minimising soil pollution will also reduce harmful substances in freshwater and the marine environments, thus contributing to SDGs 6 and 14.

- The Roadmap to Resource Efficient Europe: the Roadmap for Resource Efficient Europe provides strategic direction for the Member States by urging them to take action to achieve sustainable soil management by 2050. Actions target soil erosion, sealing and land take in general, contamination, and the decline of soil organic matter. The Roadmap promotes further research into ways of improving fertilisers, food production and bio-waste issues which could reduce dependence on mined phosphate. This will benefit soil protection, especially soil fertilisation. Finally, the Roadmap promotes further integration of resource-efficiency considerations into water policy and setting water efficiency targets. This could eventually minimise the impacts of droughts and floods by increasing 
water retention in soils and efficient irrigation, which would therefore lead to better soil protection and contribute to minimising the risk of desertification. The Roadmap is likely to contribute to all SDGs. However, it is non-binding and only recommends Member States adopt soil and land protection actions.

- The Farm to Fork Strategy: the strategy is part of the 'European Green Deal' and aims to ensure sustainable food production, food security and fighting against food loss and waste. The strategy sets the objective of allocating at least $25 \%$ of EU agricultural land to organic farming by 2030 and to significantly increase the share of organic aquaculture, achievable through incentives complementary to the CAP, fiscal incentives and mandatory minimum criteria for sustainable food supplies from public authorities. Regarding chemical pesticides, the Commission intends to take additional measures to reduce the overall use and risk of chemical pesticides by $50 \%$ and the use of more hazardous pesticides by $50 \%$ by 2030 . On excessive nutrients (nitrogen and phosphorus), the Commission will work to reduce nutrient losses by at least $50 \%$ while ensuring that soil fertility does not deteriorate. These targets and associated actions will contribute significantly to SDGs $\mathbf{2}, \mathbf{3}, \mathbf{1 3}$, and 15. They will also provide important co-benefits for SDGs 6, 11, and 14.

- The Biodiversity Strategy: the EU Biodiversity Strategy for 2020 defines the EU's 2050 long-term vision for biodiversity and sets specific targets for 2020. The Strategy does not explicitly address land and soil but Target 2, "By 2020, ecosystems and their services are maintained and enhanced by establishing green infrastructure and restoring at least $15 \%$ of degraded ecosystems", is indirectly relevant for soil protection. Sub-targets and associated actions are expected to have indirect positive impacts on soil health overall, and thus all SDGs. The new Biodiversity Strategy for 2030 formulates a number of new soil-relevant targets (see Box 2.3) which aim to significantly reduce soil pollution from fertilisers and pesticides, make significant progress with the remediation of contaminated soils, and increase the share of organically farmed land. According to the Strategy, at least EUR 20 billion per year (from public and private funding at EU and national levels) should be spent on nature spending and a significant proportion of the $25 \%$ of the EU climate action budget will be devoted to biodiversity and nature-based solutions. If all these targets of the Biodiversity Strategy can be realised, it will greatly contribute to all SDGs.

- CAP Direct payments and market measures (Pillar I) and Pillar II (Rural Development): The CAP aims to integrate ambitious standards on climate change, environmental services, and animal welfare into common farming practices. The current system deploys several instruments to this end. Direct payments are tied to cross-compliance and greening, both of which include practices that are good for the environment (and soil in particular) (Pillar I). Under Pillar 2, voluntary practices that contribute to the same objectives are rewarded with additional financial support. Direct payments are payed to farmers based on land area, with some exceptions. Cross compliance is the mechanism that links direct payments to compliance by farmers and includes two elements: statutory management requirements and good agricultural and environmental condition (GAEC). More specifically: GAEC 4 concerns minimum soil cover; GAEC 5 concerns minimum land management (important to prevent landslides/floods and thus SDGs 2 and 15); GAEC 6 concerns maintenance of organic soil matter (directly relevant for maintaining carbon storage capacities and biomass production and thus for SDGs 2 and SDG 13); in addition GAEC 1 concerns establishment of buffer strips along water courses which might reduce nutrient/chemical inputs to surface/groundwater and eventually the marine environment, this also reducing soil contamination (relevant for SDGs 6 and 14); GAEC 7 concerns retention of landscape features (indirectly contributing to preventing loss of biodiversity and potentially which are relevant for SDGs 2 and 15). Another important element that links direct payments to environmental protection is the socalled greening measures. In order to receive the last 30\% of their land-based payments, farmers must comply with conditions relating to a) crop diversity b) permanent pasture c) Ecological Focus areas. Rural development measures (Pillar II) finance more demanding activities relating to farming, the environment and the reduction of greenhouse emissions ('agri-environment-climate measures'). From a soil protection and management perspective two of the six defined priorities, upon which Member States should build their RDPs, are the most relevant: restoring, preserving and enhancing ecosystems related to agriculture and forestry (focus area 4(c) - preventing soil erosion and improving soil management); and promoting resource efficiency and supporting the shift towards a low carbon and climate resilient economy in the agriculture, food and forestry sectors (focus area 5(e) - fostering carbon conservation and sequestration in agriculture and forestry). In June 2018, the European Commission published a legislative proposal for the CAP post-2020. The current 
system identifies six priorities and 18 focus areas for rural development which does not change the current structure substantially, other than incorporating the Rural Development Regulation into the CAP under Article 65. Currently, the AECMs are an important tool to deliver on environmental objectives and are the second most important measure in terms of financial allocation. The AECMs (now called $\mathrm{AECH}$; incorporating organic, Natura 2000, water framework directive payments, animal welfare, forestry and non-productive investments) are allocated between $30-43 \%$ of the Pillar 2 budget. As in the current system, these practices must go beyond what the farmers are already doing to fulfil enhanced conditionality. In the new system, enhanced conditionality replaces the cross-compliance and greening requirements but building on the current system of Statutory Management Requirements (SMRs) and Good Agricultural and Environmental Conditions (GAECs). New conditions with the potential to improve soil health have been added. Some of the new conditions incorporate greening requirements: permanent grassland is incorporated as GAEC 1 , ecological focus areas are reflected in GAEC 9, and crop rotation is introduced to replace crop diversification as GAEC 8 . Other new additions include the protection of wetlands and peatlands (GAEC 2). Eco-schemes are an important part of the new system. In their SPs, Member States will be required to set up voluntary eco-schemes for farmers, aiming to improve the climate and environmental ambition of the CAP. Such schemes will be available to farmers based on a list of practices (established by the Member States) that are beneficial for the environment and climate. Effective implementation of the CAP should lead to a decrease of all soil threats and an improvement of soil functions but will rely to a large extent on the Member States' SPs and their specification of the various GAECs. Similar to the existing CAP, the new CAP is expected to significantly contribute to meeting SDGs 2, 13, and 15, with smaller co-benefits for SDGs 3, 6, and 14.

The analysis shows that the existing policy framework is expected to contributes to meeting the SDGs at the focus of this study. Soil threats which potentially hamper progress towards meeting SDGs 3 and 15 are directly targeted by several policies, except for compaction, salinisation and, soil sealing. None of these are addressed by existing EU legislation (c.f. EEA 2020) ${ }^{35}$. Progress towards meeting the remaining SDGs is (to date) likely to be a result of policies indirectly addressing relevant soil functions and threats (see figure below).

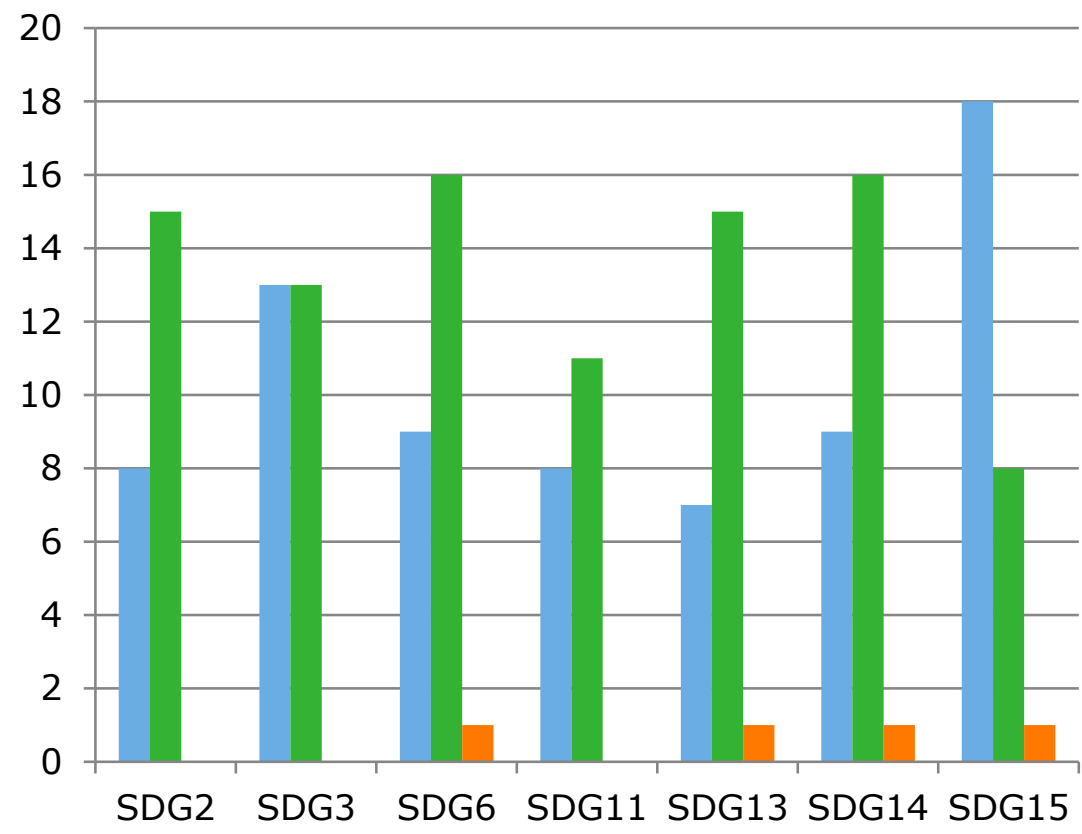

\author{
- Highly relevant \\ - Relevant \\ - Potential trade-offs
}

Figure 3.2 Number of relevant policies broken down by SDG

\footnotetext{
${ }^{35}$ Our analysis shows that these threats may indirectly be reduced through a number of horizontal policies, such as the EIA and SEA Directives as well as for example the Floods Directive (compaction) or the current CAP (salinisation). Soil Sealing is explicitly addressed by the Soil Sealing Guidelines which is however is a non-binding guidance document for the Member States.
} 
A general conclusion we can draw from our assessment is that many of the EU policies reviewed here focus on limiting or preventing soil threats rather than setting targets aiming to improve soil functions and soil health in general. This is particularly relevant for urban soils where policy focus is on preventing soil threats, most notably contamination and sealing, whilst the maintenance and improvement of soil functions which could ultimately benefit multiple SDGs remain largely ignored.

Finally, our analysis can only confirm and reiterate the conclusions offered by previous studies into the EU policy framework for land and soil (see e.g. Frelih-Larson et al 2016a and b; Glaesner et al 2014; Vrebos et al 2017): as it stands, there is no overarching, binding policy document which would clearly define EU-level priorities. Existing policies regulate various soil threats and functions; however, most land and soil outcomes are achieved as 'co-benefits' of policies on water, waste, agriculture, or climate action. Whilst this means soil protection through EU policies might not be effectively targeted, it also demonstrates that multiple environmental benefits could be realised, and subsequently a range of SDGs could be met by setting land and soil targets and through policies promoting sustainable land use and soil management.

\subsubsection{Member State actions and policies promoting land and soil-related SDGs}

The analysis of the state of play of implementation of land and soil-related SDGs in the EU Member States was carried out in two steps:

1. Data collection and analysis by Member State.

2. Comparative analysis and synthesis across all EU Member States.

Step 1 used a simple Member State template structured around the key research questions. These templates were then populated with both primary data and information from existing studies (Niestroy et al, 2019) as well as Member State reports compiled to contribute to various UN reporting exercises. The latter included Voluntary National Reviews (VNR) submitted by most Member States to the UN ${ }^{36}$, as well as reports put forward under the UNCCD's 2017-2018 Performance Review and Assessment of Implementation System (PRAIS) process ${ }^{37}$. Primary data were collected through a survey administered to the members of the EU SEG in 2019. This was complemented by information from other surveys, including a questionnaire (disseminated to the same group in 2018) on their input to preparatory work on EU soil policy development as well as a questionnaire administered within the context of the SURFACE project ${ }^{38}$.

Following the data collection phase, the templates were revised, and a factsheet produced for each Member State (see Annex 5). Step 2 aggregated Member State findings at EU level to gain a summary overview of the state of play of implementation. The table below gives an overview of the Member State coverage of the information sources consulted for each one. Whilst these sources provided enough information to deliver a snapshot of the implementation of land and soil-related SDGs within individual Member States, it failed to provide an EU-wide overview. We therefore used information available on the Soil Wiki which was produced under a previous study funded by DG Environment ${ }^{39}$. The Soil Wiki compiles the policies and activities reported by Member States relating to soil, categorising each activity as either explicitly or implicitly impacting each soil threat or function.

\footnotetext{
${ }^{36}$ Available on the UN website: https://sustainabledevelopment.un.org/vnrs/.

37 Available at https://prais.unccd.int/unccd/reports.

38 The SURFACE project on "(Inter)national Standards and Strategies for the Reduction of Land Consumption" is funded by the German Environment Agency (UBA) from 20172020. More information available at: https://www.ufz.de/surface/index.php?en=44130.

${ }^{39}$ Service contract for updated inventory and assessment of soil protection policy instruments in EU member states. The final project report was published by on their web site: http://ec.europa.eu/environment/soil/publications_en.htm.
} 
Table 3.5 Overview of Member State coverage of key sources of information

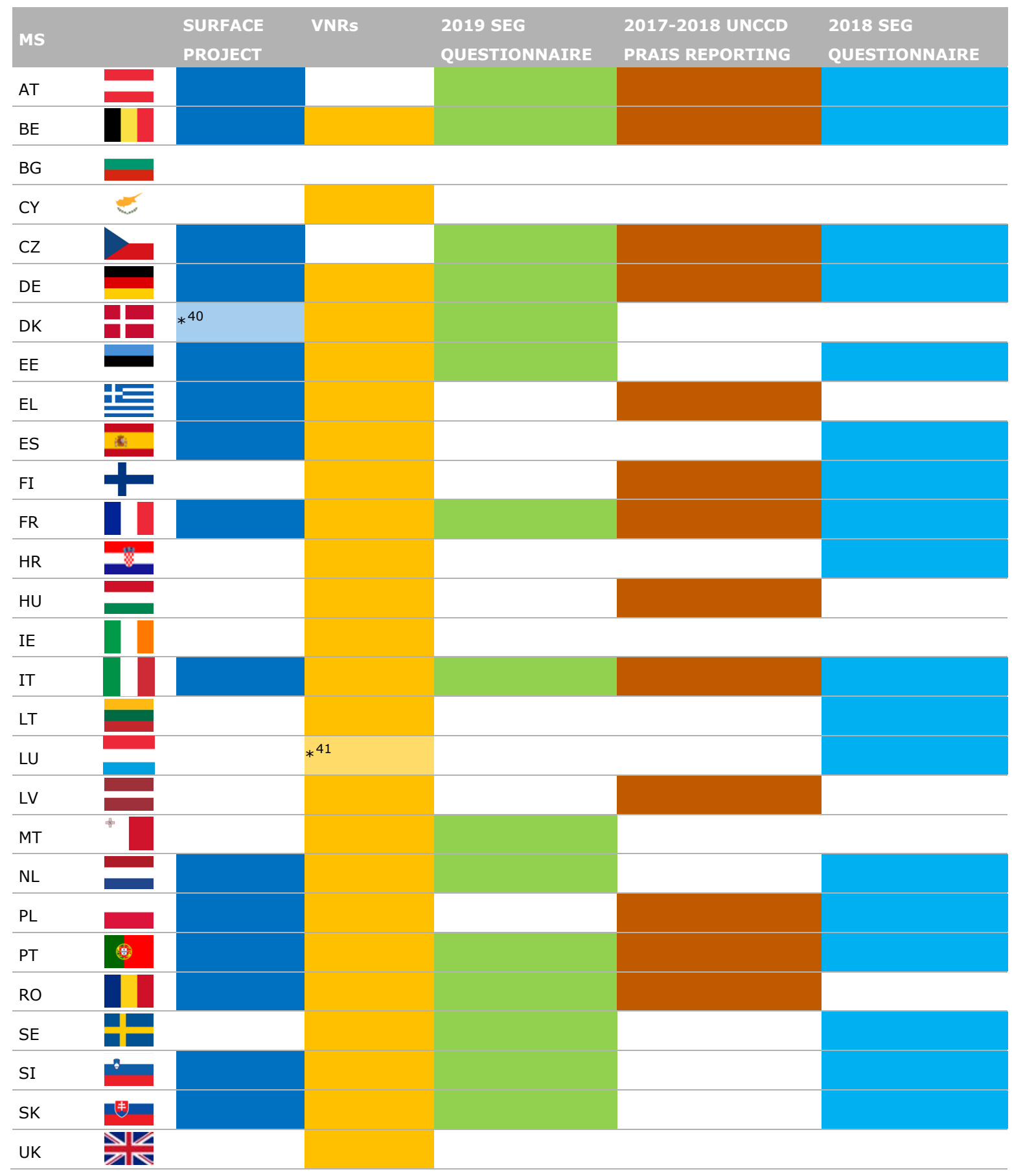

\subsubsection{SDG implementation and coordination at national level}

This section presents a summary of the findings from Member States with respect to their approaches to the implementation of the SDGs, in particular through the adoption of national sustainable development plans or strategies and the mechanisms of engaging both with authorities at various levels and other stakeholders.

Based on a recent review of SDG implementation in all EU Member States (Niestroy et al 2019), most Member States have adopted national sustainable development plans or strategies. Not all, however, address the SDGs as adopted in 2015. This may trigger the need to update these documents, a process already underway in several Member States such as Croatia, Spain, Latvia, Malta, and Lithuania (Figure 3).

\footnotetext{
${ }^{40}$ No relevant information

${ }^{41}$ In French
} 
The main authorities in charge of SDG implementation and sustainable development typically include the office of the Prime Minister, which sometimes chairs overarching commissions for sustainable development or other horizontal bodies (e.g. Czechia, France), and the Ministry of Environment (or sustainable development). In almost all Member States, the Ministry of Foreign Affairs is the external policy lead for implementation of the SDGs. Most Member States have established inter-ministerial committees or working groups to coordinate the implementation of the SDGs across the different sectors. All the Member States engage various types of stakeholders in the preparation of their sustainable development strategies. These activities take the form of online consultations, advisory councils, and the creation of special platforms to coordinate inputs from various experts and civil society organisations.

Table 3.6 provides a summary of the findings by Member State, focusing on the four research questions listed above. More detailed Member State fiches are available in Annex 5. 


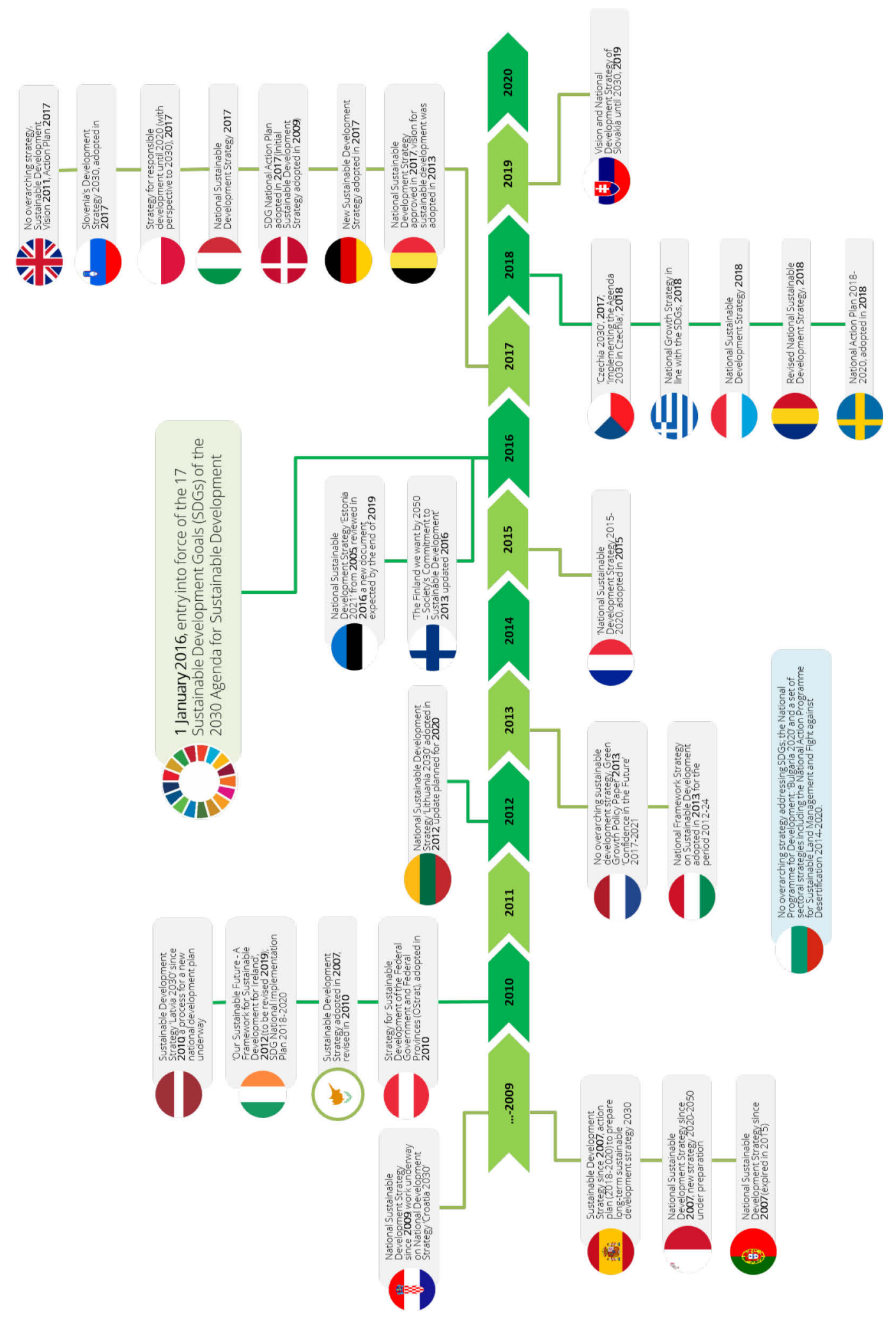

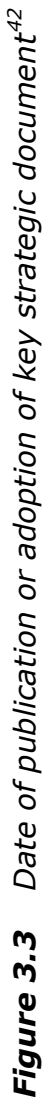




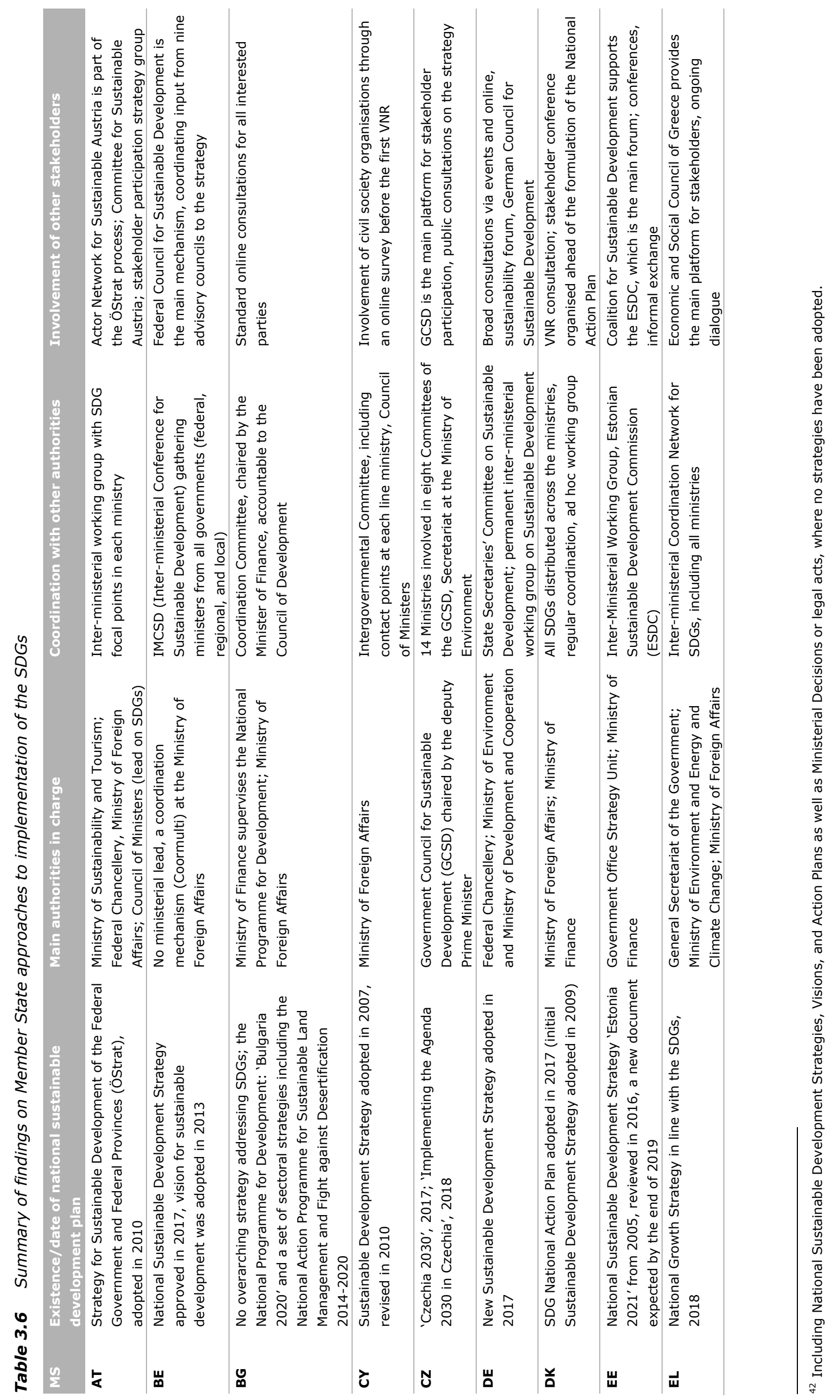




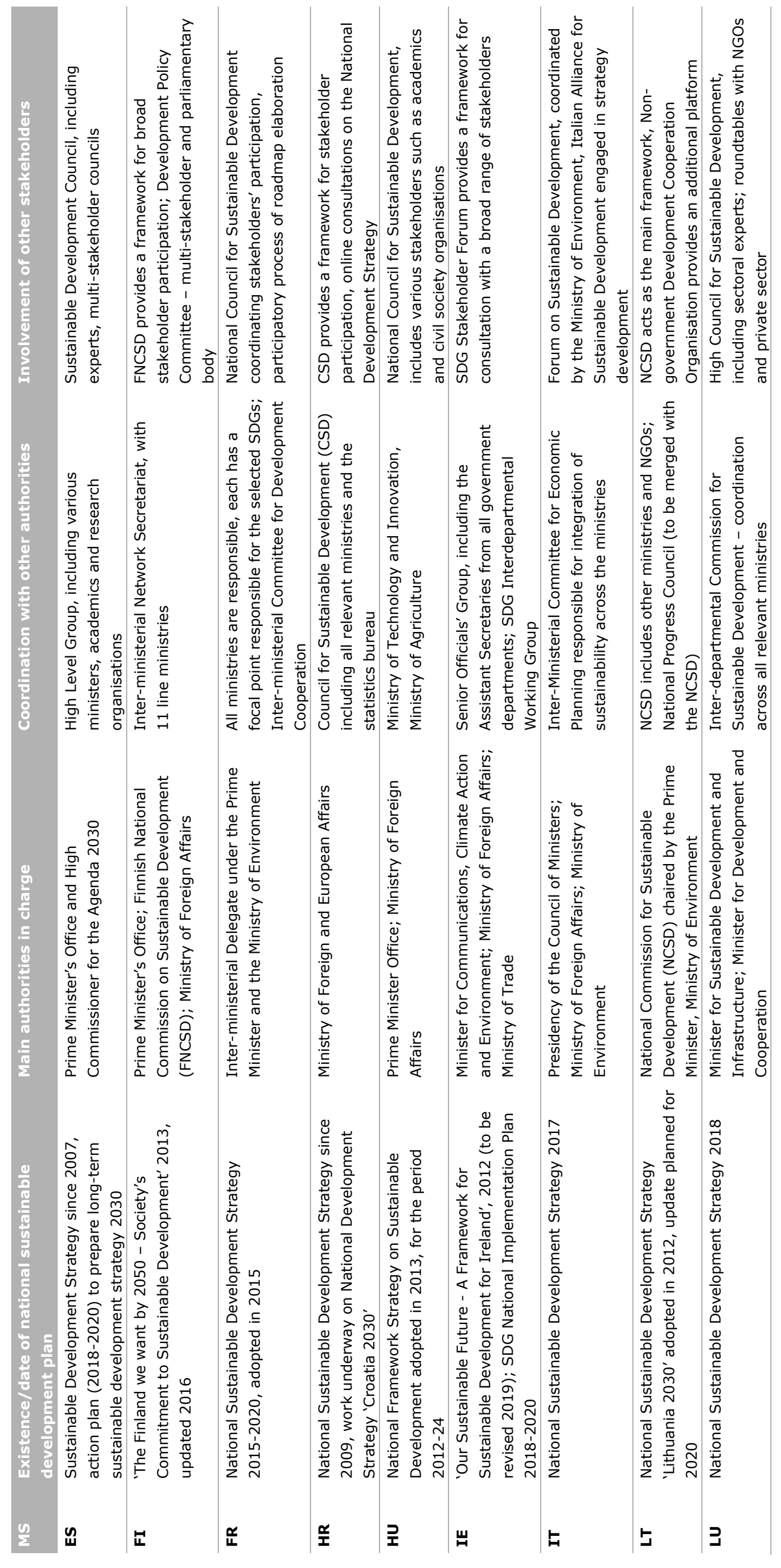




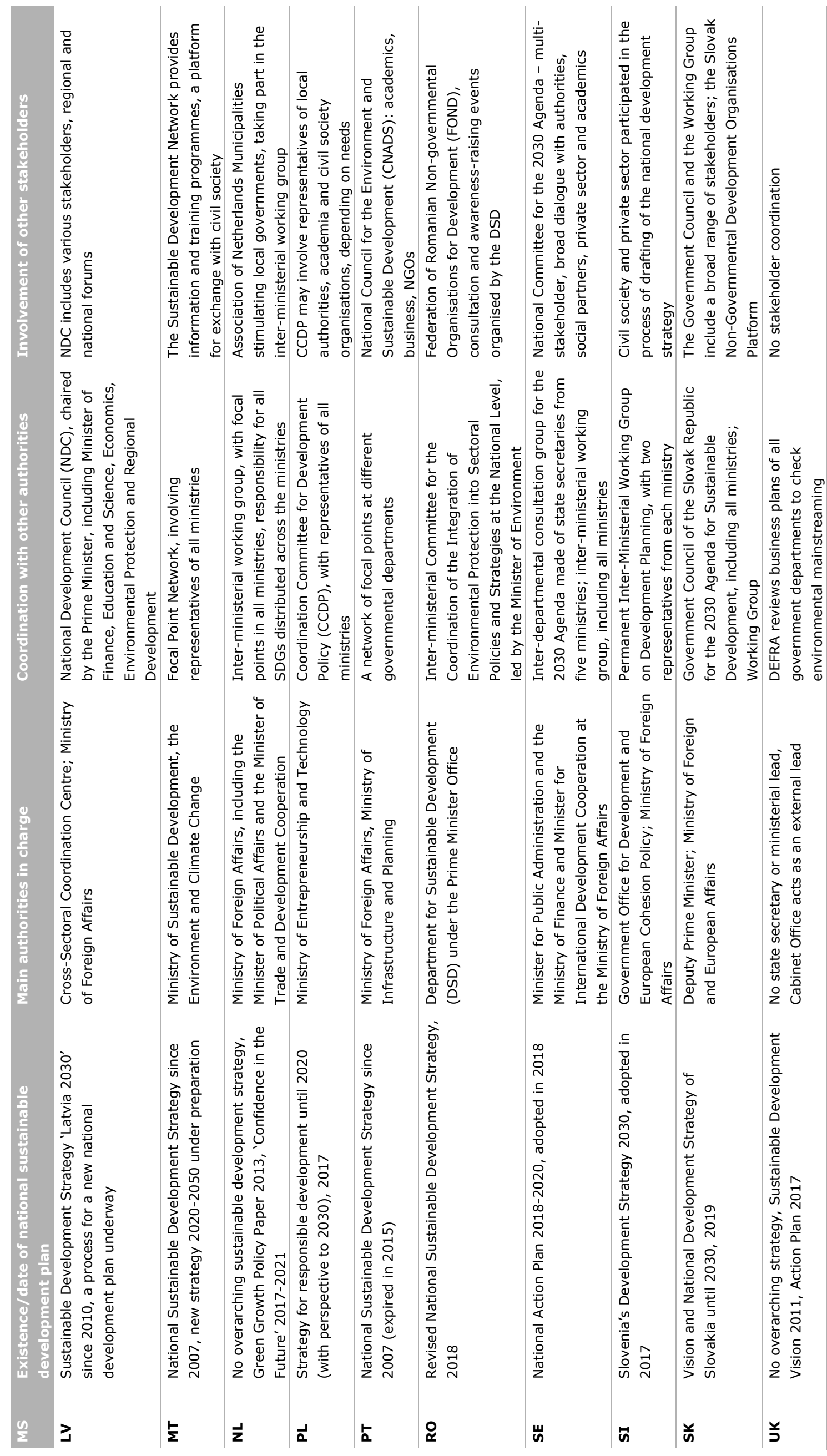




\subsubsection{Integration of land and soil-related SDGs in national sustainable development strategies}

Soil and land considerations are relevant for several SDGs, not just SDG 15.3. As such, there are many examples of elements of national sustainable development plans that affect - at least indirectly - soil and land, from the promotion of organic farming under SDG 2 to sustainable management of forests under SDG 12.

In some Member States, the national voluntary reviews gave insights into the national sustainable development plans themselves. In Cyprus, the National Action Plan for a Green Economy aims to exploit and enhance synergies between the environment and economic sectors, and includes measures across agriculture, water resources, biodiversity and green infrastructure, forests, energy, transport, industry, waste management, tourism, climate change and adaptation. Its key parameters include the provision of incentives to increase resource efficiency and enhance productivity.

Several Member States also included information in the questionnaires carried out as part of this project. Austria, for example, noted that there is no real link between the SDGs and the Austrian Strategy for Sustainable Development, as the latter predates the former.

In other Member States, the situation is more positive. In Czechia, the biodiversity chapter of the National Sustainable Development Plan covers:

- Promotion of hedges and buffer strips instead of fences and tracks on arable land;

- Leaving sufficient material on the land post-harvest;

- Well-managed organic fertilisation of arable land (e.g. using mining residue);

- Gradual development of gentle farming methods on forest land; and

- Prevention of further acidification of forest soils by cultivating trees suitable for the given environment instead of growing a monocrop of spruce.

In Germany, land take falls under SDG 11 and is covered in the National Sustainable Development Strategy with a target to decrease land consumption to less than $30 \mathrm{ha} / \mathrm{d}$ by 2030 . The relevant indicator for this is the increase in land take for settlement and traffic purposes. The Strategy focuses on biodiversity, ecosystems and forests under SDG 15 and explicitly mentions SDG target 15.3, to reach LDN by 2030. Land sealing and land take are identified as possible indicators for the implementation of LDN. The German authorities note that a new indicator is needed to identify changes in soil quality.

Other Member States did not provide such concrete information. Romania reported that its National Strategy for Sustainable Development (SNDD) includes some objectives for implementing the LDN target and land-related SDGs. Similarly, an important part of the Development Strategy of Slovenia 2030 is the sustainable management of natural resources with actions for achieving the goals. These actions include sustainable soil management and conservation of soil ecosystem services, prevention of further degradation and rehabilitation of degraded soils.

Member States were asked about their main activities at national level. Some include coordination mechanisms (which are covered in Section 0), such as the Government Council for Sustainable Development in Czechia, that implements and analyses SDGs associated with soil. Other examples include Austria's Conference on Spatial Planning (ÖROK), which mainstreams SDG 11 and is considered a remarkable step forward in enabling the mainstream efficient use of land and delimitation of land take. Similarly, Estonia pointed to the formation of the inter-ministerial and inter-institutional Estonian soil policy working group, which is intended to involve all of the main soil-related stakeholders. In the Netherlands, a congress was organised on the soil-related SDGs, attracting 500 participants from all kinds of Dutch soil networks. The Dutch survey respondent noted that there is a 'growing' awareness of the importance of land and soil for implementing the SDGs, and an increasing need for multifunctional land use.

Other activities identified included the use of economic tools targeting soil protection, such as those falling under national and EU policies (e.g. Czechia). In Denmark, regulation is supplemented by subsidy support schemes for projects reducing the load of nitrogen to Danish coastal waters. Such 
projects have a nitrogen-reduction purpose but also contribute to the protection of soils on farmland, the establishment and reestablishment of wetlands, afforestation, and set-aside of carbon-rich soils in river valleys. Despite being a sub-national activity, the Flemish subsidy scheme is also worth mentioning, where subsidies have been granted to municipalities since 2001 for:

1. Small-scale erosion control projects: the main objective of such projects is to collect as much of the surface water and sediment as possible on the plot or as quickly as possible after leaving the plot, so that the erosive effect of the water decreases, the sediment load can settle and the water can infiltrate or drain (controlled). Examples of small-scale erosion control works are: dams from plant materials; earthen dams with erosion pools; conductive earth dams; buffer basins; buffer moats; wood sides; recovery of embankments. Grass walks and grass buffer strips are also eligible for subsidies where they are physically connected to other furnishing or infrastructure works, or where construction requires the cooperation of several users.

2. the drafting of a municipal erosion control plan.

3. an erosion coordinator to guide and support the municipality in implementing the municipal erosion control plan.

Monitoring and review were also identified as activities for implementing land and soil-related SDGs. In Czechia, for example, it was noted that data from the evidence of land takes (managed by the Ministry of the Environment) is subject to annual review. In Slovenia, a project run by the Ministry of the Environment and Spatial Planning, Directorate for Spatial Planning, Construction and Housing and the Ministry of Infrastructure is seeking detailed data on built-up land.

Germany reported no new strategies for monitoring and reporting. However, initiatives on stakeholder involvement, communication, research, and development are being developed as part of the German Crop Management Strategy. Estonia noted the development of the National Soil Monitoring Programme, while Slovenia is preparing its national monitoring system for soil quality, including specific indicators.

With regard to information dissemination, Estonia's focus is on providing farmers with Big Data information and other web-based solutions to support decision-making in agriculture. At sub-national level, Wallonia's (Belgium) 'Integrated Management of Soil Erosion and Runoff' (GISER) has been in place as an Expertise and Consulting Unit since 2011. The unit makes recommendations on antierosion practices to municipalities dealing with erosion and mudslides. Its mission is to dissect the mechanisms of erosion and to propose effective control techniques. The team goes into the field, provides a detailed diagnosis and supports the implementation of specific solutions.

\subsubsection{National policies enabling implementation of land and soil-related SDGs}

The information in this section is drawn from a mix of data sources. The Member State questionnaire issued as part of this project was completed on a voluntary basis and generated only 18 responses from 15 Member States. Where possible, gaps were closed using other sources of information, such as the national voluntary reviews submitted by each Member State on their SDG progress. Whilst these sources provided enough information to deliver a snapshot of the implementation of land and soilrelated SDGs within individual Member States, it failed to provide an EU-wide overview. We therefore used information available on the Soil Wiki which was produced under a previous study funded by DG Environment ${ }^{43}$.

The Soil Wiki compiles the policies and activities reported by Member States relating to soil, categorising each activity as either explicitly or implicitly impacting each soil threat or function. This quantitative analysis is complemented by information reported by the Member States through the questionnaire administered by the project and under sources of information listed in Table 3.8.

It should be noted that activities may be regulatory and non-regulatory (such as 'awareness raising' or specific projects). Although each activity is described, it is beyond the scope of this assessment to determine whether an activity is national, regional, or local. Therefore, all activities, whether they are

\footnotetext{
${ }^{43}$ Service contract for updated inventory and assessment of soil protection policy instruments in EU Member States. The final project report was published by on their web site: http://ec.europa.eu/environment/soil/publications_en.htm.
} 
regulatory or not, national or not, have been used for the following assessment. For this reason, the results shown in this section must be viewed cautiously.

The figures below show the number of activities targeting different soil threats as reported for the Member States on the Soil Wiki. Figure 3.4 provides an overview of the total number of activities per soil threat across all Member States; the second figure shows the same information broken out by Member State. Contamination activities were identified most often, followed by those (especially implicitly) dealing with loss of soil biodiversity. The loss of soil organic matter and erosion were also covered by a large number of activities. There are very few activities either directly or indirectly addressing desertification or acidification, perhaps because of both a lack of EU-level policy and varying geographic characteristics. When comparing activities across the different Member States, it was unsurprising that those federal or strongly regional Member States reported more activities due to a high number of regional activities.

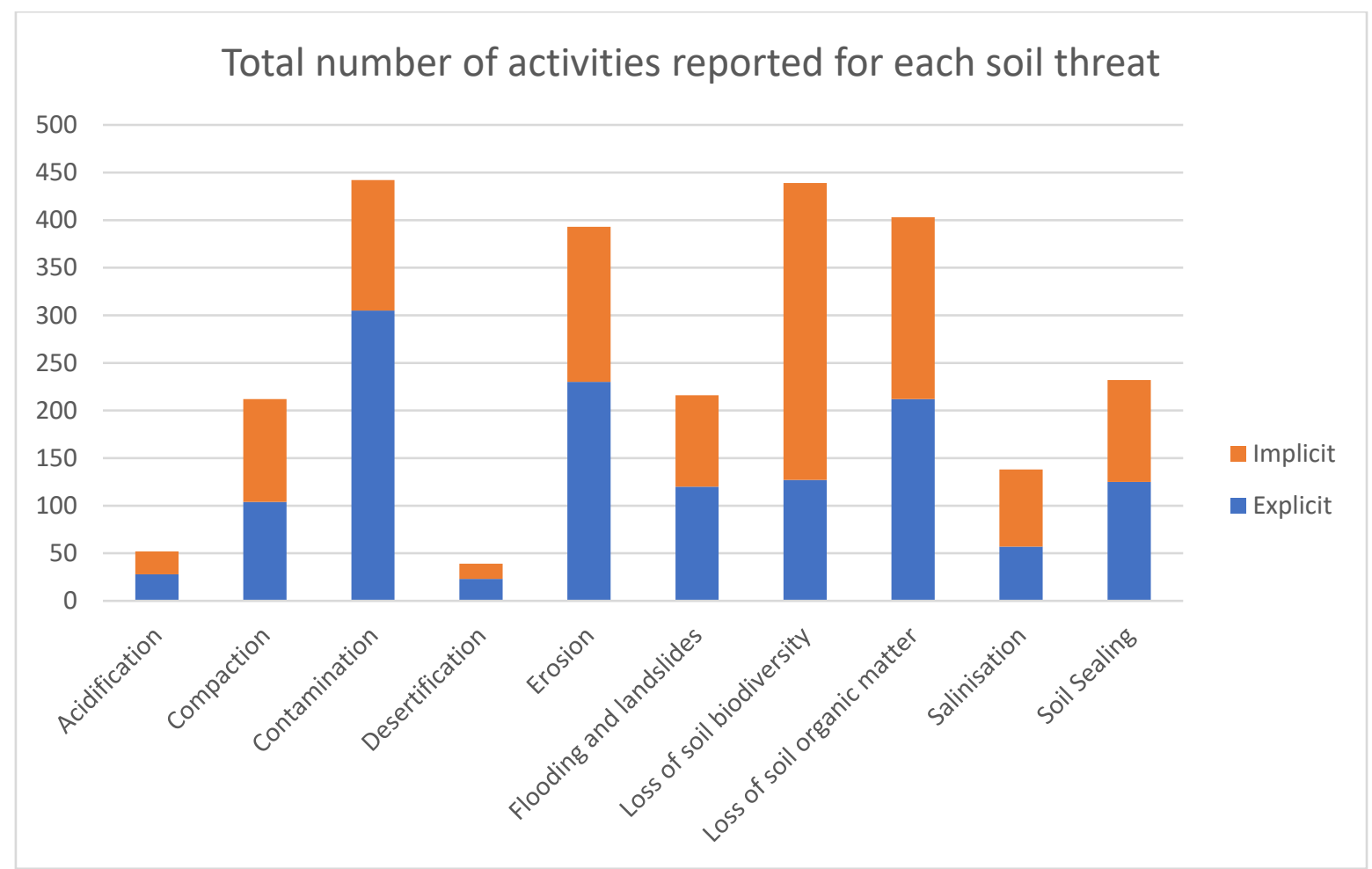

Figure 3.4 Total number of activities reported for each soil threat (Source: Soil Wiki, accessed May 2020) 


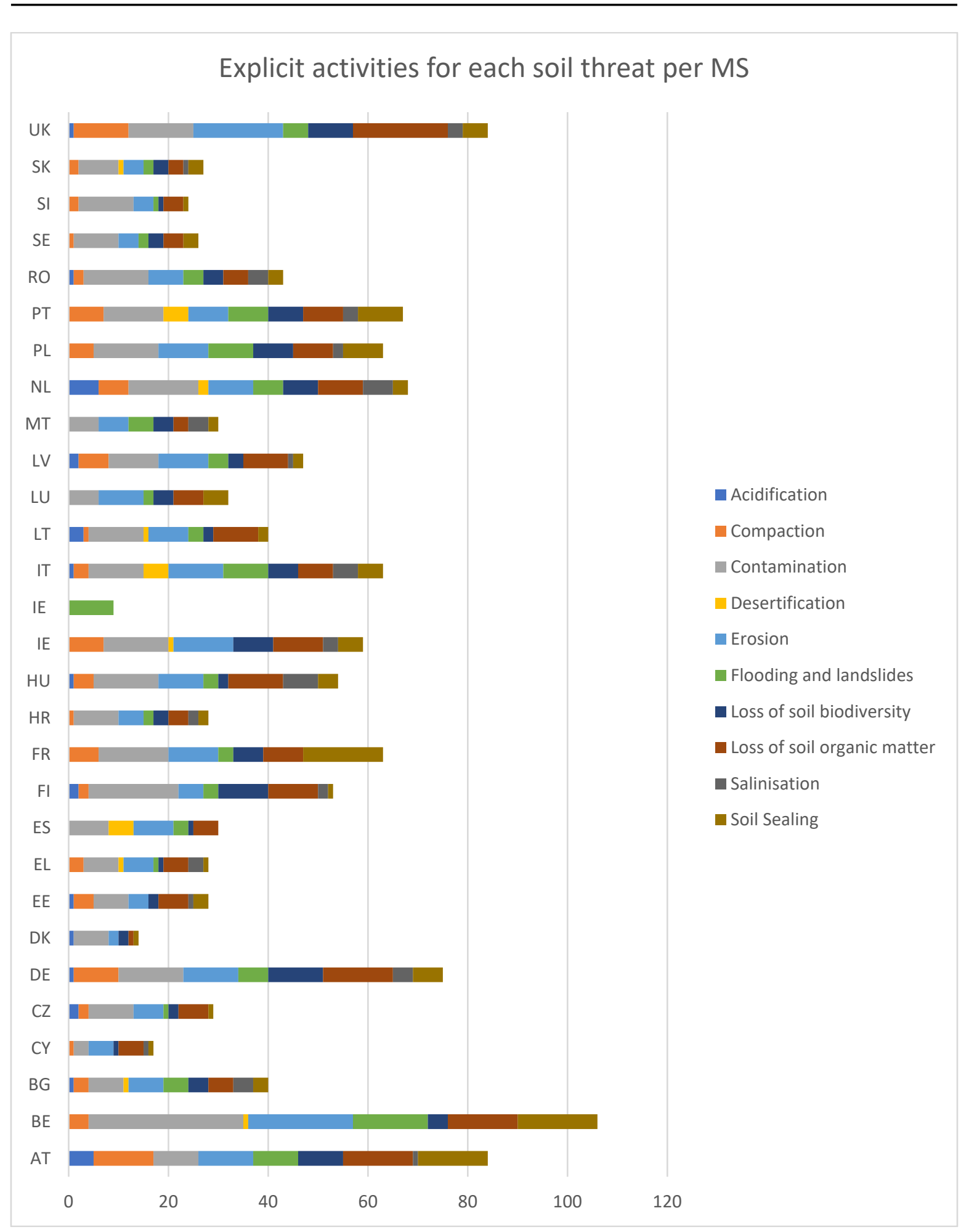

Figure 3.5 Explicit activities reported for each soil threat broken down by Member State (Source: Soil Wiki, accessed May 2020)

Several Member States also provided information on the soil/LDN policies in the various questionnaires. When asked about the most relevant soil and land policies at national level, these Member States often referred to sectoral polices (e.g. agriculture, forestry, nature protection), where soil and land concerns may be set out in a separate chapter. Few Member States report to have dedicated land or soil policies at national level.

One example is Portugal, which has a national law for 'public policy of soil, land use and urban planning' (LAW n. 31/2014 of May 30). In Cyprus, the Water and Soil Pollution Control Law concerns discharges to water and soil through a permitting system. Such legislation cannot be considered a general soil policy, but it certainly eliminates some direct soil threats, using national-level tools. 
Several Member States refer to sub-national soil polices, for example the Flemish (Belgium) soil policy is spearheaded by contamination and erosion control measures, as these soil threats are the most prominent in the region. There are numerous measures and actions to combat soil erosion, with some targeting farmers or other landowners, while other measures are implemented by local authorities (municipalities, polders, waterways...) with or without the cooperation of landowners and land users.

In several instances, references were made to new policies to protect land and soil. In Estonia, for example, a new regulation is pending (not yet approved) that will protect the valuable agricultural land and should slow down agricultural land take, as well as reducing the sealing of fertile agricultural soil. In Malta, the main national policy enabling the implementation of the LDN targets, along with the soil and land SDGs, will be the 'National Action Plan on Desertification and Land Degradation in the Maltese Islands' (currently being finalised). Czechia has several decrees, including Decree No. $153 / 2016$ Coll., on determining details in relation to the protection of soil quality, and a Decree on soil erosion that is currently being prepared and should be linked to Act No. 334/1992 Coll.

Many Member States have national policies related to land and soil issues. These are typically agricultural, forestry, or spatial planning policies, and are usually the remit of the relevant ministries. Romania specifically referred to the Ministry of Agriculture and Rural Development and Ministry of Water and Forest as responsible for specific targets, while the Ministry of Environment is responsible for the Law concerning contamination of land, subsoil and terrestrial ecosystems.

It cannot be assumed that all soil and land threats are covered (as these policies are assumed to be sector-specific). In Czechia, for example, the protection of agricultural soil (qualitatively and quantitatively) is set by law (see box below).

\section{Box 3.4 Example of soil protection measures in Czechia}

\section{Soil protection measures for agricultural soil in Czechia}

The qualitative protection of agricultural soil through prohibition of:

- Using agricultural land for non-agricultural purposes without a state permit;

- Using agricultural land in a manner inconsistent with the type of land plot;

- Application of banned substances or preparations on soil (e.g. fertilisers);

- Soil contamination by hazardous substances (heavy metals and hazardous elements above the established limits);

- Application of sludge or sediment that exceeds the limits for hazardous substances and elements;

- Threatening the soil with erosion;

- Soil compaction;

- Land drainage; and

- Growing plantations of fast-growing trees for more than 10 years.

The quantitative protection of agricultural soil (surface land protection) requires land users:

- To use primarily non-agricultural land for non-agricultural purposes;

- To use land firstly in built up (urbanised) areas for non-agricultural purposes;

- To withdraw only the necessary land from the agricultural land fund;

- To withdraw the least quality land as possible from the ALF (soil in Czechia is divided into classes according to its quality);

- To withdraw the best quality soil from the ALF only in special cases;

- To minimise the disruption of ALF organisation;

- After the end of the permitted non-agricultural activity, land reclamation is completed as soon as possible;

- To pay a fee for agricultural land withdrawal from the ALF;

- To address land and soil protection in spatial planning, during the determination of mining areas, in the documentation for construction location; and

To address the way the removed soil layer is used during construction, mining, industrial activities, etc.

Some policies had very clear provisions to improve soil and land, and in some cases, specific chapters dedicated to soil and land degradation. One example is in Slovenia, where the National Environmental Protection Programme (with a programme of measures up to 2030) is being prepared. Within the chapter on Conservation, the preservation and improvement of natural capital soil is addressed. In 
light of the soil protection and management measures foreseen, the following objectives are set out in the draft document:

1. Increased ability to implement soil ecosystem services:

a. controlling the degradation processes associated with the reduction of organic matter in the soil, preventing soil erosion, preventing soil contamination, and rehabilitating and revitalising degraded areas,

b. sustainable soil and land management and reduced net annual land take.

2. Strengthening information and data on soil.

3. Increased awareness of the importance of soil.

Czechia's Strategy on Adaptation to Climate Change (Adaptation Strategy) was approved by the Czech government in October 2015. It includes general adaptation measures for relevant sectors and the agriculture sector, namely measures such as 3.2.3.3 'Standards of Good Agricultural and Environmental Conditions', 3.2.3.6 'Reducing soil erosion' and 3.2.3.7 'Measures against agricultural drought'. These agriculture measures are further developed in the National Action Plan on Adaptation to Climate Change, which was adopted by the Czech government in January 2017.

These sectoral policies thus often have clear and valuable potential to curb soil and land degradation. Another interesting point raised by the Estonian respondents was that certain sectoral policies, such as the Estonian Planning Act, stipulate that any proposed land use change must undergo public consultation and any submissions from the public must be considered. According to the Estonian survey respondent, this has the potential to reduce the amount of land that is to be converted, thus reducing land degradation.

Several Member States provided further detail on the type of information included in their sectoral polices. In Denmark, for example, most agri-environmental regulation aims to limit/reduce nutrient losses from agriculture to the aquatic environment. However, some regulations also contribute to protecting the quality of agricultural land and soils. Until 2017, Denmark had primarily general nitrate regulations, where the same rules applied to all farmers. However, a political agreement from 2015, the Food and Agriculture Package, introduced a policy shift, supplementing the general regulation with more cost-effective, targeted nitrate regulation. Measures included catch crops, energy crops, early establishment of winter crops, etc., all of which reduce the risk of soil erosion.

In Estonia, sustainable forest management is set out as a key principle in the Forestry Development Plan (until 2020) and it also handles the protection of forest soils. For example, it underlines the need to further develop infrastructure in forests, noting that restrictions to forest management are set in the Forest Act in order to protect water and soil.

The role of EU policies was mentioned in several Member States and it can be assumed that instruments like the CAP, the Nitrates Directive, and the Water Framework Directive will be relevant in all Member States. A large number of the sectoral policies discussed in the previous section stem directly from such EU policy. However, several Member States reported that they have specifically transposed EU legislation so as to maximise soil and land protection.

In Denmark, the CAP cross-compliance standards have been implemented as follows:

- GAEC 1 - Establishment of buffer strips along watercourses. The standard is implemented nationally by Standard 1.16: $2 \mathrm{~m}$ buffer strips along natural watercourses and lakes as part of the management requirements attached to Directive 91/676/EEC. The rule applies to natural waterways, lakes, artificial streams and lakes, pursuant to the Water Framework Directive, either to satisfy the environmental objective of 'good ecological potential' or 'maximum ecological potential'. The rule does not apply for isolated lakes smaller than $100 \mathrm{~m}^{2}$.

- GAEC 4 - Minimum soil cover. The standard is implemented nationally by Standard 1.33: establishment and maintenance of plant cover on arable land lying fallow. (1) Land concerned by the single application for IACS as lying fallow shall be covered by vegetation; (2) When an area is transferred to land lying fallow, the plant cover must be established as soon as possible and no later than the 31 of May in the year of application; (3) Land lying fallow must not be used in a way that 
leads to destruction of plant cover. Temporary measures and arrangements are permitted if the plant cover is restored as soon as possible after application.

- GAEC 5 - Minimal soil cultivation reflecting site specific conditions to limit erosion. The standard is implemented nationally by Standard 1.37: protection of agricultural land against soil erosion. In the period from harvest to 15 February in the following year, inversion tillage (ploughing) is prohibited on contiguous agricultural areas over $5000 \mathrm{~m}^{2}$ that (1) has a minimum slope of 12 degrees, (2) has a high risk of soil erosion by water runoff and (3) is agricultural area (according to the Ministry's Internet LPIS map).

- GAEC 6 - Maintenance of soil organic matter. The standard is implemented by Standard 1.34: straw or other similar parts of agricultural crops must not be burned on fields or uncultivated land.

Similarly, in Estonia, soil degradation is identified as one of the important issues, and thus CAP and specific soil-related measures are implemented under RDPs (current 2014-2020). These include supporting proper crop rotation, taking soil samples, supporting farmers to keep peat and eroded soils as grassland, farmers' training, etc. The new Strategic Plan for Agriculture and Fisheries for 2030 and the Strategic Plan for implementing CAP both set the policy measures and address soil degradation as part of the environmental policy and as an asset in agricultural production. Another example was found in the Wallonia region of Belgium, where the RDP for Wallonia 2014-2020 proposes measures to support afforestation and the creation of wooded areas, to restore, preserve and strengthen ecosystems linked to agriculture and forestry, to prevent soil erosion and improve soil management, and to support the introduction and maintenance of agroforestry systems

\subsubsection{Policies with direct and indirect impacts on land and soil-related SDGs}

It is also worth noting the difference between policies with a direct and indirect impact. The box below sets out the information provided by Italy, showing not only the policies with a direct impact but also those with an indirect impact. It can be assumed that all Member States have policies and legislation that directly affect soil and land, covering anything from reducing pollution to data collection and monitoring requirements.

\section{Box 3.5 Example of soil and land protection policies in Italy}

\section{Policies on soil and land protection in Italy}

In Italy, the relevant national policy is Law n. 132 (2016), which entered into force in 2017. The Law set up the National System for Environmental Protection (SNPA), assigning it the task of operating the national land monitoring system. There is no general law on soil protection, although, like water management and protection, it has long been a central theme of action of the Italian government and has been subject to multiple regulatory interventions. Given the diverse phenomena that affect soil, the evolution of Italian legislation on soil protection is particularly broad, as it is very difficult to establish a single regulatory instrument that can respond to all environmental pressures. The main Italian policies linked directly to soil protection are the CAP, Legislative Decree n. 152/2006, Legislative Decree n. 49/2010, Law 164/2014 (which promotes the implementation of 'integrated interventions' that indirectly foster soil conservation and mitigation), and policies for contaminated sites.

Regulations not directly related to soil protection include:

- National Strategy for Biodiversity (SNBD);

- National Strategy for Adaptation to Climate Change (SNAC);

- National Strategy for Sustainable Development Goals;

- Agricultural policy instruments, with GAEC standards, greening requirements, regional RDPs;

- European Decision n.529/2013 on LULUCF reporting and accounting;

- National Plan on the Sustainable Use of Pesticides;

- National Action Plan to Combat Drought and Desertification (PAN); and

- Protocol of Soil Conservation of the Alpine Convention.

In addition, there is a proposed legislative initiative to 'Limit soil consumption and reuse of built-up areas' that sets limits on soil consumption, focusing on transforming existing urban areas and not new urbanisation, through a regulatory instrument that combines constraints and incentives. The proposed text specifically recognises the soil as a 'common good' and 'resource' that ensures non-renewable ecosystem functions and services. The concepts of reuse and regeneration of existing built-up areas are defined as fundamental principles in land and urban planning.

Recently, Italy integrated SDG Target 15.3 in their National Strategy on Sustainable Development, opening up the way for adopting qualitative and quantitative targets which are in the process of being developed. 
The table below shows which soil threats are explicitly or implicitly addressed by existing policies per Member State. Green cells indicate soil threats which were identified as a threat in the respective Member State through the survey carried out by the project and which are covered by a policy instrument. Red highlights those cases, where soil threats reported by a Member State are not implicitly or explicitly - targeted by existing policy.

Table 3.7 Explicit and Implicit policies for each soil threat per Member States (Source: Soil Wiki, accessed May 2020)

\begin{tabular}{|c|c|c|c|c|c|c|c|c|c|c|}
\hline MS & $\begin{array}{l}\frac{3}{2} \\
\frac{2}{3} \\
\frac{3}{3} \\
\frac{8}{3} \\
\frac{3}{3}\end{array}$ & $\begin{array}{l}8 \\
\text { 륨 } \\
\frac{0}{0} \\
\frac{8}{3}\end{array}$ & 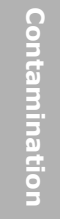 & 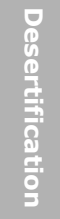 & $\begin{array}{l}\text { m. } \\
\frac{3}{3} \\
\frac{\vdots}{0} \\
\frac{0}{3}\end{array}$ & 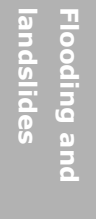 & 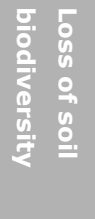 & 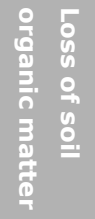 & 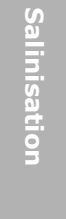 & 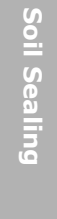 \\
\hline AT & $\mathrm{E} / \mathrm{I}$ & $\mathrm{E} / \mathrm{I}$ & $E / I$ & & $\mathrm{E} / \mathrm{I}$ & $E / I$ & $\mathrm{E} / \mathrm{I}$ & $E / I$ & $\mathrm{E} / \mathrm{I}$ & $E / I$ \\
\hline $\mathrm{BE}$ & & $\mathrm{E} / \mathrm{I}$ & $E / I$ & $E$ & $\mathrm{E} / \mathrm{I}$ & $\mathrm{E} / \mathrm{I}$ & $\mathrm{E} / \mathrm{I}$ & $\mathrm{E} / \mathrm{I}$ & I & $\mathrm{E} / \mathrm{I}$ \\
\hline BG & $\mathrm{E}$ & E & $E / I$ & $\mathrm{E} / \mathrm{I}$ & $\mathrm{E} / \mathrm{I}$ & $\mathrm{E} / \mathrm{I}$ & $\mathrm{E} / \mathrm{I}$ & $\mathrm{E} / \mathrm{I}$ & $\mathrm{E}$ & $E$ \\
\hline $\mathrm{CY}$ & & E & $E / I$ & I & $\mathrm{E} / \mathrm{I}$ & I & $\mathrm{E} / \mathrm{I}$ & $\mathrm{E} / \mathrm{I}$ & $\mathrm{E} / \mathrm{I}$ & $E / I$ \\
\hline$C Z$ & $\mathrm{E}$ & $\mathrm{E} / \mathrm{I}$ & $\mathrm{E} / \mathrm{I}$ & & $\mathrm{E} / \mathrm{I}$ & $\mathrm{E} / \mathrm{I}$ & $\mathrm{E} / \mathrm{I}$ & $\mathrm{E} / \mathrm{I}$ & I & $\mathrm{E} / \mathrm{I}$ \\
\hline $\mathrm{DE}$ & $\mathrm{E} / \mathrm{I}$ & $\mathrm{E} / \mathrm{I}$ & $E / I$ & I & $E / I$ & $\mathrm{E} / \mathrm{I}$ & $\mathrm{E} / \mathrm{I}$ & $\mathrm{E} / \mathrm{I}$ & $\mathrm{E} / \mathrm{I}$ & $E / I$ \\
\hline DK & $\mathrm{E}$ & I & $\mathrm{E} / \mathrm{I}$ & & $\mathrm{E} / \mathrm{I}$ & I & $\mathrm{E} / \mathrm{I}$ & $\mathrm{E} / \mathrm{I}$ & & $E / I$ \\
\hline $\mathrm{EE}$ & $E$ & $E / I$ & $\mathrm{E} / \mathrm{I}$ & 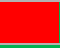 & $E / I$ & I & $\mathrm{E} / \mathrm{I}$ & $E / I$ & $\mathrm{E} / \mathrm{I}$ & $E / I$ \\
\hline EL & & $\mathrm{E}$ & $\mathrm{E} / \mathrm{I}$ & $E$ & $\mathrm{E} / \mathrm{I}$ & $\mathrm{E} / \mathrm{I}$ & $E / I$ & $\mathrm{E} / \mathrm{I}$ & $\mathrm{E} / \mathrm{I}$ & $E / I$ \\
\hline ES & & & $\mathrm{E} / \mathrm{I}$ & $\mathrm{E} / \mathrm{I}$ & $\mathrm{E} / \mathrm{I}$ & $\mathrm{E}$ & $\mathrm{E} / \mathrm{I}$ & $\mathrm{E} / \mathrm{I}$ & & \\
\hline FI & $\mathrm{E}$ & $\mathrm{E} / \mathrm{I}$ & $\mathrm{E} / \mathrm{I}$ & & $\mathrm{E} / \mathrm{I}$ & $\mathrm{E} / \mathrm{I}$ & $\mathrm{E} / \mathrm{I}$ & $\mathrm{E} / \mathrm{I}$ & $\mathrm{E} / \mathrm{I}$ & $\mathrm{E} / \mathrm{I}$ \\
\hline FR & & $\mathrm{E} / \mathrm{I}$ & $E / I$ & & $E / I$ & $\mathrm{E} / \mathrm{I}$ & $\mathrm{E} / \mathrm{I}$ & $\mathrm{E} / \mathrm{I}$ & I & $E / I$ \\
\hline $\mathrm{HR}$ & & $\mathrm{E} / \mathrm{I}$ & $\mathrm{E} / \mathrm{I}$ & & $\mathrm{E} / \mathrm{I}$ & $\mathrm{E} / \mathrm{I}$ & $\mathrm{E} / \mathrm{I}$ & $\mathrm{E} / \mathrm{I}$ & $\mathrm{E} / \mathrm{I}$ & $\mathrm{E} / \mathrm{I}$ \\
\hline $\mathrm{HU}$ & $\mathrm{E}$ & $E$ & $\mathrm{E} / \mathrm{I}$ & & $\mathrm{E} / \mathrm{I}$ & $\mathrm{E} / \mathrm{I}$ & $\mathrm{E} / \mathrm{I}$ & $\mathrm{E} / \mathrm{I}$ & $\mathrm{E}$ & $\mathrm{E} / \mathrm{I}$ \\
\hline IE & $\mathrm{E}$ & $\mathrm{E} / \mathrm{I}$ & $\mathrm{E} / \mathrm{I}$ & $\mathrm{E} / \mathrm{I}$ & $\mathrm{E} / \mathrm{I}$ & $\mathrm{E} / \mathrm{I}$ & $\mathrm{E} / \mathrm{I}$ & $\mathrm{E} / \mathrm{I}$ & $\mathrm{E} / \mathrm{I}$ & $E / I$ \\
\hline IT & $\mathrm{E} / \mathrm{I}$ & $\mathrm{E} / \mathrm{I}$ & $\mathrm{E} / \mathrm{I}$ & $\mathrm{E} / \mathrm{I}$ & $\mathrm{E} / \mathrm{I}$ & $\mathrm{E} / \mathrm{I}$ & $\mathrm{E} / \mathrm{I}$ & $\mathrm{E} / \mathrm{I}$ & $\mathrm{E} / \mathrm{I}$ & $\mathrm{E} / \mathrm{I}$ \\
\hline LT & $\mathrm{E} / \mathrm{I}$ & $\mathrm{E} / \mathrm{I}$ & $\mathrm{E} / \mathrm{I}$ & $\mathrm{E} / \mathrm{I}$ & $\mathrm{E} / \mathrm{I}$ & $\mathrm{E} / \mathrm{I}$ & $\mathrm{E} / \mathrm{I}$ & $\mathrm{E} / \mathrm{I}$ & & $\mathrm{E} / \mathrm{I}$ \\
\hline LU & I & I & $\mathrm{E} / \mathrm{I}$ & & $\mathrm{E} / \mathrm{I}$ & $\mathrm{E} / \mathrm{I}$ & $\mathrm{E} / \mathrm{I}$ & $\mathrm{E} / \mathrm{I}$ & & $E / I$ \\
\hline LV & $\mathrm{E} / \mathrm{I}$ & $\mathrm{E}$ & $\mathrm{E} / \mathrm{I}$ & & $\mathrm{E} / \mathrm{I}$ & $\mathrm{E} / \mathrm{I}$ & $\mathrm{E} / \mathrm{I}$ & $\mathrm{E} / \mathrm{I}$ & $\mathrm{E} / \mathrm{I}$ & $\mathrm{E} / \mathrm{I}$ \\
\hline MT & & I & $\mathrm{E} / \mathrm{I}$ & & $E / I$ & $\mathrm{E} / \mathrm{I}$ & $\mathrm{E} / \mathrm{I}$ & $\mathrm{E} / \mathrm{I}$ & $\mathrm{E} / \mathrm{I}$ & $\mathrm{E} / \mathrm{I}$ \\
\hline $\mathrm{NL}$ & $\mathrm{E} / \mathrm{I}$ & $\mathrm{E} / \mathrm{I}$ & $E / I$ & $\mathrm{E} / \mathrm{I}$ & $\mathrm{E} / \mathrm{I}$ & $E / I$ & $\mathrm{E} / \mathrm{I}$ & $E / I$ & $\mathrm{E} / \mathrm{I}$ & $E / I$ \\
\hline PL & & $\mathrm{E} / \mathrm{I}$ & $\mathrm{E} / \mathrm{I}$ & & $\mathrm{E} / \mathrm{I}$ & $\mathrm{E} / \mathrm{I}$ & $\mathrm{E} / \mathrm{I}$ & $\mathrm{E} / \mathrm{I}$ & $\mathrm{E} / \mathrm{I}$ & $\mathrm{E} / \mathrm{I}$ \\
\hline PT & & $\mathrm{E} / \mathrm{I}$ & $\mathrm{E} / \mathrm{I}$ & $\mathrm{E} / \mathrm{I}$ & $\mathrm{E} / \mathrm{I}$ & $\mathrm{E} / \mathrm{I}$ & $\mathrm{E} / \mathrm{I}$ & $\mathrm{E} / \mathrm{I}$ & $\mathrm{E} / \mathrm{I}$ & $\mathrm{E} / \mathrm{I}$ \\
\hline RO & $\mathrm{E} / \mathrm{I}$ & $\mathrm{E} / \mathrm{I}$ & $E / I$ & & $E / I$ & $\mathrm{E} / \mathrm{I}$ & $\mathrm{E} / \mathrm{I}$ & $\mathrm{E} / \mathrm{I}$ & $\mathrm{E} / \mathrm{I}$ & $E / I$ \\
\hline SE & I & $\mathrm{E} / \mathrm{I}$ & $\mathrm{E} / \mathrm{I}$ & & $\mathrm{E} / \mathrm{I}$ & $\mathrm{E} / \mathrm{I}$ & $\mathrm{E} / \mathrm{I}$ & $\mathrm{E} / \mathrm{I}$ & I & $\mathrm{E} / \mathrm{I}$ \\
\hline SI & & $\mathrm{E} / \mathrm{I}$ & $\mathrm{E} / \mathrm{I}$ & & $\mathrm{E} / \mathrm{I}$ & $\mathrm{E}$ & $\mathrm{E} / \mathrm{I}$ & $\mathrm{E} / \mathrm{I}$ & & $\mathrm{E} / \mathrm{I}$ \\
\hline SK & I & $\mathrm{E} / \mathrm{I}$ & $E / I$ & $\mathrm{E}$ & $E / I$ & $\mathrm{E} / \mathrm{I}$ & $\mathrm{E} / \mathrm{I}$ & $\mathrm{E} / \mathrm{I}$ & $\mathrm{E} / \mathrm{I}$ & $E / I$ \\
\hline UK & $E$ & $\mathrm{E} / \mathrm{I}$ & $\mathrm{E} / \mathrm{I}$ & & $\mathrm{E} / \mathrm{I}$ & $\mathrm{E} / \mathrm{I}$ & $\mathrm{E} / \mathrm{I}$ & $\mathrm{E} / \mathrm{I}$ & $\mathrm{E} / \mathrm{I}$ & $\mathrm{E} / \mathrm{I}$ \\
\hline
\end{tabular}

$E=$ Explicit activities

$\mathrm{I}=$ Implicit activities

$E / I=$ Explicit and Implicit activities

Green: identified as a threat in surveys and activities in place

Red: identified as a threat in surveys and no activities in place

When looking at the soil functions, all Member States reported explicit actions to promote soil functions, except those highlighted in red below. The number shows the number of implicit activities in place (noting that some are also zero). There are only a few instances where Member States have no activities to promote specific soil functions ( $C Y$ and $D K$ ), in most cases there are a number of implicit activities in place, which might collectively be sufficient to cover the soil function. 
Table 3.8 Soil functions currently not addressed by Member state policies (Source: Soil Wiki, accessed: May 2020)

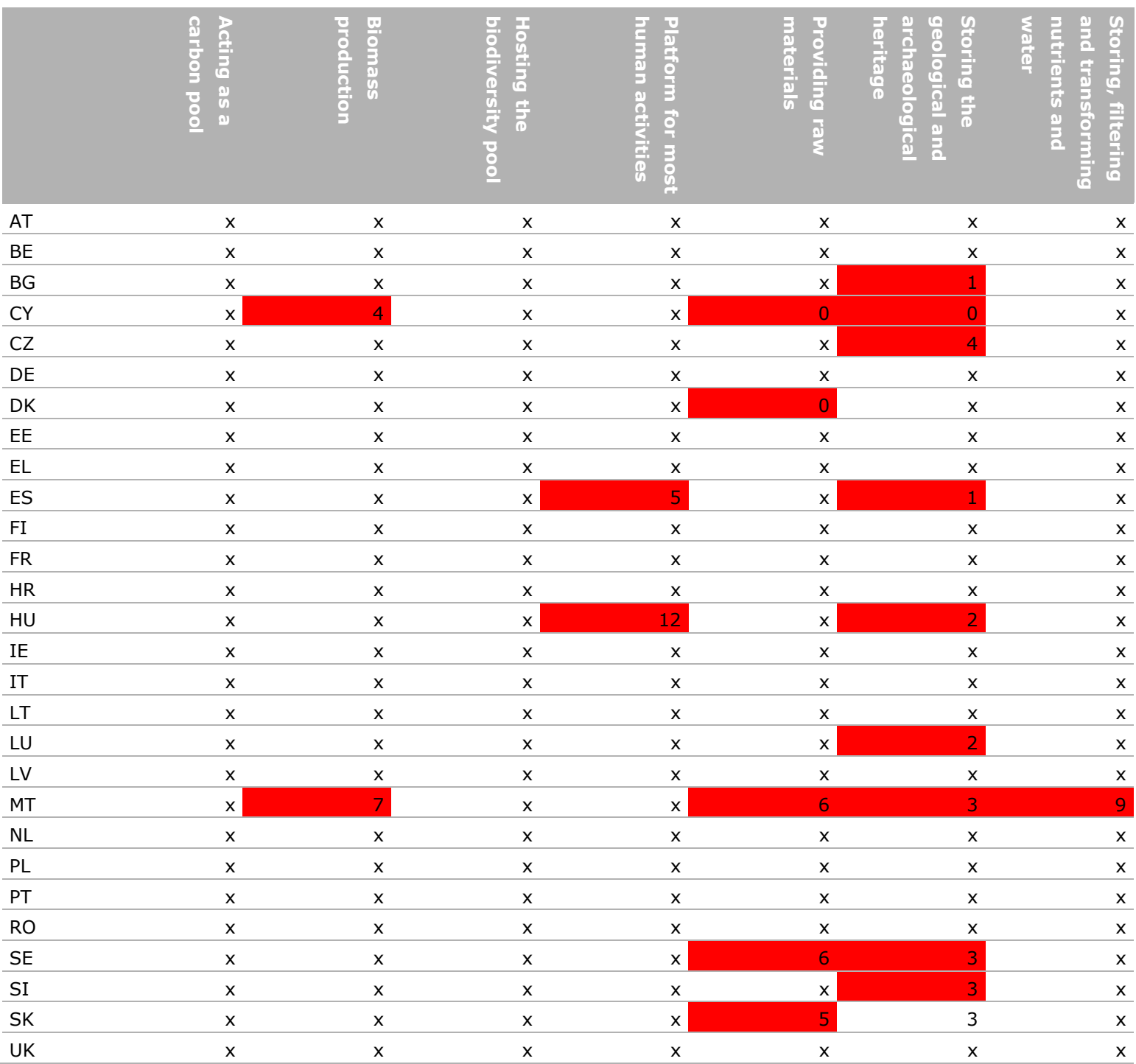

A total of 405 explicit activities cover soil functions in Europe. Of those activities, a number can be considered as sectoral plans. The table below shows the number of activities in each Member State which can be considered to contribute to SDGs other than SDG15. It is assumed that since all activities were identified as promoting soil functions that they all contribute to life on land ${ }^{44}$. The table also shows that nine MSs specifically identified their general sustainable development strategy/plan as having an impact on soil functions.

Some Member States devolve responsibility for land and soil to the sub-national authorities. This made it impossible to collect data on all policies, although several examples were noted in the questionnaires. In Lower Austria, for example, SDGs are implemented through the actions of the Lower Austrian Climate and Energy Programme 2020, by means of more than 200 different

\footnotetext{
${ }^{44}$ The activities in the table represent regulatory and non-regulatory activities, and were determined based on the title of the activity reported to the Soil Wiki - activities were only counted if there was a clear reference in the title to one of the sectors covered by the relevant SDGs, more general activities (with the exception of overall sustainable development plans/strategies) are not represented, although they may also be relevant for the SDGs in the table. Examples of activities include (note that some activities have been counted under more than one SDG): SDG 2: agricultural activities, including increased production (pesticide and fertiliser management) as well as promotion of organic and sustainable farming practices. All CAP activities have been counted, as have sewerage sludge activities; SDG 3: most common activities include the mitigation of contaminated land and the reduction of hazardous substances (not explicitly linked to agriculture); SDG 6 and 14: water activities have been counted together, as they often cover water for human consumption (SDG 6) and aquatic life (SDG 14). Urban wastewater activities were often listed, as were activities to reduce water contamination; SDG 11: spatial planning activities, urban waste water activities, and urban greening measures; SDG 13: specific climate activities, usually climate action plans.
} 
instruments. In the field of agriculture and forestry alone, 29 instruments are applied. Similarly, in the Netherlands, the municipalities are responsible for land policy, with a national policy unlikely to be adopted.

Another example was given by France, which reported that the national approach does not completely match SDG 15.3. Respondents explained that the Law on Nature Protection predates the SDGs, although it does refer to land degradation (specifically a switch to artificial land/soil sealing or artificial green areas).

Several Member States have dedicated soil policies at sub-national level. In Denmark, for example, the regional Soil Plan for the Capital Region supports the implementation of SDGs 3, 6, 11, 12, 13, 15 and 17 .

Table 3.9 Number of Member State policies potentially contributing to meeting the SDGs

\begin{tabular}{|c|c|c|c|c|c|c|}
\hline MS & 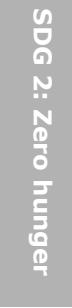 & 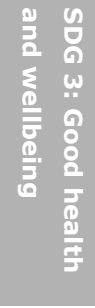 & 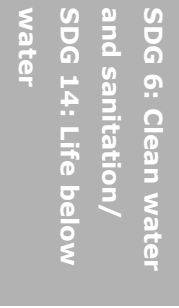 & 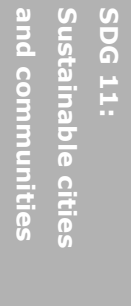 & 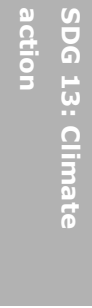 & 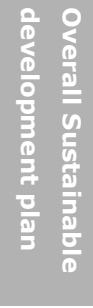 \\
\hline AT & 7 & 1 & 2 & 6 & 1 & 1 \\
\hline BE & 8 & 2 & 6 & 9 & 1 & 2 \\
\hline BG & 5 & & & & & 1 \\
\hline CY & 3 & 1 & 3 & 1 & & \\
\hline CZ & 9 & 1 & 1 & 1 & & \\
\hline DE & 8 & & 1 & 2 & & 1 \\
\hline DK & 9 & 1 & 1 & 1 & & \\
\hline EE & 5 & 1 & 1 & 4 & & \\
\hline EL & 5 & 1 & 3 & 2 & & \\
\hline ES & 6 & 1 & 1 & 2 & & \\
\hline FI & 8 & 5 & 3 & 2 & 1 & \\
\hline FR & 10 & 3 & 3 & 3 & & 1 \\
\hline HR & 11 & & 3 & 2 & & 1 \\
\hline HU & 10 & & 4 & 3 & 1 & 1 \\
\hline IE & 6 & 2 & 3 & 6 & & \\
\hline IT & 7 & & 4 & 6 & 1 & \\
\hline LT & 7 & 3 & 2 & 3 & & 1 \\
\hline LU & 5 & 1 & & 4 & & \\
\hline LV & 5 & 1 & 2 & 4 & & \\
\hline MT & 6 & & 2 & 2 & 1 & 1 \\
\hline NL & 6 & & 1 & & & \\
\hline PL & 7 & 1 & 2 & 3 & & \\
\hline PT & 10 & & 5 & 2 & & \\
\hline RO & 5 & 1 & 3 & 1 & & \\
\hline SE & 3 & 4 & & 2 & & \\
\hline SI & 4 & 4 & 3 & 1 & & \\
\hline SK & 6 & & 3 & & & \\
\hline UK & 17 & 2 & 6 & 4 & & \\
\hline Total & 198 & 36 & 65 & 76 & 6 & 10 \\
\hline
\end{tabular}

Whilst we cannot evaluate the effectiveness of existing policies in tackling soil threats or improving soil functions, the analysis clearly demonstrates that many Member States already have soil and land management policies in place, or that relevant objectives and measures are integrated in environmental or sectoral policies (e.g. agriculture). Reflecting EU-level findings, this suggests that the existing policy framework already contributes to meeting the SDGs, especially SDG 2 and SDG 11 . 


\subsection{Soil and land degradation and land degradation neutrality}

\subsubsection{Land degradation}

Land degradation: 'The reduction or loss, in arid, semi-arid and dry sub-humid areas, of the biological or economic productivity and complexity of rainfed cropland, irrigated cropland, or rangeland, pasture, forest and woodlands resulting from land uses or from a process or combination of processes, including processes arising from human activities and habitation patterns, such as: (i) soil erosion caused by wind and/or water; (ii) deterioration of the physical, chemical and biological or economic properties of soil; and (iii) long-term loss of natural vegetation' (UNCCDb, 1994).

The UNCCD initially focused primarily on drylands. Nowadays, however, it has extended its responsibility and aims to make a lasting global contribution to the achievement of sustainable land management in all ecosystems. Vogt (Vogt, J.V. et al., 2011) has also highlighted the need for an agreed definition for monitoring and assessing land degradation.

To show the diversity of definitions found in literature, a brief and non-exhaustive overview is presented below:

- The Millennium Ecosystem Assessment (Millennium Ecosystem Assessment, 2005) refers to land degradation as the 'the loss of primary production, often through soil erosion but also through changes in vegetation and through processes such as salinisation and shifting sand' (p. 35).

- Reed et al. (Reed, M.S. \& Stringer, L.C., 2016): 'Land degradation: i) is a phenomenon caused by human activities and exacerbated by certain climate and topographic characteristics; ii) is characterised by changes in ecosystem processes and levels of natural capital that affect the flow of ecosystem services to society; iii) causes an effectively permanent decrease in the capacity of the land system as managed to meet its user demands; and iv) is a threat to the long-term biological and/or economic resilience and adaptive capacity of the ecosystem and the populations who depend on it.'

- EEA (2016): 'In Europe, land degradation can be considered in terms of the loss of actual or potential productivity or utility as a result of natural or anthropic factors; it is the decline in land quality or reduction in its productivity. In the context of productivity, land degradation results from a mismatch between land quality and land use.'

- The Thematic Assessment on Land Degradation and Restoration of the IPBES (IPBES, 2015): "'...degraded land' is defined as land in a state that results from persistent decline or loss of biodiversity and ecosystem functions and services that cannot fully recover unaided within decadal time scales. 'Land degradation', in turn, refers to the many processes that drive the decline or loss of biodiversity, ecosystem functions or services and includes the degradation of all terrestrial ecosystems. 'Restoration' is defined as any intentional activity that initiates or accelerates the recovery of an ecosystem from a degraded state."

- The Intergovernmental Panel on Climate Change (IPCC) special report for 2018, and the JRC report on land productivity dynamics in Europe (Cherlet et al., 2013), refer to land degradation in relation to desertification, indicating the seven major associated issues. Those issues are: (a) overuse of agricultural land, intensification, inappropriate agricultural practices / non-Sustainable Land Management, increased soil erosion; (b) increase in intensive irrigation, overuse of water resources, salinisation; (c) grazing mismanagement, overgrazing and decreasing NPP in rangelands, soil degradation, sand encroachment; (d) deforestation; (e) increased aridity or drought; (f) socioeconomic issues, changes in population distribution and density, rural migration/land abandonment, urban sprawl; and ( $\mathrm{g}$ ) uncontrolled expansion of mineral mining and industrial activities, extensive air and water pollution by waste materials, soil loss by contamination.

- There is a similar and ongoing debate on how to measure land degradation and land degradation neutrality (see Figure 3.6). 
Comparison of the Commission's and the UNCCD's indicators for land degradation according to ECA, 2018 (page 29)

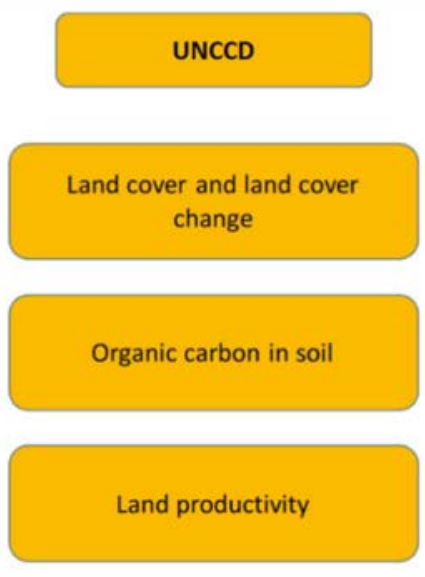

Update: Indicators to monitor land degradation: EU SDG monitoring report 2019
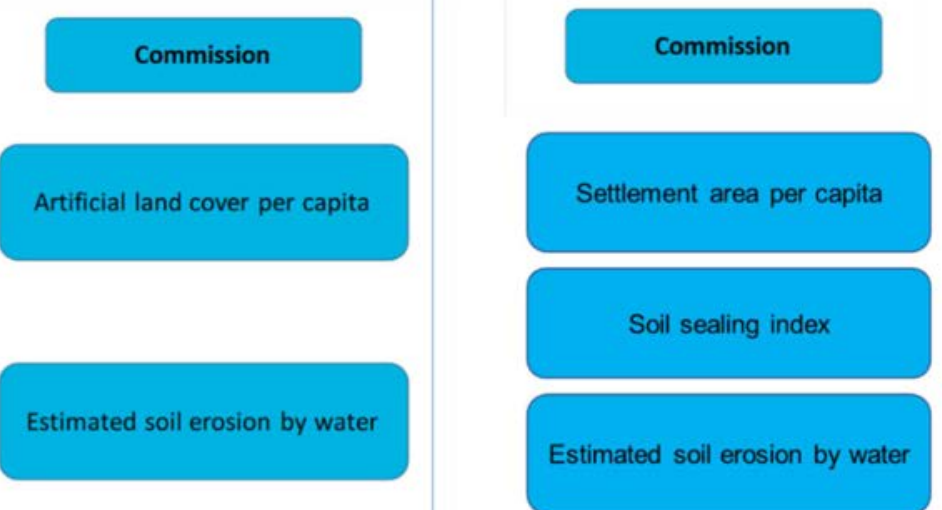

Figure 3.6 Comparison of the UNCCD's (left) and (updated) Commission's (right) proposed (sub-) indicators for land degradation (neutrality) (ECA 2018, Eurostat, 2019)

There is no generally accepted definition of land degradation in environmental science and policy. The policy report with scenarios for the UNCCD's Global Land Outlook (Van der Esch et al. 2017) chooses not to directly quantify 'land degradation' because of the differences between definitions and the subjectivity of the term itself. Instead, the study assessed changes in land condition and ecosystem functions relative to the natural or undisturbed state in order to determine human impact.

However, some common elements can be identified in the definitions: declining land function, threatened or declining soil function and declining ecosystem functions or services.

Together, these show the deterioration of the benefits that humans derive from terrestrial ecosystems.

The following processes have been described in respect of land degradation:

1. Erosion: 105 million ha (16\%) of Europe's total land area (excluding Russia) were estimated to be affected by water erosion in the 1990s. 42 million ha are affected by wind erosion. A recent model of soil erosion by water constructed by the JRC has estimated the surface area affected in EU-27 at 1.3 million $\mathrm{km}^{2}$. Almost $20 \%$ is subject to a soil loss in excess of $10 \mathrm{t} / \mathrm{ha} / \mathrm{yr}^{45,46}$.

2. Organic matter decline: organic matter is a key component of soil, controlling many vital functions. Some $45 \%$ of soils in Europe have a low or very low organic matter content (0-2\%). This is particularly evident in the soils of many southern European countries, but is also evident in parts of France, the UK, Germany, Norway and Belgium. A key driver is the conversion of woodland and grassland to arable crops. The soils of EU-27 Member States are estimated to store between 73 and 79 billion tons of carbon $^{47}$

3. Sealing occurs when agricultural or non-developed land is lost to urban sprawl, industrial development or transport infrastructure. It normally includes the removal of topsoil layers and

\footnotetext{
${ }^{45}$ Panagos, P., Ballabio, C., Poesen, J., Lugato, E., Scarpa, S., Montanarella, L., \& Borrelli, P. (2020). A Soil Erosion Indicator for Supporting Agricultural, Environmental and Climate Policies in the European Union. Remote Sensing, 12(9), 1365.

${ }^{46}$ Panagos, P., Borrelli, P., Poesen, J., Ballabio, C., Lugato, E., Meusburger, K., Montanarella, L., Alewell, C., 2015. The new assessment of soil loss by water erosion in Europe. Environ. Sci. Policy 54, 438-447. https://doi.org/10.1016/j.envsci.2015.08.012.

47 Orgiazzi, A., Panagos, P., Yigini, Y., Dunbar, M.B., Gardi, C., Montanarella, L. and Ballabio, C. (2016). A knowledge-based approach to estimating the magnitude and spatial patterns of potential threats to soil biodiversity. Science of The Total Environment, Volumes 545-546, pp. 11-20. Available at: https://doi.org/10.1016/j.scitotenv.2015.12.092 Link: 
leads to the loss of important soil functions, such as food production, water storage or temperature regulation. On average, built-up and other man-made areas account for around $4 \%$ of the total area in the countries of the European Economic Area (EEA) (data exclude Greece, Switzerland and the UK) but not all of this is actually sealed. Between 1990 and 2000, at least 275 hectares of soil were lost per day in the EU, amounting to 1,000 km²/year. Between 2000 and 2006 , the EU average loss increased by $3 \%$, with highs of $14 \%$ in Ireland and Cyprus, and $15 \%$ in Spain. In the period 1990-2006, 19 Member States lost a potential agricultural production capability equivalent to a total of 6.1 million tons of wheat, with large regional variations.

4. Compaction can be induced by the use of heavy machinery in agriculture. Compaction reduces the capacity of soil to store and conduct water, makes it less permeable for plant roots, and increases the risk of soil loss by water erosion. Estimates of areas at risk of soil compaction vary, with some authors estimating that $36 \%$ of European subsoils have high or very high susceptibility to compaction. Other sources report $32 \%$ of soils as being highly susceptible and $18 \%$ moderately affected.

5. Biodiversity decline: soil biodiversity reflects the enormous variety of organisms, from bacteria to mammals, which shape the metabolic capacity of terrestrial ecosystems and much of soil function. Soil biodiversity is affected by all of the threats and degradation processes listed below.

6. Landslides can be triggered by factors such as land abandonment and land use change. They occur more frequently in areas with highly erodible soils or clay-based sub-soils on steeply sloping ground under intense and abundant precipitation. While there are no data on the total affected area in Europe, over 630,000 landslides are currently registered in national databases.

7. Contamination: after more than 200 years of industrialisation, soil contamination is a widespread problem in Europe. The most frequent contaminants are heavy metals and mineral oil. The number of sites where potentially polluting activities have taken place now stands at approximately 3 million.

8. Salinisation is the result of the accumulation of salts and other substances from irrigation water and fertilisers. High levels of salt will eventually make soils unsuitable for plant growth. It affects approximately 3.8 million ha in Europe. The main driver is the inappropriate management of irrigated agricultural land.

9. Desertification is a type of land degradation in arid, semi-arid and dry sub-humid regions resulting from various factors, including climatic variations and human activities.

Floods, acidification, desertification and drought can all be considered degradation processes / soil pressures or threats (see Table 3.10). 
Table 3.10 Soil pressures in the Soil Thematic Strategy (European Commission, 2006a), SOER 2020 (European Environment Agency, 2020 48), SWSR 2015 (FAO and ITPS, 2015), and RECARE (Stolte, J., et al, 2016) studies

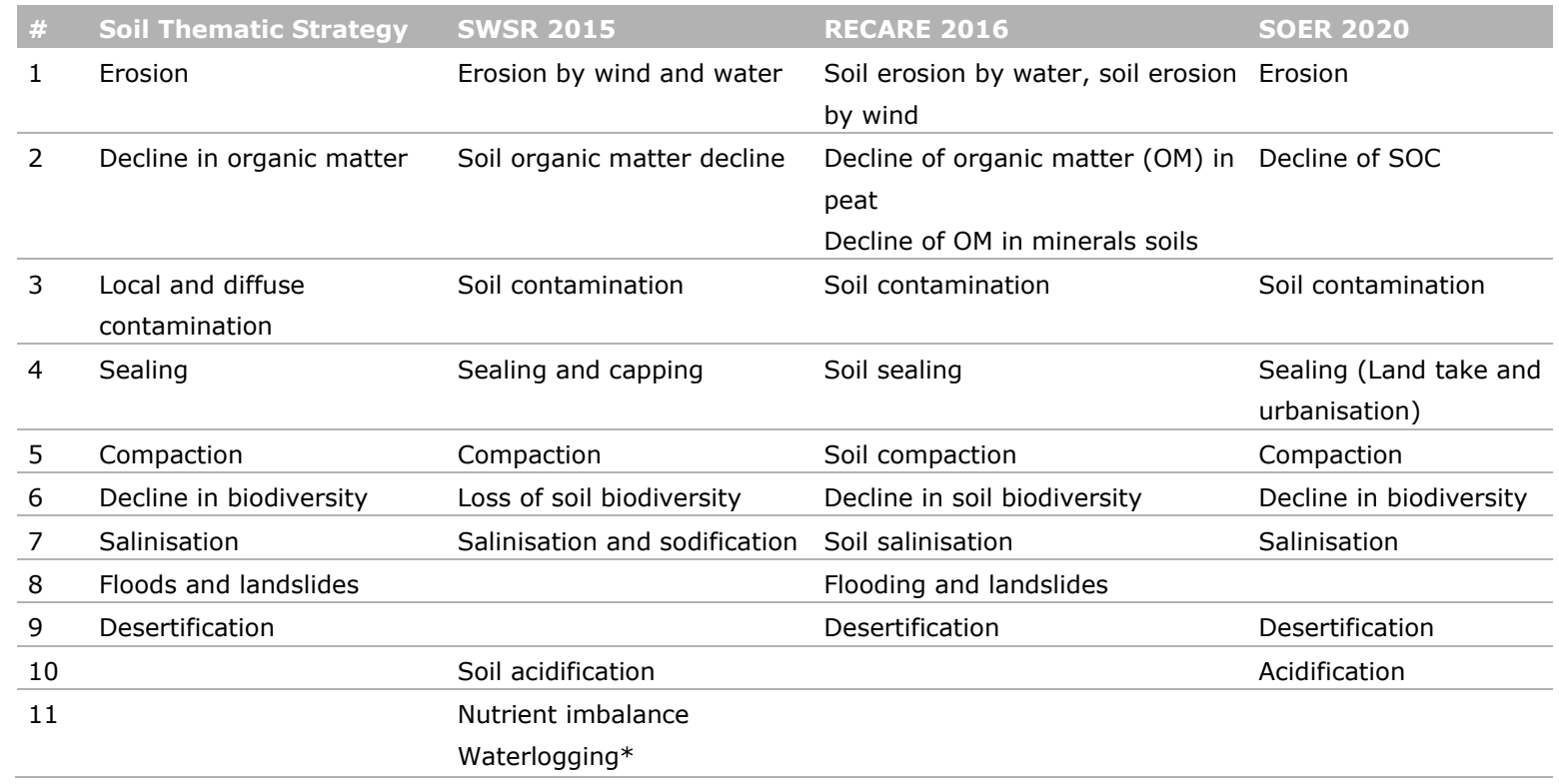

*Waterlogging is mostly associated with irrigation in Central Asian countries and is therefore outside the scope of this report

\subsubsection{Land Degradation Neutrality (LDN)}

It is similarly important to clarify the term Land Degradation Neutrality (LDN). The term originates from SDG 15 'Life on Land', specifically SDG target 15.3 which states: 'By 2030, combat desertification, restore degraded land and soil, including land affected by desertification, drought and floods, and strive to achieve a land degradation-neutral world.' The UNCCD is responsible for monitoring SDG indicator 15.3.1 ('Proportion of land that is degraded over total land area') ${ }^{49}$. This indicator was proposed by the Inter-Agency and Expert Group on SDG indicators (IAEG-SDGs) and adopted by the United Nations Statistical Commission (UNSC) in March 2017 to monitor progress towards achieving SDG target $15.3^{50}$.

SDG indicator 15.3.1 is reported as a simple binary: degraded/not degraded. This is, in principle, based on comparable and standardised official national data sources. The SDG indicator 15.3.1 (the indicator') assesses changes in i) land cover, ii) land productivity, and iii) carbon stocks ('the subindicators'), which need to be validated and reported by national authorities.

SDG indicator 15.3.1 makes use of geospatial information and digital data from national, regional and global sources. The method of computation follows the 'One Out, All Out' statistical principle. It is based on the baseline assessment (the year 2000) and evaluation of change in the sub-indicators to determine the extent of degraded land over total land area.

These assessments were voluntary and, of the Member States, only Italy created a national plan to reach LDN.

\footnotetext{
${ }^{48}$ EEA. (2020). SOER 2020 - The European environment - state and outlook 2020. [online] Available at: https://www.eea.europa.eu/publications/soer-2020 (Accessed on 11 August 2020).

${ }^{49}$ Orr, B.J., A.L. Cowie, V.M. Castillo Sanchez, P. Chasek, N.D. Crossman, A. Erlewein, G. Louwagie, M. Maron, G.I. Metternicht, S. Minelli, A.E. Tengberg, S. Walter, and S. Welton. 2017. Scientific Conceptual Framework for Land Degradation Neutrality. A Report of the Science-Policy Interface. United Nations Convention to Combat Desertification (UNCCD), Bonn, Germany.

50 Sims, N., Green, C., Newnham, G., England, J. R., Held, A., Wulder, M. A., ... \& Vizcarra-Rossel, R. A., 2017. Good practice guidance. SDG Indicator 15.3. 1: Proportion of land that is degraded over total land area. Version 1.0.
} 
'a state whereby the amount and quality of land resources necessary to support ecosystem functions and services and enhance food security remain stable or increase within specified temporal and spatial scales and ecosystems' (UNCCD, 2015)

The book Land Degradation, Desertification and Climate Change (Reed, M.S. \& Stringer, L.C., 2016.), which was endorsed by the UNCCD, defines LDN as 'the avoidance of the degradation of healthy ecosystems and the restoration and rehabilitation of degraded ones'.

For desertification and LDN at European level, the European Court of Auditors 2018 report (European Court of Auditors., 2018) concluded that:

- There is no clear picture of challenges.

- The steps taken to combat desertification lack coherence.

- There is no progress towards meeting the commitment to achieving LDN by 2030.

- There is no full assessment / data analysis at EU level, and no methodology on how to do so has been agreed.

- There is no focused EU-level strategy / action plan / spending programme.

- There is no coordination between the Member States, and no practical guidance.

- There is no clear, shared vision in the EU about how land degradation neutrality will be achieved by 2030.

They made three main recommendations: 1) understanding land degradation and desertification in the EU; 2) assessing the need to enhance the EU legal framework for soil; and 3) achieving LDN in the EU by 2030 .

These recommendations include the development of a methodology and indicators (starting with the UNCCD's three indicators: land cover and land cover change, land productivity and organic carbon in soil, see Figure 3.1) to assess the extent of desertification and land degradation in the EU. They also include giving guidance to Member States on the practical aspects of preserving soil and achieving LDN in the EU, including dissemination of good practices.

\subsubsection{Priorities on land degradation/LDN at national level}

This project's questionnaire to the EU SEG addressed the different research questions about soil and land degradation. Of the countries that replied, only Slovakia has an official definition ${ }^{51}$ of land degradation, while Czechia and Romania have a definition of land degradation. None of the responding countries has a definition of LDN. However, some countries state that they follow international definitions: Italy, Malta and Germany use the UNCCD definitions. Austria indicated that it is working on national definitions.

Despite the lack of common definitions, Member States nevertheless have priorities in respect of specific land and soil degradation processes ${ }^{52}$ (see Section 3.2.1). The table below shows an overview from the questionnaires. Of the countries that mention land degradation processes, they note the top three problems as soil erosion, contamination and sealing, closely followed by declining organic matter and soil compaction.

Other land degradation priorities mentioned include unsustainable land management / overexploitation of resources and climate change.

\footnotetext{
${ }^{51}$ Slovak definition: Official definition for Land degradation is anchored in Act No. 220/2004 Code (Law on Soil Protection) in the basic terms: (f) degradation of physical, chemical and biological damage and deterioration of agricultural land, such as water erosion and wind erosion, compaction, acidification, contamination by hazardous substances, harmful plant organisms and animal organisms and micro-organisms; microbial biomass and unnatural reduction of biological activity in soil).

52 Information drawn from the questionnaire sent to the EU SEG, supplemented with expert input from non-responding countries. Information from the SURFACE project (https://www.ufz.de/surface/index.php?en=43795) (which asked about land degradation priorities in a questionnaire) was also included.
} 


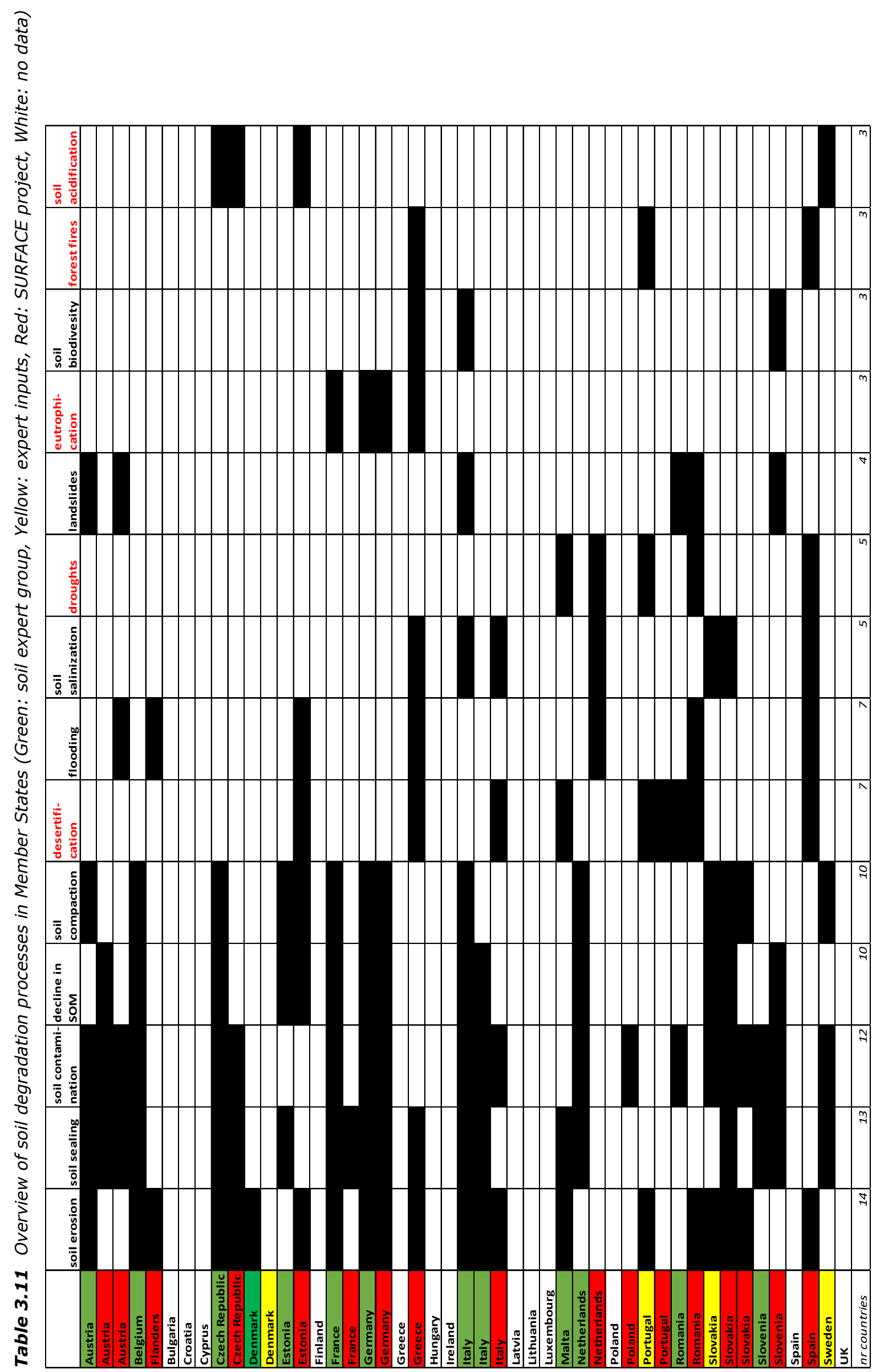




\subsubsection{Land and soil-related SDG indicators and sub-indicators}

This section deals with the SDG indicators that relate to soil and land. Both existing literature and the responses to the questionnaire (which specifically asked about land degradation indicators) were taken into account.

According to Tóth et al (2018), there are five groups of SDGs, although not all address soil and land. They assigned indicators only to those where soil plays a central role, namely those that:

- Explicitly include productivity (SDGs 2.3, 2.4);

- Explicitly include soil degradation (SDG 15.3);

- Name soil in the SDG, although no soil-based indicator has been proposed (SDG 3.9);

- Have direct relevance to soil resources, with explicit reference to land resources but no reference to soil (SDG 11.3);

- Have direct relevance of soil to SDG without naming soil in the SDG or including soil-related SDG indicators (SDGs 6.4, 6.5, 13.2, 14.1, 15.5).

(See Annex 3 for a list of the indicators proposed by Tóth et al. 2018) and their targets.)

Questionnaire responses provided insights into Member States' approaches to soil and land degradation. While this section deals with land and soil-related SDG indicators, the interviewees were asked about land degradation, which caused a certain bias in the answers. The questionnaire addressed the monitoring of soil and land degradation, potential indicators and their baseline and data sources, among other topics. (See Annex 2 for the main questions.)

The range of responses was broad and varied considerably between Member States - and even between different regions within a Member State - in their approaches to issues related to soil and land degradation. All of the countries that replied to the questionnaire carry out some form of monitoring. Countries such as Czechia, Slovakia and Sweden have comprehensive monitoring systems in place that include several parameters associated with soil and land degradation, translated into indicators. Most countries focus on five parameters: soil erosion, soil sealing, soil contamination, decline in OM and soil compaction, and do not specify precisely how they are measured.

Several discrepancies were noted between the responses from different experts from the same country, which indicates a lack of a common understanding and a clear national approach to soil and land degradation (indicators and monitoring).

There is no consensus between different Member States on what constitutes the baseline. Some follow UNCCD guidelines (e.g. Malta), others set their own baseline according to past data (e.g. Austria), others are still debating an appropriate baseline or have not defined one yet (e.g. Slovenia and Spain), while others (e.g. Sweden) state that it is not possible to set a baseline, given that this is an ongoing process. This suggests that without a common baseline, even if there is agreement on a set of common indicators, it would not be possible to compare different Member States, complicating the definition of an EU-wide understanding of soil and land degradation.

\subsubsection{National approaches to LDN}

Section 3.1.3 addressed the land degradation priorities and LDN among the different Member States. While some countries have either officially or unofficially defined land degradation, use a global definition, or have no definition at all, LDN is neither defined nor addressed by the Member States.

Some interviewees from Denmark, Romania and Slovakia recognise the importance of LDN but note that there is no current approach to achieving it. One interviewee from Italy, for example, agrees with LDN as a balance between restored degraded land and newly degraded land, but emphasises that existing methodologies would first need to be updated.

Overall, there is a lack of information on LDN approaches at national and sub-national level, with half of the countries failing to respond to this question. Of those that did provide an answer, some 
mentioned that these topics are dealt with at ministerial or federal (e.g. Germany) level. There was no mention of other institutions on a sub-national level.

The project proposes to assess the impact of soil and land management measures on the SDGs. The focus is therefore on developing an approach rather than simply taking a full inventory of Member State activity. This approach, which is detailed in the subsequent sections, selects successful measures for different zones/groups of countries in Europe, based on biophysical and socioeconomic settings. For each of these zones, examples of successful and unsuccessful measures will be highlighted, with an evaluation of why certain measures work well. Given the limited data availability, a sub-set of Member States and soil threats are used as illustrative examples.

\subsection{A new approach to assessing measures}

\subsubsection{Introduction}

The approach starts by connecting the SDGs to the soil threats (Figure 3.2). For each SDG, the impact of each soil threat on the achievement of that particular SDG was assessed, using the steps described by Keesstra et al. (Keesstra et al., 2016). They took a stepped approach to link the soil functions via the ecosystem services to the SDGs. The second step was to assess how much of the area of each environmental zone in Europe (Metzger et al, 2005) is affected by each soil threat. Environmental zones were preferred to countries because environmental characteristics (climate/soil/relief) do not coincide with country borders. The variability within countries would be too high to make any sensible suggestions for preferred soil management strategies. The two sources of information (impact soil threat on SDGs and soil threat occurrence in environmental zones) were combined, identifying lighthouse measures for the most urgent soil threat / environmental zone combination and how the selected measure would be of benefit. This approach would allow a handling perspective for each zone. It should be noted that the list of lighthouse measures is not complete and simply serves as an illustration for this approach. The conference will provide a forum to obtain feedback on the lighthouse measures selected and allow for discussion of the approach itself. 
- Connect SDGs and soil threats to environmental zones

- Show how each management choice implies choices in which SDGs will be achieved

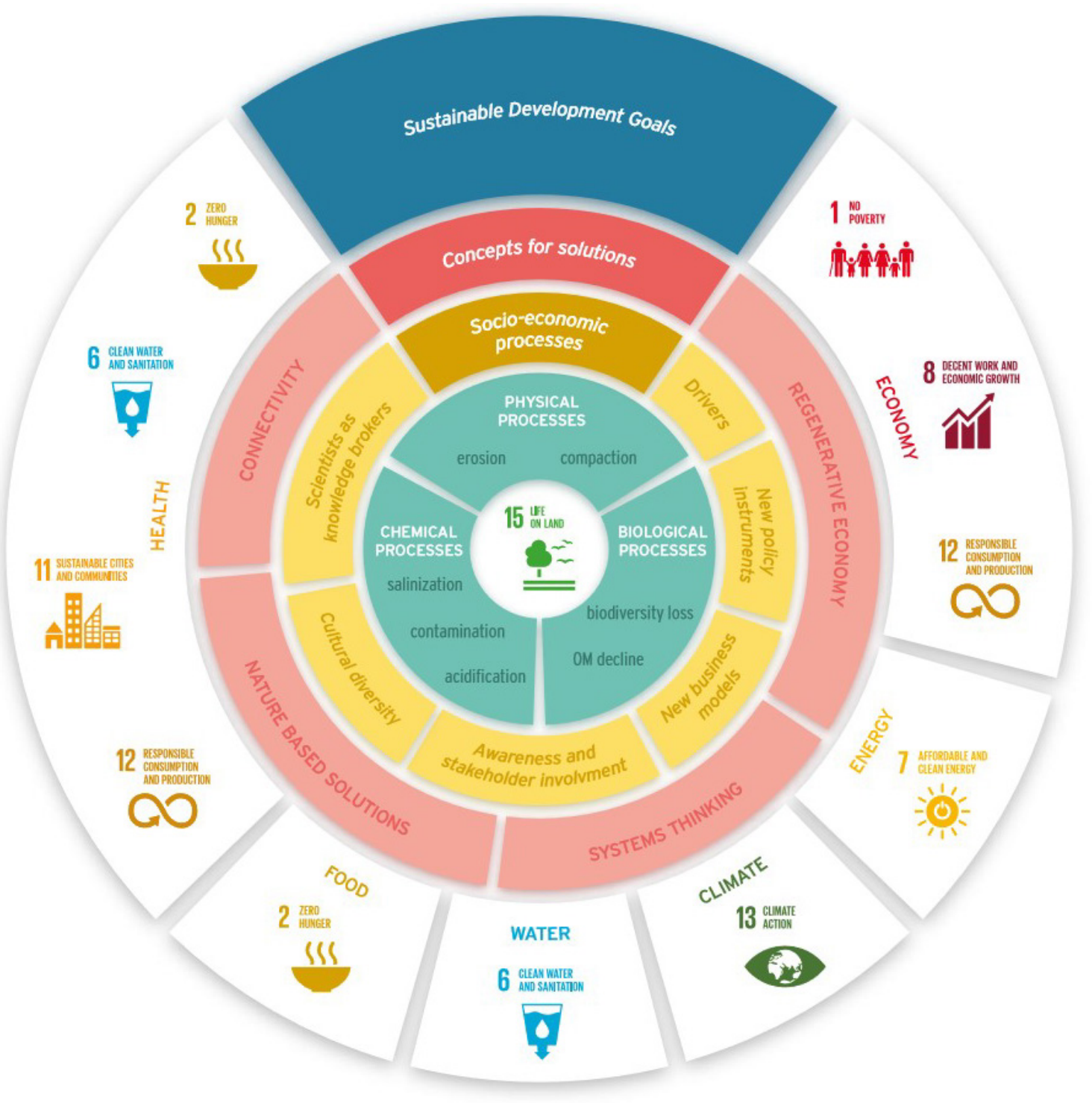

Figure 3.7 Linkages between SDGs and soil and ecosystem-based approaches (Keesstra et al., 2018).

Each selected measure was evaluated using the diagram in Figure 3.2. This method allows the assessment of a selected measure that was initially designed to achieve SDG 15 in terms of its contribution towards other SDGs. The chosen measure should be evaluated by its biophysical processes and their impact on the goal (in this case, SDG 15). In order to make the measure acceptable and sustainable, it should also be evaluated for its impact on the socioeconomic structure of the area in which it is implemented. The diagram argues that only measures designed according to these concepts (systems thinking; connectivity; nature-based solutions, regenerative economics) will be acceptable from both a biophysical and socioeconomic perspective. The final step is to evaluate the chosen measure according to its impact on serving different SDGs at the same time. The diagram 
roughly groups the SDGs in goals related to: health, food, water, climate, energy and economy. In the evaluation that follows, an explanation is given of how the measure fits into this method.

\subsubsection{Mapping soil threats}

In order to map soil threats, a spatial analysis was undertaken, using the best available information. The eight soil threats were mapped according to the specification explained in Table 3.11. The final column of the table indicates the thresholds used to map areas as having a soil threat. Boxes 1, 2 and 3 provide further background information on the input data layers used to map the different soil threats.

Table 3.12 Approach and data used to map soil threats

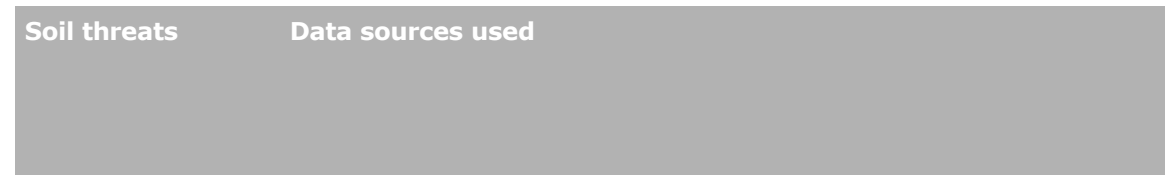

1. Soil erosion by wind and water

Wind erosion. The map is based on an Index of Land Susceptibility to Wind Erosion (ILSWE) which was created by combining spatio-temporal variations of the most influential wind erosion factors. See further details in Box 3 and at:

http://eusoils.jrc.ec.europa.eu/library/themes/erosion/winderosion/ JRC database. Main reference Borrelli et al. (2014).

Soil Erosion by water- JRC database developed through the application of the WaTEM/SEDEM model long-term averages of annual soil loss and deposition rates were computed (Borreli et al., 2018). Database link: http://eusoils.jrc.ec.europa.eu/ESDB_Archive/pesera/pesera_data.html

2. Soil organic matter decline Combination of different layers:

1. Copernicus imperviousness change (2006-2012)

2. Volante (1990-2006) dominant land use change trajectories (Levers, et al., 2014)

3. Land use intensity maps gridded in PEGASUS based on Perez-Soba et al. (2015), high, medium and low intensity farmland NDVI-HANTS phenotype dataset. (Roerink et al., 2011)
Mapping approach: indicators and thresholds used for the final mapping of soil threat

Wind erosion: areas mapped as soil threat 'wind erosion'

overlap with wind susceptibility classes (in ILSWE) 'High' and 'Very High'.

To map the lands that are under threat for soil erosion by water the WaTEM class > 100 ton/ha/yr of soil loss was taken

Lands classified as having soil organic matter decline as a major soil threat are those that have:

SOC loss of $>0.1 \mathrm{mg}$ $\mathrm{C} / \mathrm{ha} / \mathrm{yr}$. This overlaps with ESDAC map class 'high' and 'very high' risk for SOC loss

Lands classified as having soil sealing as a major soil threat are those that have:

1. PEGASUS class high and medium intensity

Where built-up area increased over the assessed years based on information from 3 input layers (Copernicus, VOLANTE \& NDVI-HANTS)

4. Compaction JRC (2008). Natural susceptibility to soil compaction in Europe. Data set is included in the soil threats database of ESDAC:

https://esdac.jrc.ec.europa.eu/content/natural-susceptibility-soilcompaction-europe

The map of natural soil susceptibility to compaction was created from the evaluation of selected parameters from the European Soil Database (ESDB). The soil susceptibility to compaction was divided into four categories. Two additional categories represent the data concerning places where this evaluation was either not relevant or could not be provided because of lack of information. In total there are six categories: $\bullet 0$ - no soil. This represents water bodies, glaciers and rock outcrops
Lands classified as having risk soil threat are those that have:

Classes high and very high in the JRC database on natural susceptibility to soil compaction for compaction as a major 


\begin{tabular}{|c|c|c|}
\hline Soil threats & Data sources used & $\begin{array}{l}\text { Mapping approach: } \\
\text { indicators and thresholds } \\
\text { used for the final mapping } \\
\text { of soil threat }\end{array}$ \\
\hline & $\begin{array}{l}\text {-1 - low susceptibility to compaction } \\
\text {-2. - medium susceptibility to compaction } \\
\bullet 3 \text {. - high susceptibility to compaction } \\
\bullet 4 \text {. - very high susceptibility to compaction } \\
\bullet 9 . \text { - no evaluation possible. This was the case of towns, including soils, } \\
\text { soils disturbed by man and marshes }\end{array}$ & \\
\hline $\begin{array}{l}\text { 5. Soil biodiversity } \\
\text { decline }\end{array}$ & $\begin{array}{l}\text { JRC (2016). Potential threats to soil biodiversity in Europe. Data set is } \\
\text { included in the soil threats database of ESDAC: } \\
\text { https://esdac.jrc.ec.europa.eu/content/potential-threats-soil- } \\
\text { biodiversity-europe } \\
\text { See Box } 3 \text { for more information }\end{array}$ & $\begin{array}{l}\text { Lands classified as having } \\
\text { loss in soil biodiversity as a } \\
\text { major soil threat are those } \\
\text { that have: } \\
\text { Classes moderate-high and } \\
\text { high in at least one of the } \\
\text { three biodiversity threat } \\
\text { layers the soil biodiversity } \\
\text { threats database comprises }\end{array}$ \\
\hline 6. Landslides & $\begin{array}{l}\text { JRC (2016). European Landslide Susceptibility Map version } 2 \text { (ELSUS } \\
\text { v2). Data set is included in the soil threats database of ESDAC: } \\
\text { https://esdac.jrc.ec.europa.eu/content/european-landslide- } \\
\text { susceptibility-map-elsus-v2 } \\
\text { The spatial dataset (GIS map) shows landslide susceptibility levels at } \\
\text { European scale, derived from heuristic-statistical modelling of main } \\
\text { landslide conditioning factors also using landslide location data. It covers } \\
\text { all EU Member States except Malta. The map was produced by } \\
\text { regionalising the study area based on elevation and climatic conditions, } \\
\text { followed by spatial multi-criteria evaluation modelling using pan- } \\
\text { European slope angle, shallow sub-surface lithology, and land cover } \\
\text { spatial datasets as the main landslide conditioning factors. In addition, } \\
\text { the location of over } 149,000 \text { landslides across Europe was used for } \\
\text { model calibration and map validation }\end{array}$ & $\begin{array}{l}\text { Lands classified as having } \\
\text { landslides threat as a major } \\
\text { soil threat are those that } \\
\text { score 'high' and 'very high' in } \\
\text { the landslides database }\end{array}$ \\
\hline 7. Pollution & No Europe-wide data linking to a clear definition of pollution threat & - \\
\hline 8. Salinisation & No Europe-wide data linking to a clear definition of salinisation threat & \\
\hline 9.Desertification & No Europe-wide data linking to a clear definition of desertification threat & \\
\hline
\end{tabular}

Box 3.6 Description of the ILSWE dataset predicting wind erosion susceptibility of land in Europe

For wind erosion, we used the dataset developed by the JRC (Borrelli et al., 2014). The dataset predicts the susceptibility to wind erosion. The map is based on an ILSWE, which was created by combining spatio-temporal variations of the most influential wind erosion factors. For the assessment of understanding the sensitivity to wind erosion of marginal lands, the lands that overlapped with wind susceptibility classes (in ILSWE) 'high' and 'very high' were determined.

The ILSWE is based on the combination of the most influential parameters, i.e. climate (wind, rainfall and evaporation), soil characteristics (sand, silt, clay, $\mathrm{CaCO} 3$, organic matter, water-retention capacity and soil moisture) and land use (land use, percent of vegetation cover and landscape roughness). The spatial and temporal variability of factors are appropriately defined through GIS analyses. Harmonised datasets and a unified methodology were employed to suit the pan-European scale and avoid generating misleading findings that could result from heterogeneous input data. The selected soil erosion parameters were divided into three groups, namely (i) Climate Erosivity, (ii) Soil Erodibility and (iii) Vegetation Cover and Landscape Roughness. Sensitivity to the contributing group of factors was calculated using the fuzzy logic technique, which allows the sensitivity range of each factor in Europe to be unambiguously defined.

Borrelli, P., Panagos, P., Ballabio, C., Lugato, E., Weynants, M. and Montanarella, L. (2014). Towards a pan-European assessment of land susceptibility to wind erosion. Land Degradation \& Development. In Press. Available at doi: $10.1002 / \mathrm{ldr} .2318$

(Source: https://esdac.jrc.ec.europa.eu/content/Soil_erosion_by_wind) 
The JRC, in collaboration with the University of Basel and Université Catholique de Louvain, quantified the potential spatial displacement and transport of soil sediment due to water erosion at European scale. With the WaTEM/SEDEM model, long-term averages of annual soil loss and deposition rates were computed. The findings indicate that soil loss from Europe in the riverine systems is about $15 \%$ of the estimated gross on-site erosion.

Input data: RUSLE2015 soil erosion estimates, Digital Elevation Model (DEM) at 25m.

The estimated sediment yield totals $0.164 \pm 0.013 \mathrm{Pg} \mathrm{yr}^{-1}$ (which corresponds to $4.62 \pm 0.37 \mathrm{Mg} \mathrm{ha}^{-1} \mathrm{yr}^{-1}$ in the erosion area). The greatest amount of gross on-site erosion, as well as soil loss to rivers, occurs in agricultural land $(93.5 \%)$. The Sediment Delivery Ration (SDR), i.e. the ratio between sediment yield (SY) and gross erosion, indicates that the sediment routed down the hillslopes to the riverine system accounts for $15.3 \%$ of the total eroded soil.

To map the lands that are under threat for soil erosion by water, the WaTEM class $>100$ ton/ha/yr of soil loss was taken. For further details on the WaTEM/SEDEM water erosion risk, see: Borrelli, P., Van Oost, K., Meusburger, K., Alewell, C., Lugato, E. and Panagos, P. (2018). A step towards a holistic assessment of soil degradation in Europe: Coupling on-site erosion with sediment transfer and carbon fluxes. Environmental Research, 161, pp. 291-298.

(Source: https://esdac.jrc.ec.europa.eu/content/estimate-net-erosion-and-sediment-transport-using-watemsedem-european-union) 
Dataset contains three GIS maps showing potential threats to soil biodiversity in Europe for soil microorganisms, fauna and biological function. To produce the database, a list of 13 potential threats to soil biodiversity was proposed to experts in order to assess the potential threat for three major components of soil biodiversity: soil microorganisms, fauna and biological function. The 13 potential threats that were scored and then mapped in 13 sub-layers were: habitat fragmentation, use of GMOs in agriculture, introduction of invasive species, climate change, soil compaction, soil sealing, soil erosion, soil salinisation, land use change, nuclear pollution, soil pollution from industry, organic matter decline and intensive human exploitation.

The results of the mapping show that intensive exploitation was identified as the highest pressure. In contrast, the use of genetically modified organisms (GMO) in agriculture was considered as the threat with least potential. The potential impact of climate change showed the highest uncertainty. Fourteen of the 27 countries have more than $40 \%$ of their soils with moderate-high to high potential risk for all three components of soil biodiversity. Arable soils are the most exposed to pressures. Soils within the boreal biogeographic region showed the lowest risk potential.

For further details on the database see:

Orgiazzi, A., Panagos, P., Yigini, Y., Dunbar, M.B., Gardi, C., Montanarella, L. and Ballabio, C. (2016). A knowledge-based approach to estimating the magnitude and spatial patterns of potential threats to soil biodiversity. Science of The Total Environment, Volumes 545-546, pp. 11-20. Available at:

https://doi.org/10.1016/j.scitotenv.2015.12.092 Link:

https://www.sciencedirect.com/science/article/pii/S004896971531247X

Map: Areas at risk of soil biodiversity loss:

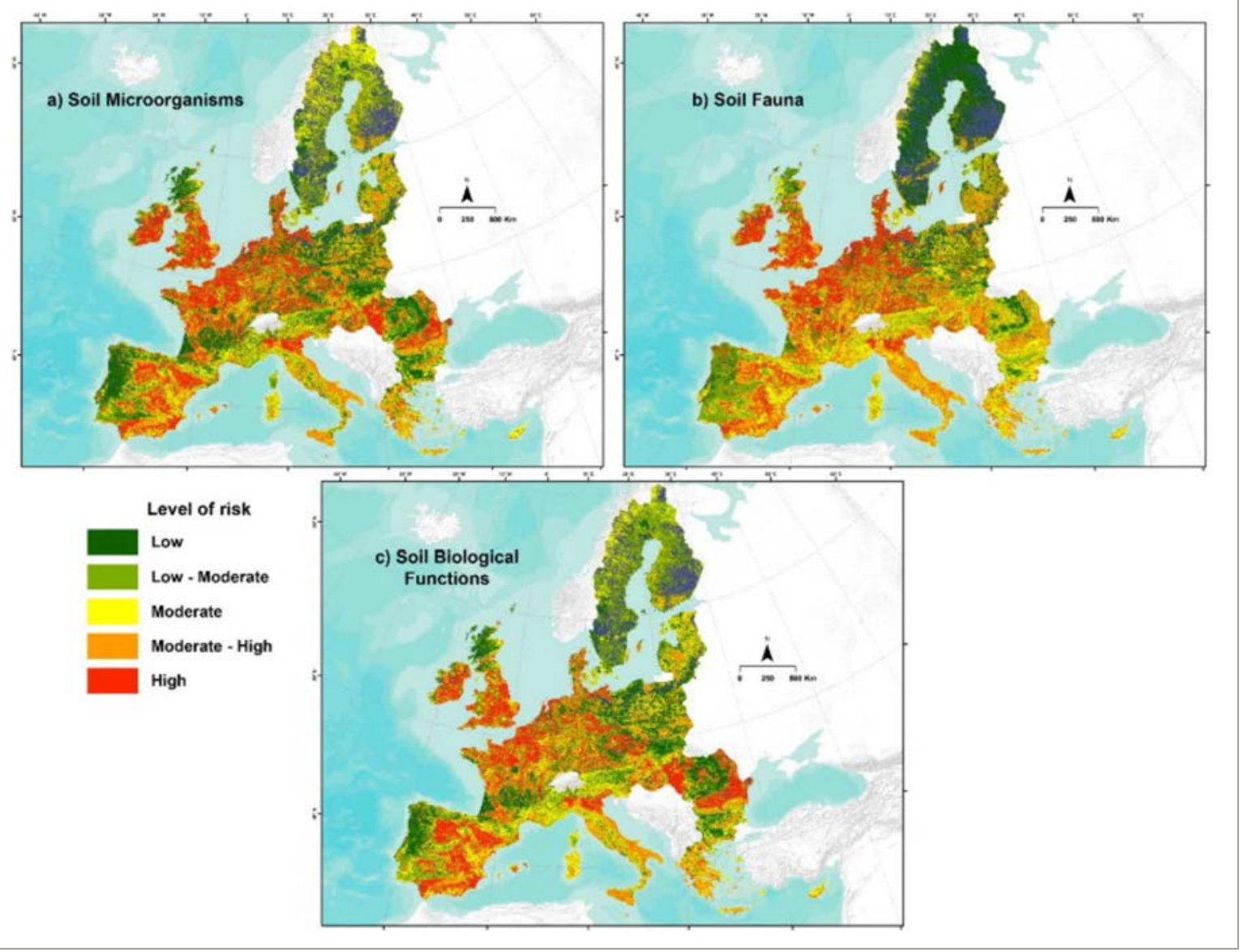

(Source: https://esdac.jrc.ec.europa.eu/content/potential-threats-soil-biodiversity-europe)

In order to understand the distribution of soil threats across Europe and identify concentration zones, the mapped results were further classified according to environmental zones. Metzger et al. (2005) was used for the classification of environmental zones (EnZ) (see Box 3.8). 
The Environmental Stratification (Metzger et al., 2005) is the result of a principal component analysis (PCA) of the 20 most relevant and available environmental variables (grouped under climate, geomorphology, oceanicity and northing), combined using an ISODATA principal component analysis (PCA) clustering. The resulting 84 strata of the Environmental Stratification (EnS) are aggregated into 13 environmental zones (EnZ). The resulting Environmental Stratification is a vector dataset, hierarchically built up with environmental zones and strata.

The PCA was used to explain $88 \%$ of the variation into three dimensions, which were subsequently clustered into 84 strata using an ISODATA clustering routine. The mean first principal component values of the classification variables were used to aggregate the strata into 13 Environmental Zones (EnZ), which provides a basis for a consistent nomenclature. The EnZs are used as the climatic basis for the development of the Agri-Environmental Zonation (AEnZ).

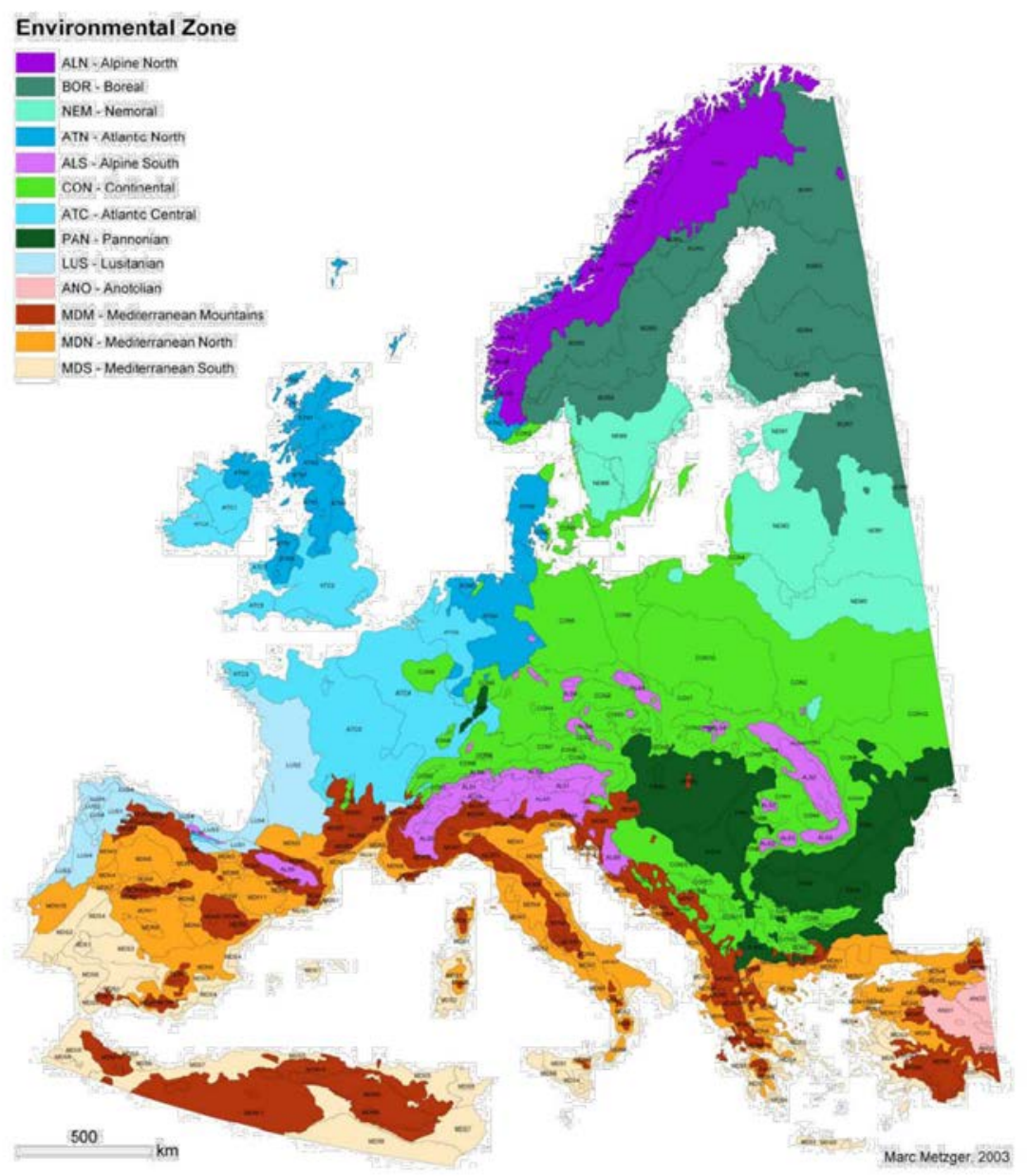

Figure 1 The 84 strata of the Environmental Stratification (EnS) are aggregated into 13 environmental zones (EnZ)

Reference: Metzger, M.J., Bunce, R.G.H., Jongman, R.H.G., Mücher, C.A. and Watkins, J.W. (2005). A climatic stratification of the environment of Europe. Global Ecology and Biogeography, 14, pp. 549-563. Metzger, M.J., Bunce, R.G.H., Leemans, R. and Viner, D. (2009). Projected environmental shifts under climate change: European trends and regional impacts. Environmental Conservation, 35, pp. 64-75. 


\subsubsection{Results of mapping soil threats}

The integrated mapping of soil threats allows conclusions to be drawn on the environmental zones and countries in which specific soil threats are most dominant, as well as those where they are not relevant.

The mapped results are presented in Figure 3.4. An integrated summary view of the overlay of soil threat per environmental zone is presented in Figure 3.3. Detailed statistics on the area shares of the different soil threats per environmental zones are presented in Figure 3.8. The methodology we followed is based on data sets available for the European scale as explained in Table 3.11. It is important to realise that the results as presented in Fig. 3.7/3.8 and Table 3.12 are based on surface areas. This means that some important threats such as soil sealing do not score very high. This, however, does not mean that they are not important, as the soil threat may have a major impact on the local scale such as soil sealing is in peri-urban areas; or areas where large greenhouse fields are established. Also, the surface areas does not discriminate between irreversible degraded state (such as soil sealing) and ongoing degradation process (e.g. decline in soil biodiversity). This exercise has been carried out on the European scale; however, the lighthouse example approach as presented in the next section zooms in to the local scale. The identified soil threats per environmental zone will allow to transfer useful lighthouse examples within the same environmental zone.

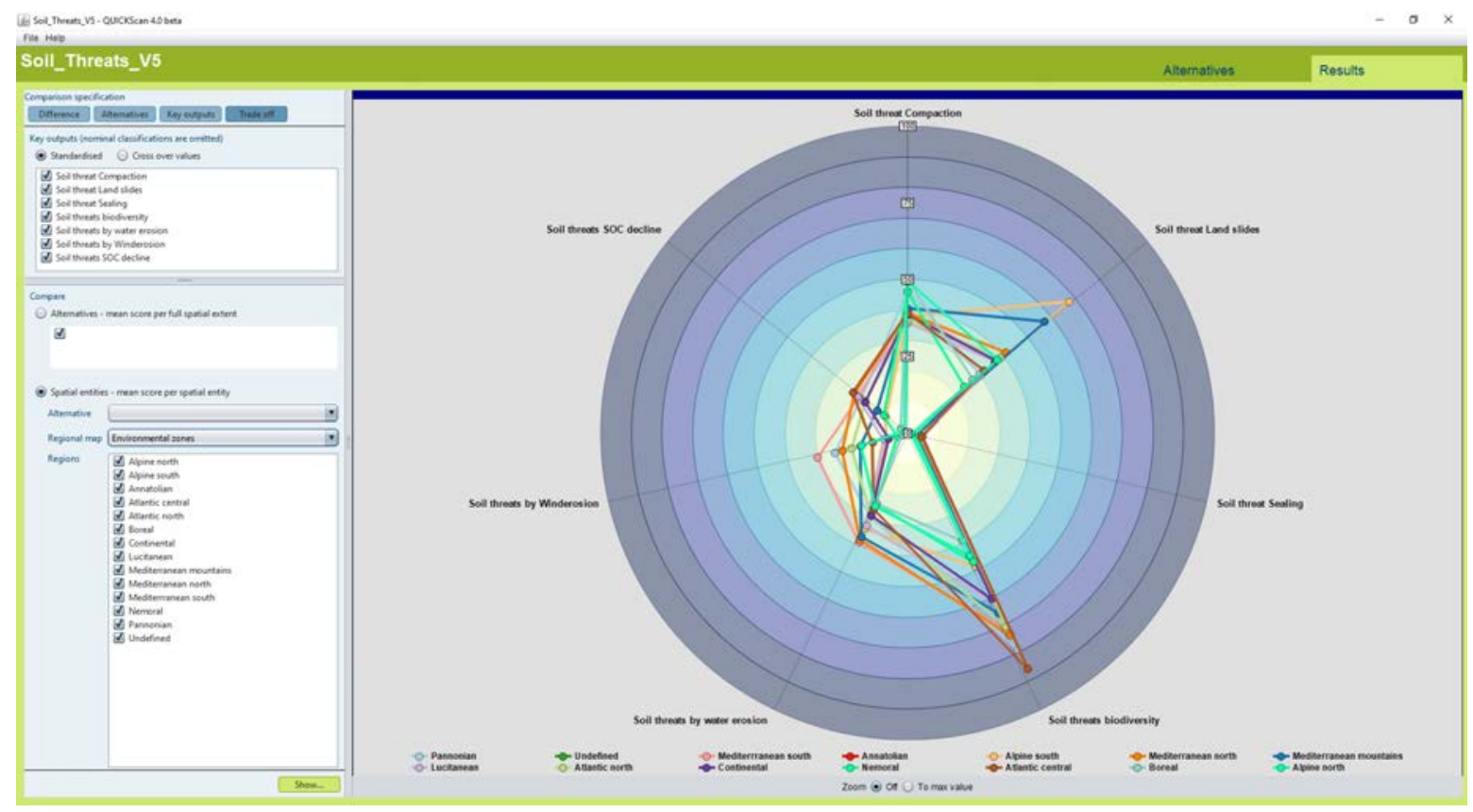

Figure 3.8 Overview of extension of different soil threats in all 13 environmental zones in EU-28 


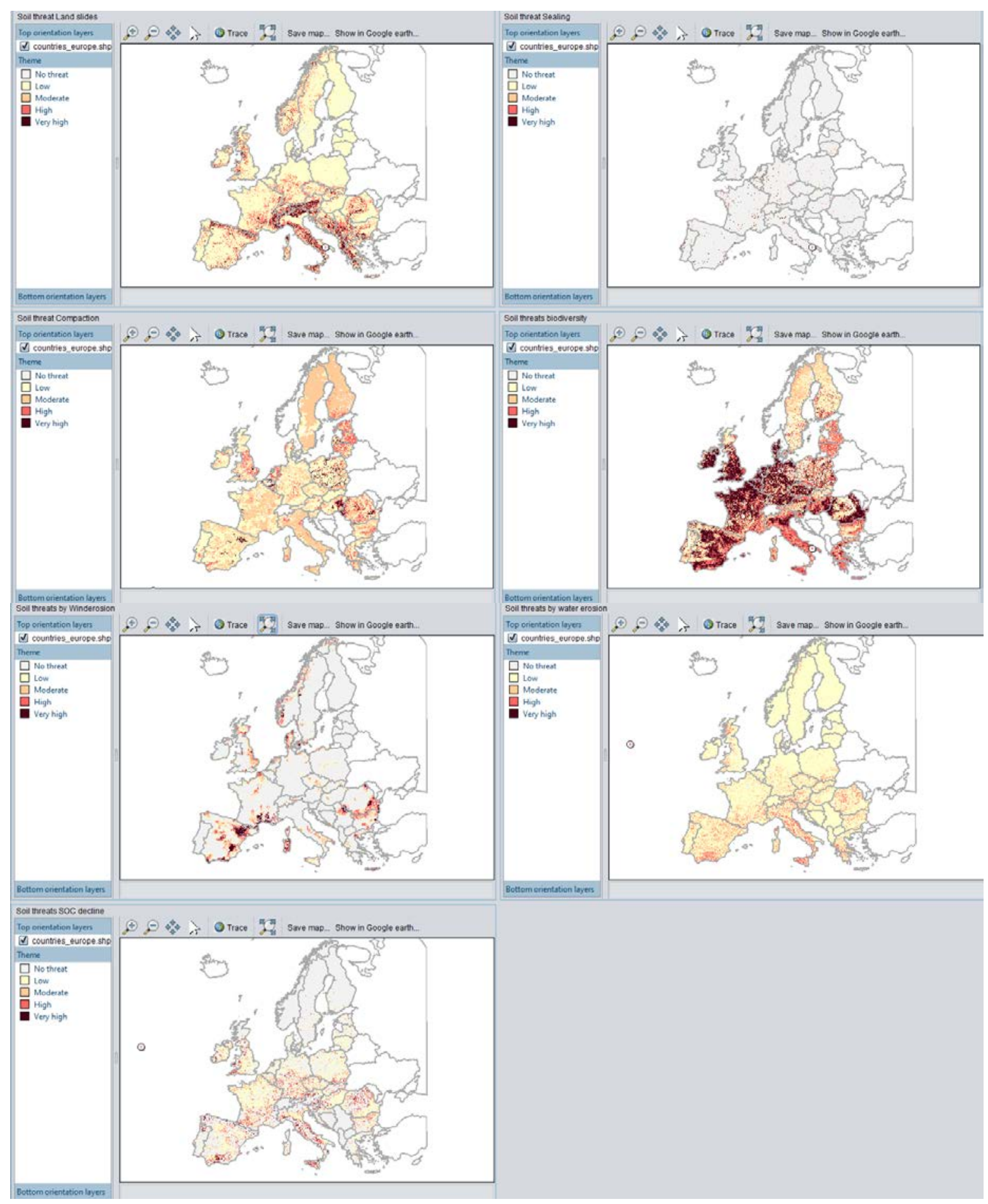

Figure 3.9 Result maps for soil threats landslides, soil sealing, compaction, soil biodiversity, erosion and SOC decline 
Table 3.13 Soil threat most likely to prohibit the achievement of LDN per environmental zone in Europe

\begin{tabular}{lrrrrrrrrrrrr}
$\begin{array}{l}\text { Environmental zone: } \\
\text { Soil threats: }\end{array}$ & ALN & BOR & NEM & ATN & ALS & CON & ATC & PAN & LUS & MDM & MDN \\
Erosion by wind & 10 & 0 & 1 & 11 & 4 & 3 & 6 & 20 & 3 & 11 & 15 & 25 \\
\hline Erosion by water & 1 & 0 & 0 & 3 & 11 & 2 & 1 & 3 & 5 & 12 & 11 & 11 \\
\hline Organic matter decline & 0 & 0 & 1 & 9 & 7 & 9 & 7 & 6 & 12 & 9 & 13 & 10 \\
\hline Sealing & 0 & 0 & 1 & 1 & 0 & 1 & 3 & 1 & 3 & 1 & 3 & 3 \\
\hline Compaction & 0 & 8 & 23 & 13 & 2 & 13 & 10 & 26 & 2 & 4 & 5 & 11 \\
\hline Soil biodiversity decline & 6 & 13 & 40 & 62 & 31 & 40 & 84 & 47 & 51 & 55 & 72 & 71 \\
\hline Landslides & 16 & 4 & 0 & 17 & 60 & 17 & 9 & 7 & 15 & 45 & 23 & 16 \\
\hline
\end{tabular}

Area share (\%/total area) per environmental zone covered by the threat.

Red numbers indicate a soil threat that affects an area greater than $10 \%$. Soil contamination, soil salinisation and desertification are not included due to the lack of EU-wide information.

The evaluation of all soil threats across all environmental zones in Europe (Table 3.13) shows that:

- Erosion by water is most strongly a threat in the Alpine south and the three Mediterranean zones. Wind erosion is a less widespread threat in the EU but is far more prominent in certain zones, e.g. the Pannonian, Mediterranean and Atlantic and Alpine North.

- In this analysis SOM decline does not appear as a very extensive soil threat. However, in arable land and especially peatland areas it can affect soil health and productivity, which is especially evident in the Mediterranean and Lusitanian area where it can affect up to $13 \%$ of the area. Also important to know is that many soils already have a low soil carbon stock, which can therefore not decline even further ${ }^{53}$. It is of importance to focus on increasing soil carbon in those areas ${ }^{54}$; however, this is not included in this analysis.

- The soil compaction threat is occurring in almost all environmental zones but is most prominent in the Pannonion, Nemoral and Atlantic zones, where wetness is more often a challenge in agricultural soils.

- Soil sealing is the least widespread threat in terms of area coverage. It is most prominent in Atlantic central, Lusitanian and in two of the Mediterranean zones. These are generally the zones with highest urbanisation dynamics. However, even though it is not an important threat in terms of surface areas affected it is a very important threat in the most densely populated areas. Especially in peri-urban areas, industrial developments are sealing fertile soil rapidly ${ }^{55}$. This does not show in the analysis done with the full area of Europe; but this does not mean it is not a significant threat.

- Soil biodiversity decline is spread over a large share of the territory of all environmental zones, but is most prominent in the Atlantic, Mediterranean and Pannonian zones.

- Landslides are the second most widespread threat, particularly in zones covering many mountains, such as the Alpine south and north, and Mediterranean mountains and north. Even though this soil threat is important in terms of area covered, it is not so urgent in most countries. This is because the areas affected are not densely populated in most countries and consist of very steep mountainous areas that are now nature areas or used by extensive grazing activities. In addition, many of those areas are steep and do not have a productive soil that is threatened.

For the other soil threats, desertification, soil contamination and soil salinisation there is no EU-wide reliable spatial information available of sufficient quality to make this assessment.

\subsubsection{Lighthouse examples to serve as good practice advice}

The analysis took a stepped approach to assess the types of land management strategies that may be useful in addressing the most important soil threats for different environmental zones.

\footnotetext{
53 Parras-Alcántara, L., Lozano-García, B., Brevik, E.C., Cerdá, A., 2015. Soil organic carbon stocks assessment in Mediterranean natural areas: A comparison of entire soil profiles and soil control sections. J. Environ. Manage. 155, 219-228. https://doi.org/10.1016/j.jenvman.2015.03.039.

54 Novara, A., Pulido, M., Rodrigo-Comino, J., Di Prima, S., Smith, P., Gristina, L., ... \& Keesstra, S. (2019). Long-term organic farming on a citrus plantation results in soil organic carbon recovery. Cuadernos de Investigación Geográfica.

55 Ferreira, C. S. S., Walsh, R. P. D., Kalantari, Z., \& Ferreira, A. J. D. (2020). Impact of Land-Use Changes on Spatiotemporal Suspended Sediment Dynamics within a Peri-Urban Catchment. Water, 12(3), 665.
} 
In each case, a lighthouse land management strategy was identified, that was to be evaluated with the SDGs in mind. Figure 3.3 clarifies why these measures are suitable to promote the achievement of the SDGs. The examples highlighted as lighthouses were collected through a literature review and based on EU-funded projects RECARE and SOILCARE (www.recare-project.eu; www.soilcare-

project.eu).

For each assessed strategy we have indicated in Figure 3.4 which SDGs and associated overarching societal issues the specific strategy works towards. In addition, this is also highlighted in the tables at the end of each lighthouse example description. The table indicates which SDG is working towards each specific societal issue (Health, Food, Water, Climate, Energy, Economy, Soil/Land). The numbers that have been highlighted green are those which are positively influenced by the presented lighthouse example.

\subsubsection{Soil threat 1: soil erosion by wind and water}

Soil erosion by wind is especially evident in the Mediterranean areas, in the Pannonian and Atlantic North.

In the current systems, after harvesting the soils are left bare and exposed to the wind during the entire winter period until seeding happens in spring. Depending on the soil type, the soil is easily eroded and transported elsewhere, where it may clog sewers and reservoirs. In addition, the soil particles may contain contaminants and pollutants that threaten human health in adjacent towns.

\section{Lighthouse example for wind erosion}

The use of stubble as a natural mulch This system carries out annual ploughing just prior to seeding, limiting the time in which the soil is bare and vulnerable to wind erosion. During the winter period, after harvesting, the crop stubble eliminates the stress of the wind on the surface.

This approach is suitable for all areas suffering from wind erosion. As well as helping to achieve its primary goal - stop wind erosion and, with that, land degradation (SDG 15) - it also works to maintain soil fertility. Soil fertility will enhance the possibility to produce healthier food (SDG 2) in a sustainable way (SDG 12) and to allow for a better livelihood for farmers (SDG 8). Reduced tillage and leaving the roots

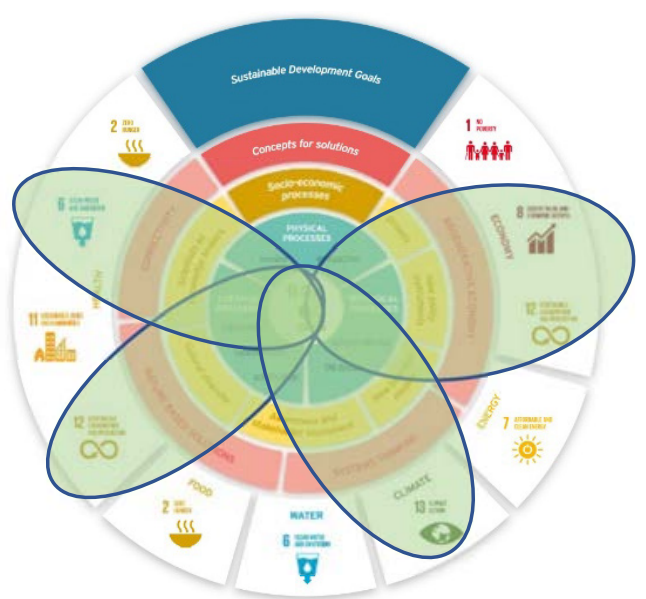
of the harvested crops will increase the infiltration of rainfall (SDG 6), increase soil carbon stocks (SDG 13) and reduce landslide risks (SDG 15).

\begin{tabular}{lllllll} 
Health & Food & Water & Climate & Energy & Economy & Soil//and \\
\hline 2 & 2 & 6 & 13 & 7 & 1 & 8 \\
\hline 6 & & & & 12 & 15 \\
\hline 11 & & & & \\
\hline 12 & & & & \\
\hline
\end{tabular}

\section{Soil erosion by water}

Soil erosion by water emerges as a major threat in the Alpine South and Mediterranean areas, where relief and bare soils are combined. Under these circumstances intensive rainstorms can cause significant damage. Intense rainfall events are more common in areas with warmer climates, therefore, under climate change extreme events will occur more frequently. 


\section{Lighthouse examples for water erosion:}

The use of mulching and cover crops in orchards and vineyards Straw mulch has proved to be an effective and potentially acceptable measure in orchards in Mediterranean Spain. In the dry summers in the Mediterranean, strong thunderstorms can cause massive erosion damage in just a few hours. Mulching or cover crops have been proven to reduce erosion by more than an order of magnitude. The implementation of this measure will help to achieve SDG 15 and will also improve water quality (SDG 6), mitigate climate change by improving the soil carbon stock (SDG 13), improve long-term crop growth and production and a sustainable livelihood for the producer (SDG 2, 8 and 12). The offsite effects will improve infrastructure in the area by not damaging roads and reservoirs.

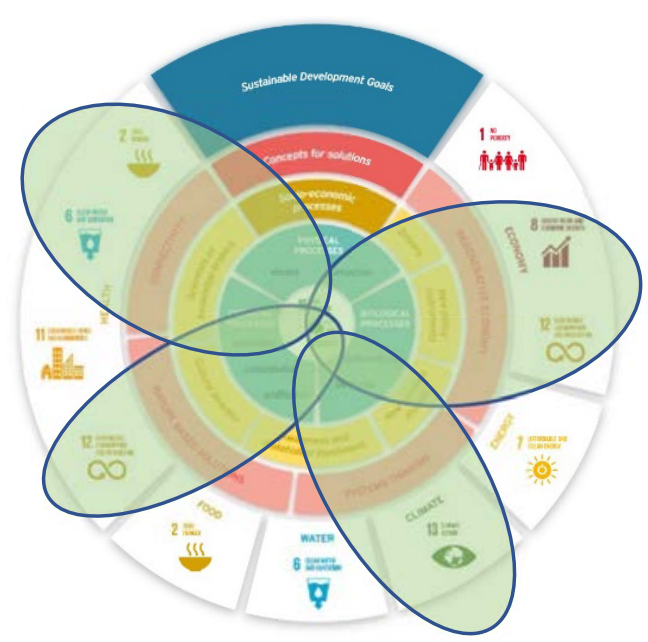

\begin{tabular}{|c|c|c|c|c|c|c|}
\hline Health & Food & Water & Climate & Energy & Economy & Soil/land \\
\hline 2 & 2 & 6 & 13 & 7 & 1 & 15 \\
\hline 6 & & & & & 8 & \\
\hline 11 & & & & & 12 & \\
\hline 12 & & & & & & \\
\hline
\end{tabular}

\section{Maintained terrace structures}

Well-maintained terraces are an excellent means of avoiding soil erosion by water. They also form part of the cultural heritage of a region, enhancing tourism and improving the infrastructure and livelihood of a region. This measure works towards more than its original goal (SDG 15), also helping to achieve SDG 8: decent work and economic growth and a more sustainable production (SDG 12) of agricultural products. It also enhances infiltration, which may increase water availability for crops (reducing the irrigation needs in dryland areas) and recharge the aquifer (SDG 6).

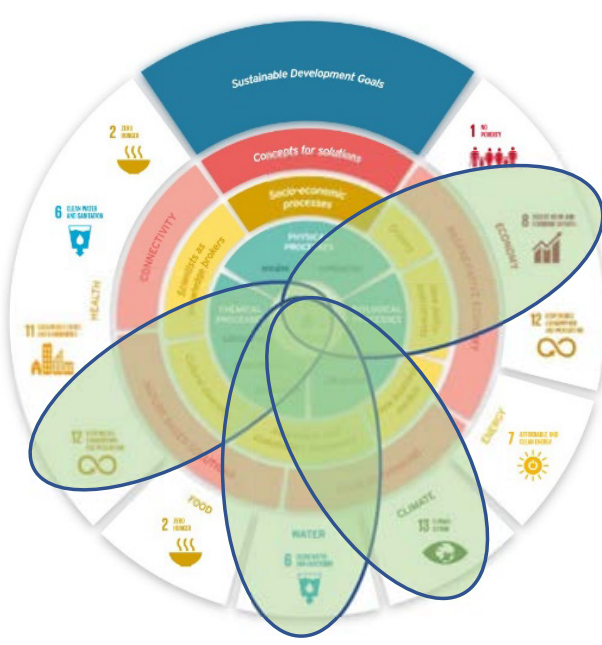

\begin{tabular}{|c|c|c|c|c|c|c|}
\hline Health & Food & Water & Climate & Energy & Economy & Soil/land \\
\hline 2 & 2 & 6 & 13 & 7 & 1 & 15 \\
\hline 6 & & & & & 8 & \\
\hline 11 & & & & & 12 & \\
\hline 12 & & & & & & \\
\hline
\end{tabular}

\subsubsection{Soil threat 2: soil organic matter decline}

Organic matter decline has been listed as a major problem in all Mediterranean regions and in Lusitania (which includes north Portugal, northeast Spain and southwest France). In addition, it is known to be a soil threat in arable land, especially for peat soils.

SOM can be defined as the total organic content of a soil after excluding non-decayed plant and animal remains. Carbon is the primary element of SOM, comprising about half of the total weight of the organic matter, making soil the second largest pool of carbon on Earth. To protect SOM in agricultural soils, it is important to prevent its oxidation and promote the formation of new SOM. 


\section{Lighthouse examples for organic matter}

\section{Cover crops and catch crops}

To prevent oxidation of organic matter in soils, turnover of the soil should be avoided as much as possible. No, or minimum, tillage is therefore a good option.

However, to eliminate the negative effects of weeds, farmers in many areas use herbicides to eliminate weeds in their fields, replacing the tillage practices used previously. Although there are sophisticated precision farming and mechanical weeding techniques available, many farmers still often excessively use herbicides. This excessive use of chemical weed eliminating products has a negative effect on soil life/biodiversity and pesticides may leach into below ground water bodies and cause diffuse pollution, which is undesirable from an SDG point of view.

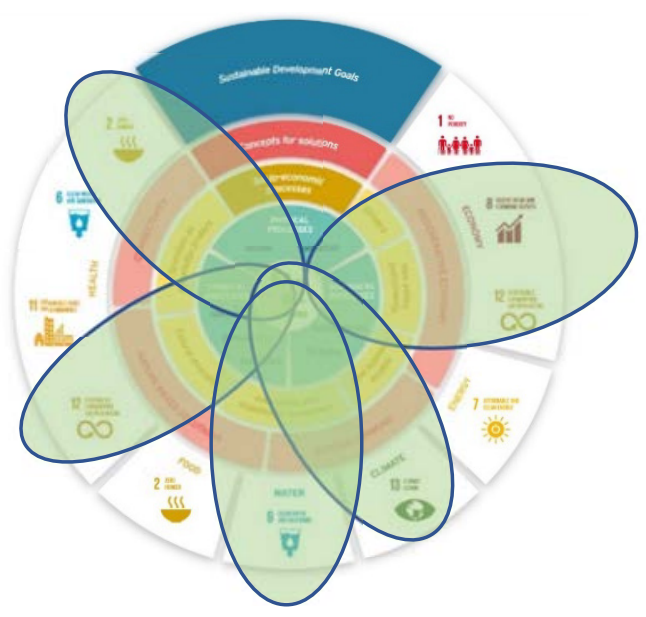
The focus must be placed on combining benefits. A lighthouse for stopping SOM decline - or even enhancing SOM generation - is the use of green manure, i.e. growing a non-harvested crop between two main crop seasons. This agricultural technique improves soil fertility by fixing nitrogen from the atmosphere. Before sowing the agricultural crop, the plant material is ploughed into the soil to improve its organic matter and nutrient content.

As well as increasing SOM (which helps to mitigate climate change (SDG 13)), this method also helps to achieve a better ecological situation by improving soil health and attracting biota in the soil and above, such as pollinators (SDG 15). Limiting the use of herbicides means that soil health and water quality will be improved (SDG 6). The increased soil health will reduce the fertiliser input needed, which may help farmers with good production levels in sustainable ways, from both a biophysical and socioeconomic point of view (SDGs 2, 11 and 12).

\begin{tabular}{l|lll|lll} 
Health & Food & Water & Climate & Energy & Economy & Soil/land \\
\hline 2 & 2 & 6 & 13 & 7 & 1 & 15 \\
\hline 6 & & & & 8 & \\
\hline 11 & & & & 12 & \\
\hline 12 & & & &
\end{tabular}

\subsubsection{Soil threat 3: soil sealing}

Soil sealing did not emerge from the analysis as a major soil threat in terms of area affected. However, in our urbanising environment, soils in peri-urban locations are under serious threat from sealing.

The soils under greatest threat are often the most fertile soils. Two key examples are:

1. Plaggen soils in the Atlantic North and Atlantic Central zones. These are anthropogenically improved sandy soils with extreme fertility. Typically, these soils are close to village centres, as they were used in the past as the source of crops to feed the village. Nowadays, these areas are often transformed into industrial areas.

2. Irrigated fields in the Mediterranean North and South near cities (in Spain, these are called 'huertas'). Traditionally these areas are used to produce vegetables for the city. Nowadays, more and more vegetables come from greenhouses and drip irrigation enables these crops to be grown elsewhere. As these areas are in the peri-urban zone, they are now being transformed into industrial areas or suburbs.

In all of these areas, the economic SDGs prevail over the society and biosphere-related SDGs. 


\section{Lighthouse example for soil sealing}

To mitigate soil sealing in peri-urban areas we are looking for an alternative land management strategy that is an economically viable enterprise and can replace typical soil sealing activities, such as industrial developments. Pixel-farming is one example that could keep at least part of these fertile soils in production and is considered a lighthouse to mitigate the process of soil sealing by urban sprawl.

\section{Pixel farming: a lighthouse for all peri-urban areas in Europe}

Pixel Farming is an innovative entrepreneurial farming system that enables a digital approach to the full food production chain, allowing food to be produced in an

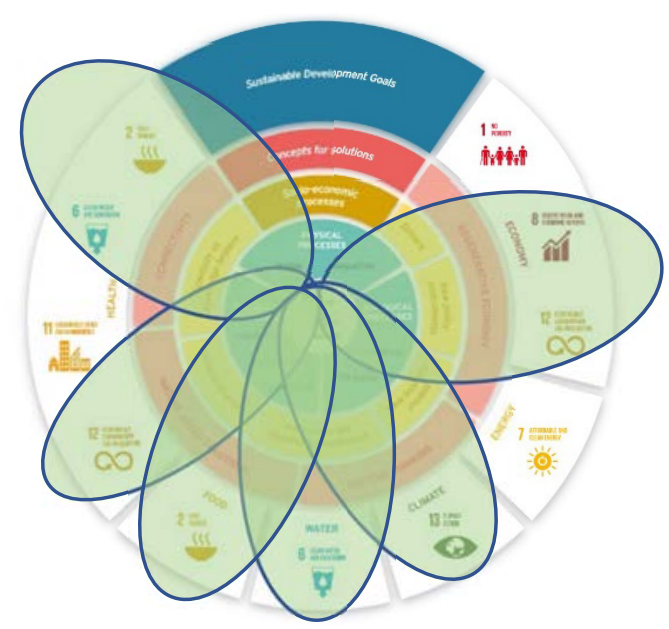
environmentally friendly way by utilising the power of natural capital such as soil and biodiversity as well as robotica and big data. This lighthouse is based on a truly transitional idea: an out-of-the-box new approach in farming. The customer rents a small plot and decides what to grow, then Big Data technology and autonomous self-driving robots take care of the land, instructed by an online system. The systems typically have a high diversity of crops, use no fertilisers or pesticides and with that attract more pollinators and keep the soil healthy. The farmer manages the robots, plots and online customer system as a true entrepreneur.

This new approach works towards much more than the original objectives: sustainable business and production (SDG 8 and 12), but also brings the source of food closer to the customer, raising awareness for food and soil (SDG 2 and 15). The small scale of this type of farming system is beneficial for soil health, which improves water availability and quality (SDG 6) and, if soil carbon is increased, will work towards climate mitigation (SDG 13).

\begin{tabular}{l|llllll} 
Health & Food & Water & Climate & Energy & Economy & Soil/land \\
\hline 2 & 2 & 6 & 13 & 7 & 1 & 15 \\
\hline 6 & & & & 8 & \\
\hline 11 & & & & 12 & \\
\hline 12 & & & &
\end{tabular}

\subsubsection{Soil threat 4: soil compaction}

Soil compaction is a widespread phenomenon in agricultural soils in the Nemorial, Atlantic North and Central, Continental and Pannonian zones.

Soil compaction can be divided into two main types: superficial compaction and sub-soil compaction. Compaction is caused and exacerbated by the increasing use of large machinery in agriculture. These heavy machines and certain ploughing practices compact the soil to a depth of more than one metre.

The superficial compaction is easy to mitigate by improving soil properties (such as organic matter content) using dry manure and the use of low-pressure tyres on the agricultural machinery. However, sub-soil compaction is not as easy to relieve.

Secondly, soil compaction can be divided into clay and sandy soils, each of which requires a different mitigation approach. Clay soils are more resilient and have the capacity to restore themselves by their swelling and shrinking characteristics, once the heavy machinery has been removed from the management. Intervention is needed in sandy soils, however ${ }^{56} 57$.

${ }^{56}$ Williams, M., Brevik, E.C., 2010. Effect of traffic rate and type on soil compaction in sandy South Georgia soils. Soil Horizons 51. https://doi.org/10.2136/sh2010.3.0088.

${ }^{57}$ Keller, T., Sandin, M., Colombi, T., Horn, R., \& Or, D. (2019). Historical increase in agricultural machinery weights enhanced soil stress levels and adversely affected soil functioning. Soil and Tillage Research, 194, 104293. 


\section{Lighthouse example for soil compaction:}

Deep-rooting crops in a crop rotational system Deep-rooting crops will break the deeper plough pan that cannot be mitigated in any another way. This will improve soil biodiversity and soil health (SDG15), improve productivity of the crops, which will lead to more food production (SDG2), and a better livelihood for farmers (SDG 8 and 12). The water-holding capacity and infiltration will also improve, leading to benefits for water quantity and quality (SDG 6). Lastly, the extra roots will increase SOM which will help to mitigate climate change (SDG 13).

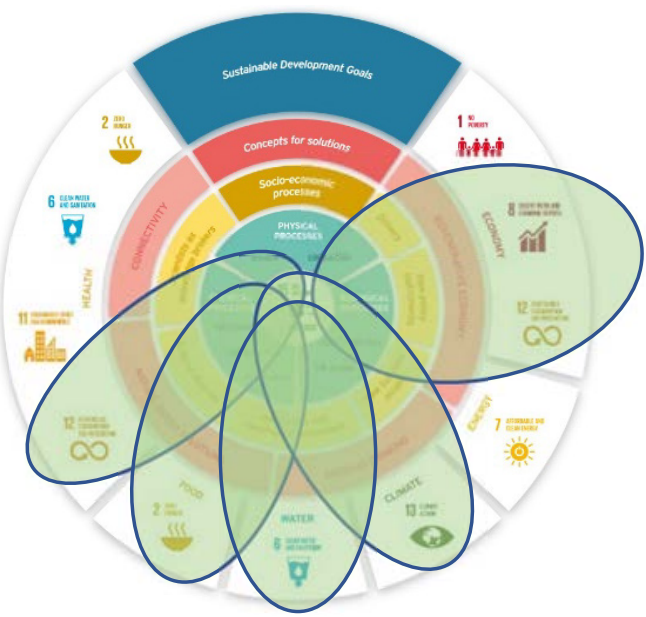

\begin{tabular}{|c|c|c|c|c|c|c|}
\hline Health & Food & Water & Climate & Energy & Economy & Soil/land \\
\hline 2 & 2 & 6 & 13 & 7 & 1 & 15 \\
\hline 6 & & & & & 8 & \\
\hline
\end{tabular}

\subsubsection{Soil threat 5: soil biodiversity decline}

The analysis suggests that soil biodiversity is in a serious situation across Europe (see Table 3.13). The main reasons are agricultural practices that involve excessive amounts of fertilisers, herbicides and pesticides.

Soil biodiversity can be linked to any of the other soil threats, such as erosion, organic matter depletion, salinisation, contamination and compaction. Soil under agriculture in general has low biodiversity. With increased input of carbon and nitrogen to the soil, however, microbial populations may increase. In general, any crop management technique that increases SOM, improves soil structure and reduces soil disturbance which will increase soil health and, in turn, biodiversity.

\section{Lighthouse example for soil biodiversity:}

\section{Diversified farming to improve soil health}

Several recommendations can be made to improve soil health and enhance soil biodiversity. Firstly, pesticides and fertilisers should be minimised, and all tillage and soil traffic by heavy machinery avoided where possible. Secondly, organic matter input to the soil should be promoted, not only by using different types of mulch, but also by live organic matter created by plants growing in the soil. Cover crops in the fallow period and crop rotation will promote organic matter accumulation and improve nutrient and carbon cycling in the soil. Together, these ecological systems will improve soil health, which is essential to host healthy soil biota.

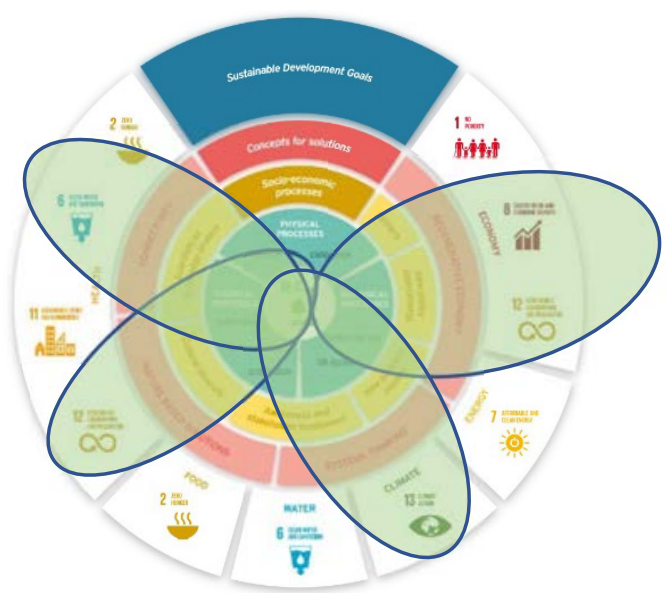

An example of this is the Dehesa agroforestry system, which combines perennial grass, chestnut trees and growing livestock (pigs and cattle). The combination of trees and perennial grass enriches the organic carbon stock better than mono-cropping systems and improves the nutrient cycle, due to the trees in the system. This enhances the soil microbial community that forms the basis of the biota community as a whole (SDG 15). This extensive system forms a sustainable livelihood for the farmers 
in the region (SDG 8 and 12). Perennial grass is the best soil cover to protect against erosion (SGD 15) and store carbon in the soil (SDG 13).

\begin{tabular}{lllllll} 
Health & Food & Water & Climate & Energy & Economy & Soil/land \\
\hline 2 & 2 & 6 & 13 & 7 & 1 & 8 \\
\hline 6 & & & & 12 & \\
\hline 11 & & & & \\
\hline 12 & & & & \\
\hline
\end{tabular}

\subsubsection{Soil threat 6: landslides}

Landslides are a major threat in all environmental zones with significant relief, particularly those with high relief. They can be divided into deep landslides and shallow landslides. The very deep landslides originating from tectonic activities cannot be mitigated and the only option is to adapt accordingly, e.g. not building in these landslide-prone areas. Shallow landslides, however, are induced by the dynamics between soil and water pressure and usually follow large rainfall events or extended periods of precipitation. Landslides cause problems by removing soil but create even greater issues when they deposit the sediment, with mudflows and rockfalls harming people and infrastructures.

\section{Lighthouse example for floods and landslides:}

Tree-rich agroforestry systems One possible solution to prevent landslides is tree-rich agroforestry systems. This measure, which combines trees and crops in the same area, offers a greater degree of slope stabilisation, especially in the shallow soils that often cover the bedrock. In Europe, the AGFORWARD project for instance is promoting the implementation of Agroforestry (AGroFORestry that will advance rural development (https://www.agforward.eu/index.php/fr/). One of the objectives is to evaluate innovative agroforestry designs and practices for locations where agroforestry is currently not-practised or is declining, and to quantify the opportunities for uptake at a field-, farm- and landscape-scale in order to promote the wider adoption.

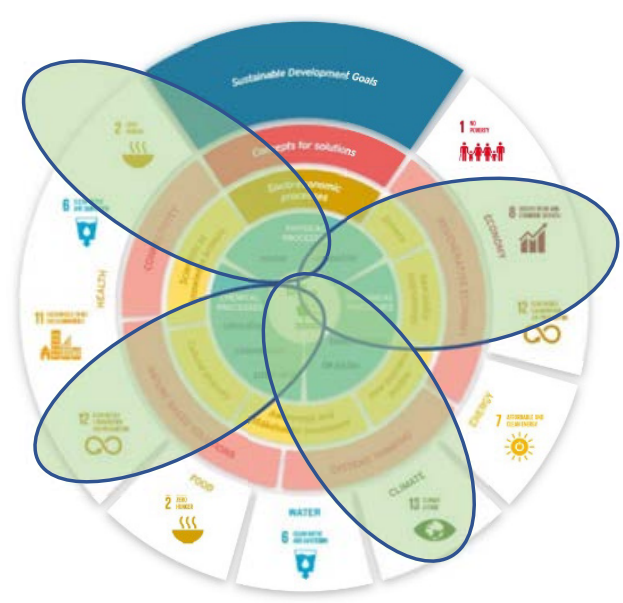

The measures include multi-story cropping where food, herbal, botanical or decorative crops are grown underneath a forest canopy. Another example is silvopasture, which combines trees with livestock that forages underneath the trees. The trees provide timber, fruits and nuts, while the livestock is generally for meat production.

In a system like this, the primary goal is to prevent landslides (SDG 15). However, it is also sustainable from a socioeconomic point of view, with tree-rich systems working towards several other SDGs, such as 2, 8 and 12 for a sustainable economic situation. There are also environmental benefits for climate mitigation through permanent soil cover-induced carbon storage (SDG 13), better infiltration and less runoff (SDG 8).

\begin{tabular}{l|lll|lll} 
Health & Food & Water & Climate & Energy & Economy & Soil/land \\
\hline 2 & 2 & 6 & 13 & 7 & 1 & 15 \\
\hline 6 & & & & 8 & \\
\hline 11 & & & & 12 & \\
\hline 12 & & & & \\
\hline
\end{tabular}




\subsubsection{Soil threat 7: soil contamination}

Soil contamination is mainly an anthropogenic issue, which can be relevant to all environmental zones.

Pesticides are as common nowadays as fertilisers and tractors, with this kind of chemical farming generally regarded as normal practice. This unsustainable use of natural resources is accepted, even by legislation. Organic farming or even regenerative agriculture ${ }^{58}$ can be a good option to reduce the impact of farming on the soil system and still maintain a good agricultural production and livelihood for the farmers ${ }^{59,}{ }^{60}$. By contrast, in order to be classified as organic, a farmer must comply with extensive bureaucracy, including ensuring that their farm is protected from their neighbours' spraying. Many farmers, therefore, do not switch to organic farming as they think it is too complicated ${ }^{61,62}$. Options to switch towards regenerative agriculture can be promoted by legislation; each step towards this is a positive one ${ }^{63}$. However, the benefits of organic farming for the SDGs are significant.

In addition to agricultural soil pollution, there are many instances of pollution in industrial and urban areas and along infrastructures. Soil pollution in industrial areas tends to be so-called point pollution, directly correlated to a polluting source. In urban areas and along roads, more diffuse pollution is caused by continuous human pressure.

\section{Lighthouse example for soil contamination:}

\section{Organic farming combined with minimum tillage}

This lighthouse focuses on a different form of agricultural practice that avoids environmental pollution more. Organic farming does not use any environmentally harmful chemical products but, rather, relies on ecological processes adapted to local conditions that use the natural cycles and resilience of the soil system. Combined with minimum tillage, this can yield the healthy soil that is key to maintaining or restoring biodiversity, and halting and reversing land degradation (SDG15). It can also make the agricultural production system more resilient to the impact of climate change and can even help to mitigate climate change by storing carbon in the soil (SDG 13). Of course, organic farming carries risks that

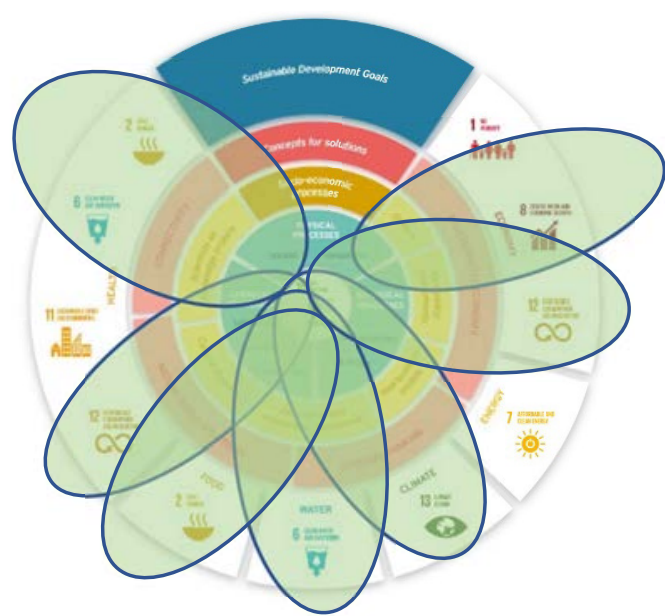
a farmer may not be able to fight pests attacking their crops, creating economic uncertainty. However, the ecological system will become more resilient over time. A strategy like minimum chemical input, combined with minimum tillage, could be a way forward. Organic farming would thus help to achieve better agricultural production while maintaining a good livelihood for farmers (SDGs 2, 8, 12). In addition, water quality will improve (SDG 6).

\begin{tabular}{lllllll} 
Health & Food & Water & Climate & Energy & Economy & 15 \\
\hline 2 & 2 & 6 & 13 & 7 & 1 & 8 \\
\hline 6 & & & & 12 & \\
\hline 11 & & & & \\
\hline 12 & & & & \\
\hline
\end{tabular}

\footnotetext{
${ }^{58}$ Rhodes, C. J. (2017). The imperative for regenerative agriculture. Science Progress, 100(1), 80-129.

${ }^{59}$ Nair, C. M., Salin, K. R., Joseph, J., Aneesh, B., Geethalakshmi, V., \& New, M. B. (2014). Organic rice-prawn farming yields 20\% higher revenues. Agronomy for sustainable development, 34(3), 569-581.

60 Patil, S., Reidsma, P., Shah, P., Purushothaman, S., \& Wolf, J. (2014). Comparing conventional and organic agriculture in Karnataka, India: Where and when can organic farming be sustainable?. Land use policy, 37, 40-51.

${ }^{61}$ Cerdà, A., Rodrigo-Comino, J., Giménez-Morera, A., \& Keesstra, S. D. (2017). An economic, perception and biophysical approach to the use of oat straw as mulch in Mediterranean rainfed agriculture land. Ecological Engineering, 108, $162-171$.

${ }^{62}$ Cerdà, A., Rodrigo-Comino, J., Giménez-Morera, A., \& Keesstra, S. D. (2018). Hydrological and erosional impact and farmer's perception on catch crops and weeds in citrus organic farming in Canyoles river watershed, Eastern Spain. Agriculture, Ecosystems \& Environment, 258, 49-58.

${ }^{63}$ Gosnell, H., Gill, N., \& Voyer, M. (2019). Transformational adaptation on the farm: Processes of change and persistence in transitions to 'climate-smart'regenerative agriculture. Global Environmental Change, 59, 101965.
} 


\subsubsection{Soil threat 8: salinisation}

Soil salinisation occurs when water-soluble salts accumulate in the soil to a level that impacts agricultural production and environmental health. Minor salinisation has a negative effect on soil organisms and on soil health in general, which may lead to reduced agricultural yields. Severe salinisation can make the soil completely infertile for all soil life and vegetation. Salinisation of agricultural soils is mainly caused by high evapotranspiration rates and soil characteristics that impede water drainage and cause salt accumulation in the upper layers. It can occur in coastal areas where seawater enters the aquifer and in inland areas where salts are naturally present in soils. The problem can be aggravated by improper management practices, poor irrigation water quality and variations in rainfall and temperature patterns due to climate change ${ }^{64}$.

\section{Lighthouse example for soil salinisation:}

The lighthouse example for the soil threat of salinisation, while still maintaining a profitable farm, is to use a combination of salt tolerant crops with salt tolerant cover crops for the fallow period. Salt tolerant crops such as asparagus and beets, but also barley and sunflowers can produce a good yield on a saline soil. Which will ensure a good income for the farmer. In addition, in the fallow period of the year a salt tolerant cover crop can be sown to increase soil organic matter content and with that infiltration capacity to leach out salts from the surface. These deep rooting cover crops, such as salt tolerant varieties of alfa, can slowly mitigate the salinity problem in the soil. Deep rooted cover crops are best

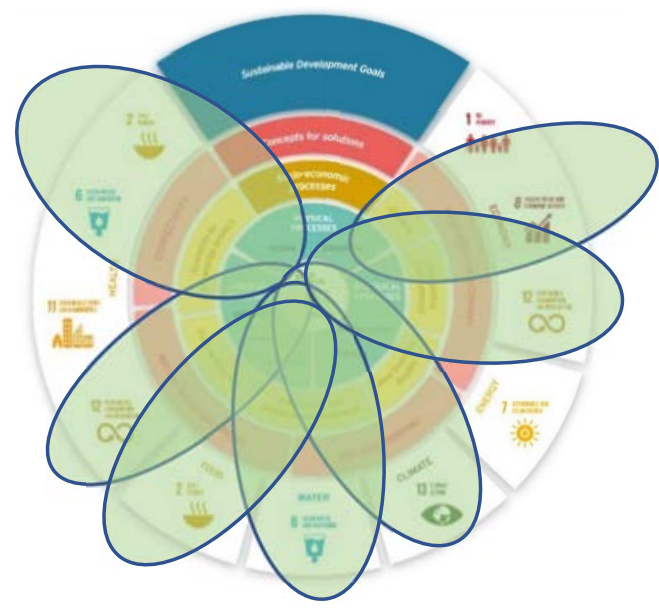
for this. The increased infiltration and better soil structure will enable the soil to flush the excess salt in the profile. In this way the soil becomes more healthy and can contain more biodiversity (SDG15); the farmer will maintain and in the long term increase the farm's yield (SDG 8, 12); healthy food will be grown (SDG 2) while storing more carbon in the soil (SDG13); and the water quality in the soil will be improved (SDG 6).

\begin{tabular}{l|lll|lll} 
Health & Food & Water & Climate & Energy & Economy & Soil/land \\
2 & 2 & 6 & 13 & 7 & 1 & 15 \\
\hline 6 & & & & 8 & \\
\hline 11 & & & & 12 & \\
\hline 12 & & & & \\
\hline
\end{tabular}

\subsubsection{Soil threat 9: Desertification}

Desertification is usually defined as a type of land degradation in drylands in which biological productivity is lost due to natural or human induced processes whereby fertile areas become increasingly more arid. However, it can also be defined more broadly as any progressive and unsustainable reduction in the ecosystem services provided by the soil.", which includes also areas other than drylands. It is caused by a variety of factors, such as through climate change (particularly the current global warming) and through the overexploitation of soil through human activity, which causes soil erosion, loss of soil fertility and long-term loss of natural or desirable vegetation. 


\section{Lighthouse example for desertification: Dehesa system}

The lighthouse example for the soil threat of desertification is the Dehesa system. The Dehesa system is a multifunctional, agrosylvopastoral system mainly used on the Iberian Peninsula. It combines sustained, extensive livestock farming with farming and forestry activities to try to conserve and ensure the sustainability of biodiversity and economic sustainability. The Dehesa system is specifically suitable for semi-arid regions; because of its permanent grass cover the soil is protected any form of degradation. Because of this desertification due to human actions cannot take place. The Dehesa system is a dryland system and therefore needs no irrigation and usually uses no, or limited, chemical input. In

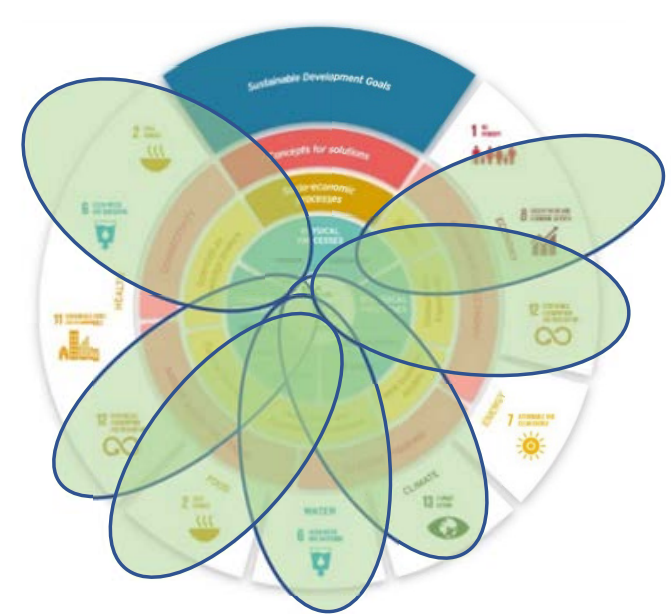
addition, it is considered a cultural heritage landscape and that provides an income for the local people by the production of high-quality meat and providing hunting locations. With this system there are biodiversity and soil health benefits (SDG 15); but also farmers have the opportunity to sustainably produce food in an animal friendly way (SDG 2, 8 and 12). Water resources are not exploited (SDG 6) and carbon is stored in the soil (SDG 13).

\begin{tabular}{|c|c|c|c|c|c|c|}
\hline Health & Food & Water & Climate & Energy & Economy & Soil/land \\
\hline 2 & 2 & 6 & 13 & 7 & 1 & 15 \\
\hline 6 & & & & & 8 & \\
\hline 11 & & & & & 12 & \\
\hline 12 & & & & & & \\
\hline
\end{tabular}




\section{$4 \quad$ Stakeholder views on the role of communication and awareness and the limitations for implementing soil and land related SDGs}

During the soil conference organised as part of this project (see Section 2.2.2), one of the panel discussions was dedicated to the issue of awareness raising for soils, which brought some interesting insights. We have highlighted the main messages for the different stakeholder groups in addition to some general comments.

It is clear that there is a need to raise awareness; all levels of society need to understand that soil and land degradation is an important issue. Everything we enjoy comes from the land; we all depend on it. To achieve the SDGs a transitional change is needed in our society. For this, the entire society must be aware that business- as-usual, or even improved business- as-usual is not enough. As President Ursula von der Leyen said, commenting on the European Green Deal6: "(...) We need to transform our way of living and working, of producing and consuming so that we live more healthily and make our businesses innovative. We can all be involved in the transition and we can all benefit from the opportunities. (...) By showing the rest of the world how to be sustainable and competitive, we can convince other countries to move with us.". It is important that the SDGs are not seen as a burden, but as an opportunity. Environmentally- friendly business does not need to be less profitable. People need to be aware of the multiple benefits that can be the result of implementing the SDGs successfully for their own lives, their families and the community as a whole.

Actual implemented examples will help to get this message across. These region-specific solutions enhance the understanding of local people, who know their area and are emotionally attached to it. Seeing sustainable solutions in their own region will raise the awareness of the potential and possibility of sustainable land and soil management. In addition, awareness should be raised of the fact that land and soils are an essential part of the solution to achieving the SDGs. Sustainable soil management should not only be aimed at agricultural soils but all soils.

A healthy soil system lies at the basis of a sustainable world. For the transformational change we need:

- Action: link soil and land to running actions on climate change, food security and biodiversity.

- Region-specific solutions: will enhance the understanding of local people, who know their area and are emotionally attached to it. Seeing sustainable solutions in their own region will raise the awareness of the potential and possibility of sustainable land and soil management.

- Technology: new technology such as precision agriculture and urban farming can provide new opportunities for sustainable business.

- Engage the private sector: the European example may become a standard in the world. Sustainability should become a business case.

- Indicators: a soil-footprint for customer products is a way to create awareness, as this is the link to people and what they do in their daily lives.

- Organic matter content can be an easy indicator of soil health.

- Indicators are essential, as this is the link to people and what they do in their daily lives.

- Young people: connect to the young people through their channels, step into their world; connect to the movement of young people's call for climate action and a sustainable world.

\section{What can we do to increase awareness?}

We do not need to make a whole new movement for this: we can build on the momentum on climate and biodiversity for soil and land. We should start from food or climate and show the link to land and soil. Soil can be linked to food security, or even the other way around: if I consume something, I should be aware of the impact, the soil or land footprint. 
Policies for soils are complicated as land is private, unlike the climate, which is not owned by anyone. There is no single soil policy. Therefore, we need to consider how we can we optimise what we have. The upcoming new Climate Law may give good opportunities for this.

When we seize the momentum of the Climate Action the European Union as a whole has the opportunity to be the example that can serve as a standard in the world. All stakeholders need to be involved in the implementation of actions in practice - including policy-makers at all levels, scientists, CSOs, the private sector and direct land users such as farmers. Therefore, the awareness raising needs to be targeted for each specific stakeholder group to give all stakeholders an action perspective by showing good, real-life examples that are connected to them and which they could implement themselves:

- For practitioners and end-users: show and tell how land restoration is the best contribution to achieve the SDGs. It is possible to use nature-based solutions to mitigate climate change and maximise resource use efficiency.

- For science: the science community has to step out of the comfort zone and show what soil can bring to society. Scientists need to learn to communicate about soil: attract, interest, desire, action as scientific evidence alone will not move policy.

- For policymakers: political leadership is needed to promote soil and land-related SDGs if we are to make real progress. Assisting countries to achieve their LDN target by showing good examples of countries where successful policies has already been implemented.

- Education: at all levels of education, starting at young ages, soil and land should be brought to their attention to show the importance of this for society in terms of food security, water resources, climate change and human health. The climate change action has a head start and can also serve the soil awareness by showing how system Earth works and how a healthy soil forms an important basis for this.

\section{Insights on limiting conditions in Europe for implementing land and soil related SDGs}

The panel discussions at the conference highlighted several limitations:

\section{Bio-physical-practical limitations:}

1. There is a need for data to be made available to monitor and report on threats, e.g. salinisation, compaction and their measurement. The proposed practices may be inspiring but more data is needed. We cannot focus solely on producing databases.

2. However, we cannot wait for the data to be available but, rather, must act now.

3. Currently there are insufficient solutions linked to soil and land and more generally, nature-based solutions, to the challenges that are high on the political agenda, such as biodiversity, food and water supply, climate change, migration and peace.

4. How we can compensate for various negative impacts - is compensation always possible and can we restore the full value and functions of soil?

\section{Political limitations:}

1. Few Member States have comprehensive policies for soils. Policies and strategies produced on paper need to be strengthened and applied on the ground.

2. Compromising the implementation of the proposed approach is the fact that at European and national level there is a need to update sustainable development plans and strategies to incorporate the SDGs. There is widespread (political) support for the implementation of the SDGs.

3. There are problems with understanding LDN. It is an exciting concept, but we need to know how to measure it and how to counterbalance the various impacts that cause land degradation.

Socio-economic limitations:

1. Incentives may currently not be enough and should be put in place to apply sustainable methods, e.g. farmers need to see that environmentally friendly methods are profitable. It is not yet evident that a more sustainable approach makes economic sense.

2. It is necessary to work together with economists because we need to know the costs and the benefits.

3. Behavioural biases need to be accounted for: not only the economic issues are important; also, it is essential to take emotions, cultural heritage and social pressure into account. 
4. Environmental measures must become the norm.

5. The fear of loss is very strong in humans and outweigh the attraction to a future benefit.

6. It is necessary to increase awareness of the importance of soil and land for achieving most of the SDGs.

7. Spreading important messages takes time as people may not understand it right away. Problems with soil should of course mean that we have to talk to farmers; but we should also be aware that soil and land issues also relate to other areas. Similarly, soil issues should be taught in schools but also outside schools.

At the conference it was stated that a new Commission will be in office soon and has announced ambitious goals for environmental policy. However, the Commission will not achieve the goals related to soil and land alone. We need to raise stakeholder awareness of the need to act. We should stress the emotional links, that soil is full of life and is essential for our existence. In this way soil could gain importance on the political agenda and become an important topic in the next years. 


\section{$5 \quad$ Conclusions and recommendations}

Increasing land take, soil sealing and loss of ecosystem functions due to soil and land degradation have been recognised as major environmental and socioeconomic challenges both in the EU and worldwide. In 2015, the UN put forward the 2030 Agenda, with 17 interdependent SDGs, that entered into force in January 2016. Many of the SDGs reflect challenges related to land and soil, particularly SDG 15, concerning life on land. This SDG strives to achieve a land degradation-neutral world. SDG 15 is a key enabler for many other SDGs, including SDG 2 (zero hunger), 6 (clean water and sanitation), and 11 (sustainable cities and communities).

The status of implementation of SDG 15 was reviewed in-depth at the High-Level Political Forum of 2018. The review found that at a global level there is progress on the indicators related to actions (e.g. numbers of protected areas), but the indicators related to status (e.g. numbers and state of species) remain negative. The monitoring framework often fails to capture essential elements related to the quality of the soil and ecosystems ${ }^{65}$.

The main aim of this study was to analyse progress on the implementation of land and soilrelated SDG targets in the EU, taking due consideration of the 2030 Agenda commitments, and to provide a platform for exchanges on best practices between Member States on the implementation of land and soil-related SDGs.

In light of the COVID-19 crisis that started in 2020 in Europe, it has become even more evident that resilience is key to sustainability. Resilience on all three main levels of the SDGs: the biosphere, society and economy. A green recovery of the crisis focusses on resilience in society and economy, but it is important to keep in mind that many of the SDGs rely on sustainably managed soil.

Therefore, action towards long-term sustainable use of land and soil is essential to reach all SDGs; without that, there is no basis for the rest. Transitional change in land management is needed to reach the land and soil related SDGs.

The broad areas of actions we have identified through this project, and which we elaborate in more detail below, include:

- Incrementally updating the policy framework: Designing coherent legislation addressing sectors and land-uses that makes transition towards sustainable land and soil management possible. The European Green Deal and its associated actions provide opportunities for defining policy targets and measures for specific pressures on land and soil resources.

- Awareness-raising: Promoting region-specific but interdisciplinary land management practices at Member State level in which the soil and landscape should play an important role, in order to assess the impact of new projects on the surrounding area, including off-site and on-site effects. EU-funded research projects and service contracts provide a wealth of information which could be effectively communicated to Member States and individual practitioners to inspire action. By the same token, the 'soil literacy'66 of the broad public needs to improve to progress towards more 'soil-friendly' behaviours and choices which might eventually drive broader shifts in food consumption, agricultural markets, and production methods.

- Methodology development: The SDGs and their associated targets for soil and land should be elaborated at EU level in order to develop a clear framework for data collection, monitoring, analysis and target setting. This would ideally involve a technical debate on how to describe the role of soil in the SDGs. At the operational level, methodologies need to be established (such as the

\footnotetext{
${ }^{65}$ Sustainable Development Goal 15: Progress and Prospects, https://sustainabledevelopment.un.org/content/documents/19647Key_messages_SDG_15_EGM_Final.pdf.

${ }^{66}$ The Global Soil Biodiversity Initiative notes that "The world needs more citizens who are soil literate-who understand how soils and humanity depend on each other for their mutual long-term existence. The insufficiency of such understanding (at societal levels) is due, in part, to the world's "soil education gap"-the shortage of soil education efforts relative to the scale of the societal need for them." (https://www.globalsoilbiodiversity.org/blog-beneath-ourfeet/2018/10/2/overcoming-challenges-of-the-soil-education-gap-part-2)
} 
lighthouse methodology proposed in this report) to assess the impact of the specific land management measures on soil and land-related SDGs, to demonstrate the trade-offs and synergies between the different SDGs impacted by those measures.

The remainder of this section presents the main conclusions resulting from our review of the state- of play of the implementation of land and soil-related SDGs in Europe and formulates recommendations for EU and national policy makers, researchers, and practitioners with a view to advancing land and soil protection as a precondition for meeting the SDGs. Conclusions and recommendations are organised along the three research themes and the key questions formulated at the outset of this project.

\subsection{Institutional coordination and implementation}

\section{What are the main EU policies enabling the implementation of LDN target and other soil and land related SDGs?}

Out of the 28 policy instruments reviewed, 14 are assessed as contributing directly to meeting at least three of the seven SDGs covered by this analysis. Our assessment identifies the following regulatory, planning, and economic instruments as highly relevant for meeting the soil and land-related SDGs:

- The Sustainable Use of Pesticides Directive

- The Water Framework Directive

- The Nitrates Directive

- The Environmental Liability Directive

- The Industrial Emissions Directive

- The Landfill Directive

- The Waste Framework Directive

- The National Emissions Ceiling Directive

- The Plant Protection Products Regulations

- The Roadmap to Resource Efficient Europe

- The Soil Thematic Strategy

- The Farm to Fork Strategy

- The Biodiversity Strategy

- The Common Agricultural policy

The analysis shows that the existing policy framework already contributes to meeting the SDGs at the focus of this study. Soil threats potentially hampering progress towards meeting SDGs 3 and 15 are directly targeted by several policies. Progress towards meeting the remaining SDGs is (to date) likely to be a result of policies indirectly addressing relevant soil functions and threats (see table below). 
Table 5.1 Number of policies that are relevant for implementing the soil and land-related SDGs

\begin{tabular}{|c|c|c|}
\hline SDG & $\begin{array}{l}\text { No. of highly relevant } \\
\text { (and relevant) policies }\end{array}$ & Highly relevant policies identified \\
\hline 2 PIBO & $8(15)$ & $\begin{array}{l}\text { ELD. IED, NECD, Roadmap to Resource Efficient Europe, Soil Thematic Strategy, } \\
\text { Farm to Fork Strategy, Biodiversity Strategy, CAP }\end{array}$ \\
\hline 3 SAOD WEITH & $13(13)$ & $\begin{array}{l}\text { SUPD, WFD, Nitrates Directive, ELD, IED, Landfill Directive, Waste Framework } \\
\text { Directive, NECD, PPPR, Soil Thematic Strategy, Farm to Fork Strategy } \\
\text { Biodiversity Strategy, }\end{array}$ \\
\hline 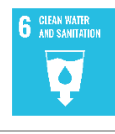 & $9(6)$ & $\begin{array}{l}\text { SUPD, WFD, Nitrates Directive, IED, Landfill Directive, Waste Framework } \\
\text { Directive, Roadmap to Resource Efficient Europe, Soil Thematic Strategy, } \\
\text { Biodiversity Strategy }\end{array}$ \\
\hline 13 gunarin & $7(15)$ & $\begin{array}{l}\text { Roadmap to Resource Efficient Europe, Soil Thematic Strategy, Farm to Fork } \\
\text { Strategy, Biodiversity Strategy, CAP }\end{array}$ \\
\hline$\underset{0}{\sim}$ & $9(16)$ & $\begin{array}{l}\text { SUPD, WFD, Nitrates Directive, IED, Landfill Directive, PPPR, Roadmap to } \\
\text { Resource Efficient Europe, Soil Thematic Strategy, Farm to Fork Strategy, } \\
\text { Biodiversity Strategy }\end{array}$ \\
\hline 15 政 & $18(8)$ & $\begin{array}{l}\text { SUPD, WFD, ELD, IED, Landfill Directive, Waste Framework Directive, NECD, } \\
\text { Roadmap to Resource Efficient Europe, Soil Thematic Strategy, Farm to Fork } \\
\text { Strategy, Biodiversity Strategy, CAP }\end{array}$ \\
\hline
\end{tabular}

Many of the policies assessed as having the strongest direct links to land and soil, and to most of the relevant SDGs, are mainly of a strategic nature, meaning that they serve as a framework for other policies. With the adoption of the Farm to Fork and Biodiversity Strategies, there is now a set of broad ambitions which can drive progress towards meeting the SDGs. However, whilst these ambitions provide a high-level framework for soil and land protection, they clearly need to be translated in measurable, action-oriented policy targets, specifying incremental steps to be taken to ensure their realisation and to directly address the various pressures causing soil and land degradation processes (and thus endangering the achievement of the SDGs). In addition, many of the policies reviewed here focus on limiting or preventing soil threats rather than defining good soil quality and functions at EUlevel or for different types of soils or regions.

Existing policies regulate various soil threats and functions; however, most land and soil outcomes are achieved as 'co-benefits' of policies on water, waste, agriculture, or climate action. Whilst this means soil protection through EU policies might not be effectively targeted, it also demonstrates that multiple environmental benefits could be realised, and subsequently a range of SDGs could be met by setting land and soil targets and through policies promoting sustainable land use and soil management.

Did the Member State publish a National Sustainable Development Plan and when? Alongside the EU-level strategic documents, Member States develop their own approaches to implementation of the SDGs. This project's mapping exercise shows that most Member States have adopted national sustainable development plans or strategies. However, only 13 strategies were adopted or updated after the SDGS entered into force in 2016.

\section{Does the National Sustainable Development Plan integrate soil and land considerations?} Soil and land considerations are relevant for several SDGs, not just SDG 15.3. As such, there are many examples of elements of national sustainable development plans that affect - at least indirectly - soil and land, from the promotion of organic farming under SDG 2 to sustainable management of forests under SDG 12. The Member State survey conducted as part of this study identified only a few countries where land and soil were explicitly addressed by the National Sustainable Development Plans (CZ, DE, RO, and SK). However, not all Member States completed the survey and supplementary 
information was not always available; hence, the results presented here might not provide an accurate picture of the integration of land and soil considerations in the European Member States' National Sustainable Development Plans.

Which MS authorities are in charge of implementing and monitoring SDGs? How do MS authorities in charge of implementing and monitoring SDGs coordinate with other, relevant MS authorities? Are the authorities in charge of soil protection and land planning involved in the development of indicators, SDG monitoring and implementation?

The main authorities in charge of implementation of the national sustainable development plans typically include the office of the Prime Minister and/or one of the sectoral ministries (e.g. Ministry of the Environment), supported by various inter-sectoral working groups, commissions for sustainable development or other horizontal bodies. In almost all Member States, the Ministry of Foreign Affairs is the external policy lead for implementation of the SDGs. All Member States have engaged with various types of stakeholders in the preparation of their sustainable development strategies. These activities take the form of online consultation, advisory councils and creation of special platforms to coordinate inputs from various experts and civil society organisations.

\section{How does the MS engage stakeholders in the implementation of SDGs as defined in the} 2030 Agenda (e.g. public consultation of stakeholders and citizens, projects, engagement of private sector)?

All Member States have engaged with various types of stakeholders in the preparation of their sustainable development strategies. These activities take the form of online consultations, advisory councils and creation of special platforms to coordinate inputs from various experts and civil society organisations.

\section{What are the main national policies and activities enabling the implementation of LDN targets and other soil and land related SDGs?}

The policy mapping exercise shows that few Member States have dedicated land or soil policies. Sectoral policies that address land and soil typically encompass agricultural, forestry and spatial planning. Many of these policies set clear provisions for improving the condition of soil and land and have the potential to contribute significantly to the implementation of the land and soil-related SDGs. It is important to note that most policies, both at EU and at national level, have been shaped before the adoption of the SDGs and therefore, they may not fully reflect the targets as formulated by the UN in 2015. Hence, there is a need to revise, update or reformulate the existing policies. New policy instruments need to be devised that can help to adjust the socioeconomic development to the limitations of our planet in line with the SDGs.

Recommendations

The European Green Deal and its associated actions as well as other overarching strategic documents need to provide the framework driving the implementation and operationalisation of the soil and land SDGs.

$>$ Whilst broad ambitions provide a high-level framework for soil and land protection, they clearly need to be translated into measurable, action-oriented policy targets, specifying incremental steps to be taken to ensure their realisation. A starting point for formulating targets is a robust understanding of the pressures impacting on the state of land and soil and thus the SDGs. On this basis, sector or land use-specific targets could be formulated. The update of key strategic policy documents, including the Soil Thematic Strategy and the 8th Environmental Action Programme, as well as actions planned under the Green Deal (e.g. the Zero Pollution Action Plan as well as the Soil Sealing and Brownfields Actions) offer opportunities to define SMART targets for specific sectors or types of land use.

Existing policies targeting the prevention of land and soil degradation remain fragmented and rely on sectoral interventions.

$>$ While environmental mainstreaming that incorporates soil and land aspects is important and can be effective, its results are dependent on the extent to which clear objectives and targets relating to land and soil can be incorporated in other policies, and on the effectiveness of their implementation. Ongoing and upcoming policy reviews, including for example the Sewage Sludge Directive and the Sustainable Pesticides Directive, need to integrate the ambitions and targets formulated by these high-level strategic documents. 
$>$ At Member State level, the adoption of quantitative targets (such as LDN and zero net land take) at Member State level would be a good step to making land and soil-related SDGs more operational. It would be useful to share Italy's experience in setting up the LDN with the other Member States.

$>$ National sustainable development plans or strategies need to be updated to integrate the SDGs and should include explicit targets and actions for sustainable land and soil management.

Member States have adopted national sustainable development plans or strategies but not all address the SDGs as adopted in 2015

$>$ Member States that have not yet updated their national strategic documents following the adoption of the Sustainable Development Goals adopted in 2015, are encouraged to initiate a strategy review to ensure that their national frameworks guiding their activities serve the ambitions of the UN's Agenda 2030.

Member States have adopted coordinated and participatory approaches to implement the SDGs but focus on involvement of organised interests

$>$ Information about the SDGs, their relevance to society as well as the individual, and the important role land and soil play in realising these ambitions, need to be widely communicated. To engage people, we should use the current momentum on climate and biodiversity to put soil and land on the agenda by showing how they link to food security and the mitigation of climate change impacts.

$>$ The update of the STS (planned by 2021) offers an opportunity to build on its positive experiences with raising awareness for soil. Mirroring recent initiatives in other policy fields ${ }^{67}$, "soil literacy"68 may be a concept which could be developed and promoted at EU level as a way of delivering a more coordinated approach to soil awareness activities in Europe. Such an initiative could involve the setting up (and financing) of a new platform connecting relevant organisations and projects or may build on the work of existing groups such as the European Network for Soil Awareness ${ }^{69}$ and the European Soil Bureau Network ${ }^{70}$.

$>$ The increased emphasis on communication and dissemination introduced with the Commission's Research Framework Programme Horizon 2020 needs to be maintained, expanded and refined to ensure widely supported outcomes that will improve uptake or research results in practice.

\subsection{Land degradation/land degradation neutrality definitions and indicators}

\section{What is the definition of LD and LDN at national level?}

There is no generally accepted definition, nor approach to land degradation in environmental science and policy. In the Member States, only Slovakia has adopted an official definition for land degradation (chapter 3.2.3) and none of the MS have defined an LDN definition, although some countries follow the UNCCD's definition.

\section{What are the priorities and what are the soil and land related SDG indicators and sub- indicators retained at national level?}

Despite the lack of common definitions, Member States nevertheless have priorities in respect of specific land and soil degradation processes. Of the countries that mention land degradation processes, they note the top three problems as soil erosion, contamination and sealing, closely followed by declining organic matter and soil compaction (chapter 3.2.3). Of the Member States, only Italy started the process to set up a national plan to reach LDN.

\footnotetext{
${ }^{67}$ See for example the EU4Ocean Coalition for Ocean Literacy which aims to bring together organisations, projects and people that contribute to ocean literacy in order to create awareness and trigger action for sustainable ocean management, build capacity and put ocean literacy on the policy agenda. Information available at: https://webgate.ec.europa.eu/maritimeforum/en/frontpage/1482

68 The Global Soil Biodiversity Initiative notes that "The world needs more citizens who are soil literate-who understand how soils and humanity depend on each other for their mutual long-term existence. The insufficiency of such understanding (at societal levels) is due, in part, to the world's "soil education gap"-the shortage of soil education efforts relative to the scale of the societal need for them." (https://www.globalsoilbiodiversity.org/blog-beneath-ourfeet/2018/10/2/overcoming-challenges-of-the-soil-education-gap-part-2)

69 http://www.bodenbuendnis.org/en/

70 https://ec.europa.eu/jrc/en/network-bureau/european-soil-bureau-network
} 


\section{What are the data sources for the indicators? Are they sufficient? What is the baseline or} how do MS intend to set it?

For the purpose of answering these questions at MS level, the questionnaire responses in this study were insufficiently addressed by the responders. For the data sources, the UNCCD and partners ${ }^{71}$ have found that in many countries, national data for one or more of the sub-indicators are available. Those national data "can be supplemented with regional and global data for all three sub-indicators and can be disaggregated at the national level for interpretation and validation by national authorities."

\section{What is the approach on LDN at national/subnational level? Is it based on a balance between restored degraded land and newly degraded land?}

As mentioned in the introduction of this chapter, at a global level there is progress on the SDG 15 indicators related to actions (e.g. numbers of protected areas), but the indicators related to status (e.g. numbers and state of species) are lagging behind.

The UNCCD is actively working on the development of indicators for the SDGs ${ }^{72}$. The UNCCD SDG indicator 15.3.1 is stated as the "proportion of degraded land over total land area" with three subindicators focusing on land cover, land productivity and carbon stocks.

At European level, Eurostat is developing indicators for all SDGs (Eurostat, 2019). Although soil degradation (SDG 15.3) covers many aspects such as soil sealing and contamination, erosion by wind and water, loss of soil biodiversity, compaction, decline in organic matter, desertification, acidification and salination, the Eurostat indicator set currently only includes soil sealing, settlement area per capita and soil erosion by water.

While these indicators are useful tools for tracking progress in achieving the LDN in the particular countries and environmental zones, there are still several challenges in the practical use of these indicators especially for areas with diverse land use, specific agricultural practices such as greenhouses and peatlands. No standard approach has yet been agreed. However, at EU level, the Commission is developing a methodology and guidance to monitor the achievement of LDN, following the recommendations of the ECA (2018), see also chapter 3.2.2.

Recommendations

The SDGs and their associated targets for land and soil should be elaborated at EU level in order to develop a clear framework for data collection, monitoring, analysis and target setting.

$>$ The methodology in Europe for monitoring and assessing the land and soil SDGs should be more clearly defined and elaborated for all soil degradation processes. Although many countries have started to measure and monitor the land and soil SDGs, there is little coordination and no standard approach yet.

> An LDN indicator based on the three UNCCD sub-indicators (land cover, land productivity, and carbon stocks) provides a good starting point for measuring progress in relation to the land and soil-related SDGs but further guidelines and coordination, as currently being worked on by the Commission, is necessary for this indicator to become fully operational. The standard indicators as defined by the UNCCD are not sufficient for the European context as they do not take into account several important issues:

> For most of the UNCCD sub-indicators there is more detailed information available in Europe than the generally used Tier 1 data.

$>$ The mosaic landscape in most European countries is not represented in the large pixels that are used in the UNCCD indicator set.

$>$ Important soil degradation processes are not taken into account in the UNCCD methodology, such as biodiversity decline (e.g. afforestation with single species); soil erosion (from terraced landscapes to large fields on sloping areas) or contamination.

Design and implement a comprehensive monitoring scheme for all ecosystems; soil is part of all terrestrial ecosystems and therefore needs well-defined targets that can be assessed with a good set of indicators to assess the impact of measures taken for protection and restoration.

\footnotetext{
${ }^{71}$ See https://unstats.un.org/sdgs/metadata/files/SDG-indicator-metadata.zip, file Metadata- 15-03-01.

72 See e.g. https://unstats.un.org/sdgs/metadata/files/SDG-indicator-metadata.zip SDG.
} 


\subsection{Measures to prevent, reduce or reverse degradation}

\section{What type of measures have been defined by MS (e.g. sustainable soil and land management measures) or best practices to prevent, reduce or reverse degradation? And what are the conditions or limitations?}

Although this project was not aimed at systematically collecting measures from all Member States, we identified several good practices (Annex 6 Most of them have not been specifically designed for achieving the SDGs. They aim to reduce a specific soil threat, to promote sustainable soil or land management or a societal goal. Therefore, they can be reasonably expected to positively contribute to meeting one or multiple soil and land related SDGs. However, since the SDGs are unlikely to have played a role in selecting and designing the measures, benefits or trade-offs were probably not factored into the decision-making process. The lighthouse example approach as we have highlighted in this report (chapter 3) may serve as a methodology to assess the overall benefit (or trade-off) of a specific measure. The approach advocates a holistic view of impacts of a measure on the system (both bio-physical as well as socio-economic). In the European Joint Programme on SOIL that started in February $2020{ }^{73}$, similar approaches are being explored for agricultural soils to make them climate resilient and sustainable from both a bio-physical as well as socio-economic point of view. Within this programme and other projects the enabling conditions of implementation of sustainable land and soil management will be assessed. Here policy, financial, social and bio-physical constraints and opportunities will be assessed. Good governance and coherent policy regarding land and soils present a major opportunity for policy makers. "Measures that promote sustainable land use, inclusive and participatory land use planning, LDN and land tenure security potentially help (and particularly emerging economies) to meet multiple SDGs, targets and indicators whilst also being cost-effective" ${ }^{\prime 74}$.

\section{Are there examples of good practices which could be expanded?}

There are many good examples, of which we have shown some in the body of this report to elaborate the use of the lighthouse example approach. The good practices in Annex 6 have the potential to be upscaled. It is important to share these examples and make them accessible to all land and soil stakeholders. WOCAT, the World Overview of Conservation Approaches and Technologies ${ }^{75}$, is a good example of how such a database may work and can be expanded to include information on the impacts of land management techniques compiled in the future database on the SDGs. Additionally, it is important not to neglect non-agricultural soils. Industrial and (peri)-urban soils especially do not receive sufficient attention. Measures for urban soils are normally only aimed at two soil threats: contamination and soil sealing. However, beneficial soil functions in urban and industrial areas, such as excess rainfall drainage by infiltration and cooling effect by trees supported by a healthy soil, are largely ignored, while they have a large influence on the realisation of the SDGs in these areas.

\section{Methodologies for assessment and monitoring and recommended concrete methodologies} Following the recommendations of the report of the European Court of Auditors on desertification (ECA 2018), the Commission is currently working on a common methodology to assess and monitor land degradation. However, currently there is no policy instrument which would require Member States to provide this information to the Commission. To ensure harmonised data collection and monitoring, an incentive to report to the Commission would be needed. In addition, the JRC EU soil observatory is currently being made which will facilitate the development of a common approach for assessing and monitoring methodologies. This reporting methodology should be well aligned between different policy areas (mainly DG ENV and DG AGRI) and be valid for all soils (agricultural, industrial, natural and urban soils).

\section{Are the cost-benefits evaluated?}

Soil threats and possible measures to mitigate these sol threats have been evaluated for their costs and benefits ${ }^{76}$ but information on the costs and benefits of measures in general and for the SDGs in particular seems largely unavailable. However, it is clear that the cost of inaction on the long-term will

\footnotetext{
73 www.ejpsoil.eu

${ }^{74}$ Grounding Sustainability: land, soils and the Sustainable Development Goals (August 2017 Authors: Nathalie van Haren, Karin van Boxtel (Both ENDS).

75 https://www.wocat. net/en/

76 https://esdac.jrc.ec.europa.eu/public_path/shared_folder/doc_pub/EUR27607.pdf
} 
outweigh the cost of actions implemented now ${ }^{77}$. The lighthouse example approach we presented in the report currently only gives a qualitative assessment of the benefits and trade-offs of a specific measure for all land and soil related SDGs. But the framework could be used as a first step towards a methodology for a true cost-benefit analysis.

The research in this field can be enhanced when accepted approaches and indicators and monitoring of land and soil related SDGs are developed.

\section{Recommendations}

\section{Availability of examples:}

$>$ Exchange region-specific solutions to enhance awareness of the importance of land and soil for local people, who know their area and are emotionally attached to it. Seeing sustainable solutions implemented in their own region will raise the awareness of the potential and possibility of sustainable land and soil management. For example:

- Land and soil degradation and restoration measures as contributions for achieving sustainable development and with that, the SDGs

- Nature-based solutions and agro-ecology principles contribute significantly to climate mitigation and adaptation, at the same time addressing biodiversity loss and land degradation

- Measures to maximise resource efficiency: reusing and recycling soil and land resources

$>$ Make new examples of region-specific solutions available via databases like WOCAT ${ }^{78}$ and/or the new EU Soil observatory of JRC (in line with the activities of the Horizon Europe Mission 5 Soil Health and Food $^{79}$ ). The development and exchange of good examples should be promoted on natural, urban and industrial land as well as for agricultural soils.

\section{Shared methodologies:}

$>$ Develop tailored good practices for specific regions. This can be helpful to make the transition to a truly new system which can replace an 'old and unsustainable' system of soil and land management.

$>$ Use a concrete methodology (for instance the lighthouse methodology proposed in this report) to assess the impact of the specific land management measures on soil and land-related SDGs, to demonstrate the trade-offs and synergies between the different SDGs impacted by those measures.

$>$ Design a methodology for evaluating the costs and benefits for specific measures for the realisation of the SDGs.

\footnotetext{
77 Nkonya, E., Mirzabaev, A., \& Von Braun, J. (2016). Economics of land degradation and improvement-a global assessment for sustainable development (p. 686). Springer Nature.

${ }^{78}$ WOCAT is a global network on Sustainable Land Management (SLM) that promotes the documentation, sharing and use of knowledge to support adaptation, innovation and decision-making in SLM. Available via https://www.wocat.net/en/.

79 https://ec.europa.eu/info/horizon-europe-next-research-and-innovation-framework-programme/mission-area-soil-healthand-food_en
} 


\section{References}

Altvater, S., Dooley, E., and Roberts, E. (2015). Legal Instruments to implement the objective "Land Degradation Neutral World" in International Law, Ecologic Institute, Berlin

Angus, A.J. \& Allen, C. (2013). 20 ways to influence business behaviour - A short guide to instrument selection for policy makers and regulators. Defra, London, UK, [online] Available at:

http://randd.defra.gov.uk/Document.aspx?Document=11687_InstrumentSelectionGuidance04111 3-external.pdf (Accessed on 28th October 2019)

Bouma, J. (2019). Soil security in sustainable development. Soil Systems, 3(1), p. 5. [online] Available at: https://www.mdpi.com/2571-8789/3/1/5 (Accessed on 28th October 2019)

Cerdà, A., Rodrigo-Comino, J., Giménez-Morera, A., \& Keesstra, S. D. (2017). An economic, perception and biophysical approach to the use of oat straw as mulch in Mediterranean rainfed agriculture land. Ecological Engineering, 108, 162-171.

Cerdà, A., Rodrigo-Comino, J., Giménez-Morera, A., \& Keesstra, S. D. (2018). Hydrological and erosional impact and farmer's perception on catch crops and weeds in citrus organic farming in Canyoles river watershed, Eastern Spain. Agriculture, Ecosystems \& Environment, 258, 49-58.

Cherlet, M. et al. (2013). Land Productivity Dynamics in Europe Towards Valuation of Land Degradation in the EU. European Commission, Brussels, Belgium

COM (2006) 231. Thematic Strategy for Soil Protection. Available at https://eur-lex.europa.eu/legalcontent/EN/TXT/?uri=CELEX:52006DC0231

COM (2013). Decision No 1386/2013/EU of the European Parliament and of the Council of 20 November 2013 on a General Union Environment Action Programme to 2020 'Living well, within the limits of our planet'. Available at: https://eur-lex.europa.eu/legal-

content/EN/TXT/?qid=15971427853918uri=CELEX:32013D1386

Council of the European Union. 2019. The 8th Environment Action Programme: Turning the Trends Together - Council conclusions. Available at:

https://www.consilium.europa.eu/media/40927/st12795-2019.pdf

COM (2019) 640 final. The European Green Deal. Available at:

https://ec.europa.eu/info/sites/info/files/european-green-deal-communication_en.pdf

COM (2020) 381. final A Farm to Fork Strategy for a fair, healthy and environmentally-friendly food system. Available at https://eur-lex.europa.eu/legal-content/EN/TXT/?uri=CELEX:52020DC0381

COM (2020) 380 final. Biodiversity Strategy for 2030 Bringing nature back into our lives. Available at: https://eur-lex.europa.eu/legal-content/EN/TXT/?qid=1590574123338\&uri=CELEX:52020DC0380

COM (2020) 380 final Biodiversity Strategy for 2030 Bringing nature back into our lives. Available at: https://eur-lex.europa.eu/legal-content/EN/TXT/?qid=1590574123338\&uri=CELEX:52020DC0380

COM (2020) 381. final A Farm to Fork Strategy for a fair, healthy and environmentally-friendly food system. Available at https://eur-lex.europa.eu/legal-content/EN/TXT/?uri=CELEX:52020DC0381

COM (2020) 380 final. Biodiversity Strategy for 2030 Bringing nature back into our lives. Available at: https://eur-lex.europa.eu/legal-content/EN/TXT/?qid=1590574123338\&uri=CELEX:52020DC0380

Cowie, A. L., Orr, B. J., Sanchez, V. M. C., Chasek, P., Crossman, N. D., Erlewein, A., ... \& Tengberg, A. E. (2018). Land in balance: The scientific conceptual framework for Land Degradation Neutrality. Environmental Science \& Policy, 79, 25-35.

Delreux, T. and Happaerts, S. (2016). Environmental policy and politics in the European Union. London: Palgrave;

Dumansky, J. (2015). Evolving concepts and opportunities in soil conservation. International Soil and Water Conservation Research Volume 3, Issue 1, 1 March 2015, Pages 1-14

EASAC. (2018). Opportunities for soil sustainability in Europe [online] Available at: https://easac.eu/fileadmin/PDF_s/reports_statements/EASAC_Soils_complete_Webready_210918.pdf (Accessed on 28 $8^{\text {th }}$ October 2019)

ESDAC. https://esdac.jrc.ec.europa.eu/public_path/shared_folder/doc_pub/EUR27607.pdf

EEA. (2016). SOER 2015 - The European environment - state and outlook 2015. [online] Available at: https://www.eea.europa.eu/soer (Accessed on 28 October 2019). 
EEA. (2018). Environmental Indicator Report 2018. In support to the monitoring of the $7^{\text {th }}$ Environment Action Programme. Copenhagen, European Environmental Agency.

EEA. (2020). SOER 2020 - The European environment - state and outlook 2020. [online] Available at: https://www.eea.europa.eu/publications/soer-2020 (Accessed on 11 August 2020).

Ehlers, K., Lobos, A. I., Montanarella, L., Muller, A., \& Weigelt, J., 2013. Soils and Land in the post2015 development agenda: A proposal for a goal to achieve a Land Degradation Neutral World in the context of sustainable development. EN DS 2013 EU soil quality plan not being dropped, 3 October 2013

ESDAC. European Soil Partnership.[online] Available at: http://esdac.jrc.ec.europa.eu/networkcooperations/european-soil-partnership (Accessed on $28^{\text {th }}$ October 2019)

European Commission a [online] Available at: http://ec.europa.eu/environment/sustainabledevelopment/SDGs/implementation/index_en.htm (Accessed on 28 ${ }^{\text {th }}$ October 2019)

European Commission b, Multi-stakeholder platform on SDGs [online] Available at: https://ec.europa.eu/info/strategy/international-strategies/sustainable-development-goals/multistakeholder-platform-sdgs_en (Accessed on $28^{\text {th }}$ October 2019)

European Commission c. The common agricultural policy at a glance. [online] Available at: https://ec.europa.eu/info/food-farming-fisheries/key-policies/common-agricultural-policy/capglance_en (Accessed on 28 ${ }^{\text {th }}$ October 2019)

European Commission, (2006a). Thematic Strategy for Soil Protection. COM(2006)231 final. [online] Available at: https://eur-lex.europa.eu/legalcontent/EN/TXT/PDF/?uri=CELEX:52006DC0231\&from=EN (Accessed on 28 ${ }^{\text {th }}$ October 2019)

European Commission. (2006b). Proposal for a Directive establishing a framework for the protection of soil COM/2006/0232. [online] Available at: https://eur-lex.europa.eu/legalcontent/EN/TXT/?uri=CELEX:52006PC0232. (Accessed on 28 ${ }^{\text {th }}$ October 2019)

European Commission. (2011a). Roadmap to a Resource Efficient Europe. COM/ 2011/0571 [online] Available at:

http://www.europarl.europa.eu/meetdocs/2009_2014/documents/com/com_com(2011)0571_/co m_com(2011)0571_en.pdf (Accessed on 28 ${ }^{\text {th }}$ October 2019)

European Commission (2011b). Analysis associated with the Roadmap to a Resource Efficient Europe, Part II, p.79. SEC(2011) 1067 final. [online] Available at:

https://ec.europa.eu/environment/resource_efficiency/pdf/working_paper_part2.pdf (Accessed on $28^{\text {th }}$ October 2019)

European Commission. (2012a). Report on the Implementation of the Soil Thematic Strategy. [online] Available at: https://eur-lex.europa.eu/legal-content/EN/TXT/?uri=CELEX:52012DC0046 (Accessed on $28^{\text {th }}$ October 2019)

European Commission (2012b). The implementation of the Soil Thematic Strategy and ongoing

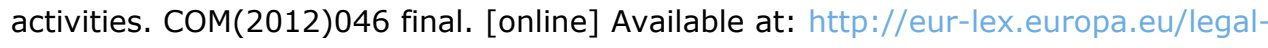
content/EN/TXT/?uri=CELEX\%3A52012DC0046 (Accessed on 28 ${ }^{\text {th }}$ October 2019)

European Commission. (2013). General Union Environment Action Programme to 2020: 'Living well, within the limits of our planet'. Decision No 1386/2013/EU of the European Parliament and of the Council of 20 November 2013. [online] Available at: https://eur-

lex.europa.eu/eli/dec/2013/1386/oj (Accessed on 28 ${ }^{\text {th }}$ October 2019)

European Commission. (2014) [online] Available https://eur-lex.europa.eu/legalcontent/EN/TXT/PDF/?uri=CELEX:52014XC0521(01)\&from=EN

European Commission. (2016a). Next steps for a sustainable European future. COM(2016) 739 final. [online] Available at: https://ec.europa.eu/europeaid/sites/devco/files/communication-next-stepssustainable-europe-20161122_en.pdf (Accessed on 28 ${ }^{\text {th }}$ October 2019)

European Commission. (2016b) COMMISSION STAFF WORKING DOCUMENT. Key European action supporting the 2030 Agenda and the Sustainable Development Goals. [online] Available at: https://ec.europa.eu/europeaid/sites/devco/files/swd-key-european-actions-2030-agenda-sdgs390-20161122_en.pdf (Accessed on 28 ${ }^{\text {th }}$ October 2019)

European Commission. (2017a). Communication on 2017 European Semester: Country-specific recommendations. (COM(2017) 500 final). [online] Available at:

https://ec.europa.eu/info/sites/info/files/2017-european-semester-country-specificrecommendations-commission-recommendations-communication.pdf (Accessed on $28^{\text {th }}$ October 2019) 
European Commission. (2017b) The Future of Food and Farming._[online] Available at:

https://ec.europa.eu/agriculture/sites/agriculture/files/future-of-

cap/future_of_food_and_farming_communication_en.pdf (Accessed on 28 ${ }^{\text {th }}$ October 2019)

European Commission. (2018a) 2018 Commission Work Programme. [online] Available at:

https://ec.europa.eu/info/publications/2018-commission-work-programme-key-documents_en

(Accessed on $28^{\text {th }}$ October 2019)

European Commission (2018b). Proposal for a Regulation of the European Parliament and of the Council on the financing, management and monitoring of the common agricultural policy and repealing Regulation (EU) No 1306/2013

European Commission (2018c). Annexes to the proposal for a Regulation of the European parliament and of the Council establishing rules on support for strategic plans to be drawn up by Member States under the Common Agricultural Policy. COM(2018) 392 final.

European Commission (2018d). Part 1 of the final Impact Assessment accompanying the proposals. $\operatorname{SWD}(2018) 301$.

European Commission (2018e). EU Budget: The CAP After 2020. [online] Available at: https://ec.europa.eu/commission/news/eu-budget-common-agricultural-policy-after-2020-2018jun-01_en (Accessed on 28 $8^{\text {th }}$ October 2019)

European Commission. (2019a) Reflection Paper. Towards a sustainable Europe by 2030. $\operatorname{COM}(2019) 22$ [online] Available at: https://ec.europa.eu/commission/sites/betapolitical/files/rp_sustainable_europe_30-01_en_web.pdf (Accessed on 28 th October 2019)

European Commission. (2019b). Supporting the Sustainable Development Goals across the world: The 2019 Joint Synthesis Report of the European Union and its Member States. (COM(2019) 232 final. [online] Available at: https://ec.europa.eu/transparency/regdoc/rep/1/2019/EN/COM-2019-232F1-EN-MAIN-PART-1.PDF (Accessed on $28^{\text {th }}$ October 2019)

European Commission. (2019c). 2019 report on Policy Coherence for Development (PCD). [online] Available at: https://ec.europa.eu/europeaid/sites/devco/files/eu-report-pcd-2019_en.pdf (Accessed on $28^{\text {th }}$ October 2019)

European Court of Auditors (ECA). (2018). Combating desertification in the EU: a growing threat in need of more action. Special report no 33. Brussels, European Union. Available at:

https://www.eca.europa.eu/Lists/ECADocuments/SR18_33/SR_DESERTIFICATION_EN.pdf (accessed on $21^{\text {st }}$ February 2020).

European Network For Rural Development. (2016). Report for the workshop on AECMs, Challenges of controllability and verifiability [online] Available at:

https://enrd.ec.europa.eu/sites/enrd/files/w12_aecm_report.pdf (accessed on 25th July 2019).

Eurostat. (2019) Sustainable development in the European Union - Monitoring report on progress towards the SDGs in an EU context - 2019 edition [online] Available at:

https://ec.europa.eu/eurostat/web/products-statistical-books/-/KS-02-19-165 (Accessed on $28^{\text {th }}$ October 2019)

Eurostat. Sustainable Development Goals - Overview [online] Available at: https://ec.europa.eu/eurostat/web/sdi/overview (Accessed on 28 ${ }^{\text {th }}$ October 2019)

FAO and ITPS. (2015). Status of the World's Soil Resources (SWSR) - Technical Summary. [online] Available at: http://www.fao.org/3/i5199e/i5199e.pdf (Accessed on 28 ${ }^{\text {th }}$ October 2019)

FAO. (2012). Appendix F, Terms of Reference of the Global Soil Partnership. [online] Available at: http://www.fao.org/docrep/meeting/027/mf558e.pdf (Accessed on 28 $8^{\text {th }}$ October 2019)

FAO. (2015). Revised World Soil Charter, pp. 6-7. [online] Available at: http://www.fao.org/3/ai4965e.pdf (Accessed on 28 ${ }^{\text {th }}$ October 2019)

FAO. (2017). Voluntary Guidelines for Sustainable Soil Management. Rome: Food and Agriculture Organization of the United Nations. [online] Available at: http://www.fao.org/3/a-bl813e.pdf (Accessed on $28^{\text {th }}$ October 2019)

FAO. European Soil Partnership [online] Available at: http://www.fao.org/global-soilpartnership/regional-partnerships/europe/en/ (Accessed on 28 ${ }^{\text {th }}$ October 2019)

Ferreira, C. S. S., Walsh, R. P. D., Kalantari, Z., \& Ferreira, A. J. D. (2020). Impact of Land-Use Changes on Spatiotemporal Suspended Sediment Dynamics within a Peri-Urban Catchment. Water, 12(3), 665.

Frelih-Larson, A., Naumann, S., Porsch, L., Dooley, E., Bell, S., and Görlach, B. (2016a). Up-to-date review of EU policies and integrated impact assessment methodology. RECARE project deliverable D9.1, http://www.recare-hub.eu/images/WP9/ 
Frelih-Larsen, A. et al (2016b). 'Updated Inventory and Assessment of Soil Protection Policy Instruments in EU Member States.' Final Report to DG Environment. Berlin: Ecologic Institute, https://ec.europa.eu/environment/soil/pdf/Soil_inventory_report.pdf

Frelih-Larsen, A., C. Bowyer, S. Albrecht, C. Keenleyside, M. Kemper, S. Nanni, S. Naumann, R., D. Mottershead, R. Landgrebe, E. Andersen, P. Banfi, S. Bell, I. Brémere, J. Cools, S. Herbert, A. Iles, E. Kampa, M. Kettunen, Z. Lukacova, G. Moreira, Z. Kiresiewa, J. Rouillard, J. Okx, M. Pantzar, K. Paquel, R. Pederson, A. Peepson, F. Pelsy, D. Petrovic, E. Psaila, B. Šarapatka, J. Sobocka, A.-C. Stan, J. Tarpey, R. Vidaurre (2016b). 'Updated Inventory and Assessment of Soil Protection Policy Instruments in EU Member States.' Final Report to DG Environment. Berlin: Ecologic Institute, https://ec.europa.eu/environment/soil/pdf/Soil_inventory_report.pdf

German Environment Agency (UBA). (2017): Extending land footprints towards characterizing sustainability of land use. UBA TEXTE 79/2017, [online\} Available at: https://www.umweltbundesamt.de/en/publikationen/extending-land-footprints-towardscharacterizing

German Environment Agency (UBA). (2018). Implementing SDG target 15.3 on Land Degradation Neutrality: development of an indicator based on land use changes and soil values', Umweltbundesamt Dessau-Roßlau, Germany. [online] Available on:

https://www.ecologic.eu/sites/files/publication/2018/2018-02-21_texte_16-2018_land-degrationnutrality_en.pdf (Accessed on 28th October 2019)Glæsner, N.; Helming, K.; De Vries, W. (2014). Do Current European Policies Prevent Soil Threats and Support Soil Functions? Sustainability, 6, 9538-9563.

Glæsner, N.; Helming, K.; De Vries, W. Do Current European Policies Prevent Soil Threats and Support Soil Functions? Sustainability 2014, 6, 9538-9563.

Gosnell, H., Gill, N., \& Voyer, M. (2019). Transformational adaptation on the farm: Processes of change and persistence in transitions to 'climate-smart'regenerative agriculture. Global Environmental Change, 59, 101965.

IEEP. (2019). Assessing and accelerating the EU progress on Sustainable Development Goals (SDGs) in 2019. A briefing to inform the UN High Level Political Forum (HLPF) and the SDG Summit in New York (9-18 July and 24-25 September 2019). [online] Available at:

https://ieep.eu/uploads/articles/attachments/52fc703c-0404-4c58-98199e31c92d3ef1/EU\%20SDG\%20briefing\%202019_IEEP.pdf?v=63729716887 (Accessed on $28^{\text {th }}$ October 2019)

International Centre for Trade and Sustainable Development. (2019). EU Commission outlines potential farm subsidy cuts in 2021-2027 proposal [online] Available at:

https://www.ictsd.org/bridges-news/bridges/news/eu-commission-outlines-potential-farmsubsidy-cuts-in-2021-2027-proposals (accessed on 20 June 2019).

IPBES (Montanarella, L., Scholes, R., and Brainich, A.). (2018). The IPBES assessment report on land degradation and restoration. Secretariat of the Intergovernmental Science-Policy Platform on Biodiversity and Ecosystem Services, Bonn, Germany.

IPBES. (2015). Scoping for a thematic assessment of land degradation and restoration. Available at: https://www.ipbes.net/sites/default/files/downloads/pdf/decision_ipbes-31_annex_viii_advance_scoping_Idr.pdf (accessed on $28^{\text {th }}$ October 2019).

Keesstra, S. D., Bouma, J., Wallinga, J., Tittonell, P., Smith, P., Cerdà, A., Montanarella, L., Quinton, J. N., Pachepsky, Y., van der Putten, W. H., Bardgett, R. D., Moolenaar, S., Mol, G., Jansen, B., and Fresco, L. O.(2016). The significance of soils and soil science towards realization of the United Nations Sustainable Development Goals, SOIL, 2, 111-128, [online] Available at: https://doi.org/10.5194/soil-2-111-2016 (Accessed on 28 ${ }^{\text {th }}$ October 2019)

Keesstra, S., Mol, G., De Leeuw, J., Okx, J., Molenaar, C., De Cleen, M. and Visser, S. (2018). SoilRelated Sustainable Development Goals: Four Concepts to Make Land Degradation Neutrality and Restoration Work. Land, 7, p. 133.

Keller, T., Sandin, M., Colombi, T., Horn, R., \& Or, D. (2019). Historical increase in agricultural machinery weights enhanced soil stress levels and adversely affected soil functioning. Soil and Tillage Research, 194, 104293.

Kuhlman, T., Stijn, R., \& Gaaff, A. 2010 Estimating the costs and benefits of soil conservation in Europe. Land Use Policy, 27(1), pp. 22-32 
Kutter, T., Louwagie, G., Schuler, J., Zander, P., Helming, K. \& Hecker, J.-M. 2011. Policy measures for agricultural soil conservation in the European Union and its member states: Policy review and classification. Land Degradation and Development 22: 18-31.

Lakner, S. et al. (2017). Is the CAP Fit for purpose? An evidence based fitness-check assessment. Leipzig, German Centre for Integrative Biodiversity Research (iDiv) Halle-Jena-Leipzig.

Legal Expert Group -Established by the First Global Soil Week, 2013. Discussion Paper on Options for a regulatory mechanism under the UNCCD for land degradation neutrality and the sustainable use, management and protection of soils and their functions.

Louwagie, G., Stephan, G., Sammeth, F \& Ratinger, T. 2011. The potential of European Union policies to address soil degradation in agriculture. Land Degradation and Development 22. 5 - 17.

Lugato, E., Paustian, K., Panagos, P., Jones, A., Borrelli, P. (2016). Quantifying the erosion effect on current carbon budget of European agricultural soils at high spatial resolution. Global Change Biology, 22(5), pp. 1976-1984. [online] Available at: doi http://dx.doi.org/10.1111/gcb.13198

McNeil, A., Bradley, H., Muro, M., Merriman, N., Pederson, R., Tugran, T., and Lukacova, Z. 2018. Inventory of opportunities and bottlenecks in policy to facilitate the adoption of soil-improving techniques, SoilCare Deliverable D7.1, [online] Available at: https://www.soilcareproject.eu/downloads/soilcare-reports-and-deliverables/85-report-9-deliverable-7-1-inventory-ofopportunities-and-bottlenecks-in-policy-to-facilitate-the-adoption-of-soil-improvingtechniques?format=html

Metzger, M.J., Bunce, R.G.H., Jongman, R.H.G., Mücher, C.A. and Watkins, J.W. (2005). A climatic stratification of the environment of Europe. Global Ecology and Biogeography, 14, pp. 549-563.

Millennium Ecosystem Assessment. (2005). Ecosystems and Human Well-Being: Synthesis. Washington, DC: Island Press.

Nair, C. M., Salin, K. R., Joseph, J., Aneesh, B., Geethalakshmi, V., \& New, M. B. (2014). Organic riceprawn farming yields 20\% higher revenues. Agronomy for sustainable development, 34(3), 569-581.

Niestroy et al. (2019). Europe's approach to implementing the Sustainable Development Goals: good practices and the way forward. [online] Available at: http://www.europarl.europa.eu/cmsdata/160360/DEVE\%20study\%20on\%20EU\%20SDG\%20impl ementation\%20formatted.pdf (Accessed on 28 ${ }^{\text {th }}$ October 2019)

Novara, A., Pulido, M., Rodrigo-Comino, J., Di Prima, S., Smith, P., Gristina, L., ... \& Keesstra, S. (2019). Long-term organic farming on a citrus plantation results in soil organic carbon recovery. Cuadernos de Investigación Geográfica.

Nkonya, E., Mirzabaev, A., \& Von Braun, J. (2016). Economics of land degradation and improvementa global assessment for sustainable development (p. 686). Springer Nature.

OECD report 'Measuring distance to SDG targets' (June 2017), [online] Available at: http://www. oecd.org/sdd/OECD-Measuring-Distance-to-SDG-Targets.pdf

Oenema, O., Heinen, M., Rietra, R., and Hessel, R. (2017). A review of soil-improving cropping systems. SoilCare Deliverable 2.1. Available at: https://soilcare-project.eu

Orr, B.J., A.L. Cowie, V.M. Castillo Sanchez, P. Chasek, N.D. Crossman, A. Erlewein, G. Louwagie, M. Maron, G.I. Metternicht, S. Minelli, A.E. Tengberg, S. Walter, and S. Welton. 2017. Scientific Conceptual Framework for Land Degradation Neutrality. A Report of the Science-Policy Interface. United Nations Convention to Combat Desertification (UNCCD), Bonn, Germany.

Overview of best practices for limiting soil sealing or mitigating its effects in EU-27, POLICY BRIEF SUSTAINABLE SOIL MANAGEMENT, SOILS4EU deliverable 1.3 (draft)

Paleari, S. 2017. Is the European Union protecting soil? A critical analysis of Community environmental policy and law. Land Use Policy 63: 163-173.

Panagos, P., Imeson, A., Meusburger, K., Borrelli, P., Poesen, J., Alewell, C., 2016. Soil Conservation in Europe: Wish or Reality? L. Degrad. Dev. 27, 1547-1551. doi:10.1002/ldr.2538

Panagos, P., Ballabio, C., Poesen, J., Lugato, E., Scarpa, S., Montanarella, L., \& Borrelli, P. (2020). A Soil Erosion Indicator for Supporting Agricultural, Environmental and Climate Policies in the European Union. Remote Sensing, 12(9), 1365.

Panagos, P., Borrelli, P., Poesen, J., Ballabio, C., Lugato, E., Meusburger, K., Montanarella, L., Alewell, C., 2015. The new assessment of soil loss by water erosion in Europe. Environ. Sci. Policy 54, 438-447. https://doi.org/10.1016/j.envsci.2015.08.012 
Patil, S., Reidsma, P., Shah, P., Purushothaman, S., \& Wolf, J. (2014). Comparing conventional and organic agriculture in Karnataka, India: Where and when can organic farming be sustainable?. Land use policy, 37, 40-51.

Parras-Alcántara, L., Lozano-García, B., Brevik, E.C., Cerdá, A., 2015. Soil organic carbon stocks assessment in Mediterranean natural areas: A comparison of entire soil profiles and soil control sections. J. Environ. Manage. 155, 219-228. https://doi.org/10.1016/j.jenvman.2015.03.039

Reed, M.S. \& Stringer, L.C., 2016. Land Degradation, Desertification and Climate Change: Anticipating, assessing and adapting to future change (Climate and Development), Routledge. [online] Available at: https://www.amazon.com/Land-Degradation-Desertification-ClimateChange/dp/1849712719 (Accessed on 28th October 2019)

Regulation (EU) No 1305/2013 of the European Parliament and of the Council of 17 December 2013 on support for rural development by the European Agricultural Fund for Rural Development (EAFRD) and repealing Council Regulation (EC) No 1698/2005.

Regulation (EU) No 1306/2013 of the European Parliament and of the Council of 17 December 2013 on the financing, management and monitoring of the common agricultural policy and repealing Council Regulations (EEC) No 352/78, (EC) No 165/94, (EC) No 2799/98, (EC) No 814/2000, (EC) No $1290 / 2005$ and (EC) No 485/2008.

Regulation (EU) No 1308/2013 of the European Parliament and of the Council of 17 December 2013 establishing a common organisation of the markets in agricultural products and repealing Council Regulations (EEC) No 922/72, (EEC) No 234/79, (EC) No 1037/2001 and (EC) No 1234/2007

Regulation (EU) No 1307/2013 of the European Parliament and of the Council of 17 December 2013 establishing rules for direct payments to farmers under support schemes within the framework of the common agricultural policy and repealing Council Regulation (EC) No 637/2008 and Council Regulation (EC) No 73/2009

Rhodes, C. J. (2017). The imperative for regenerative agriculture. Science Progress, 100(1), 80-129.

Roerink, G et al. (2011). Deriving plant phenology from remote sensing. $20116^{\text {th }}$ International Workshop on the Analysis of Multi-temporal Remote Sensing Images (Multi-Temp).

Sims, N., Green, C., Newnham, G., England, J. R., Held, A., Wulder, M. A., ... \& Vizcarra-Rossel, R. A., 2017. Good practice guidance. SDG Indicator 15.3. 1: Proportion of land that is degraded over total land area. Version 1.0.

Stolte J., Mehreteab Tesfai, Lillian Øygarden, Sigrun Kværnø, Jacob Keizer, Frank Verheijen, Panos Panagos, Cristiano Ballabio, Rudi Hessel (2016); Soil threats in Europe; doi: $10.2788 / 488054$ (print); doi: $10.2788 / 828742$

SWD(2019) 181 final $\operatorname{COM(2019)~} 233$ final. Evaluation of the $7^{\text {th }}$ Environment Action Programme to 2020 "Living well, within the limits of our planet" Accompanying the document Report from the Commission to the European Parliament, the Council, the European Economic and Social Committee and the Committee of the Regions on the evaluation of the $7^{\text {th }}$ Environment Action Programme COM(2019) 233 final. Available at: https://ec.europa.eu/environment/actionprogramme/pdf/SWD_2019_181_F1_OTHER_STAFF_WORKING_PAPER_EN_V3_P2_1022341.pdf

Tóth, G., Hermann, T., da Silva, M.R. and Montanarella, L. (2018). Monitoring of soil for sustainable development and land degradation neutrality. Environmental Monitoring and Assessment 190:57. [online] Available at: https://link.springer.com/article/10.1007\%2Fs10661-017-6415-3 (Accessed on $28^{\text {th }}$ October 2019)

Transboundary drivers and impacts of soil degradation (draft) SOILS4EU deliverable 1.1

Turpin N. et al. (2015) Policy bundles framing agricultural soil protection in EU and selected member states. D524 CATCH-C Project. [online] Available at: www.catch-c.eu (Accessed on $28^{\text {th }}$ October 2019)

UNCCD (2015). COP12. Ankara, Turkey. Available at: https://www.unccd.int/sites/default/files/relevant-links/2017-03/Idn_ts_low_res.pdf (Accessed on $28^{\text {th }}$ October 2019)

UNCCD a. [online] Available at: http://www2.unccd.int/convention/about-convention (Accessed on $28^{\text {th }}$ October 2019)

UNCCD b. UNCCD Convention text [online] Available at: http://www2.unccd.int/sites/default/files/relevant-links/2017-01/UNCCD_Convention_ENG_0.pdf (Accessed on $28^{\text {th }}$ October 2019) 
UNCCD c. UNCCD Ratification list [online] Available at:

http://www.unccd.int/Documents/Ratification\%20list\%20Dec2016.pdf (link didn't work on $28^{\text {th }}$ October 2019)

United Nations. (2012). The future we want. Resolution adopted by the General Assembly on 27 July 2012 (66/288). [online] Available at: https://sustainabledevelopment.un.org/rio20/futurewewant (Accessed on $28^{\text {th }}$ October 2019)

Van der Esch, S. et al. (2017). Exploring future changes in land use and land condition and the impacts on food, water, climate change and biodiversity Scenarios for the UNCCD Global Land Outlook Policy Report. The Hague. [online] Available at:

http://www.pbl.nl/sites/default/files/cms/publicaties/pbl-2017-exploring-future-changes-in-landuse-and-land-condition-2076.pdf (accessed on 8 August 2017).

Van der Meulen, S.M. and Maring L. (2018). Mapping and Assessment of Ecosystems and their Services. Soil ecosystems. Deliverable 1.2 SOIL4EU-project Service contract No 7.0201/2016/742739/SER/ENV.D.I.

Virto, I. \& Imaz, María \& Fernández-Ugalde, Oihane \& Gartzia-Bengoetxea, Nahia \& Enrique, Alberto \& Bescansa, Paloma \& Karlen, Douglas. (2015). Soil Degradation and Soil Quality in Western Europe: Current Situation and Future Perspectives. Sustainability (Switzerland). 2015. 313-365. $10.3390 /$ su7010313.

Vogt, J.V. et al. (2011). Monitoring and assessment of land degradation and desertification: Towards new conceptual and integrated approaches. Land Degradation and Development, 22(2), pp. $150-165$.

Vrebos, D., Bampa, F., Creamer, R., Gardi, C., Ghaley, B.B., Jones, A., Rutgers, M., Sanden, T., Staes, J, and Meire, P. 2017. The impact of policy instruments on soil multifunctionality in the European Union. Sustainability, 9, 407.

Williams, M., Brevik, E.C., 2010. Effect of traffic rate and type on soil compaction in sandy South Georgia soils. Soil Horizons 51. https://doi.org/10.2136/sh2010.3.0088

WOCAT: global network on Sustainable Land Management (SLM) that promotes the documentation, sharing and use of knowledge to support adaptation, innovation and decision-making in SLM. Available via https://www.wocat. net/en/

Yougova, D. 2018. LIFE programmefor2021-2027. Financing environmental and climate objective. BRIEFING EU Legislation in Progress 2021-2027 MFF. European Parliamentary Research Service. 


\section{Annex 1 Overview of the project's research questions}

The work carried out in this project was guided by a set of research questions which were listed in the Tender Specifications and subsequently slightly refined and reorganised during the inception phase:

Research questions

\section{Institutional coordination and implementation}

- Did the Member State publish a National Sustainable Development Plan and when?

- Does the National Sustainable Development Plan integrate soil and land considerations?

- Which MS authorities are in charge of implementing and monitoring SDGs?

- How to MS authorities in charge of implementing and monitoring SDGs coordinate with other, relevant MS authorities?

- Are the authorities in charge of soil protection and land planning involved in the development of indicators, SDG monitoring and implementation?

- What are the main EU policies enabling the implementation of LDN target and other soil and land related SDGs?

- What are the main national policies enabling the implementation of LDN target and other soil and land related SDGs?

- What are the main activities identified at national level for implementing the land-soil related SDGs?

- How does the MS engage stakeholders in the implementation of SDGs as defined in the 2030 Agenda (e.g. public consultation of stakeholders and citizens, projects, engagement of private sector)?

Land degradation/land degradation neutrality definitions and indicators

- What is the definition of LD and LDN at national level?

- What are the priorities and what are the soil and land related SDG indicators and subindicators retained at national level?

- What are the data sources for the indicators? Are they sufficient?

- What is the baseline or how do MS intend to set it?

- What is the approach on LDN at national/subnational level? Is it based on a balance between restored degraded land and newly degraded land?

\section{Measures to prevent, reduce or reverse degradation}

- What type of measures have been defined by MS (e.g. sustainable soil and land management measures) or best practices to prevent, reduce or reverse degradation?

- Are there examples of good practices which could be expanded?

- What are the conditions or limitations?

- Are the cost-benefits evaluated?

\section{Section in the report}

Section 3.1

Section 3.2

Section 3.3 


\section{Annex 2 Questionnaire sent to the Soil Expert Group}

1. What country do you represent? And what is your affiliation (institute name \& position)?

2. How is the SDGs coordination ensured at national level? Are the authorities in charge of soil protection and land planning involved in the development of indicators, SDG monitoring and implementation?

3. Is there a (an official) definition for Land degradation (LD) and for Land Degradation Neutrality (LDN) in your country? If yes can you share these definitions with us?

4. What are the main land degradation issues/threats in your country?

5. Are you monitoring soil and land degradation processes in your country? if yes continue with question 4, if no, please indicate how you think it should be implemented in your country

6. Are there specific indicators in your country for monitoring these soil and land degradation processes? If yes, what are these indicators? If no, what could it be?

7. What are/could be the data sources used for monitoring the land degradation processes in your country? Do you think these data are sufficient for your country to get a reliable picture of the process of land degradation?

8. When monitoring land degradation, it is important to set a baseline. What is/could be the baseline for the land degradation indicator(s) used in your country or how does your country intend to set it?

9. What is/could be the approach to define and monitor the progress of Land Degradation Neutrality (LDN) in your country? Is it based on a balance between restored degraded land and newly degraded land?

10. Can you identify the main national (sub-national) policies (potentially) enabling the implementation of the LDN target and other soil and land related SDGs?

11. Are there any activities at (sub)national/regional level for implementing the land-soil related SDGs, for example new strategy or policy developments, establishment of monitoring or reporting systems, stakeholder platforms or initiatives? 


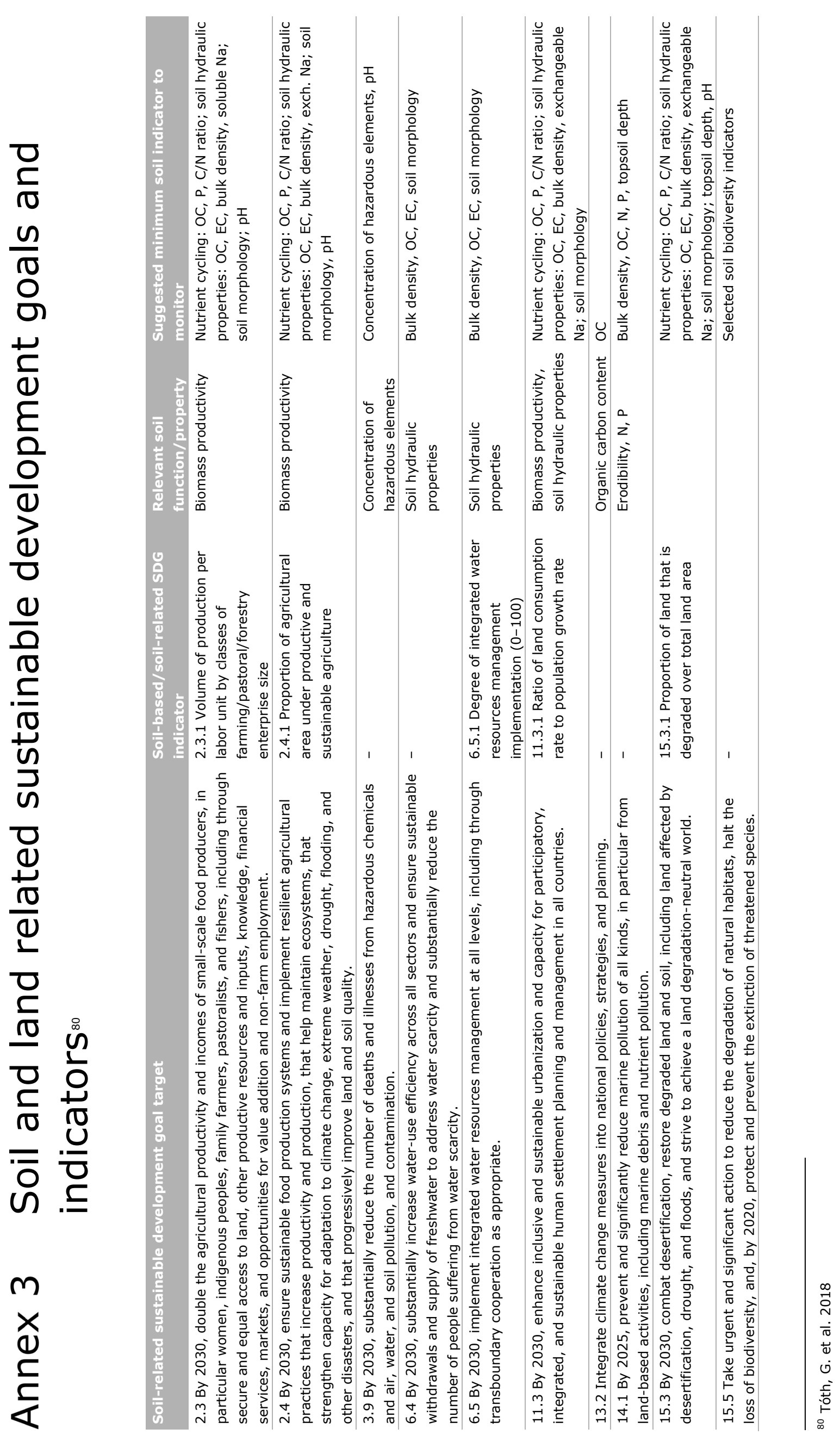



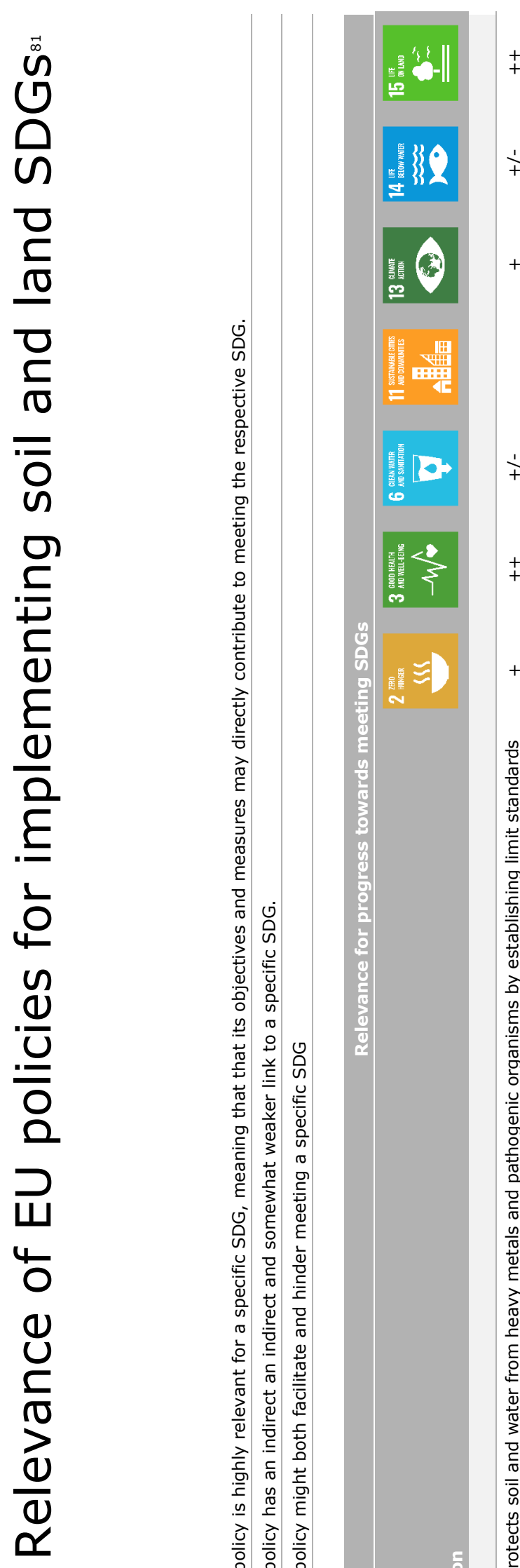

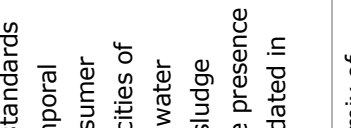

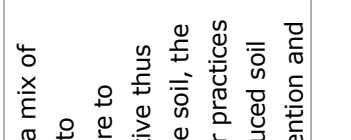

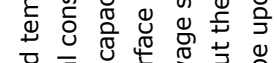

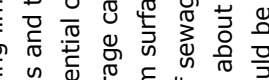

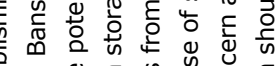

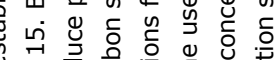

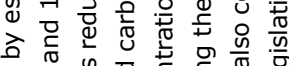
ต

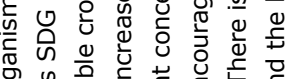

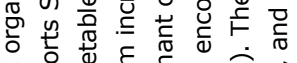

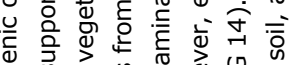

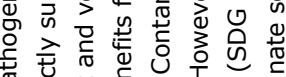

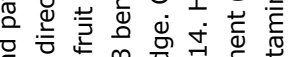

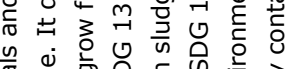
号

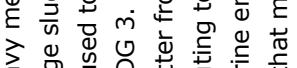

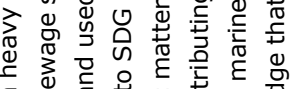

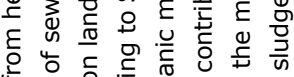

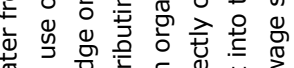

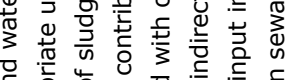

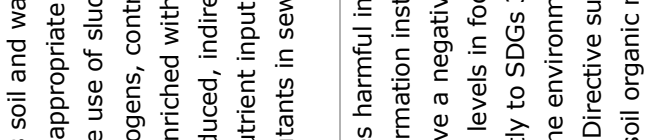

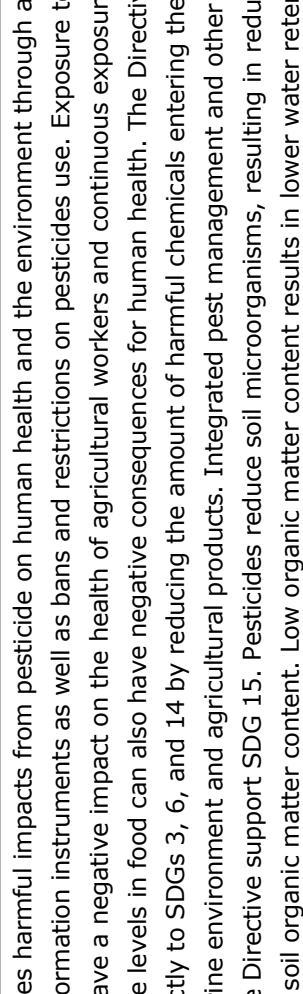
$\begin{array}{llllll} & \\ 0 & & \\ 0\end{array}$

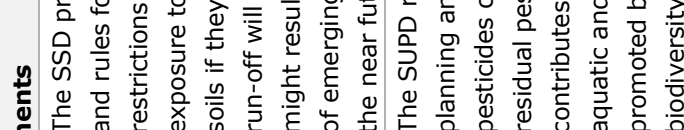

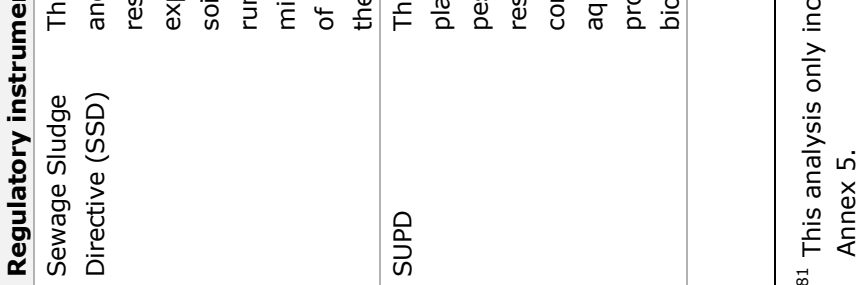




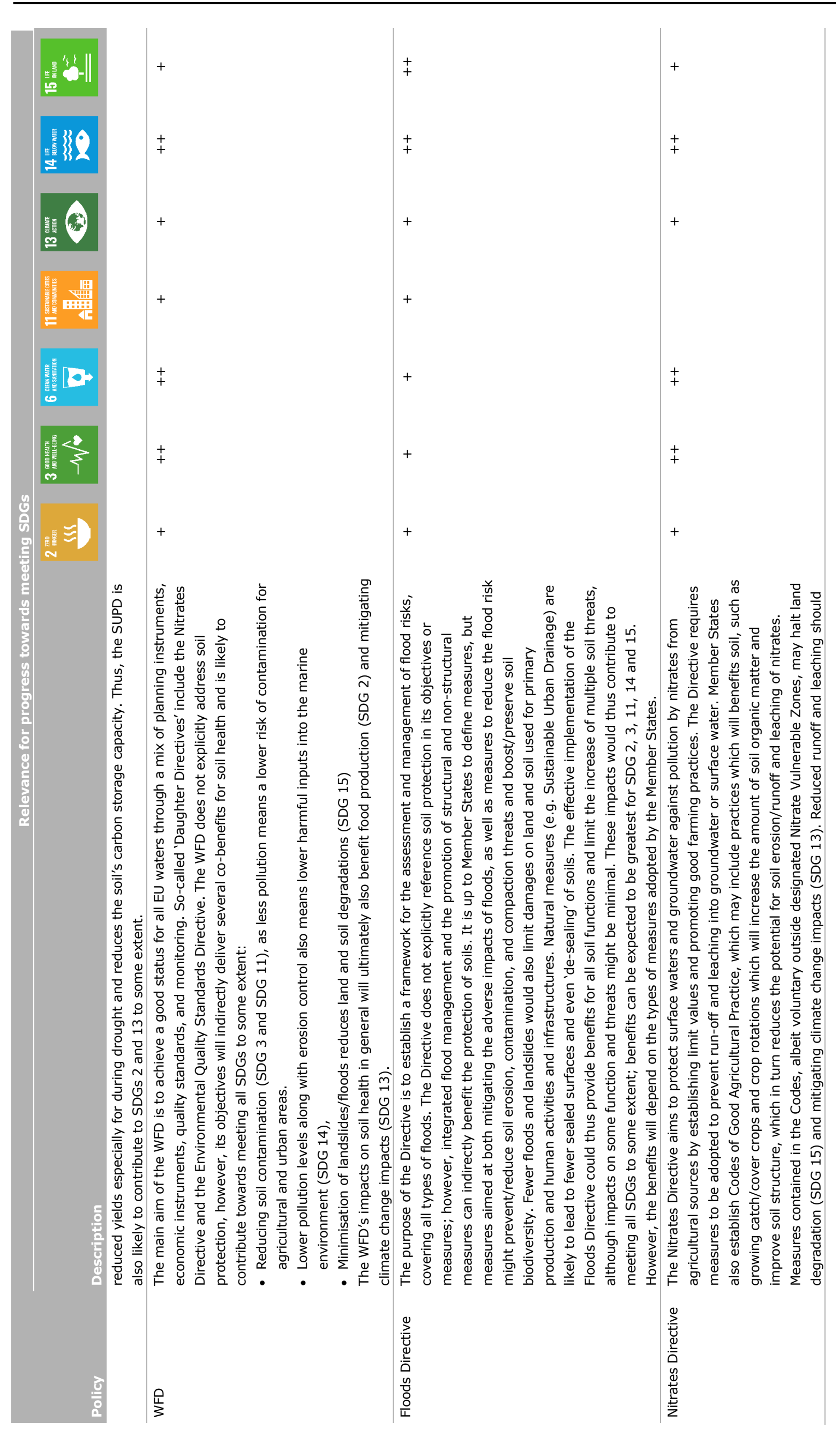




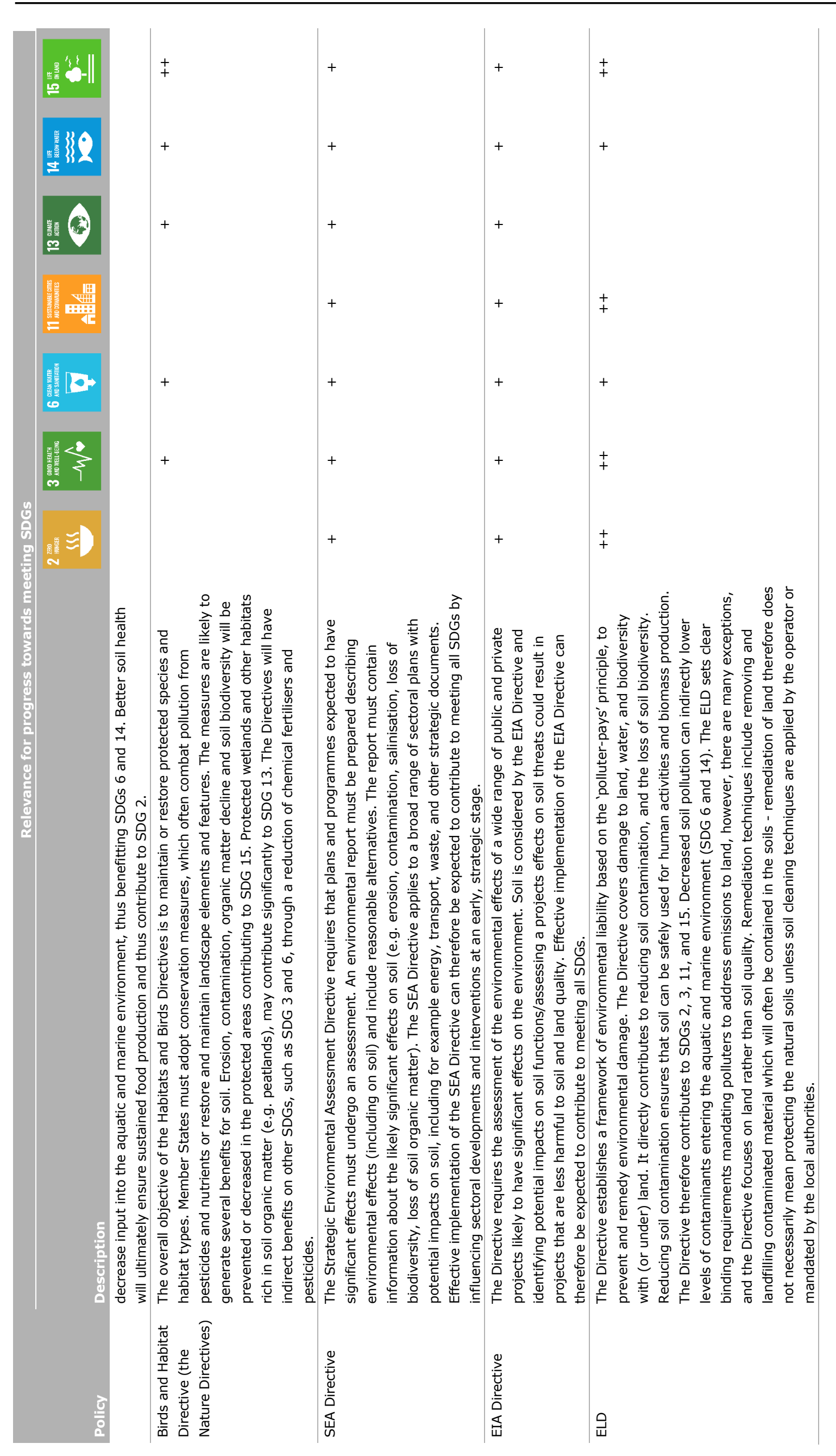




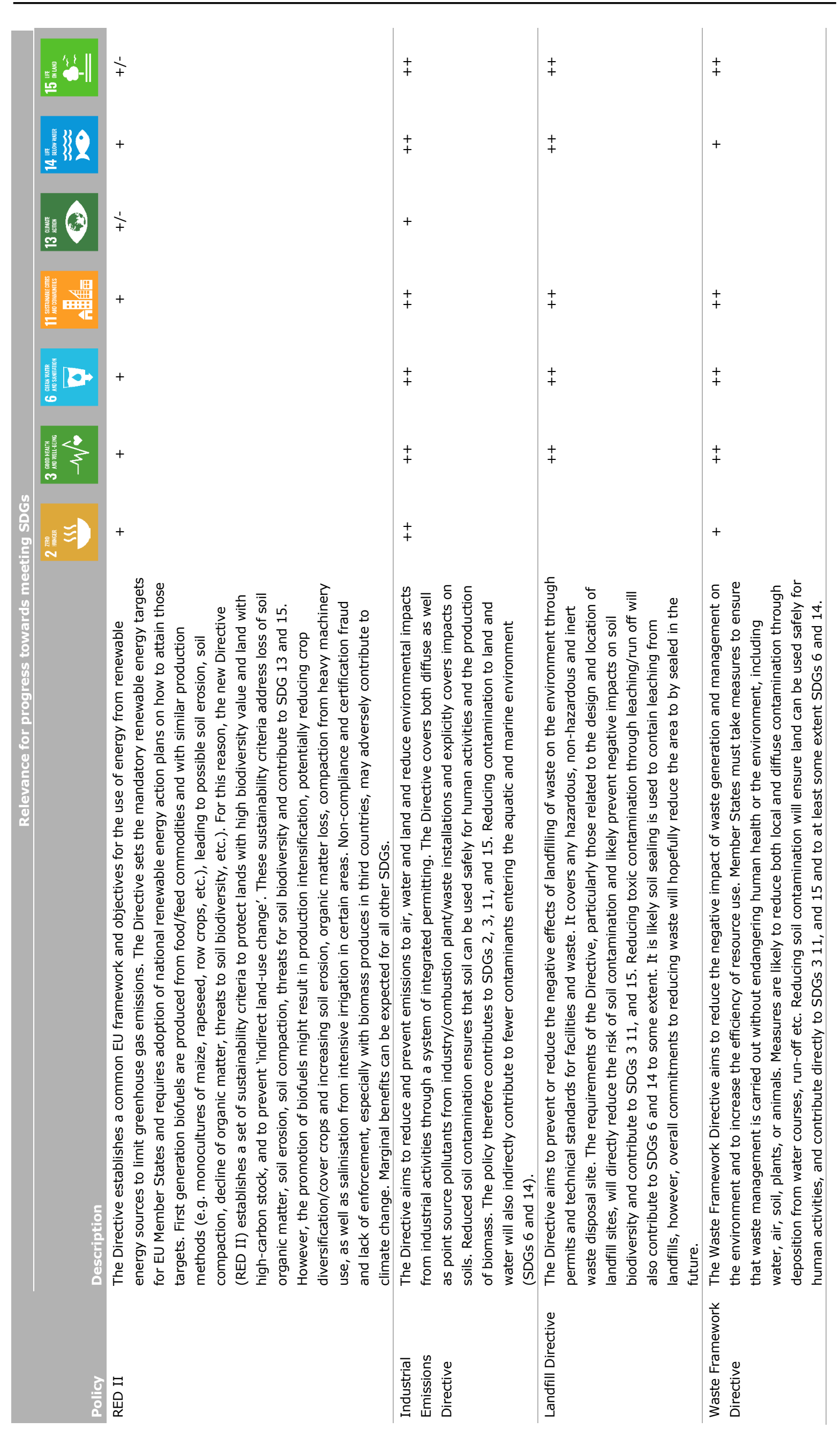




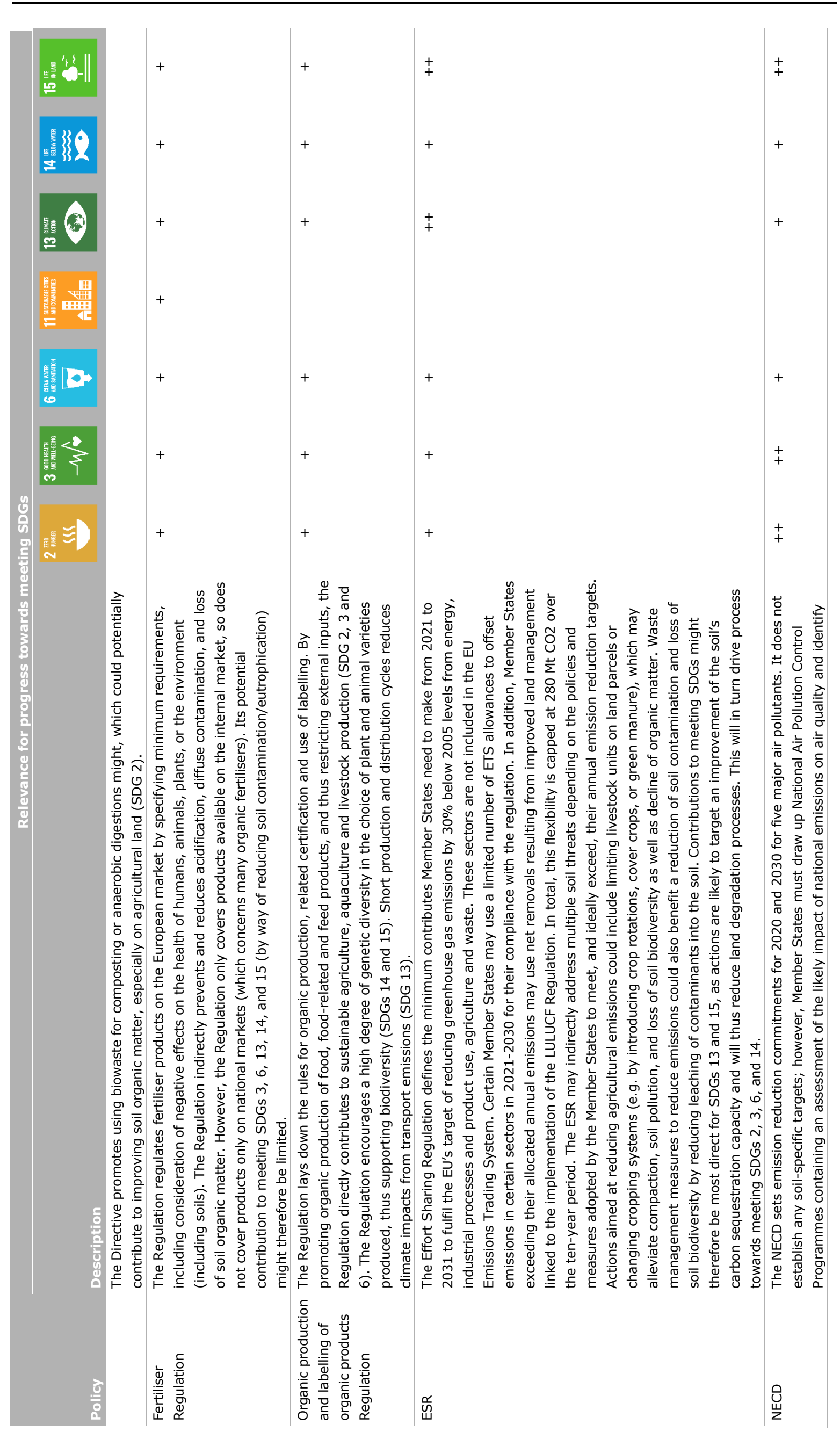




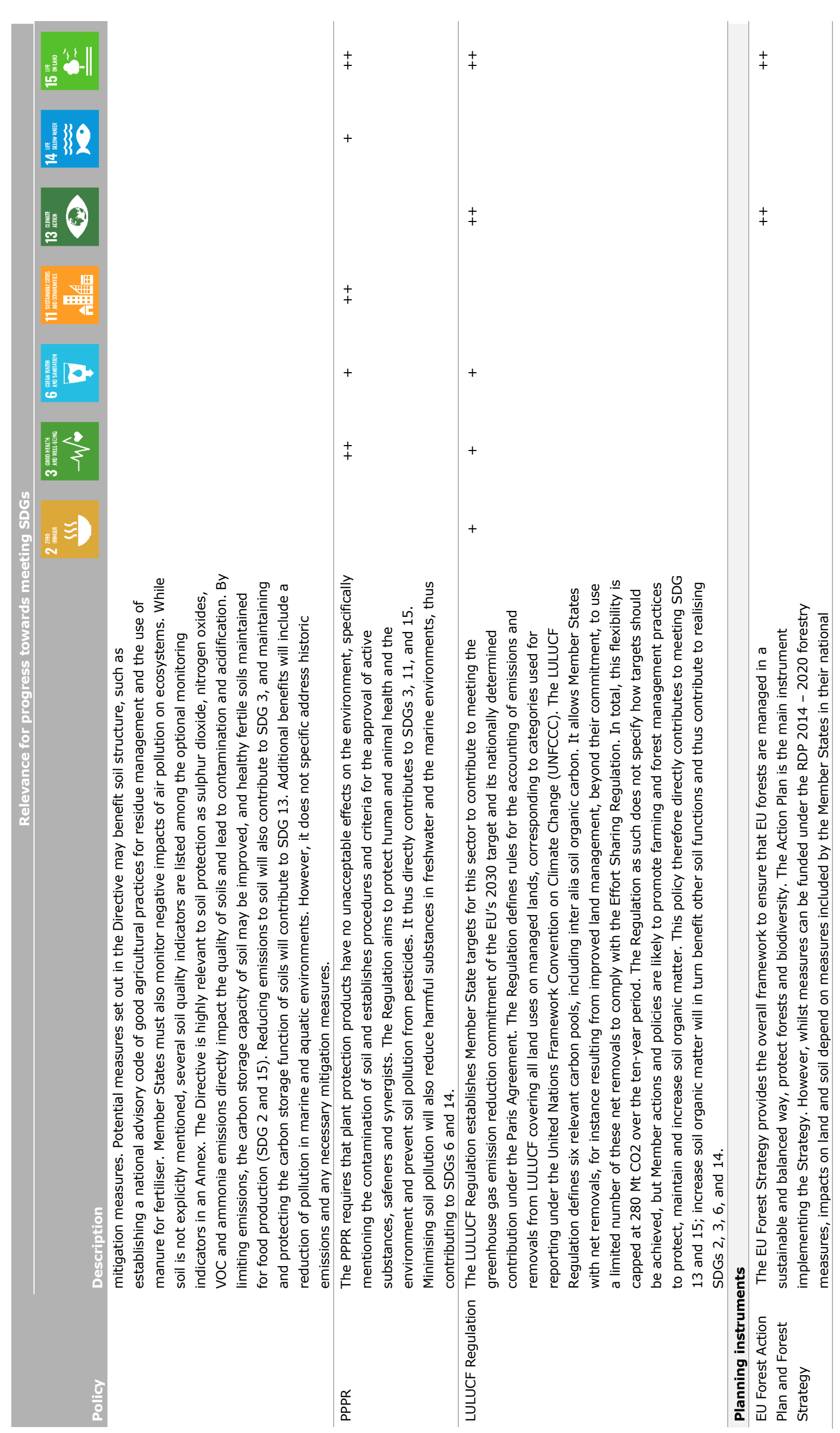




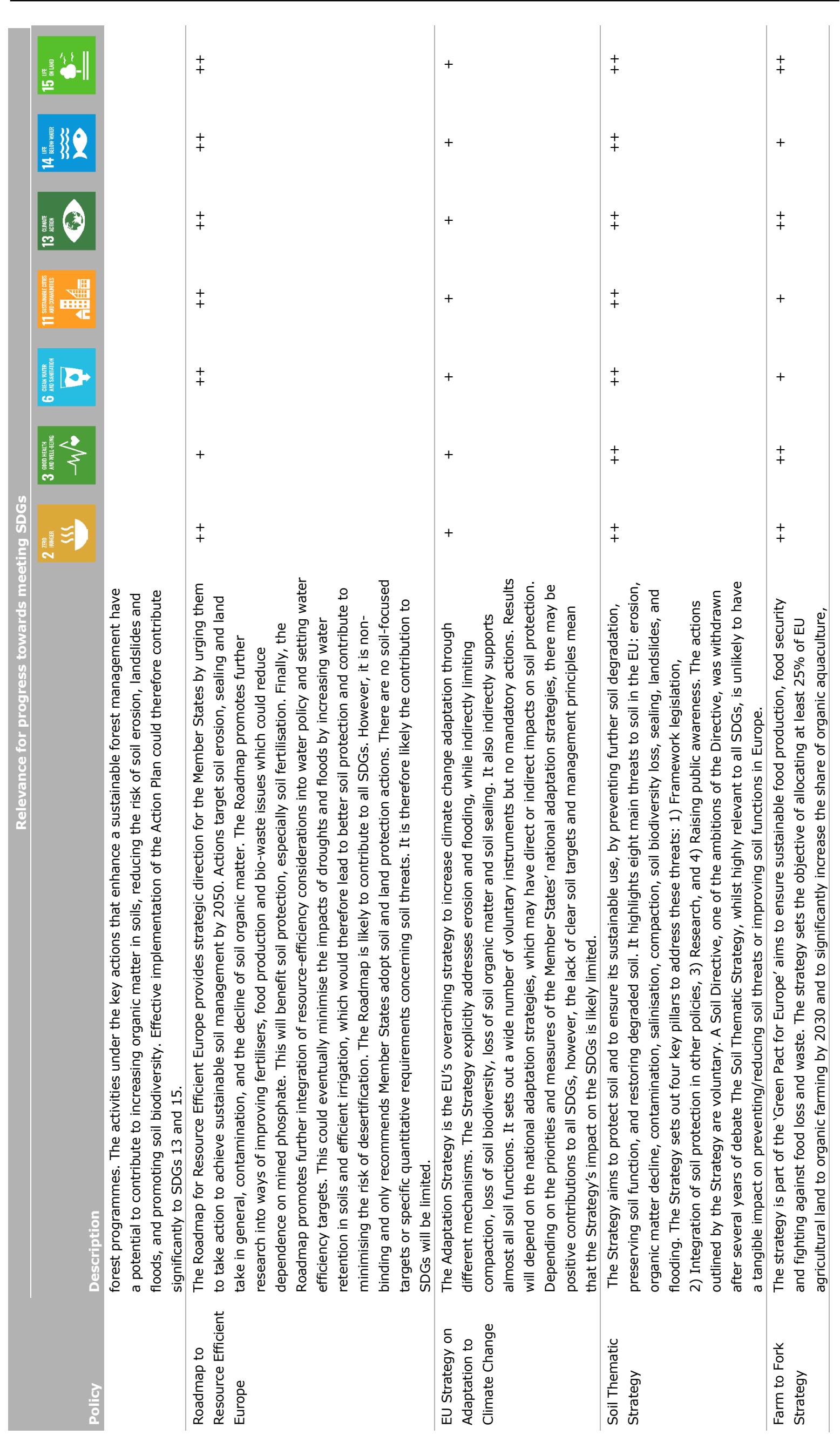




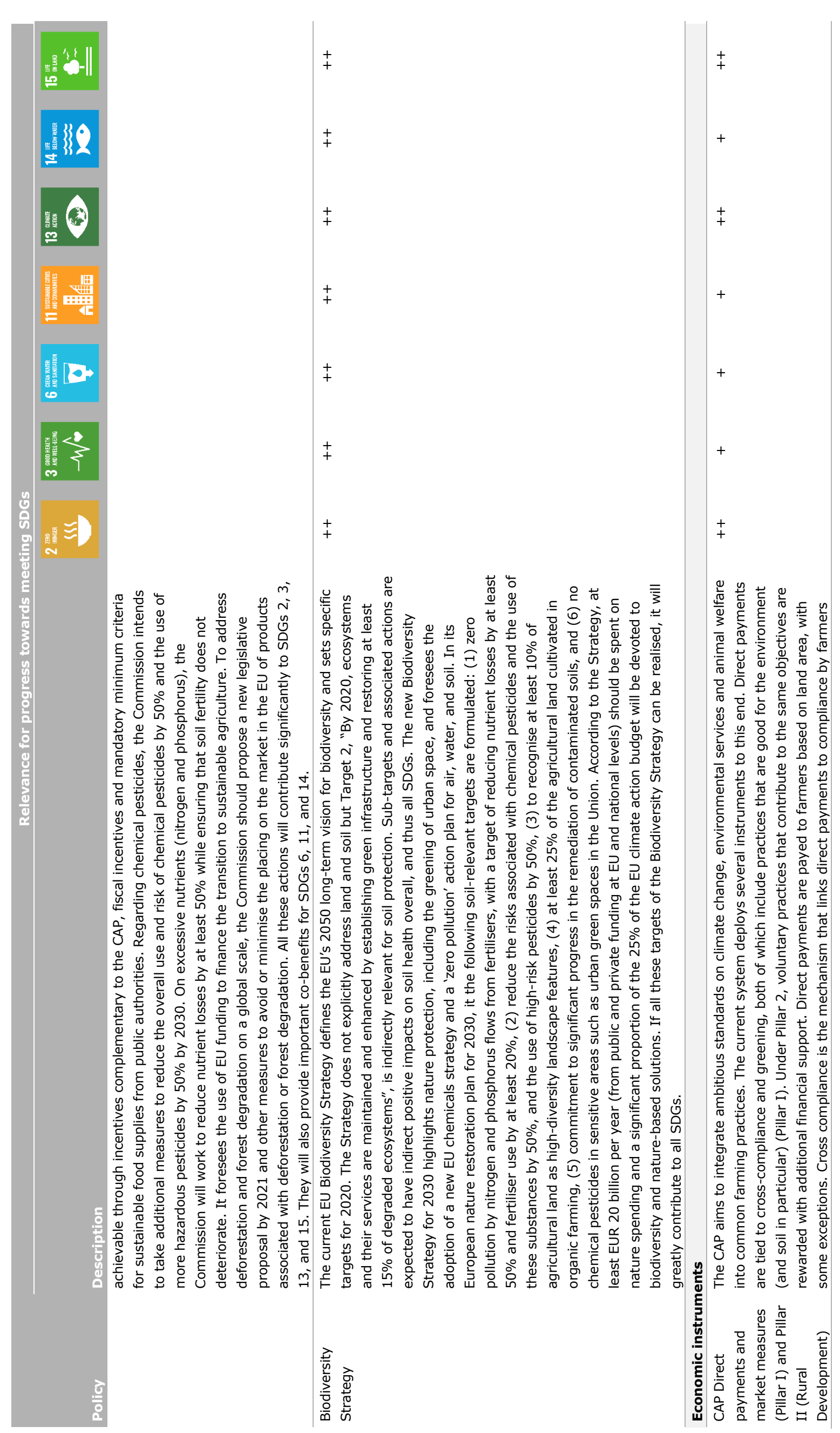




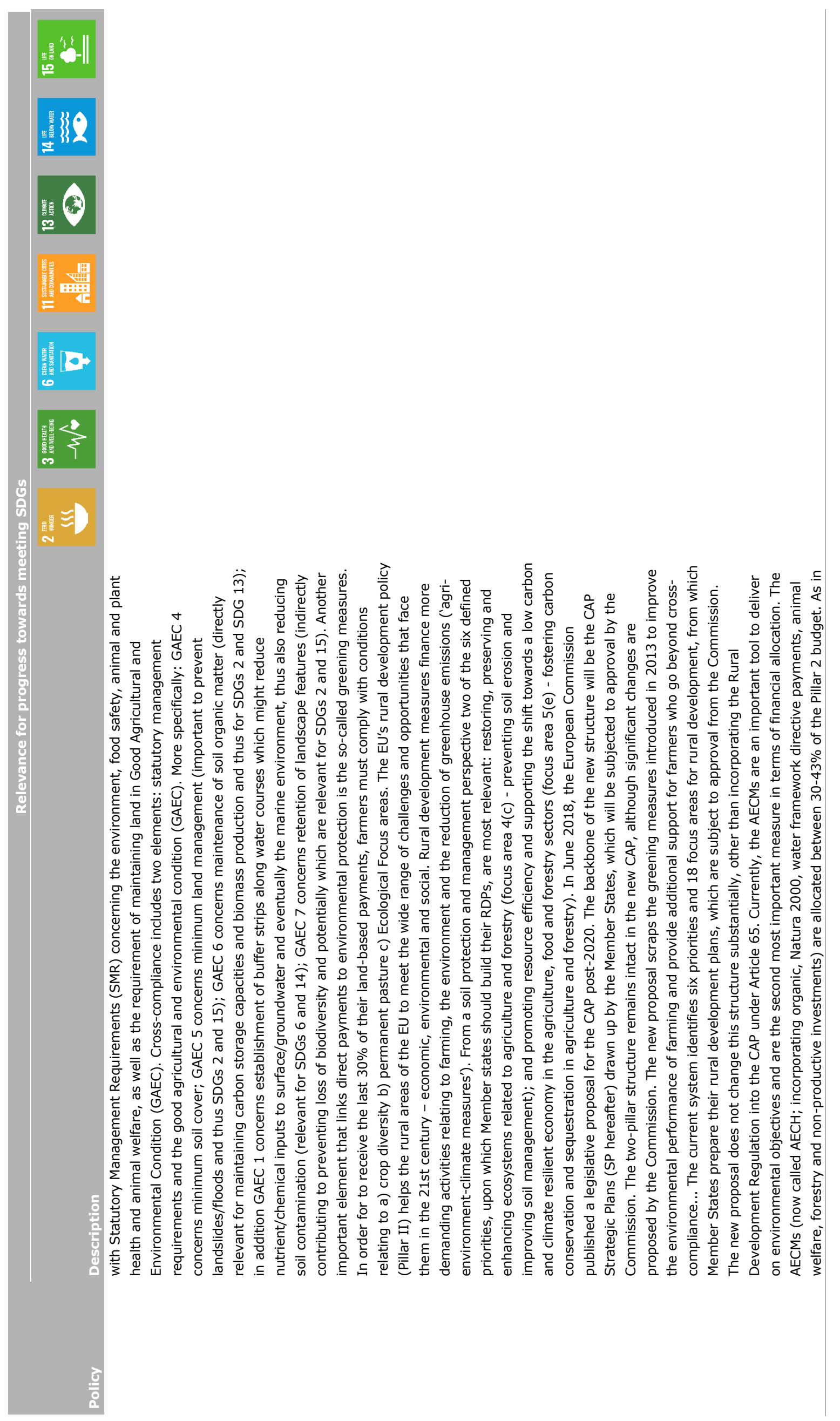




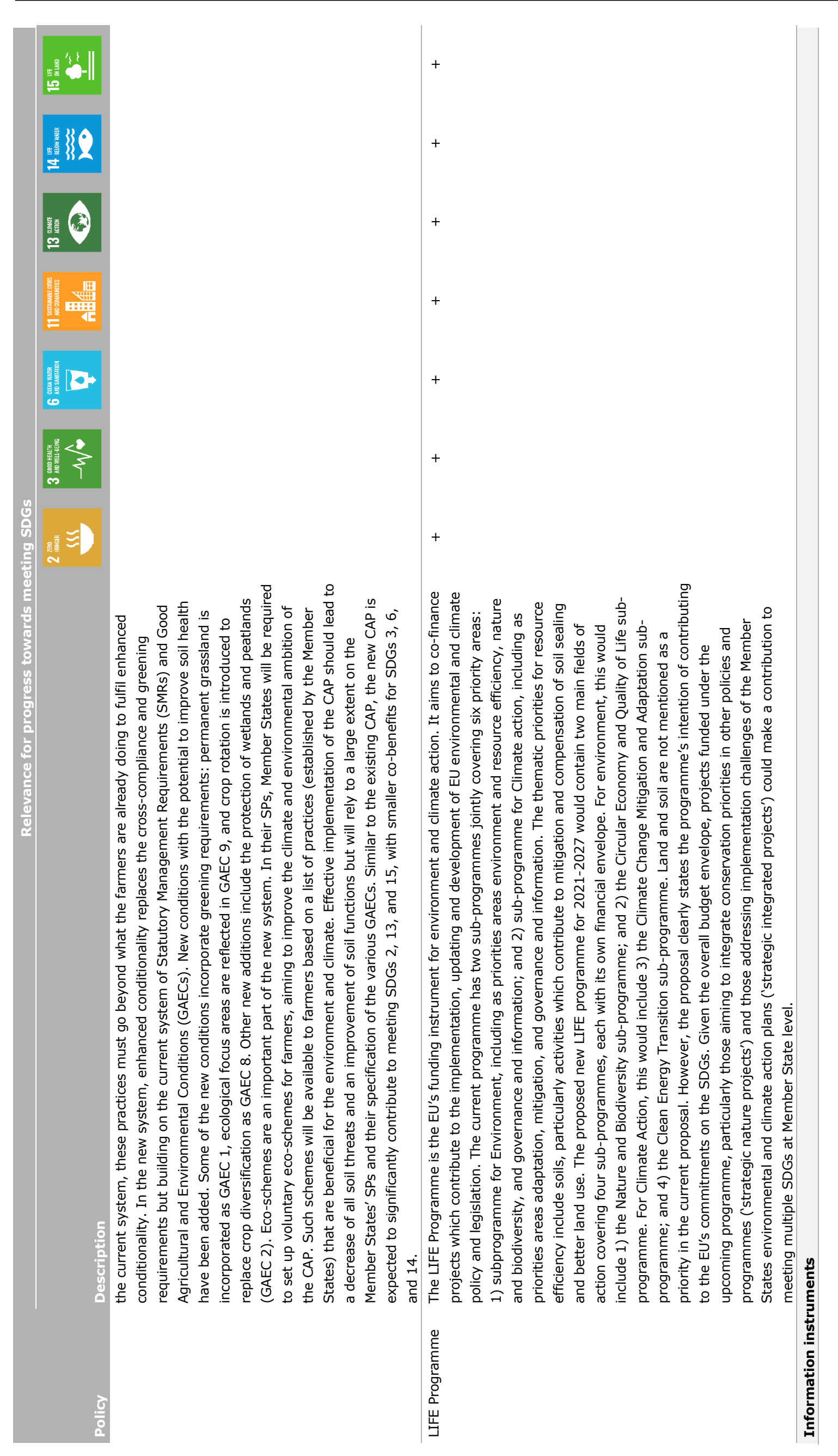




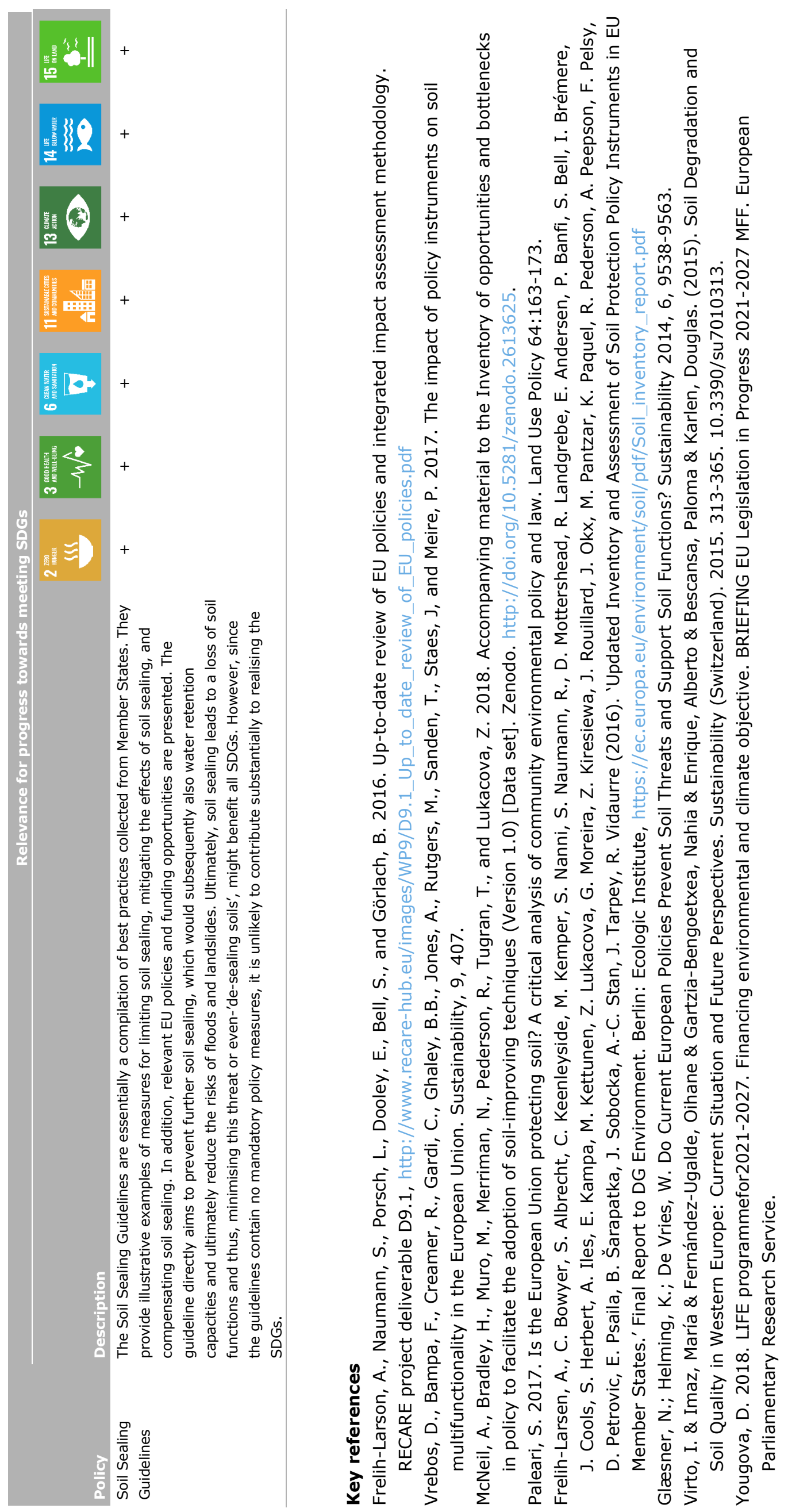




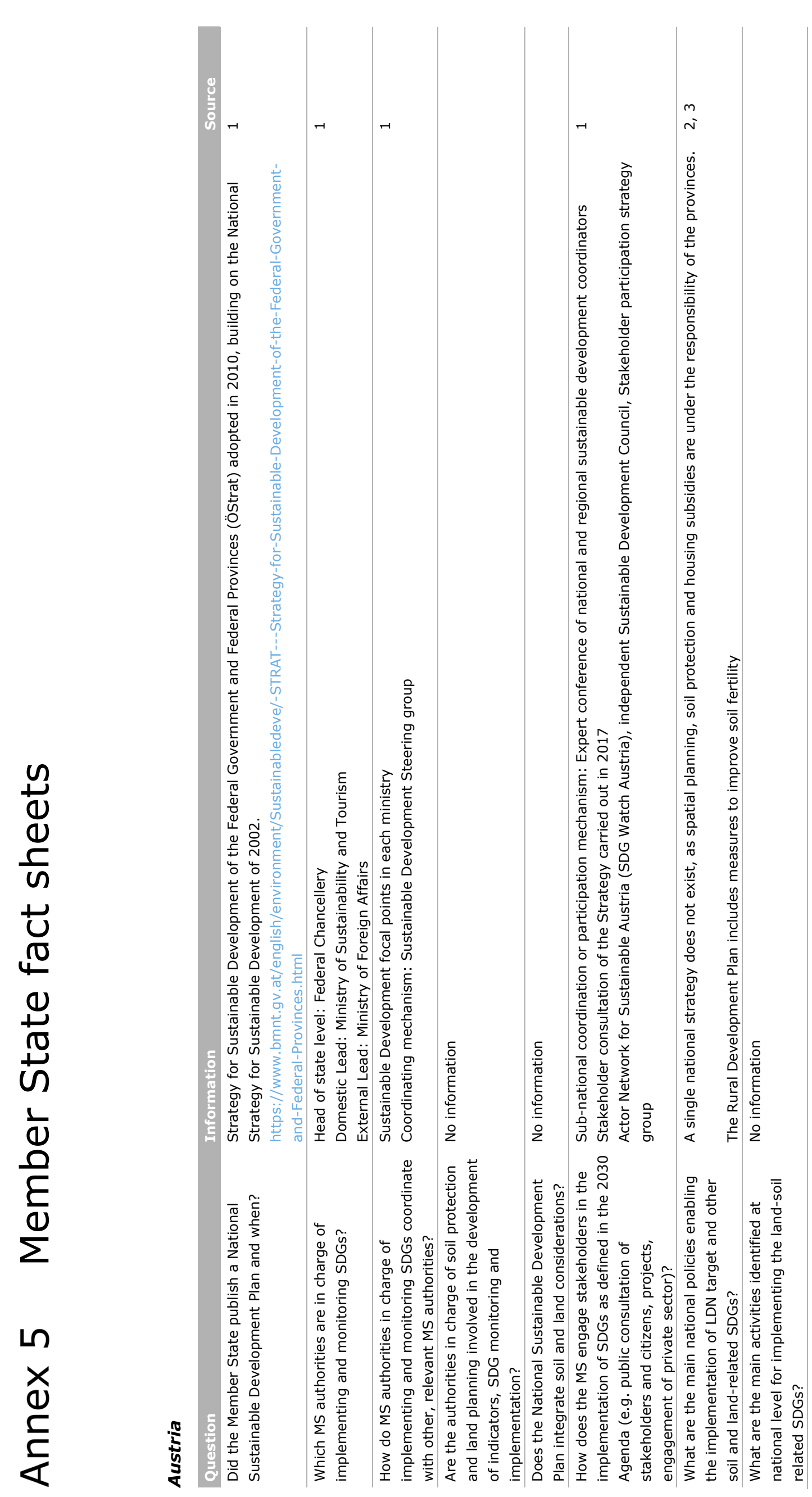


مे

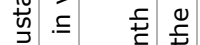

i 5 क

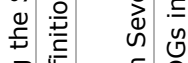

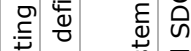

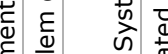

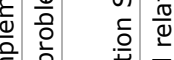

है

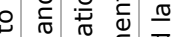

它

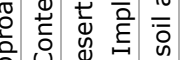

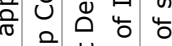

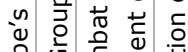

응 닝 है ह

昰苛

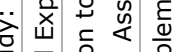

总言亮它产

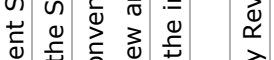

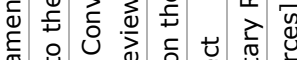

党

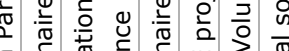

듕ำ

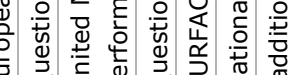

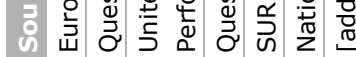

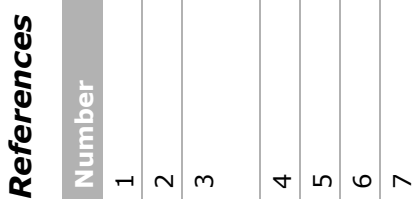




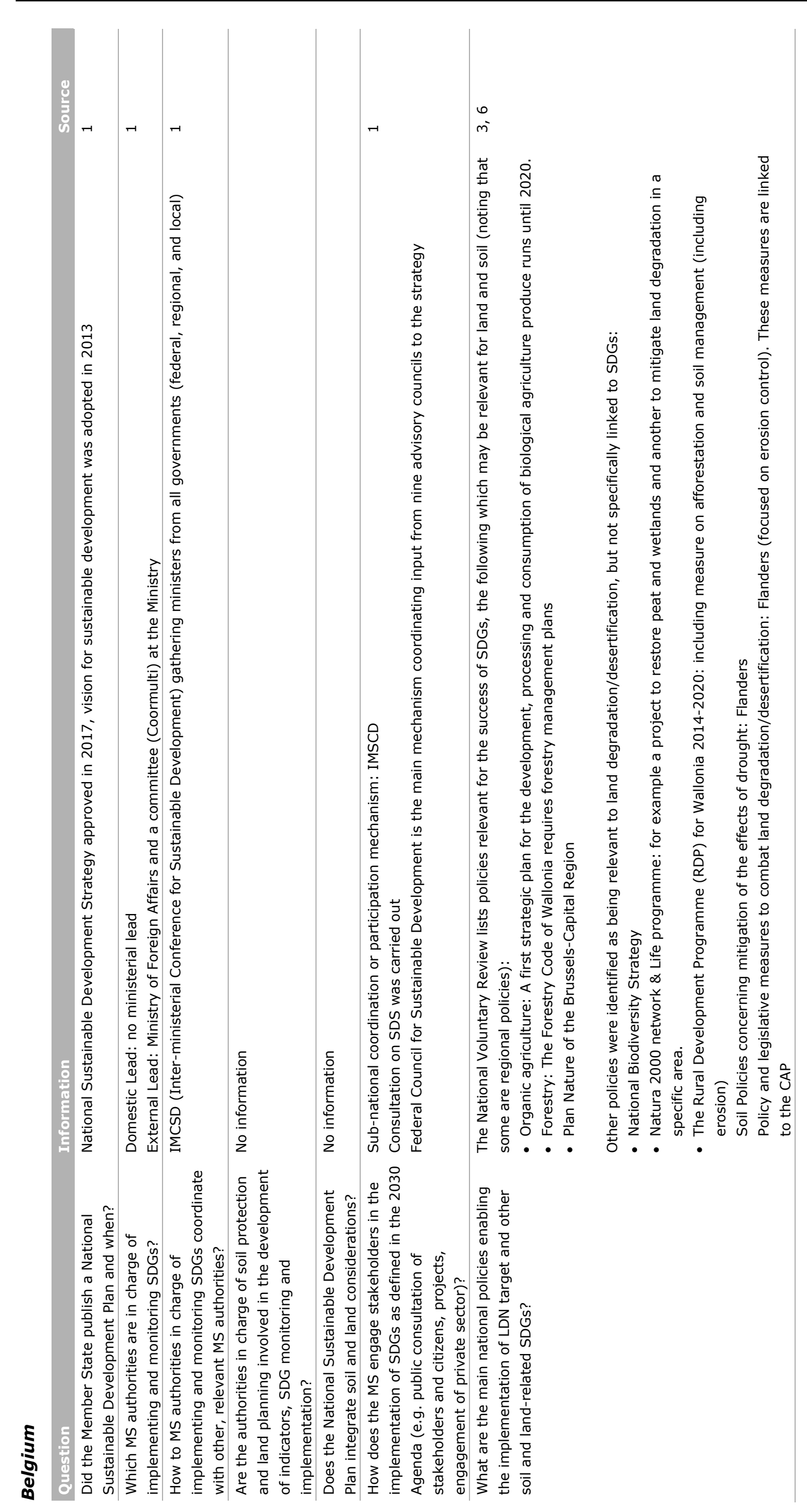




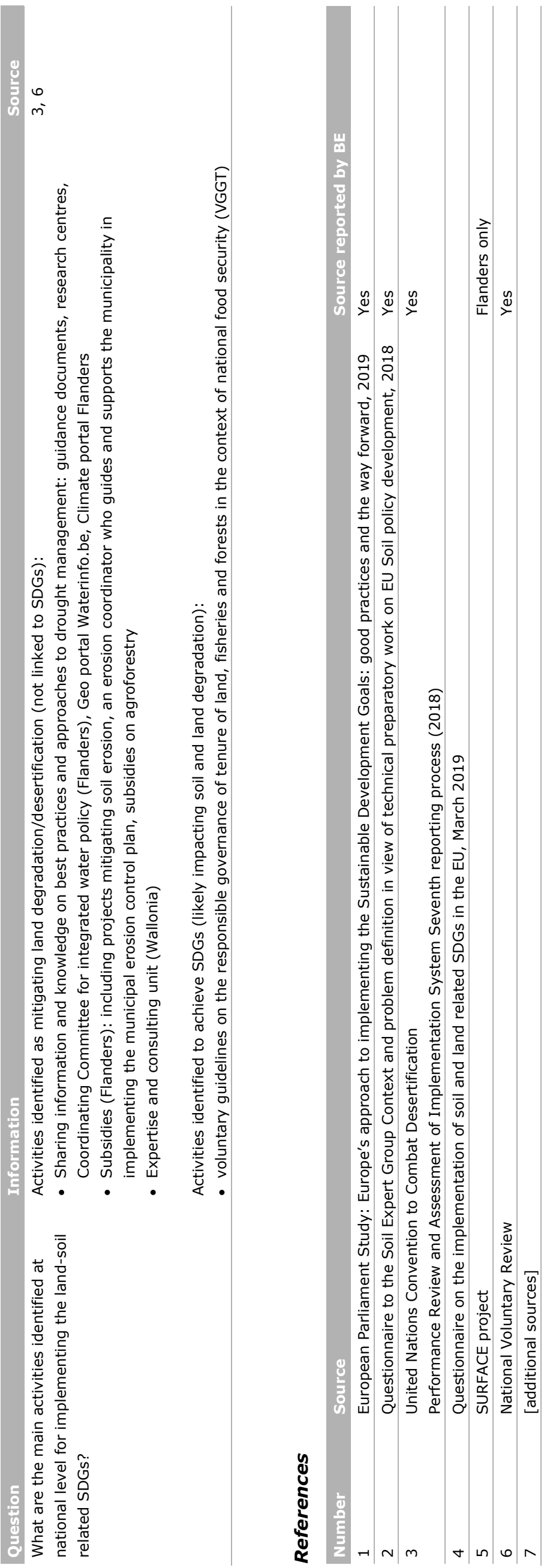




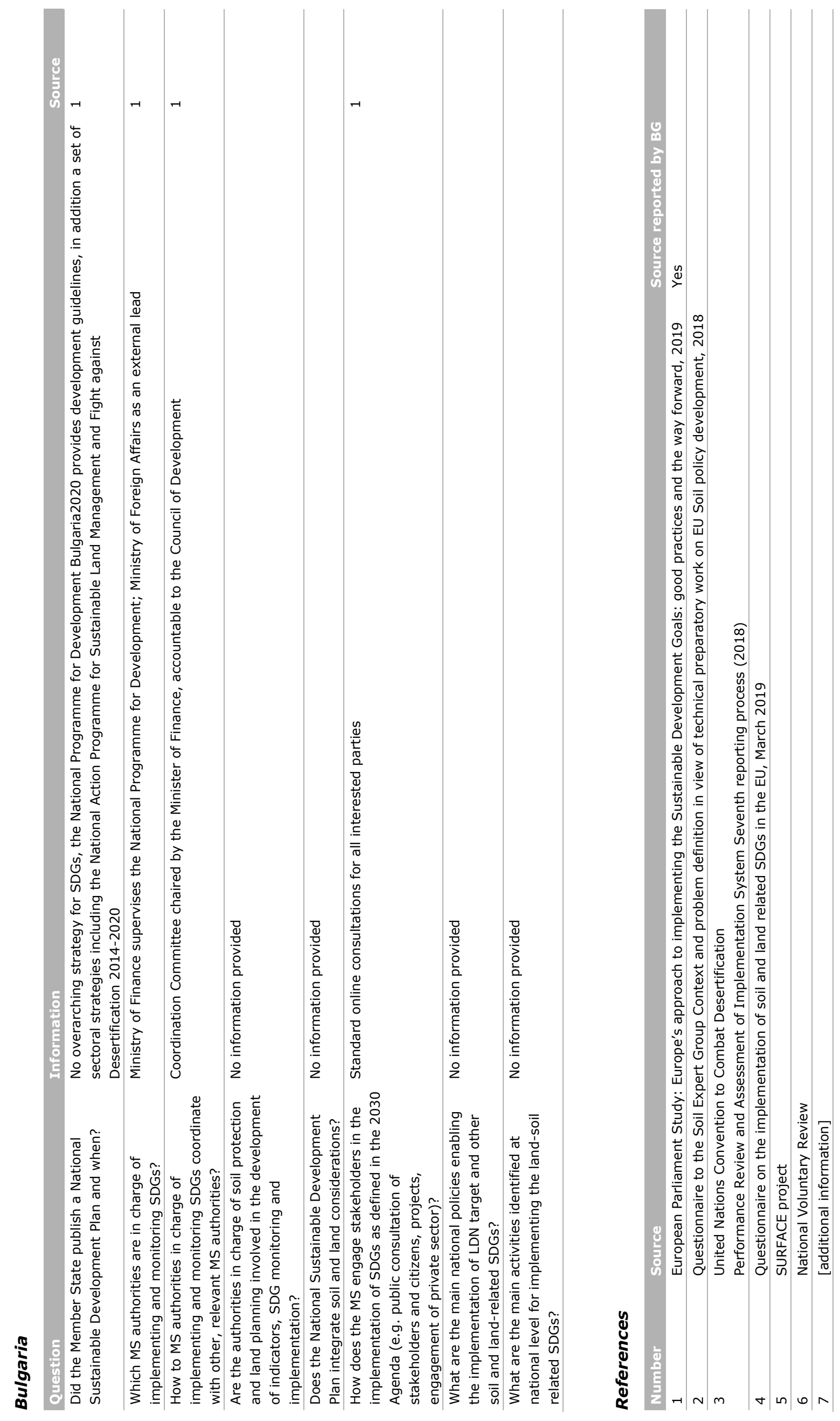




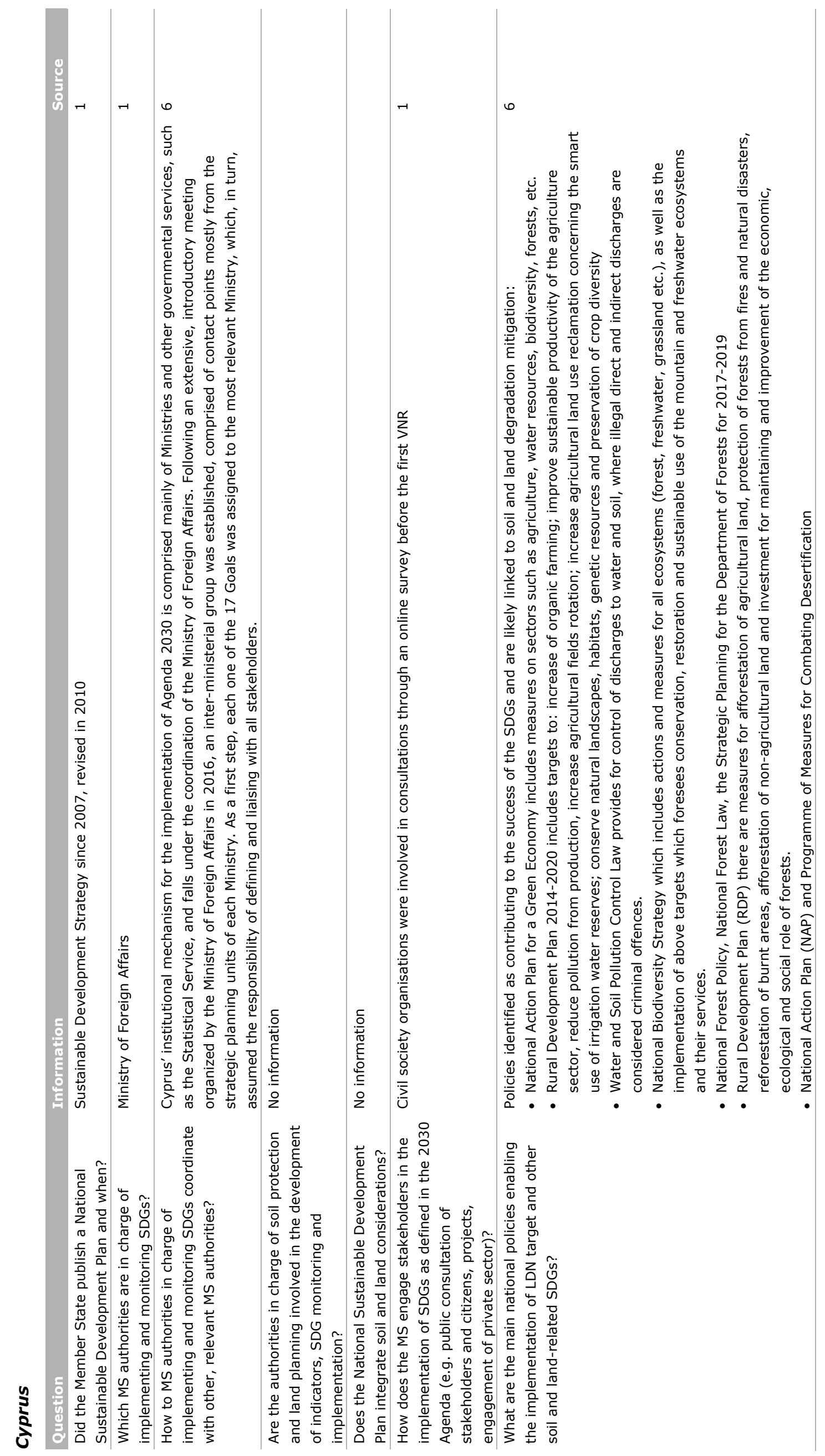




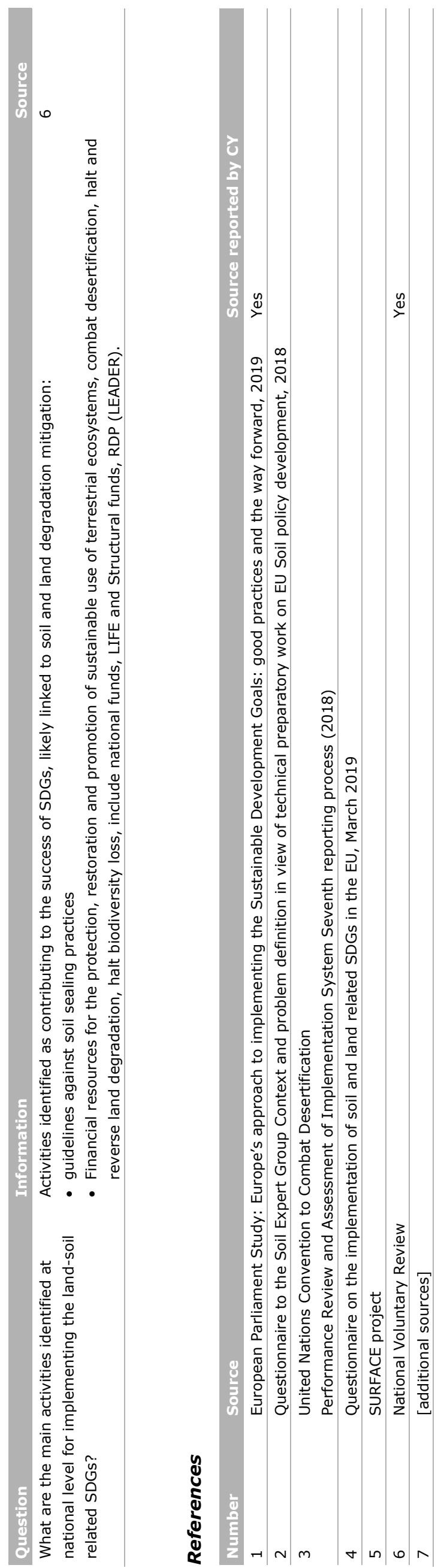




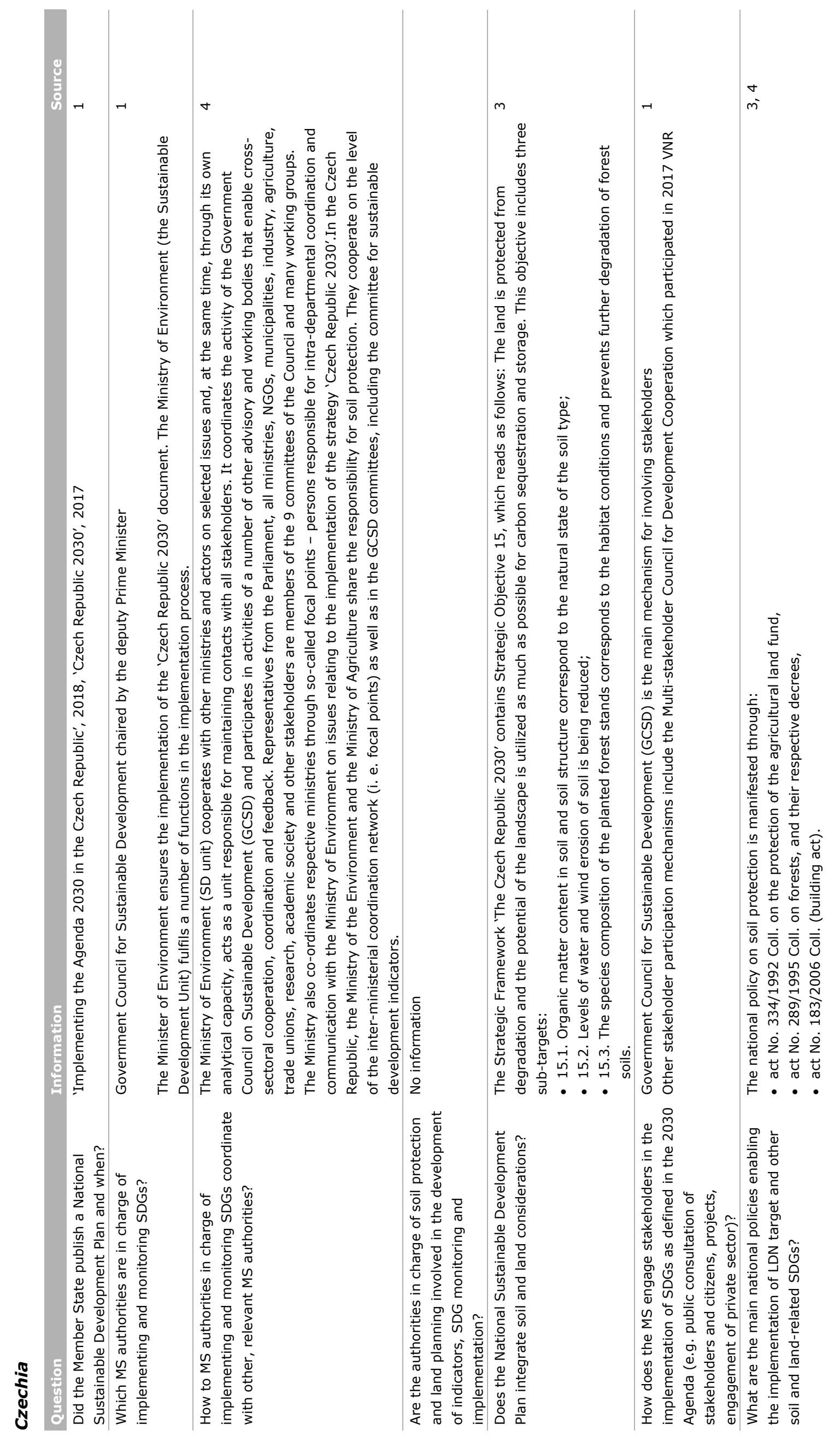




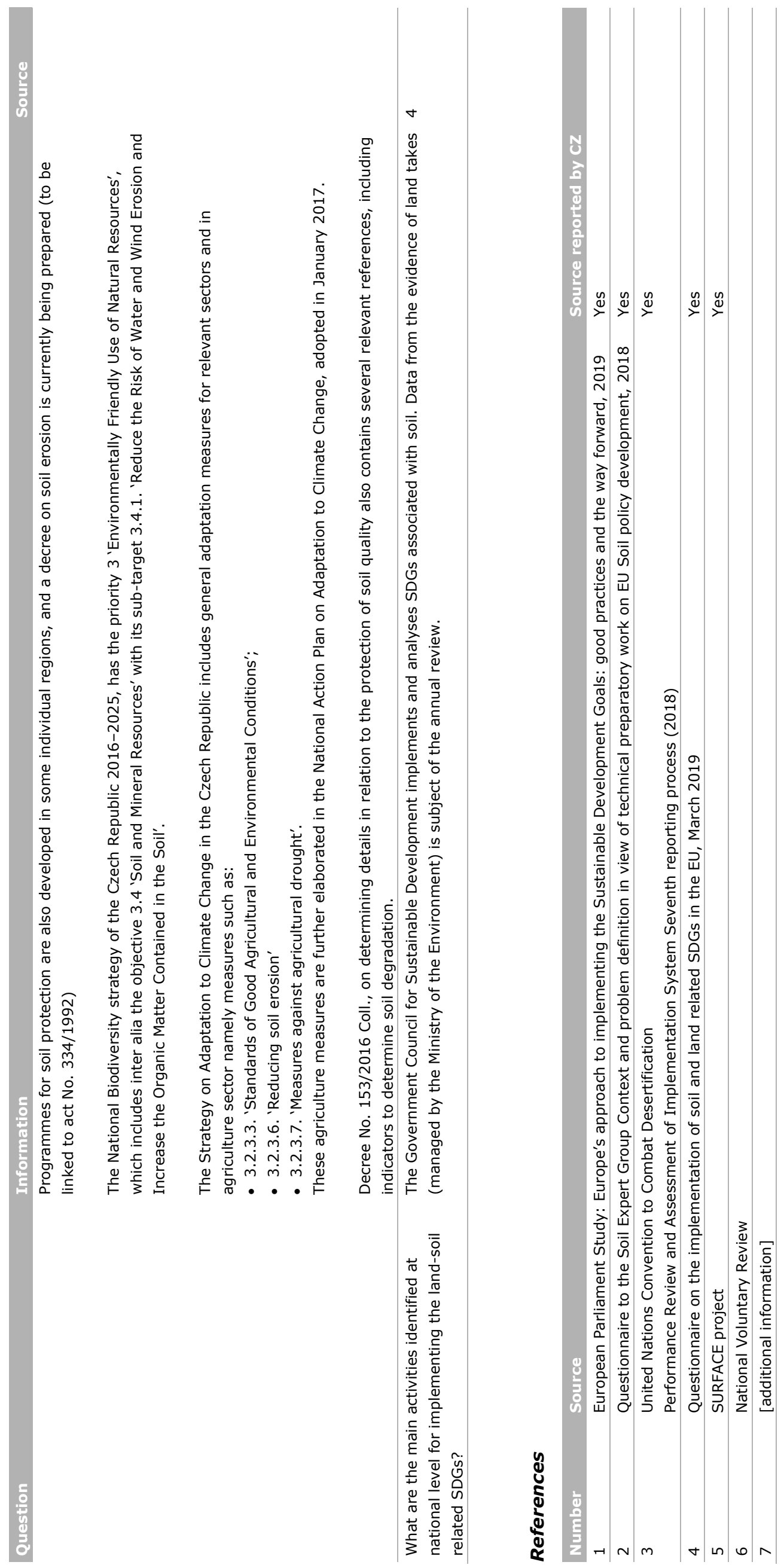




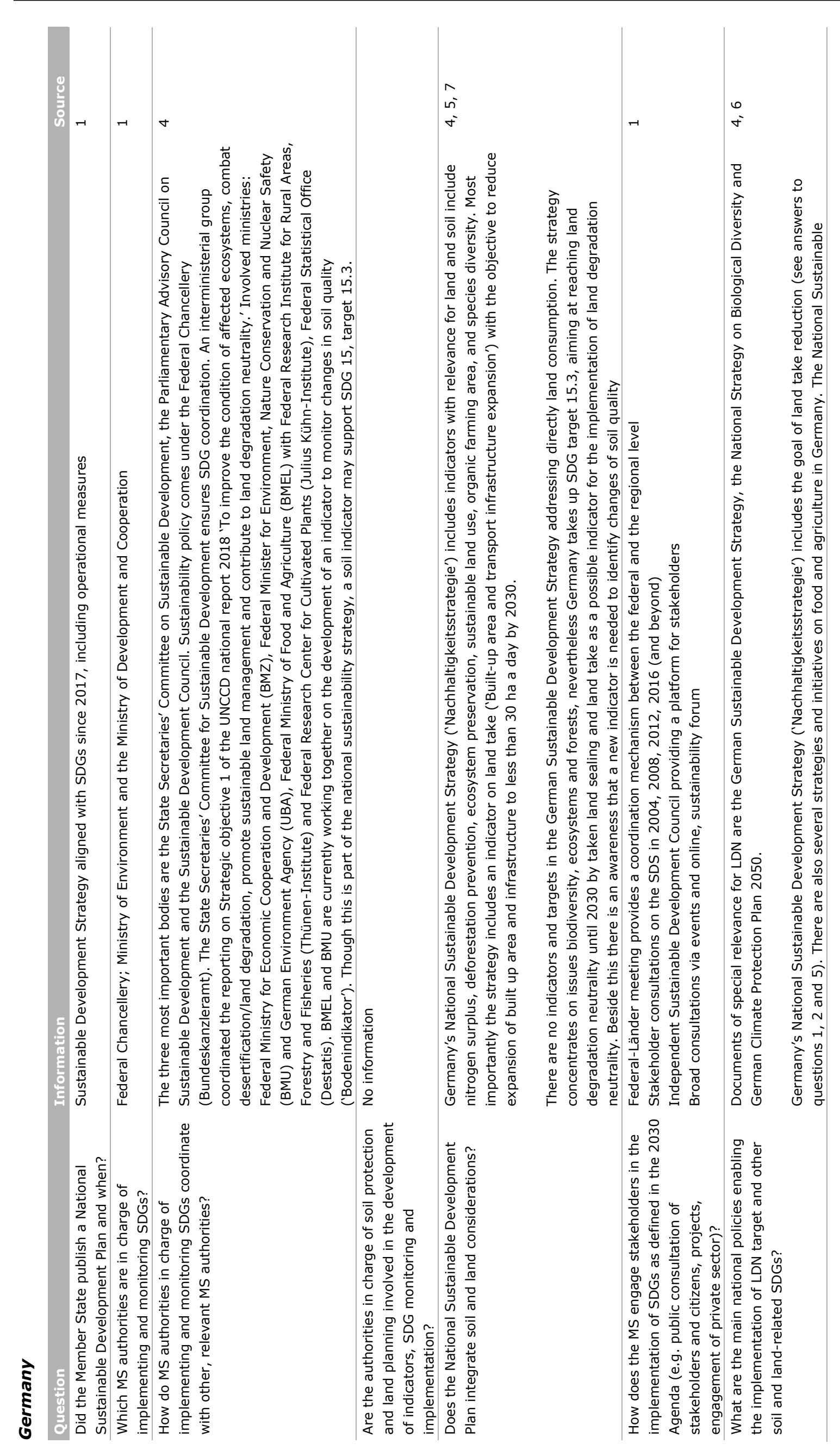




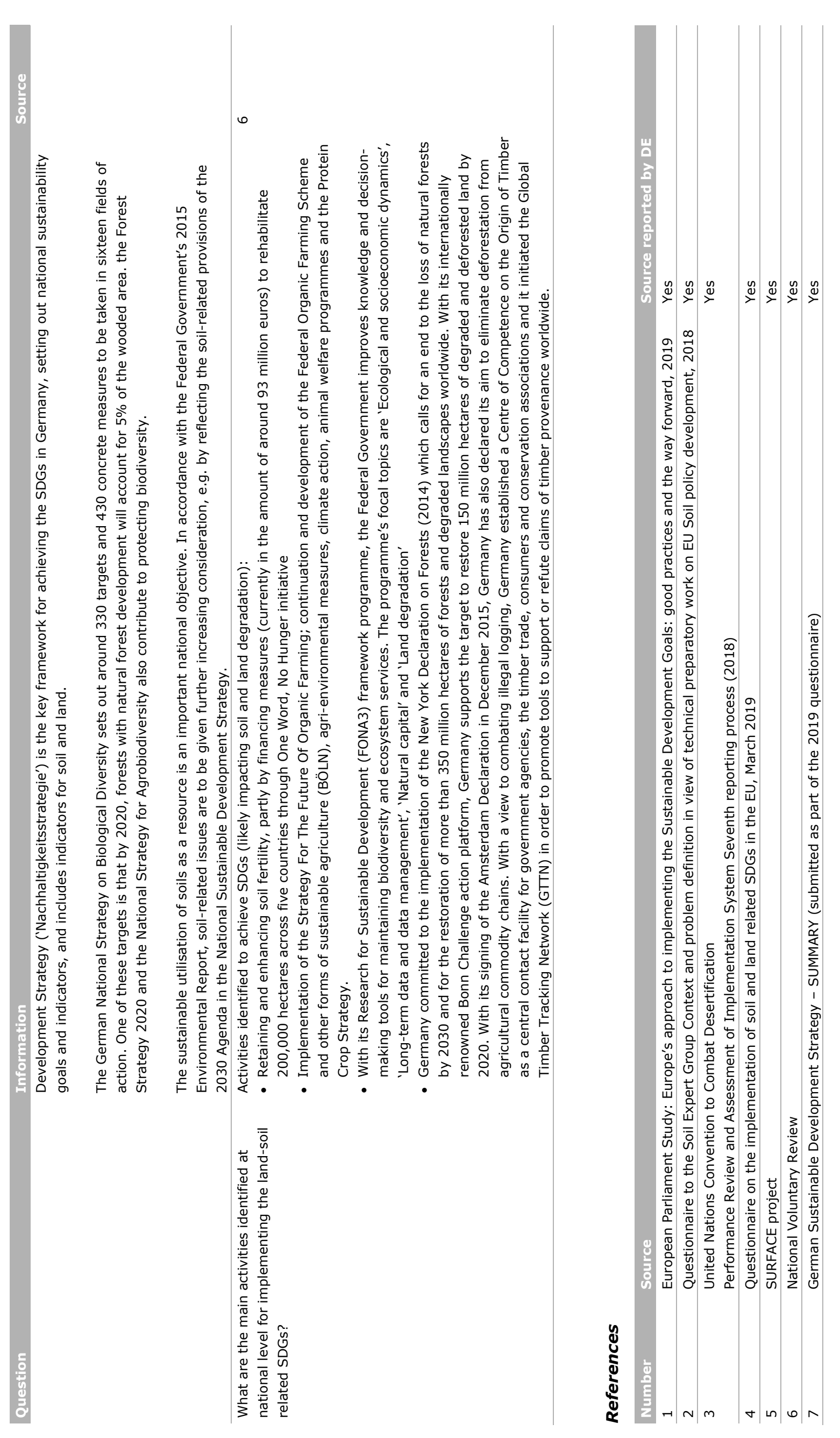




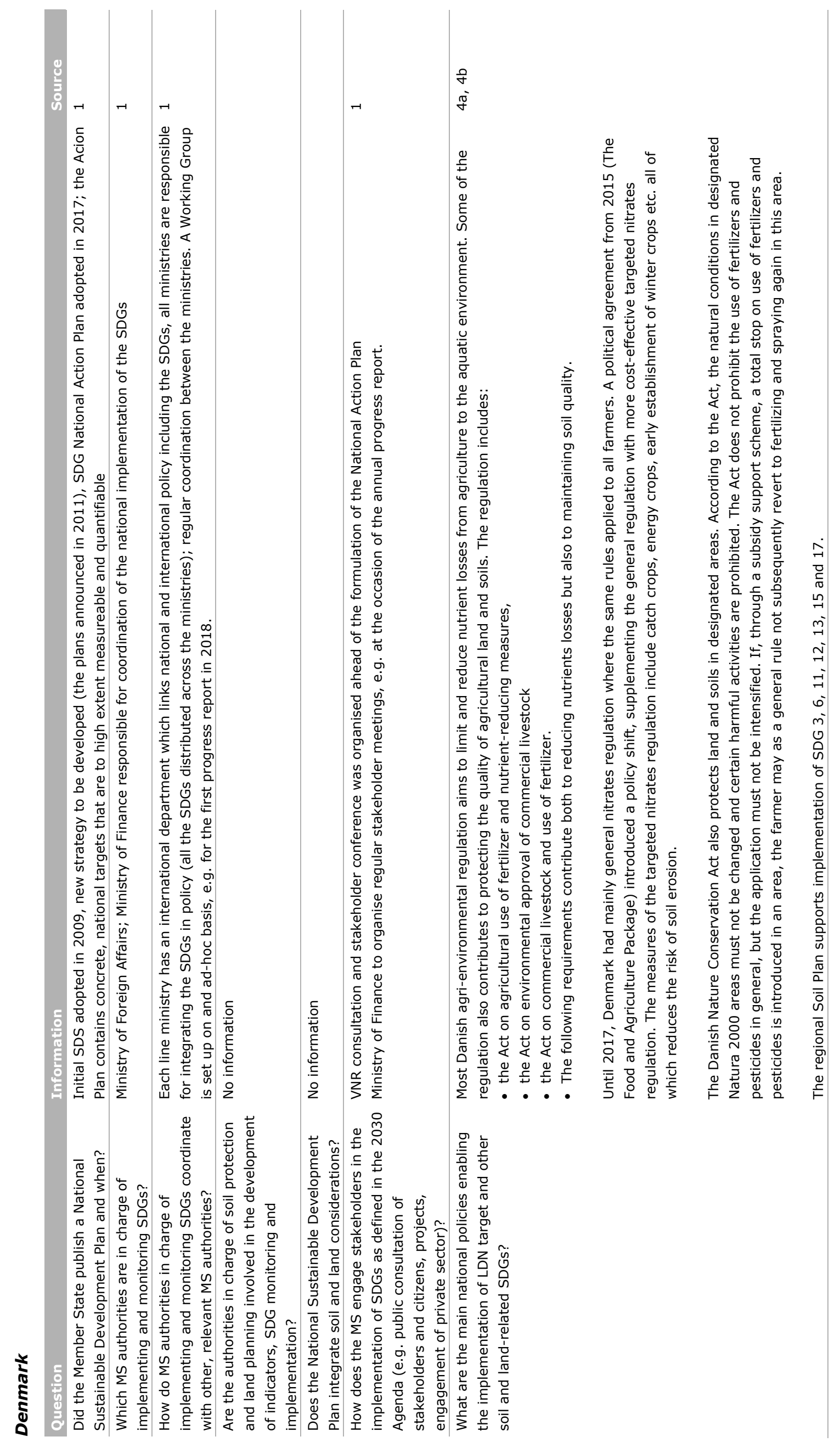




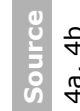

过

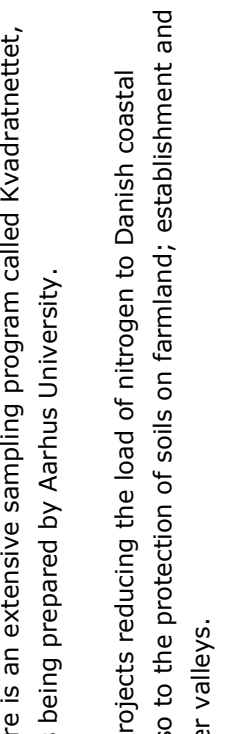

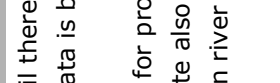

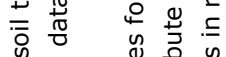

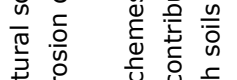

类

㽦皆

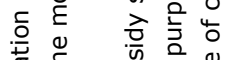

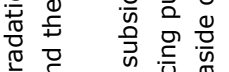

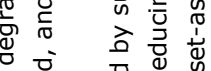

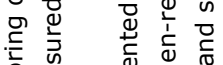

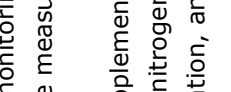

ह

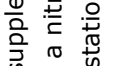

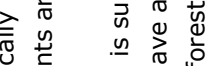

豕

다에

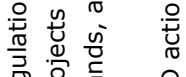

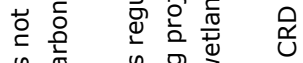

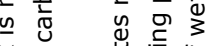

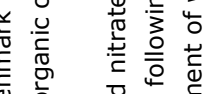

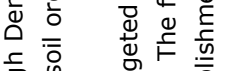

告

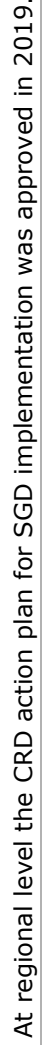

वे

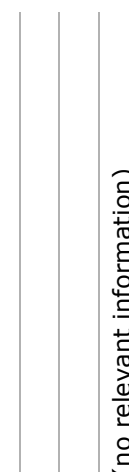

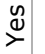

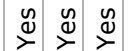

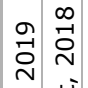

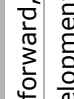

㲾

站

要

焉

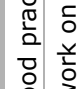

i⿱ $)$ 究

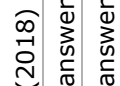

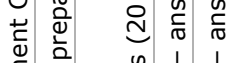

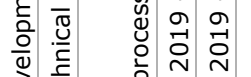

ปัป

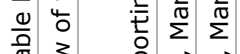

亭

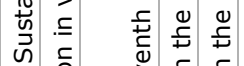

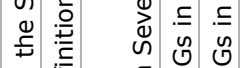

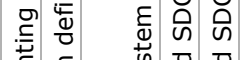

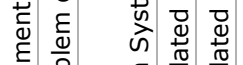

응 응 $5 \frac{\pi}{0} \frac{\pi}{0}$

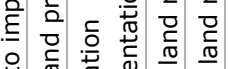

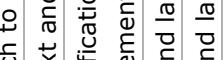

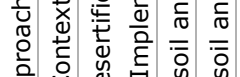

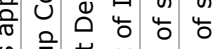

品

인

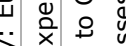

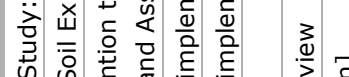

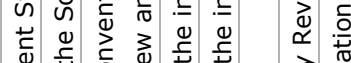

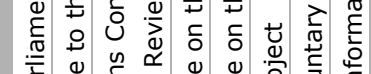

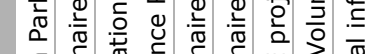

8

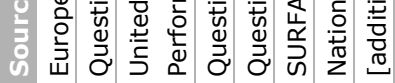

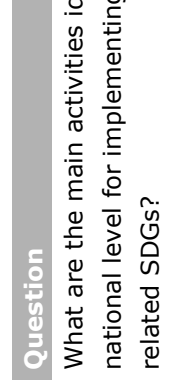

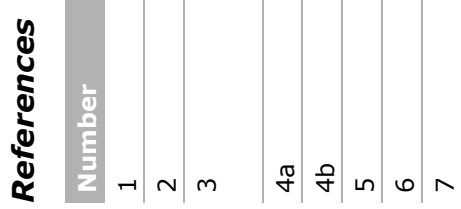




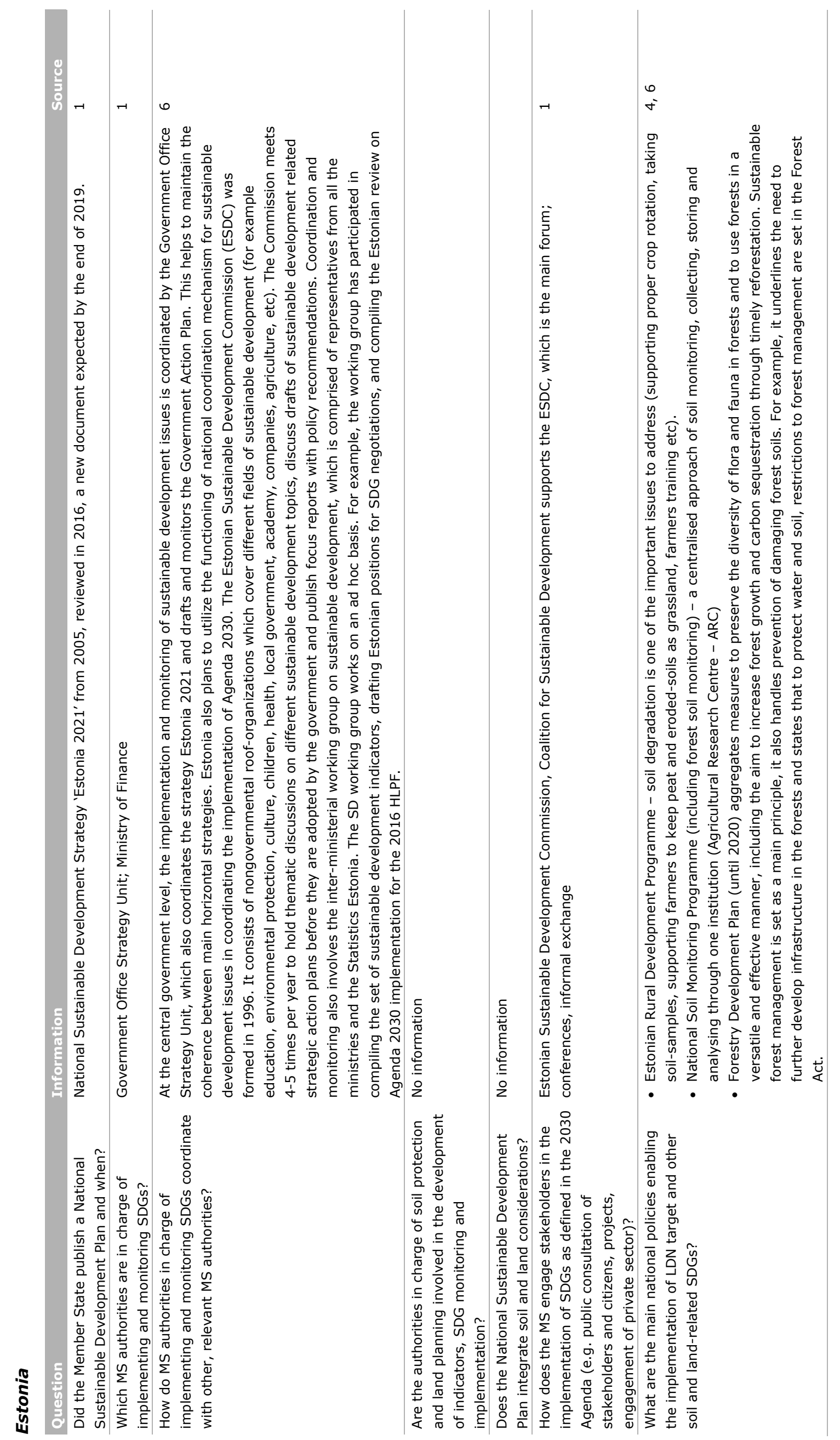




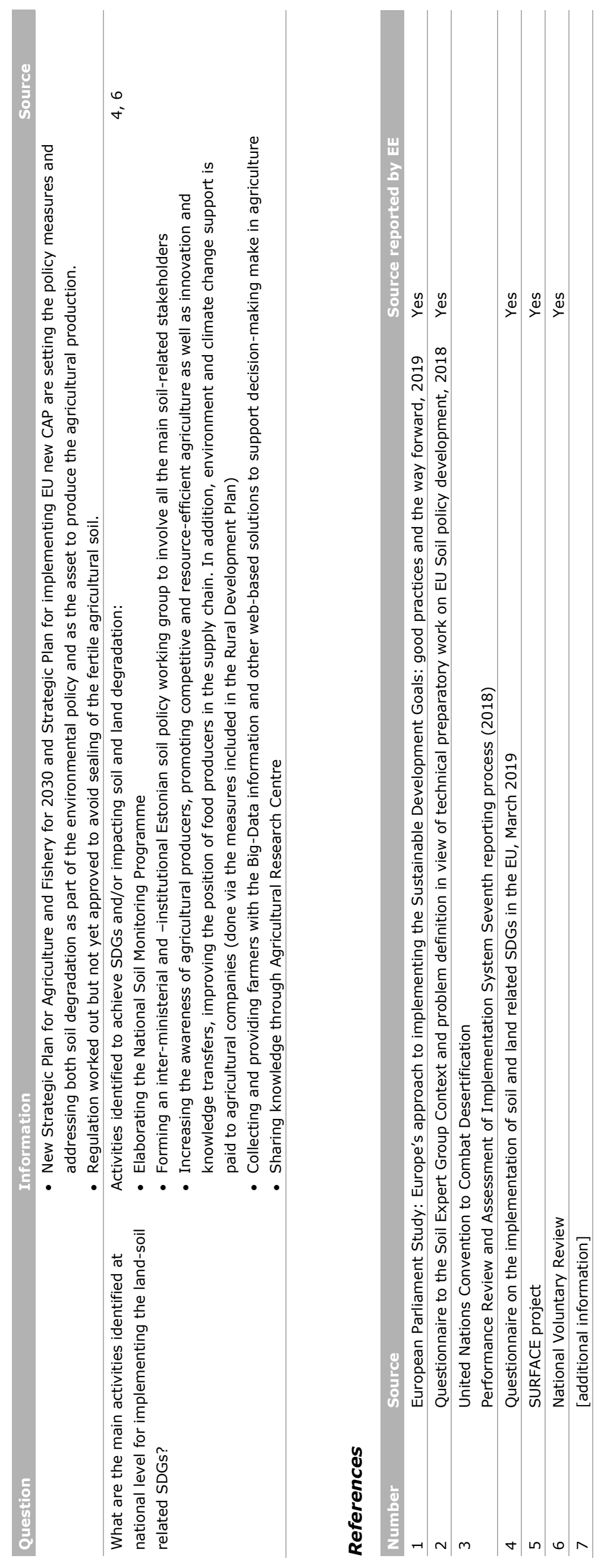




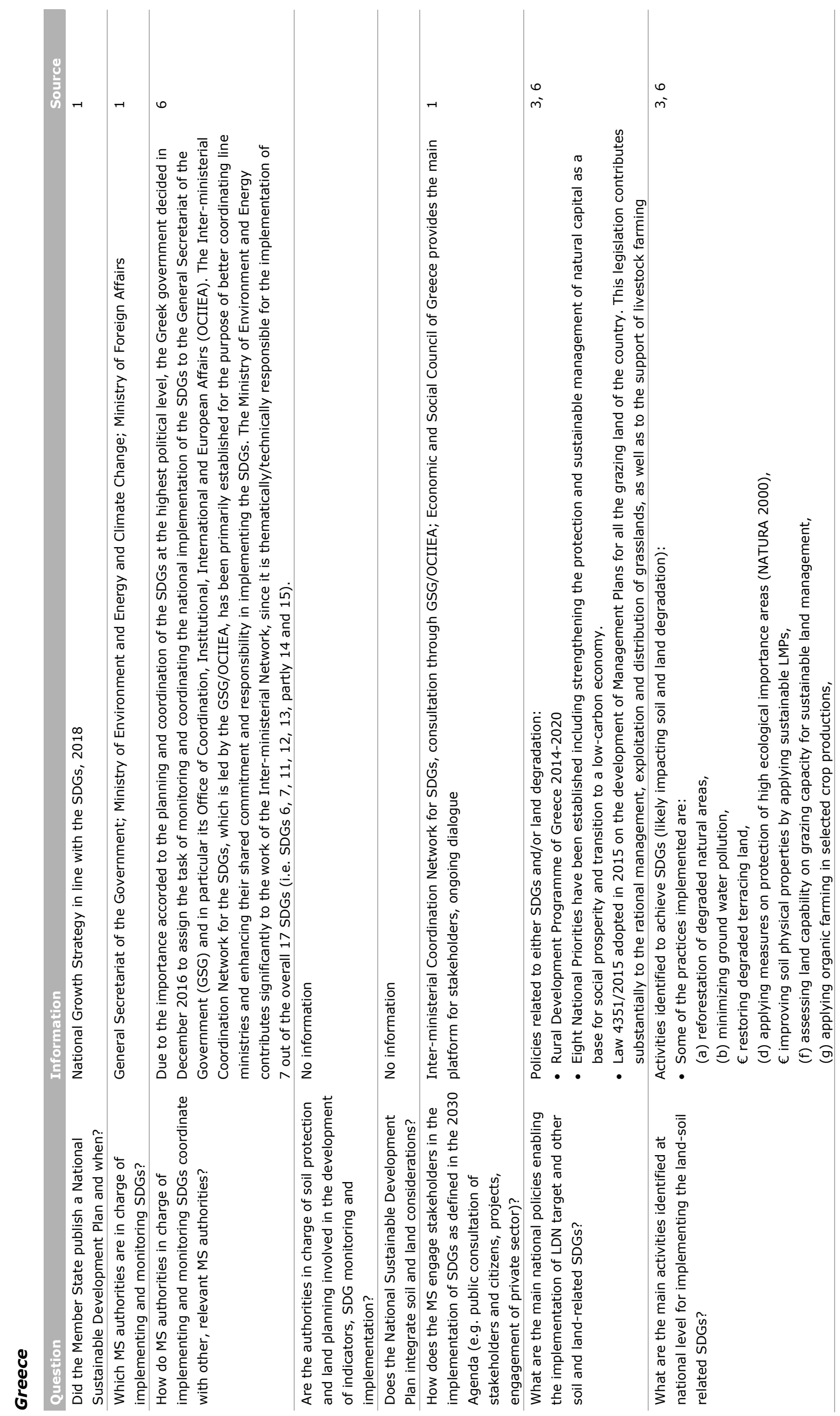




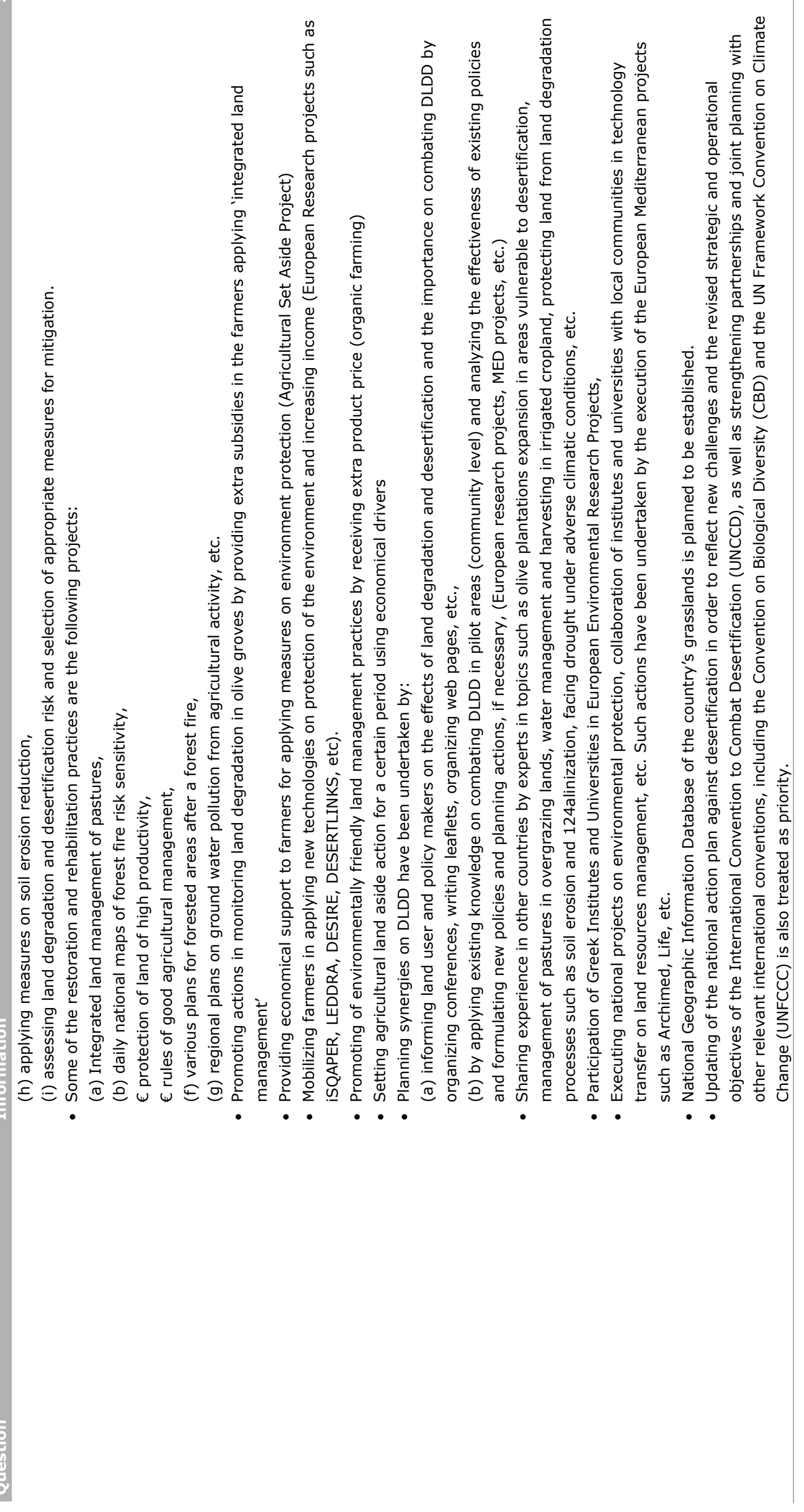



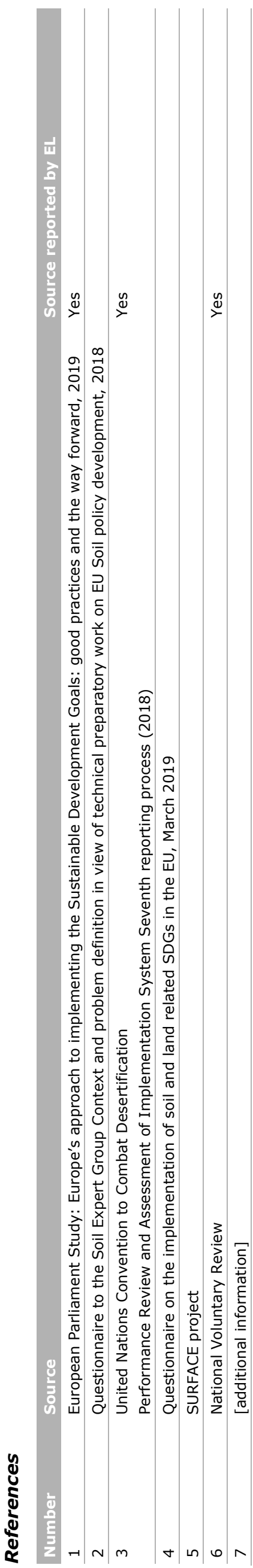


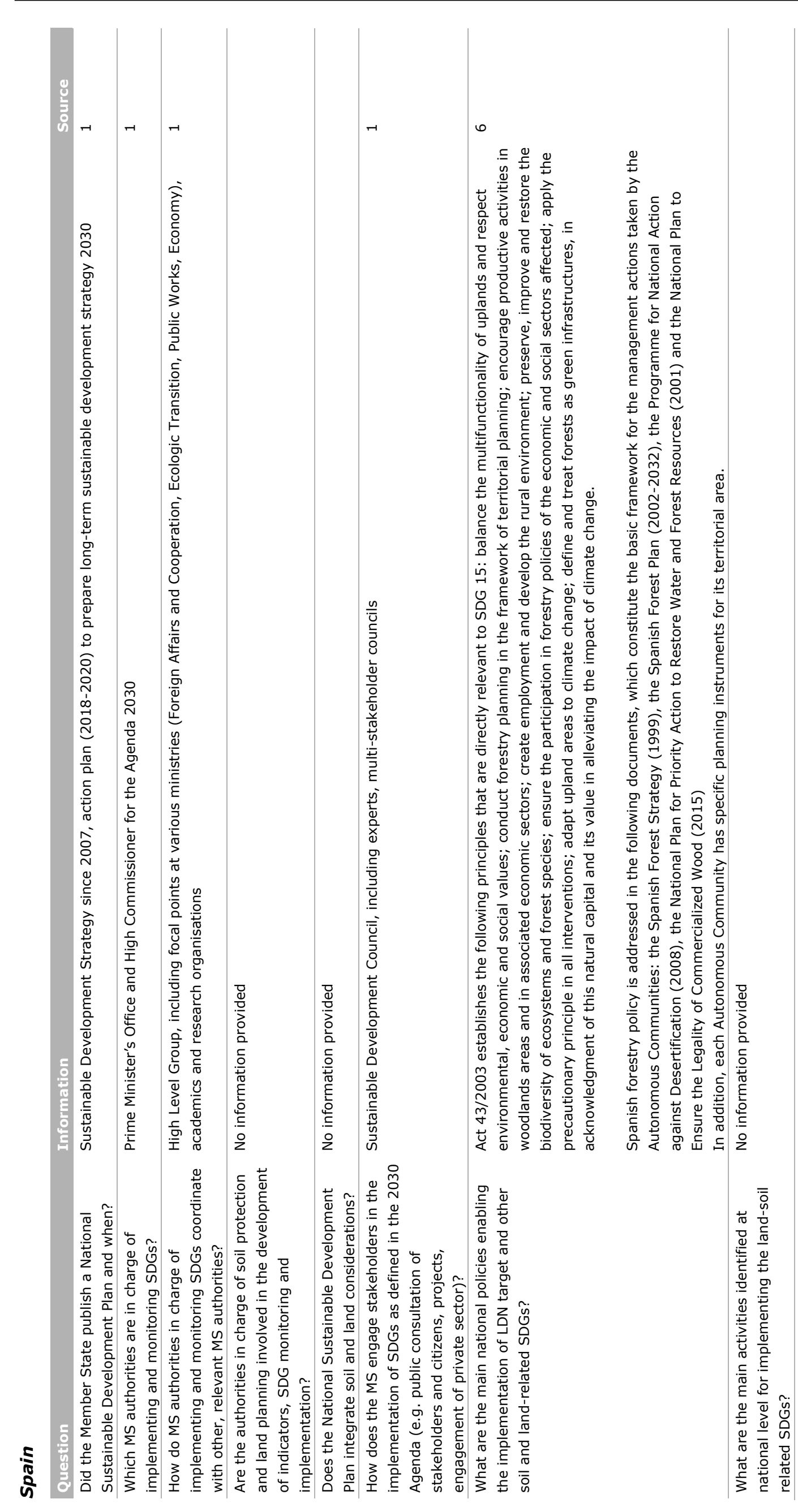




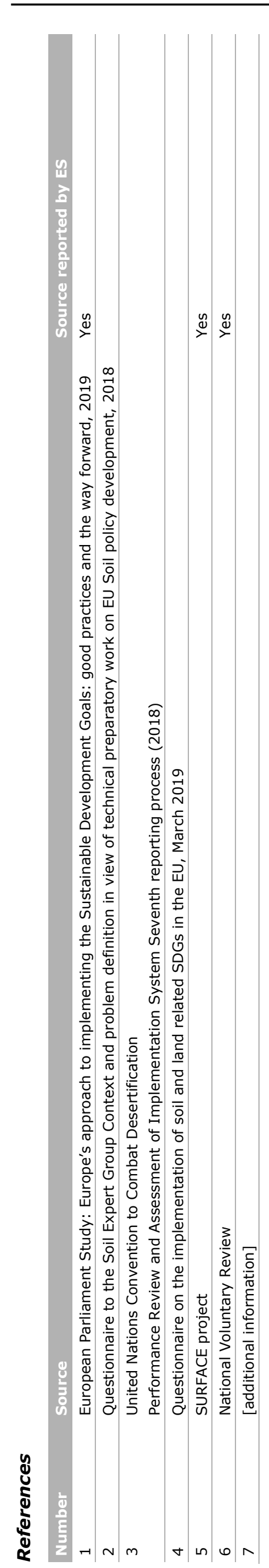

Wageningen Environmental Research report 3032| 127 


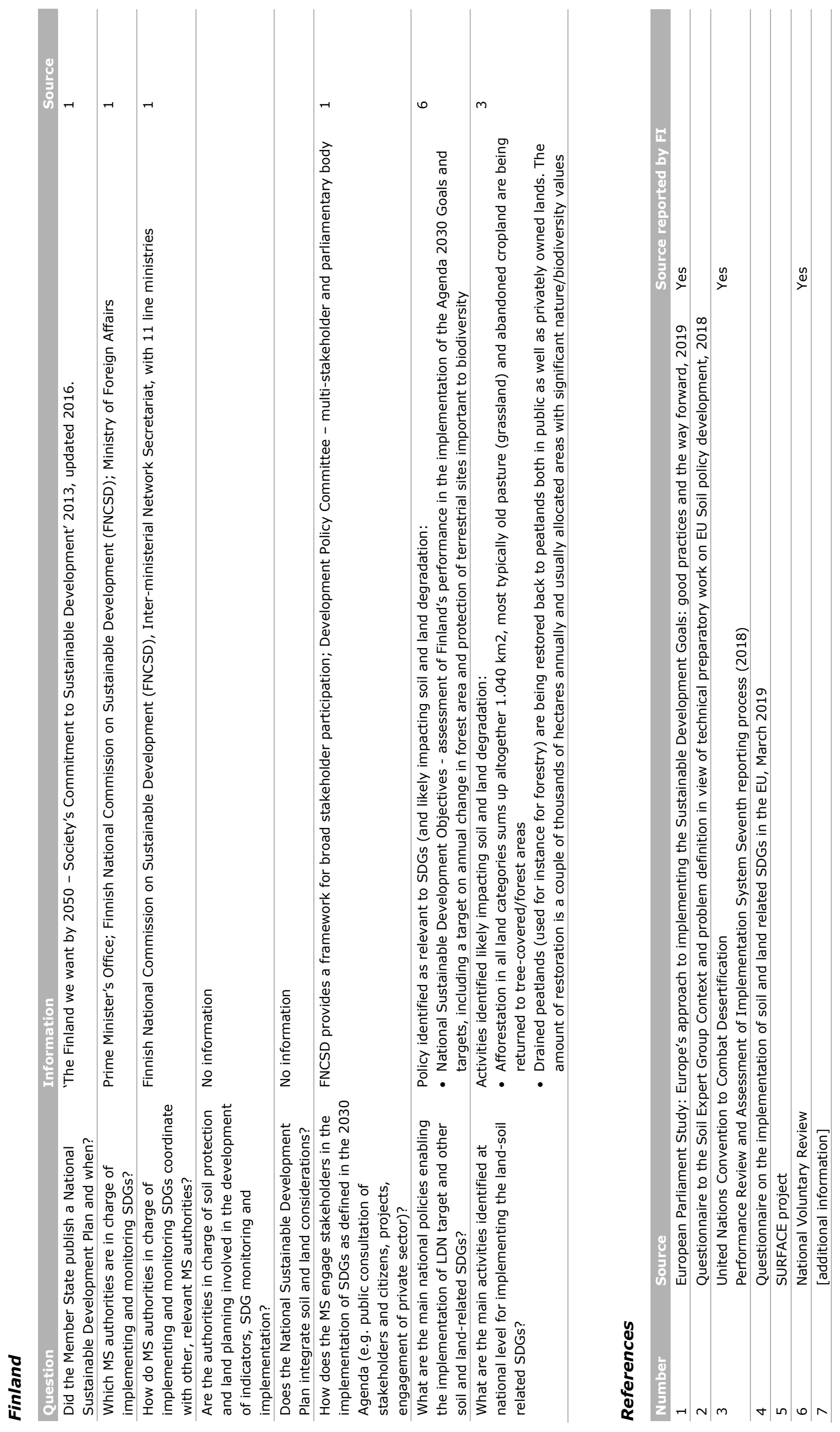




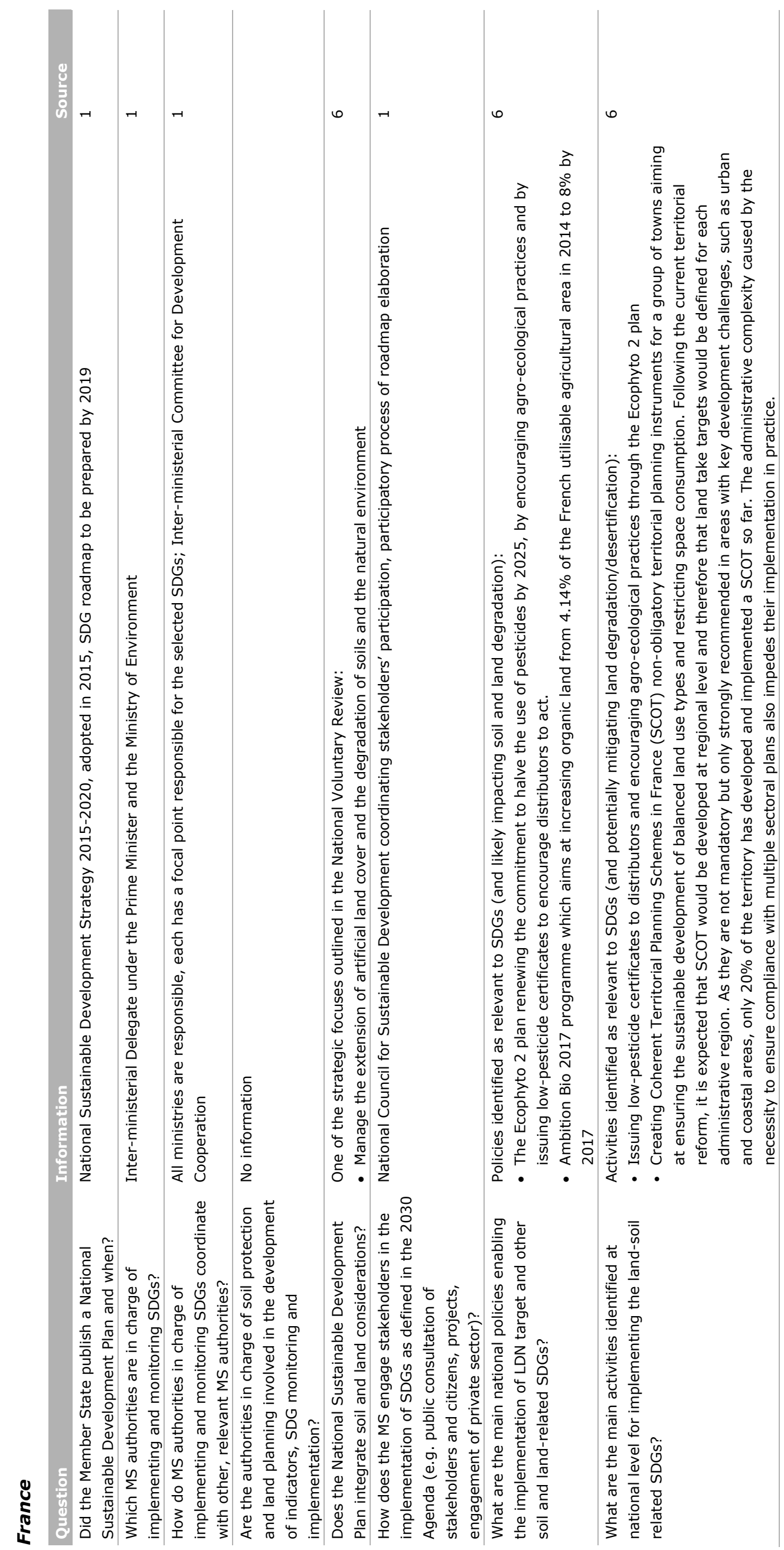



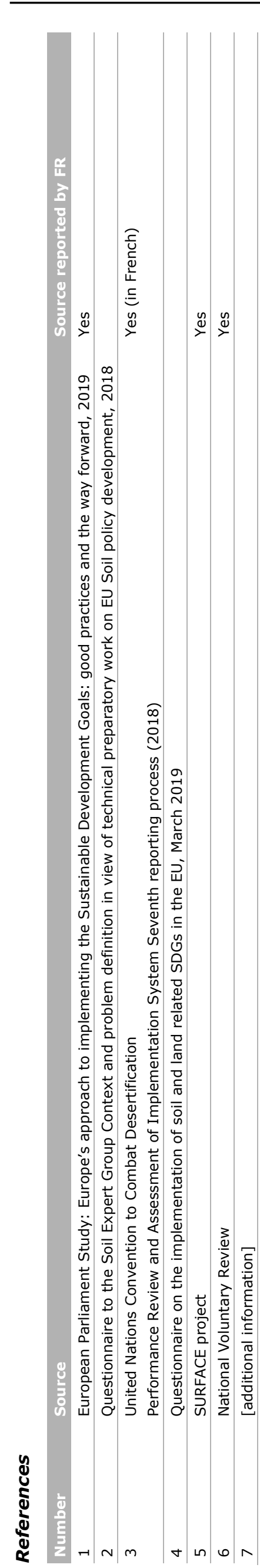


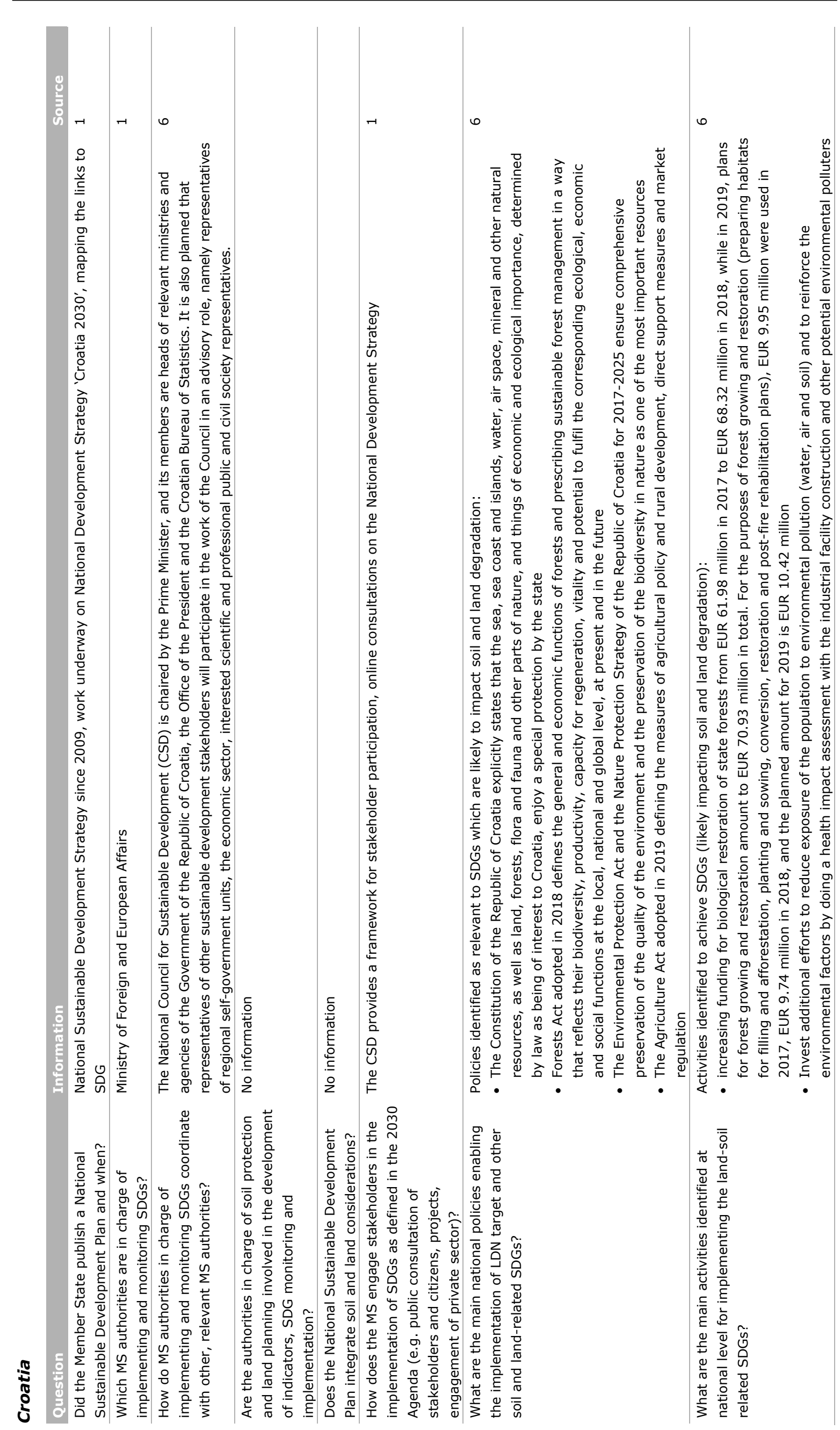




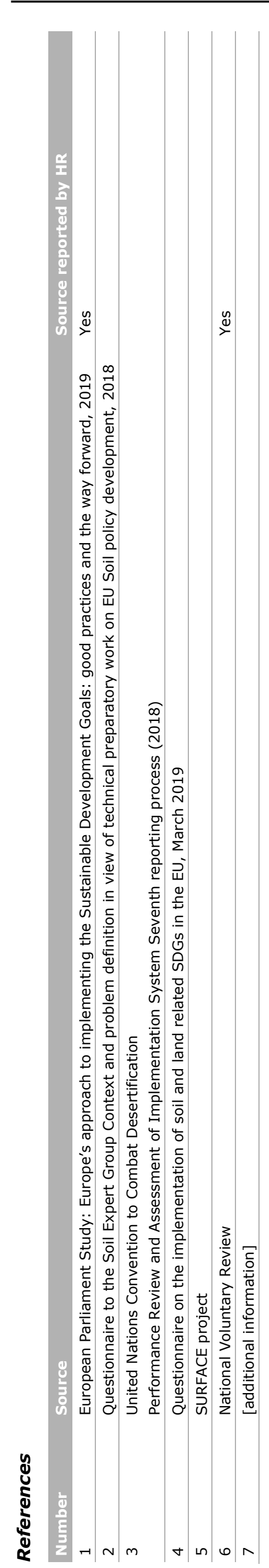




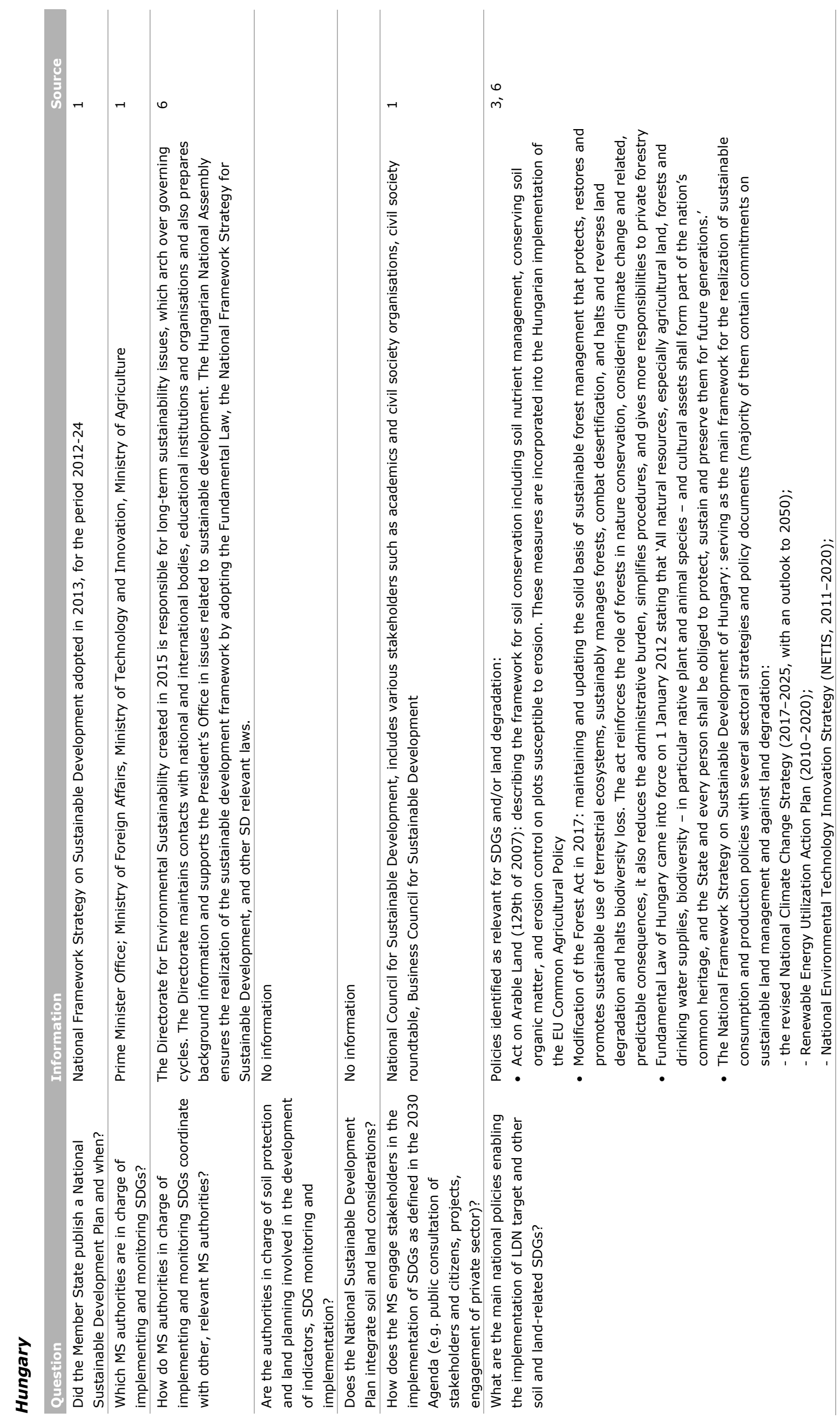




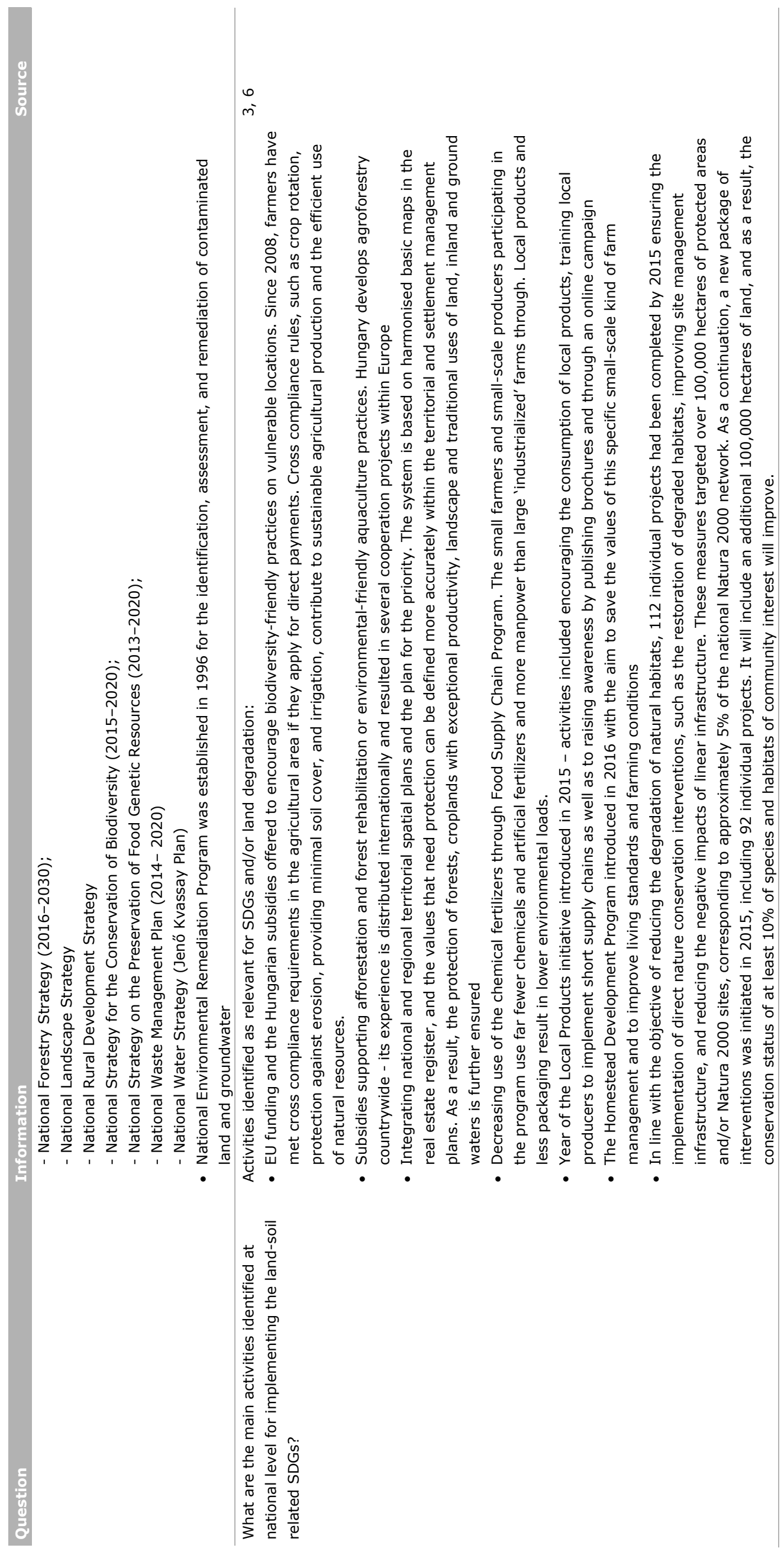




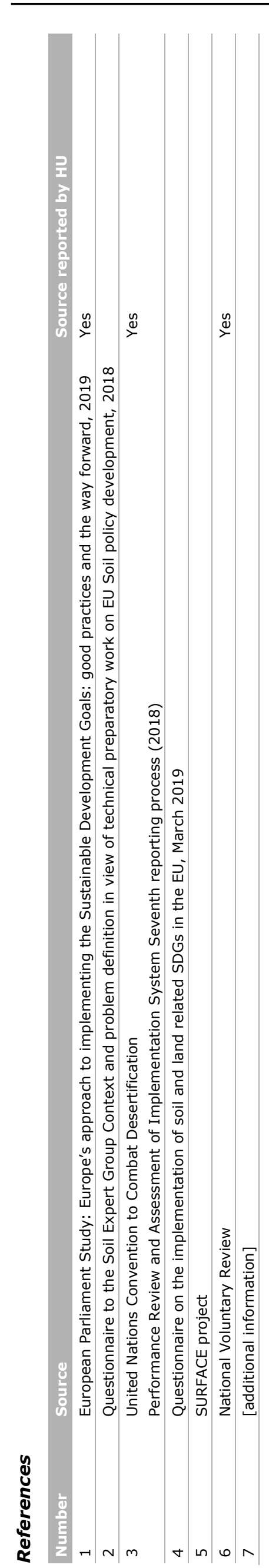

Wageningen Environmental Research report 3032| 135 


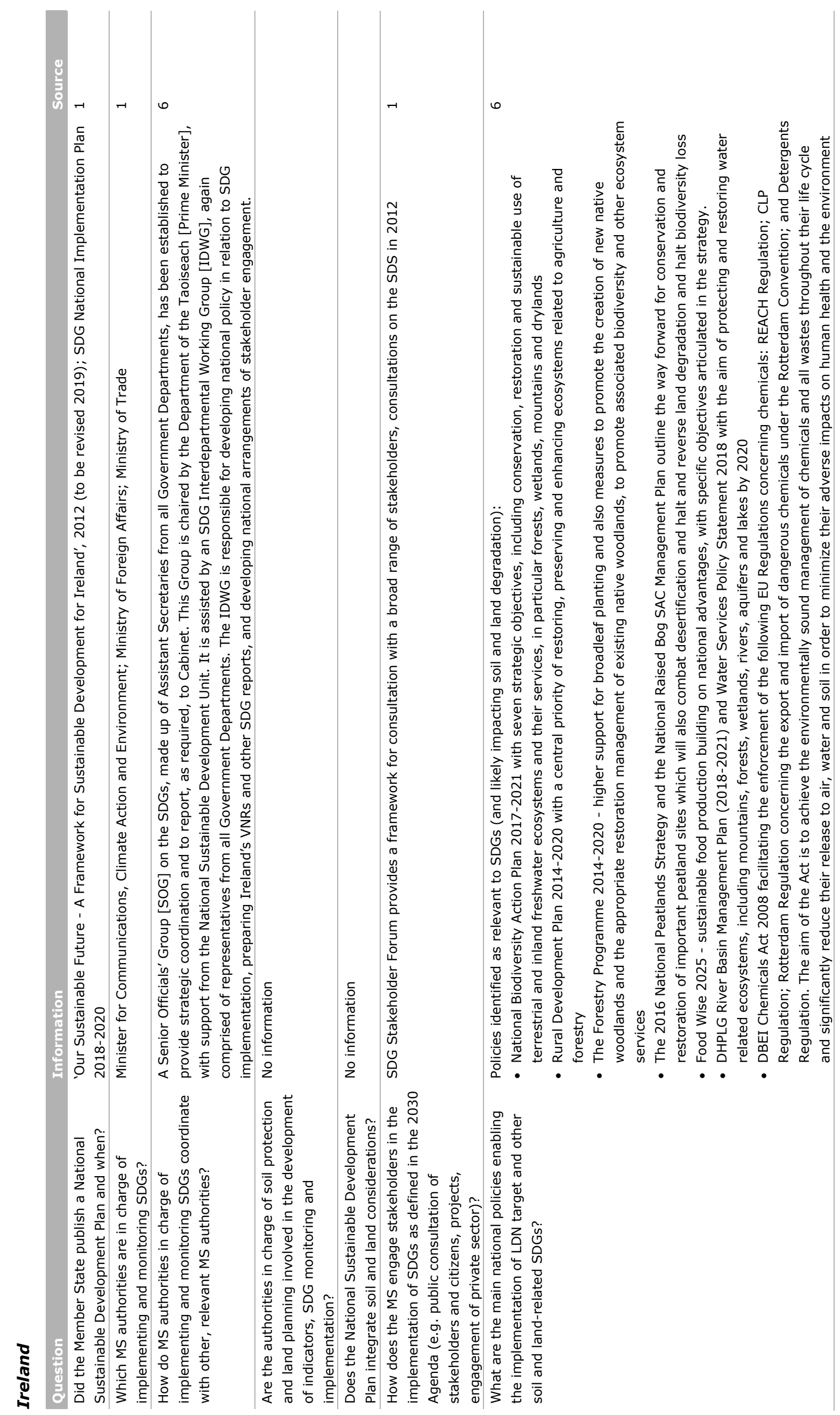




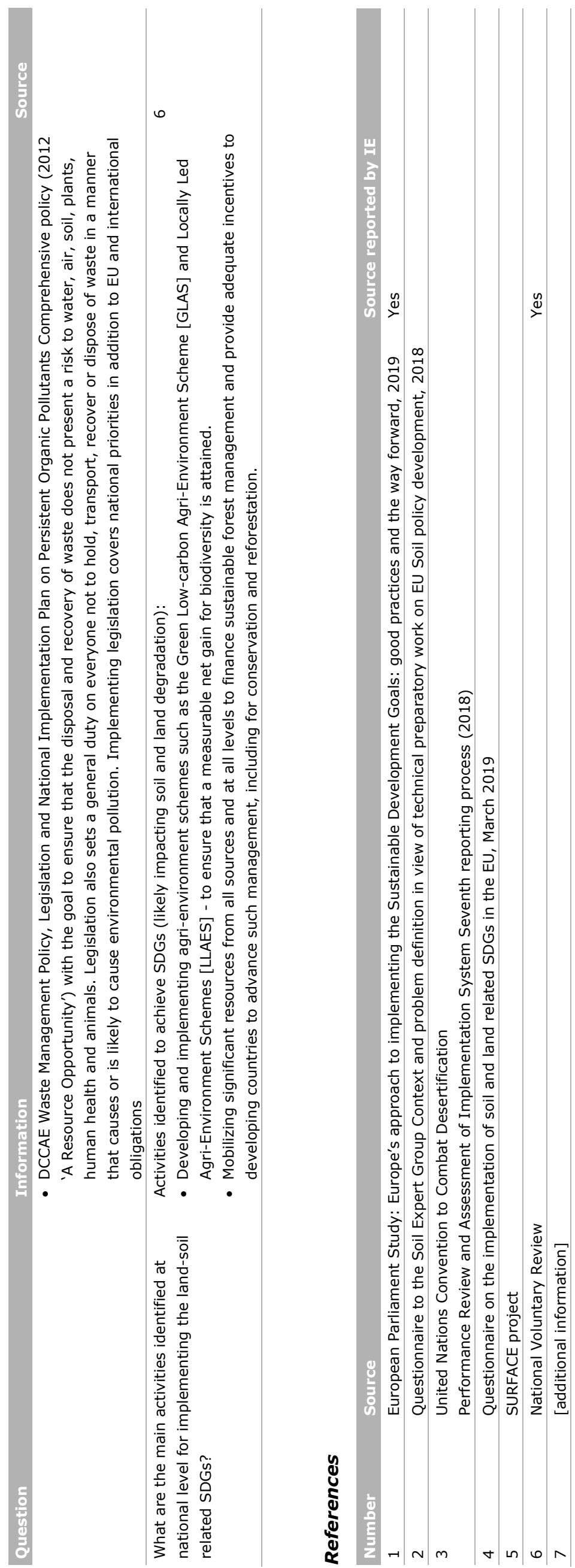




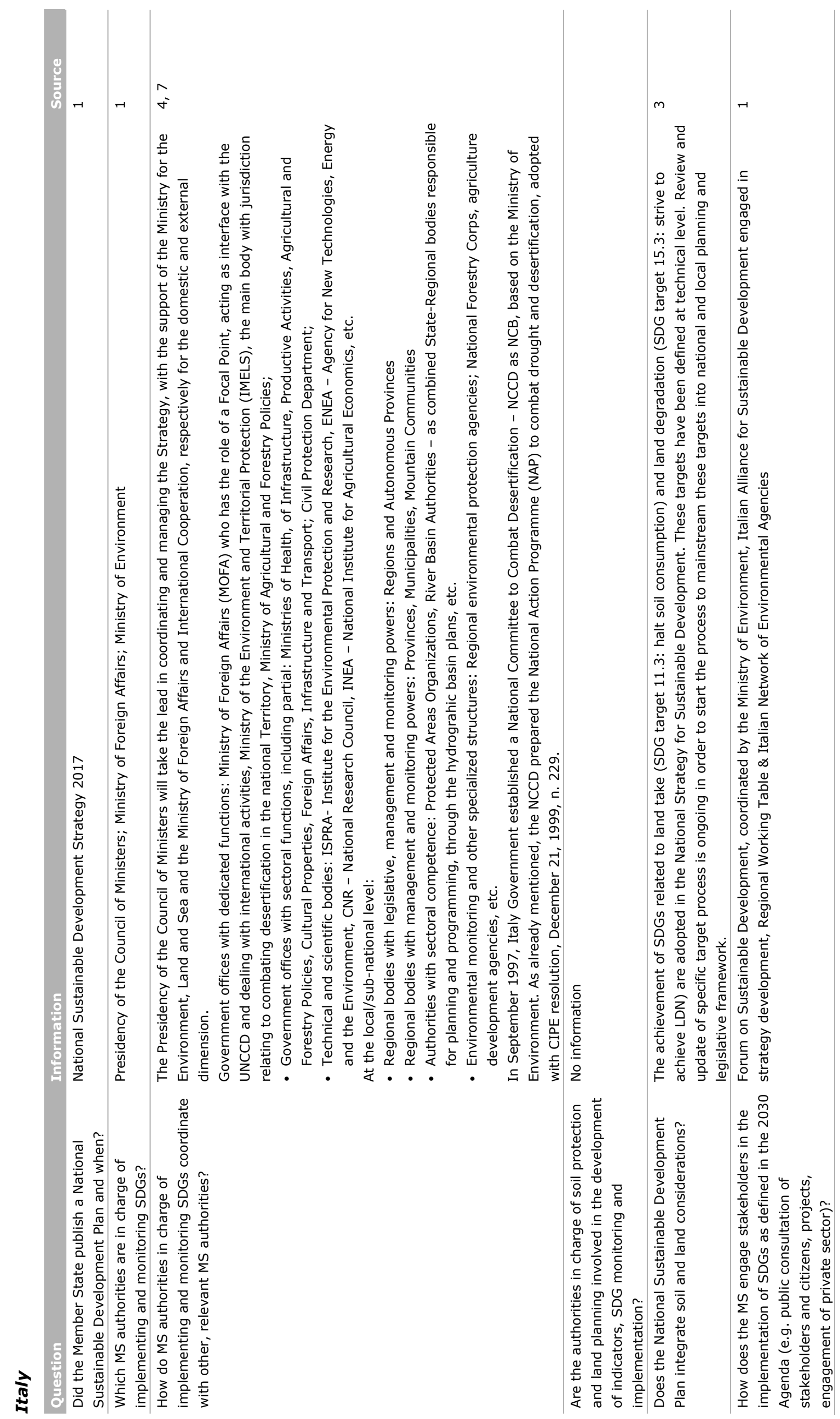




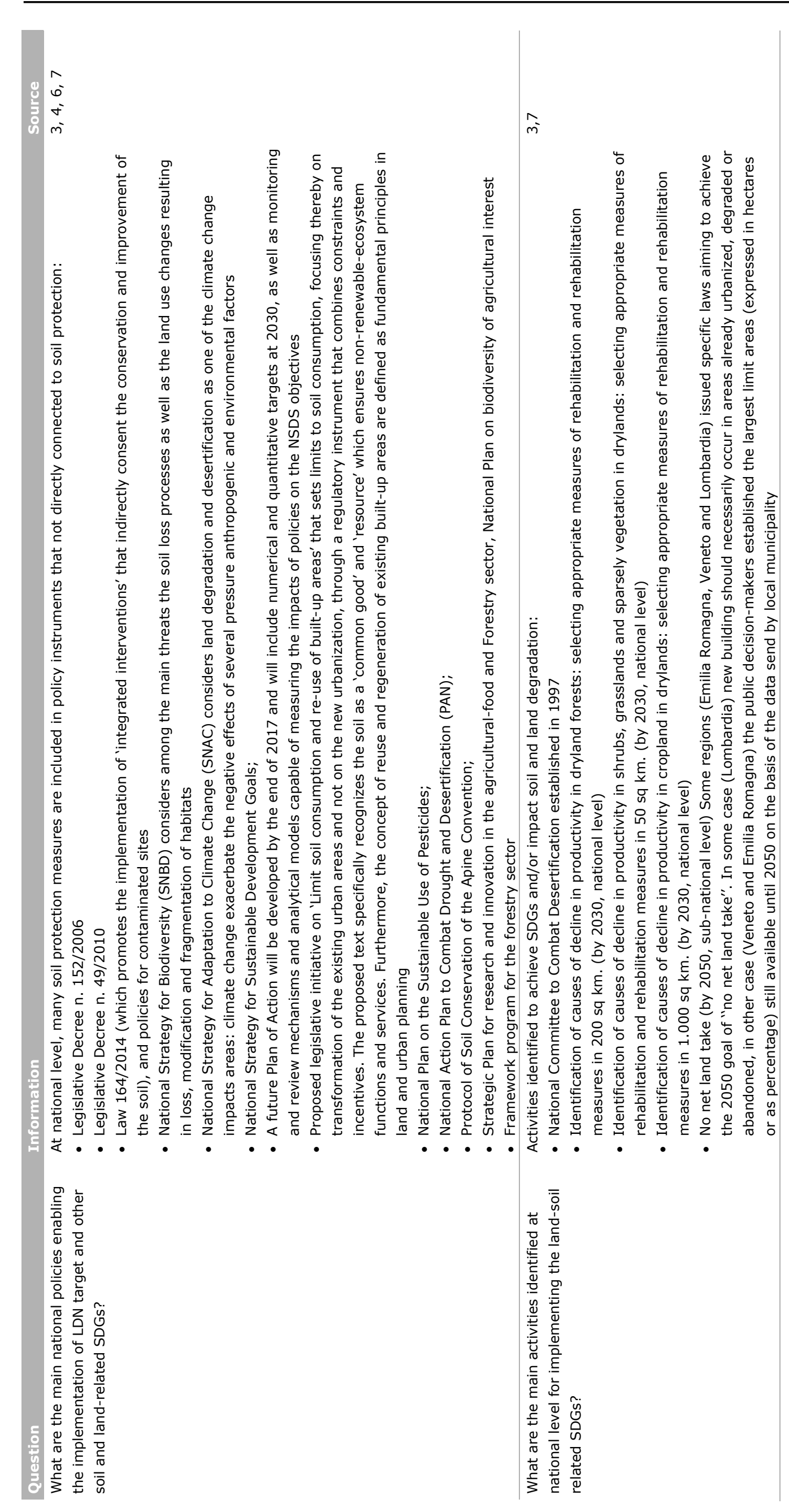




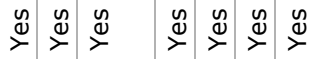

ํํำ

$\sum_{0}^{0}$

高要

亲

产

焉

둘

竞

일

范

薃

$\frac{10}{2}$

은

Фั

4.

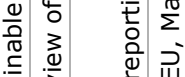

需

$\vec{n} \subseteq$

ง

空

空

递

焉章

离.

E⿺辶寸

जे प्ष

늠 은 닌

ह

인

喜

늠

(1)

先

䇋壳

芒炁

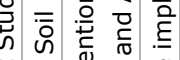

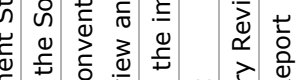

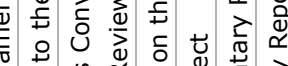

竞竞

ᄃ

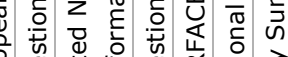

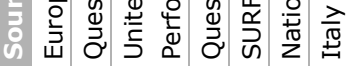

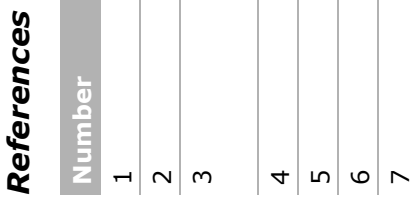




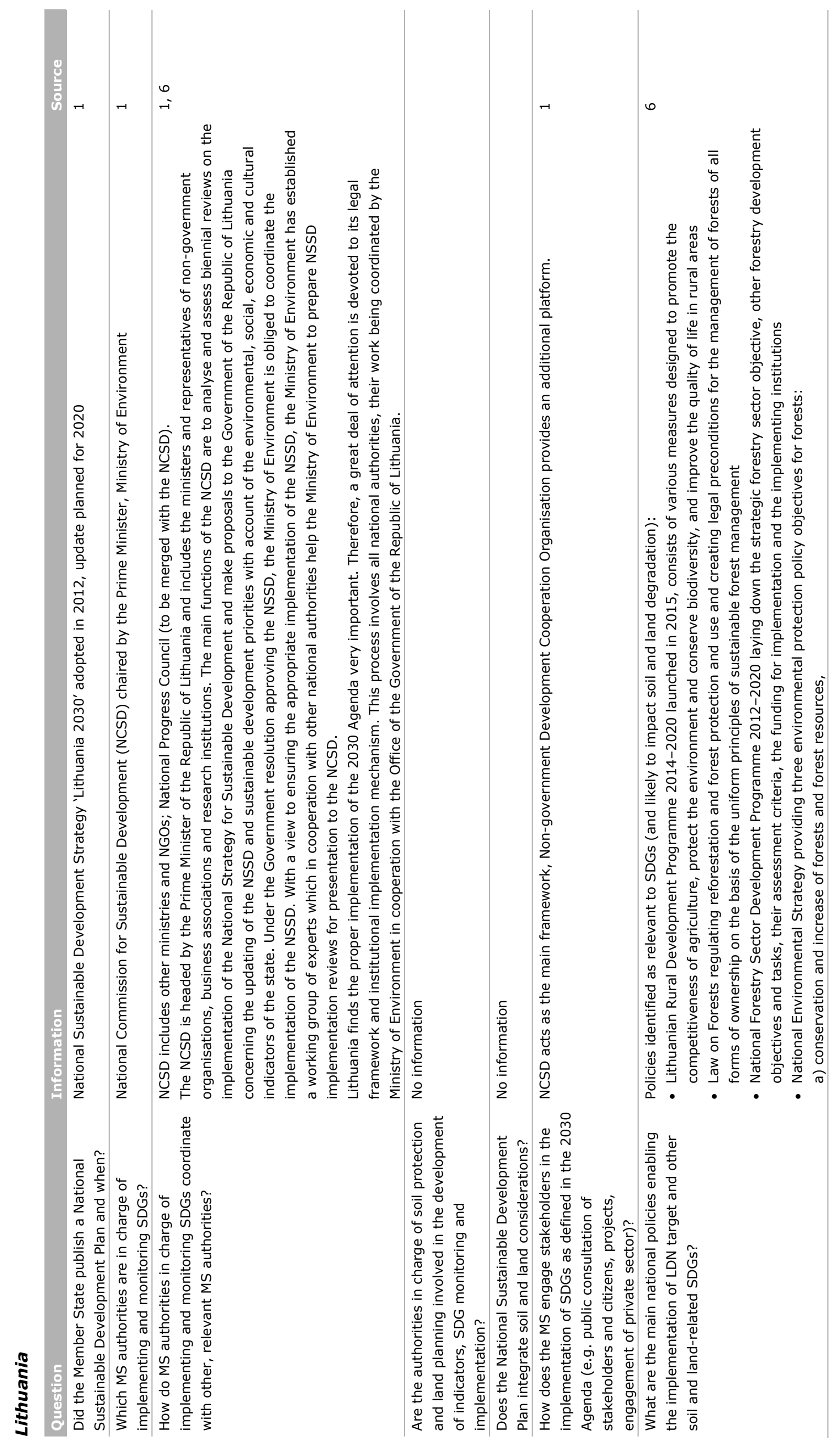




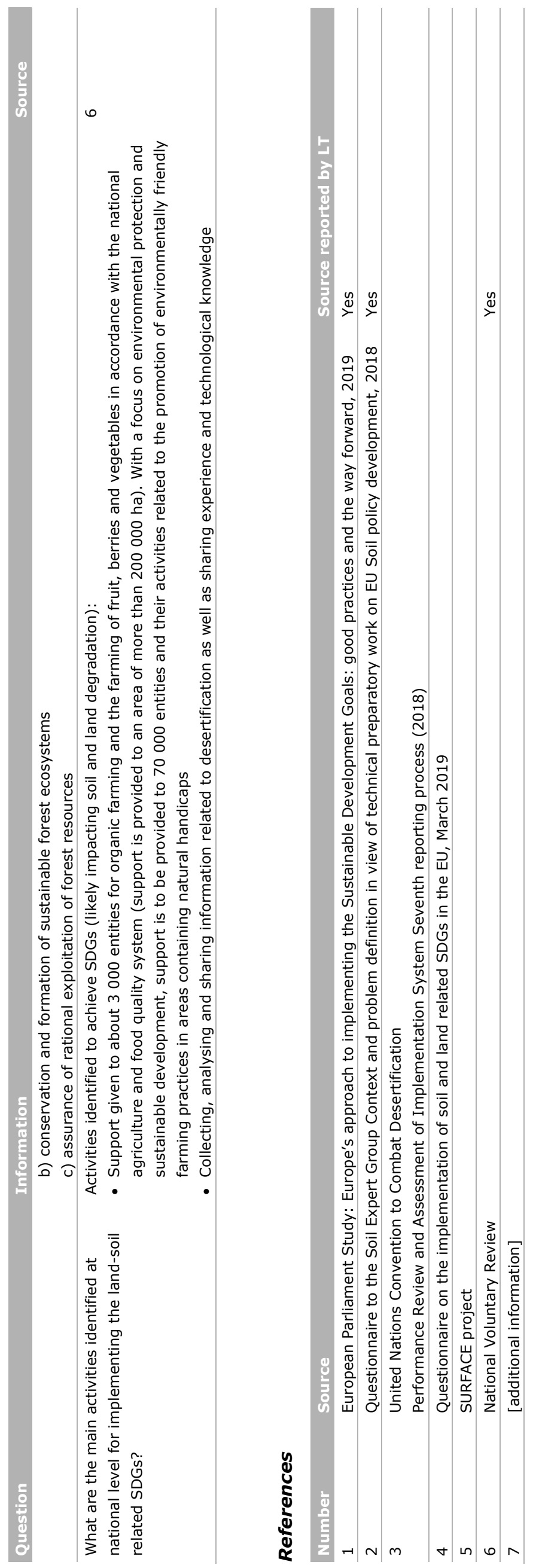




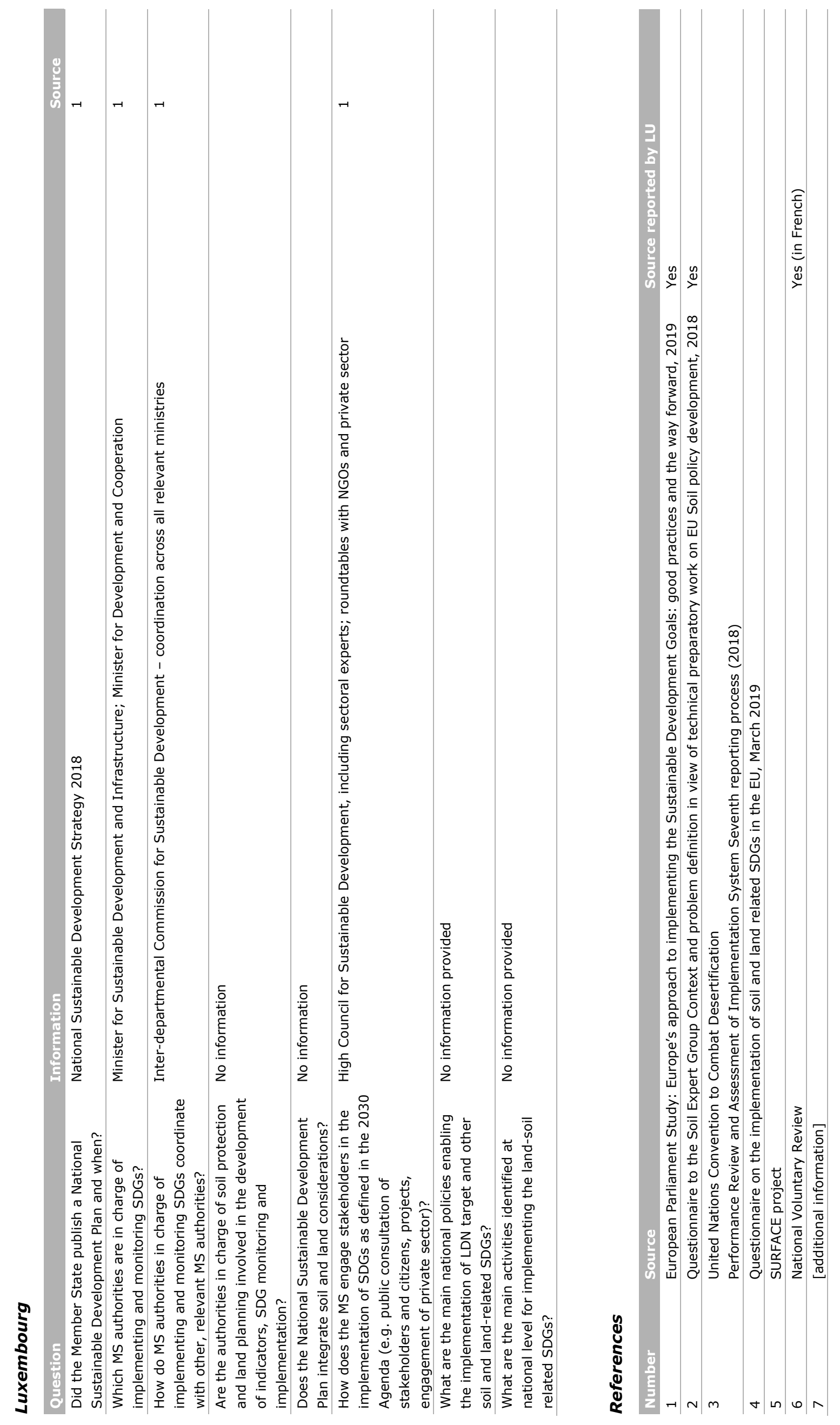




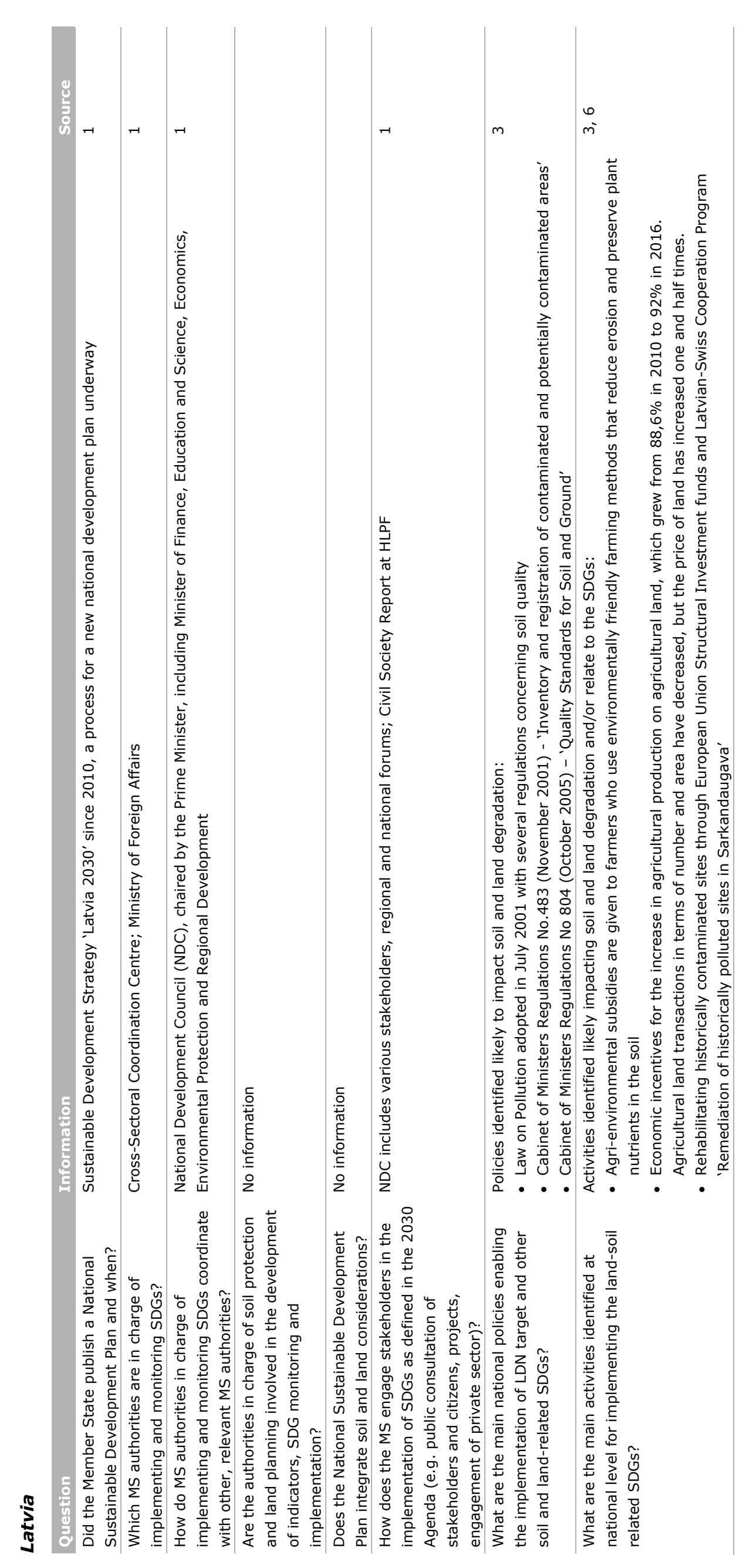




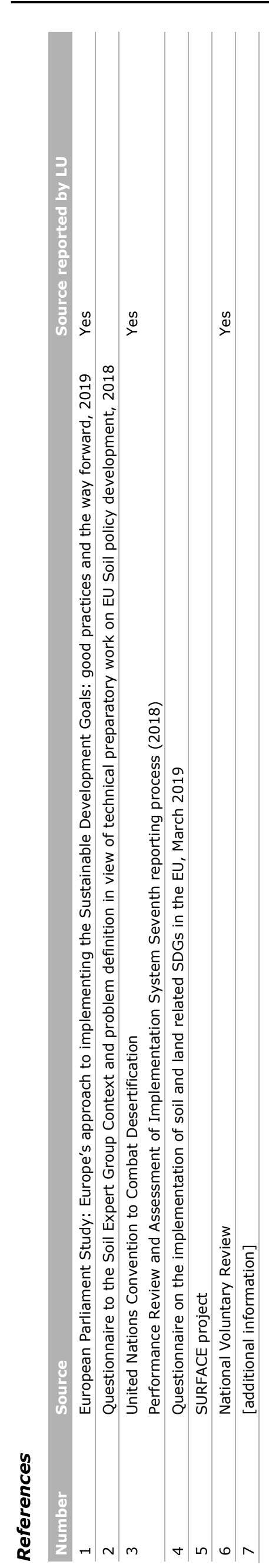

Wageningen Environmental Research report 3032| 145 


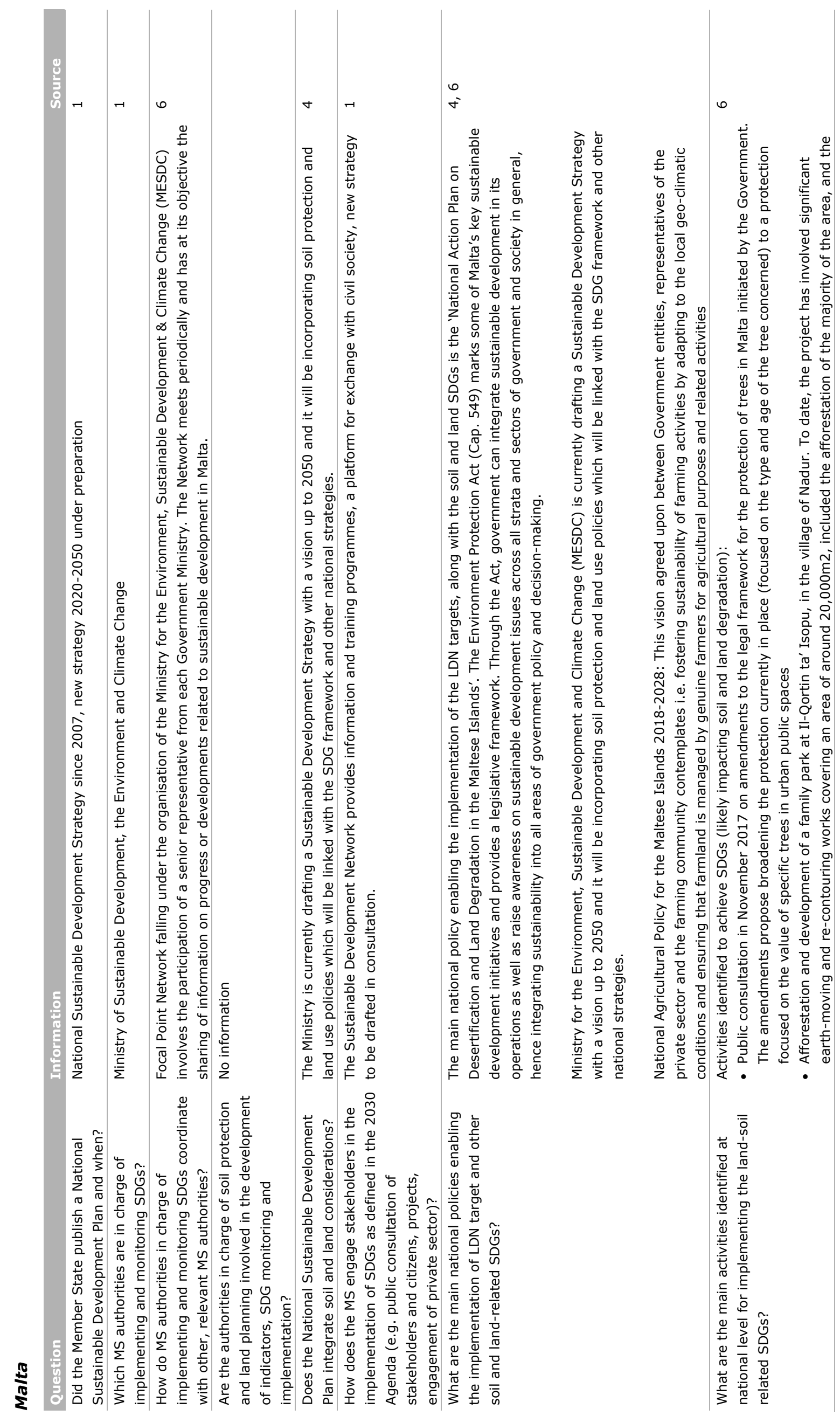




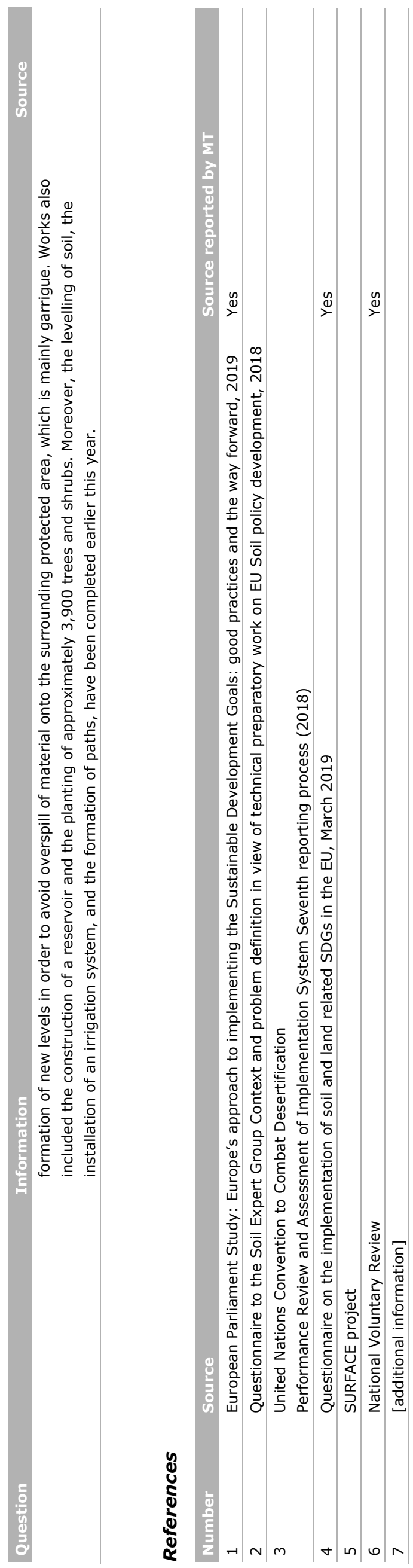




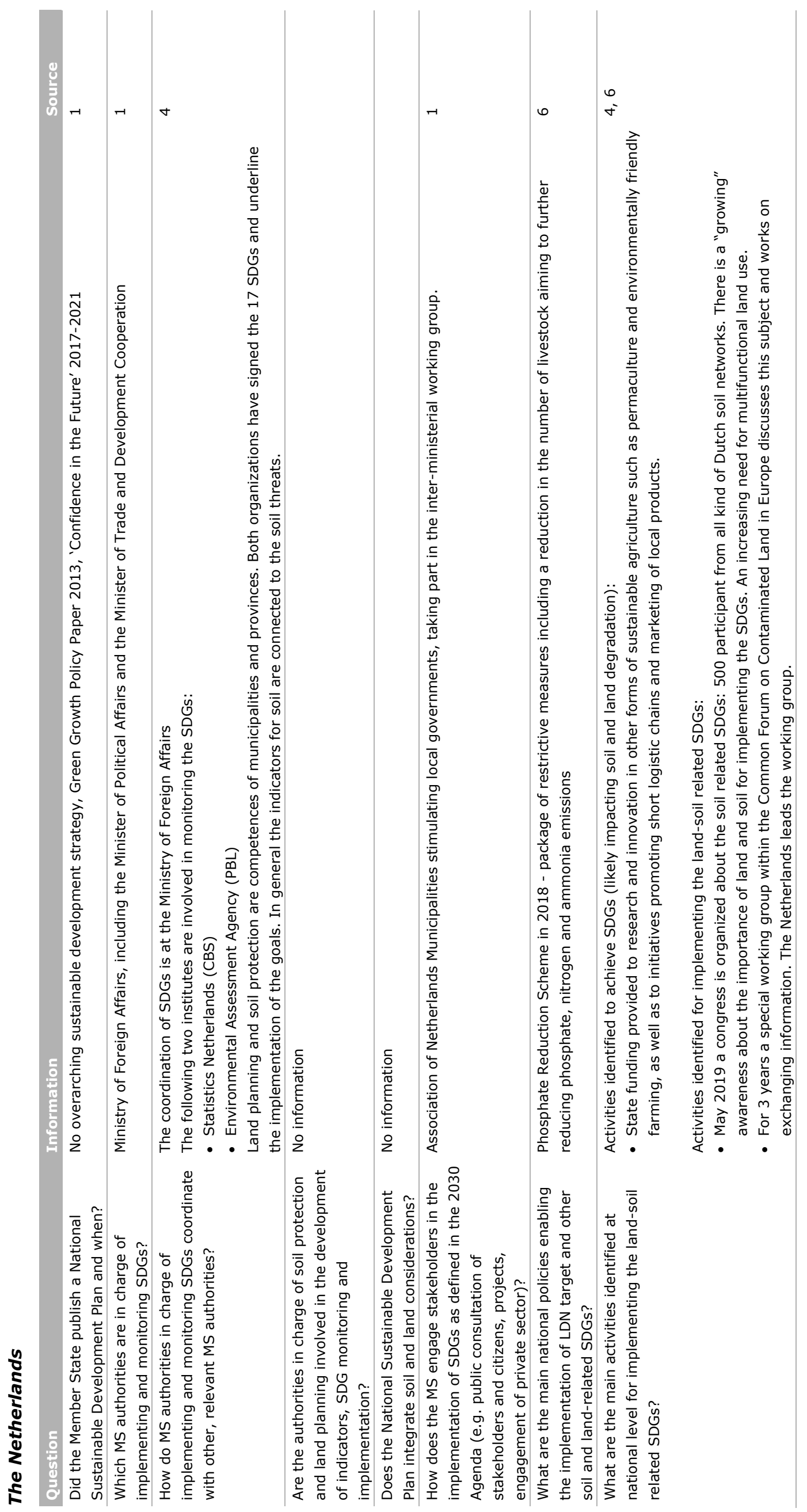




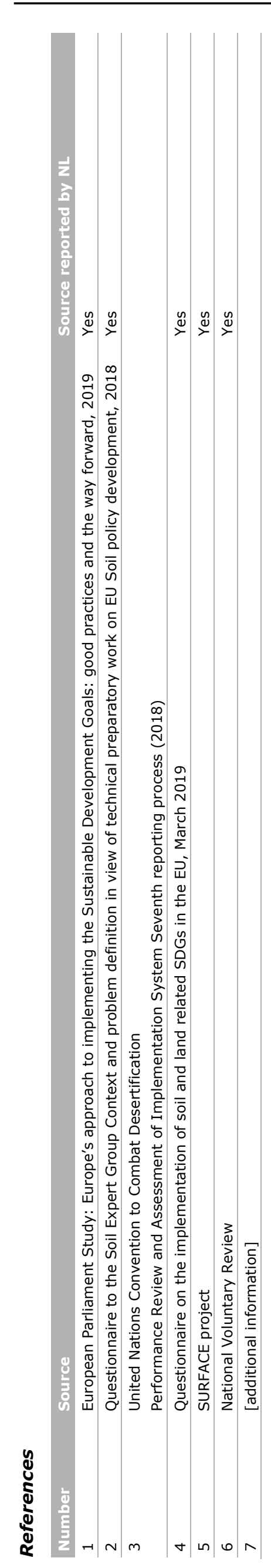




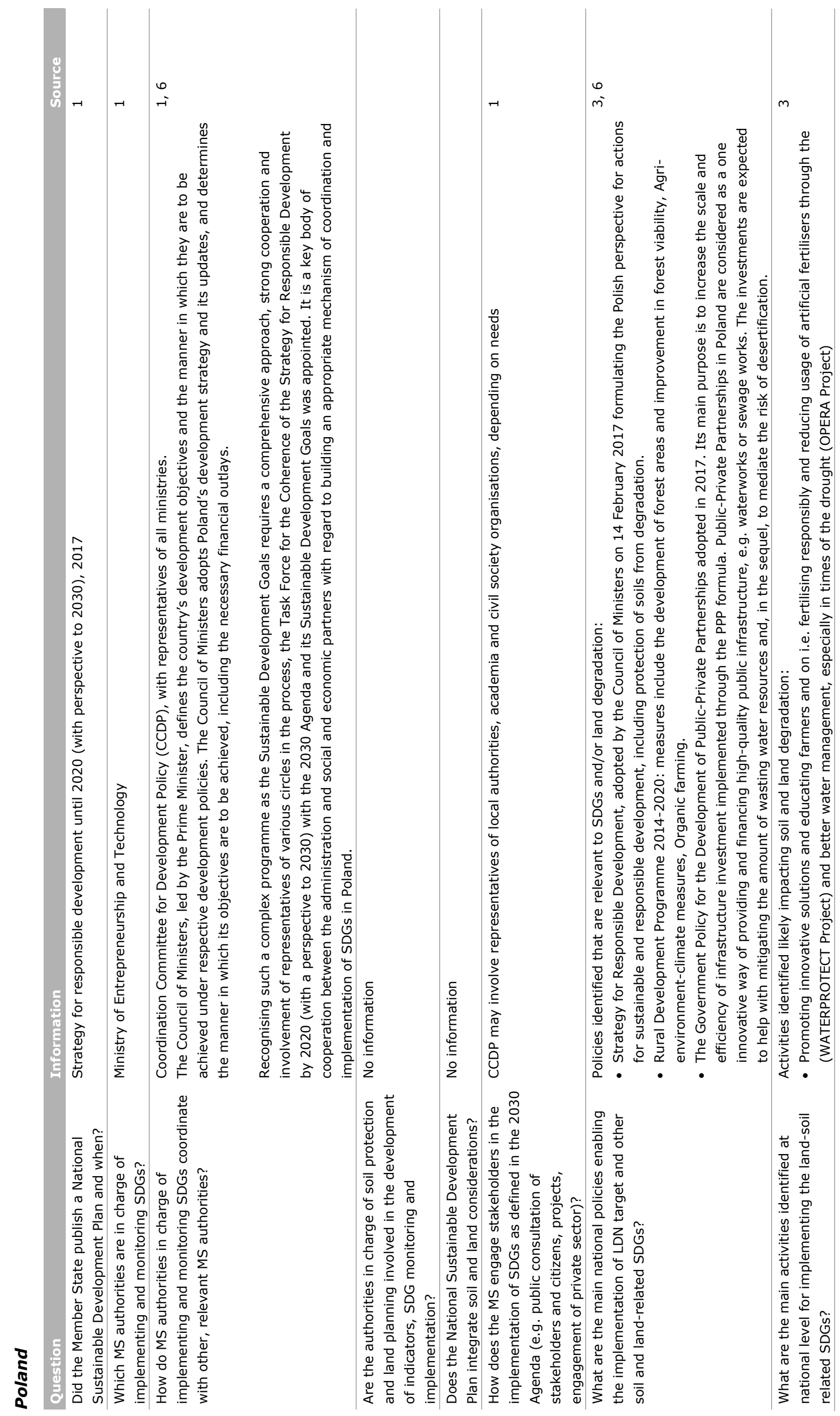




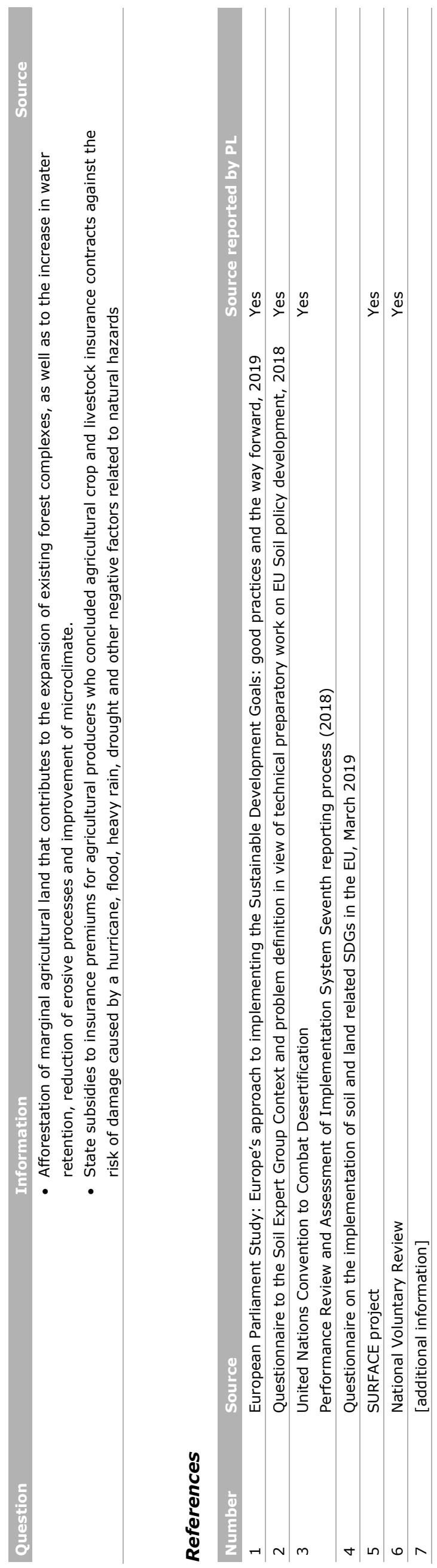

\begin{tabular}{l|l} 
Wageningen Environmental Research report 3032 & 151
\end{tabular} 


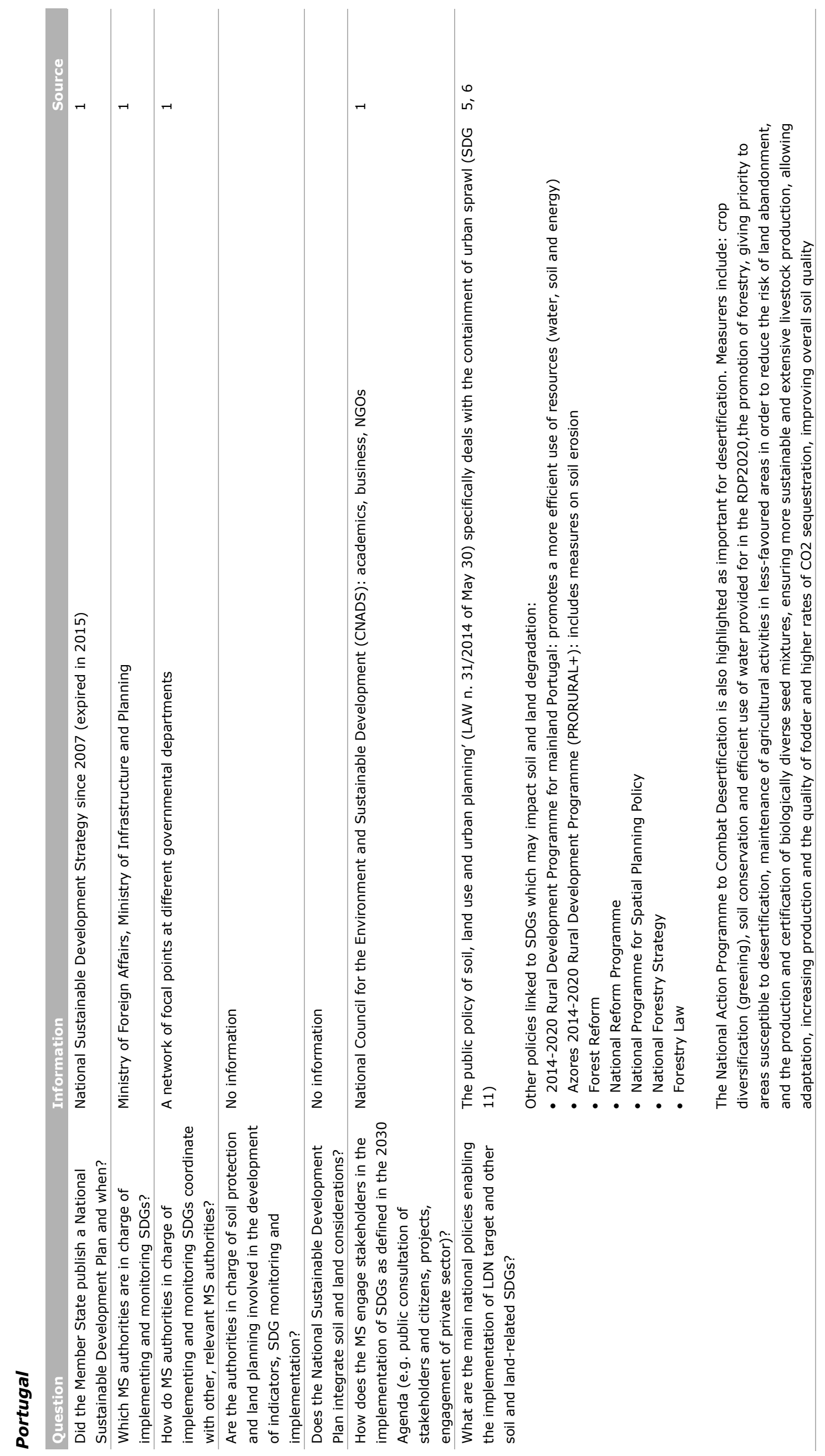




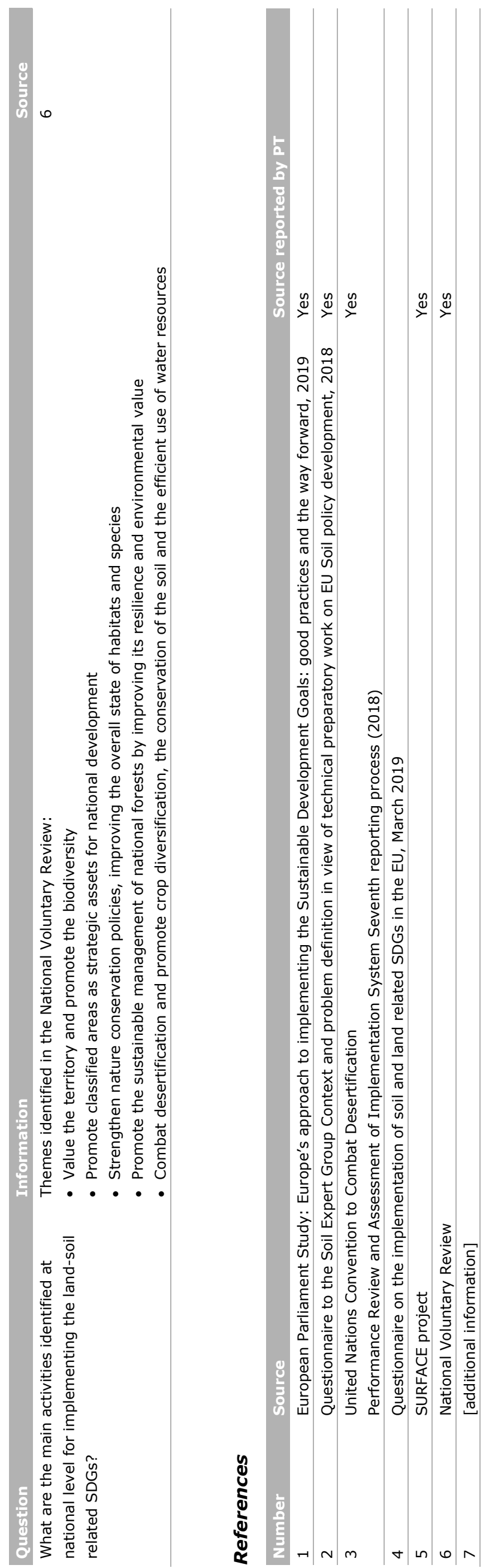

Wageningen Environmental Research report 3032| 153 


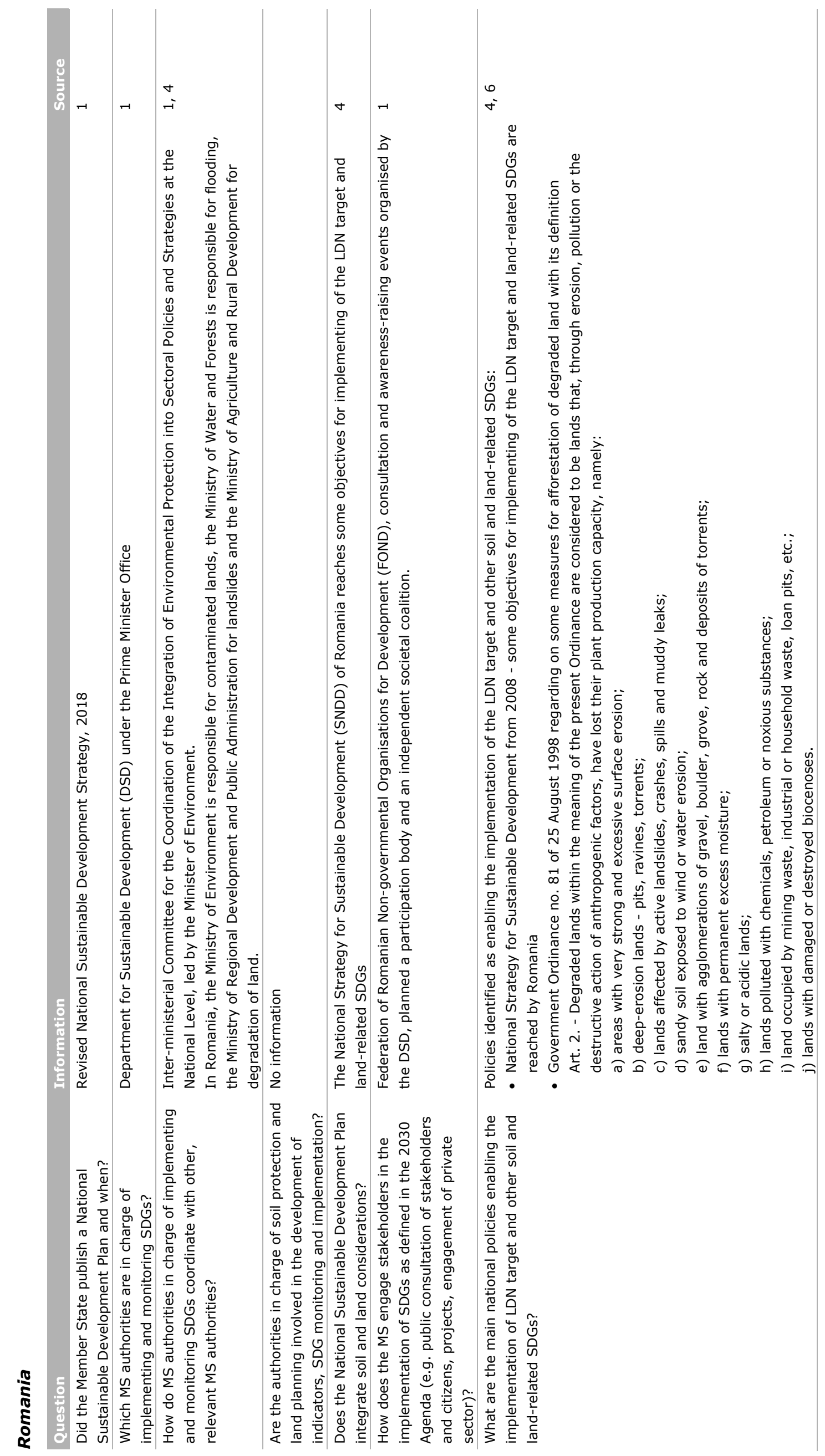




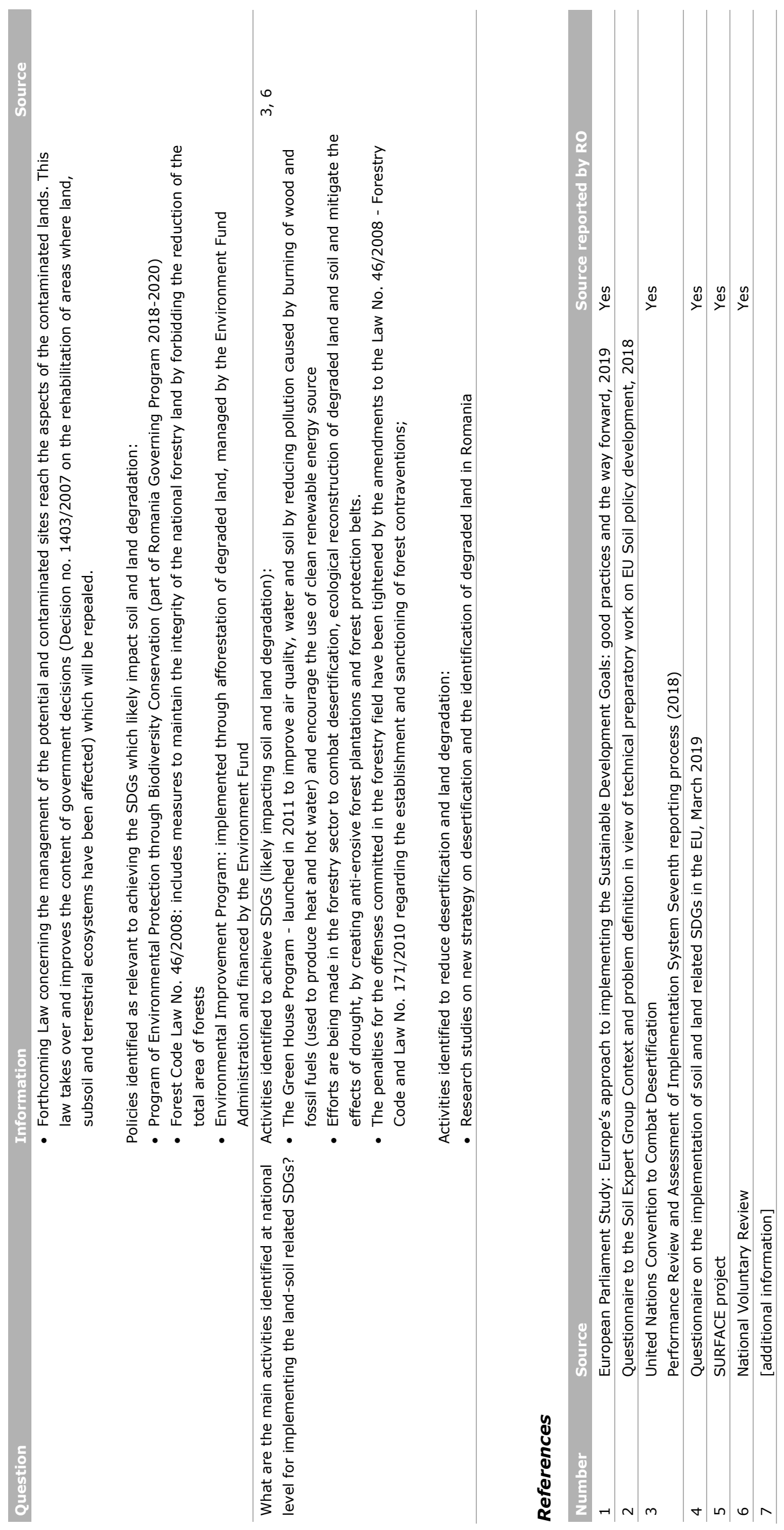




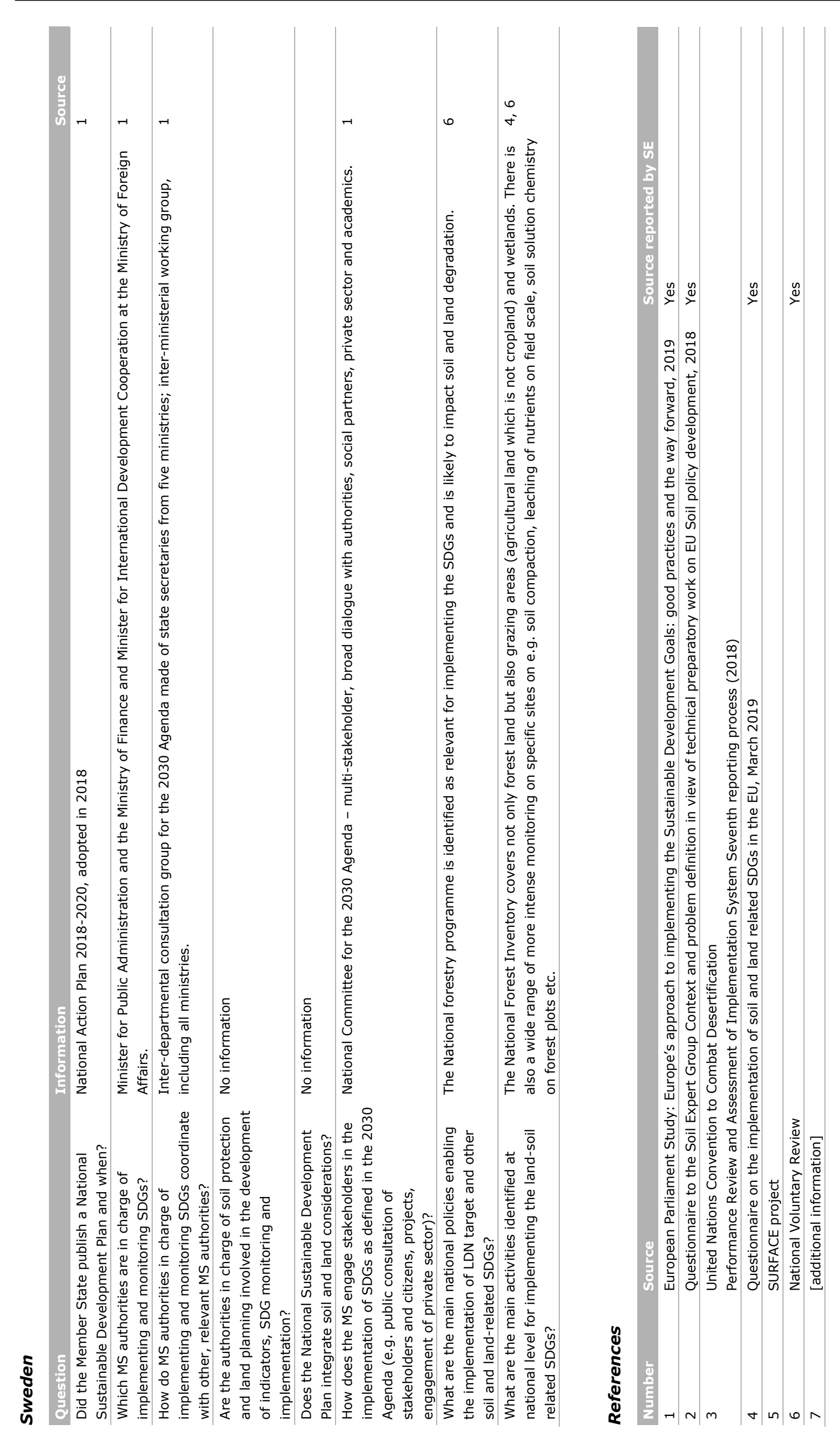




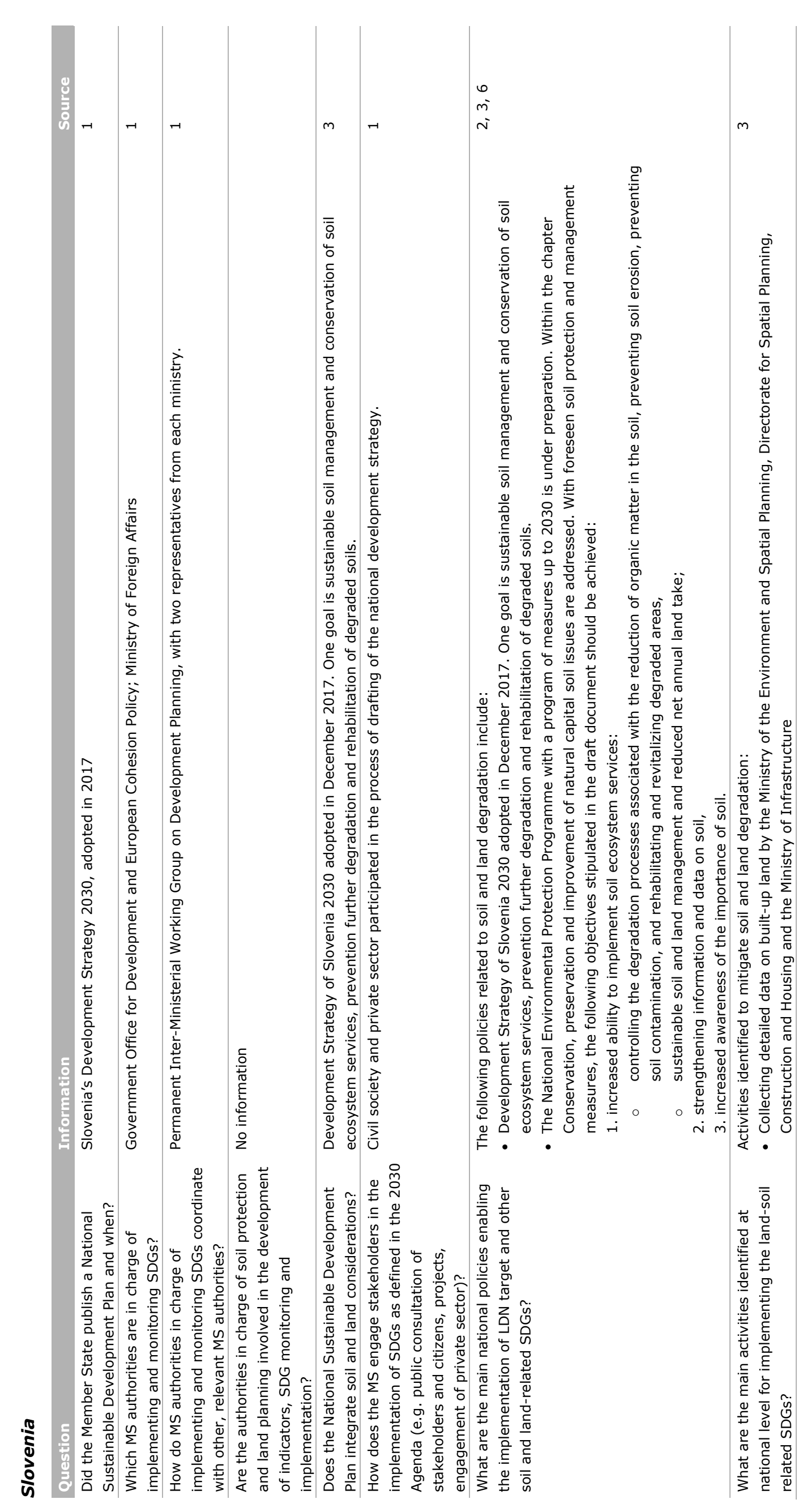



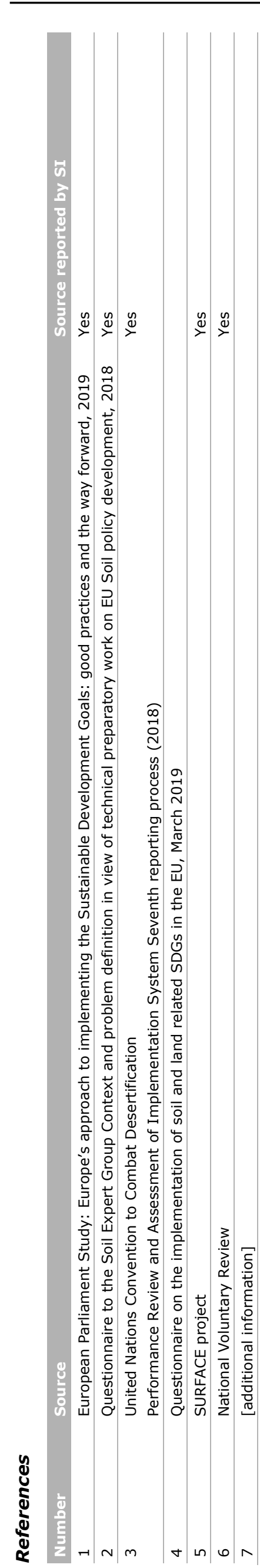


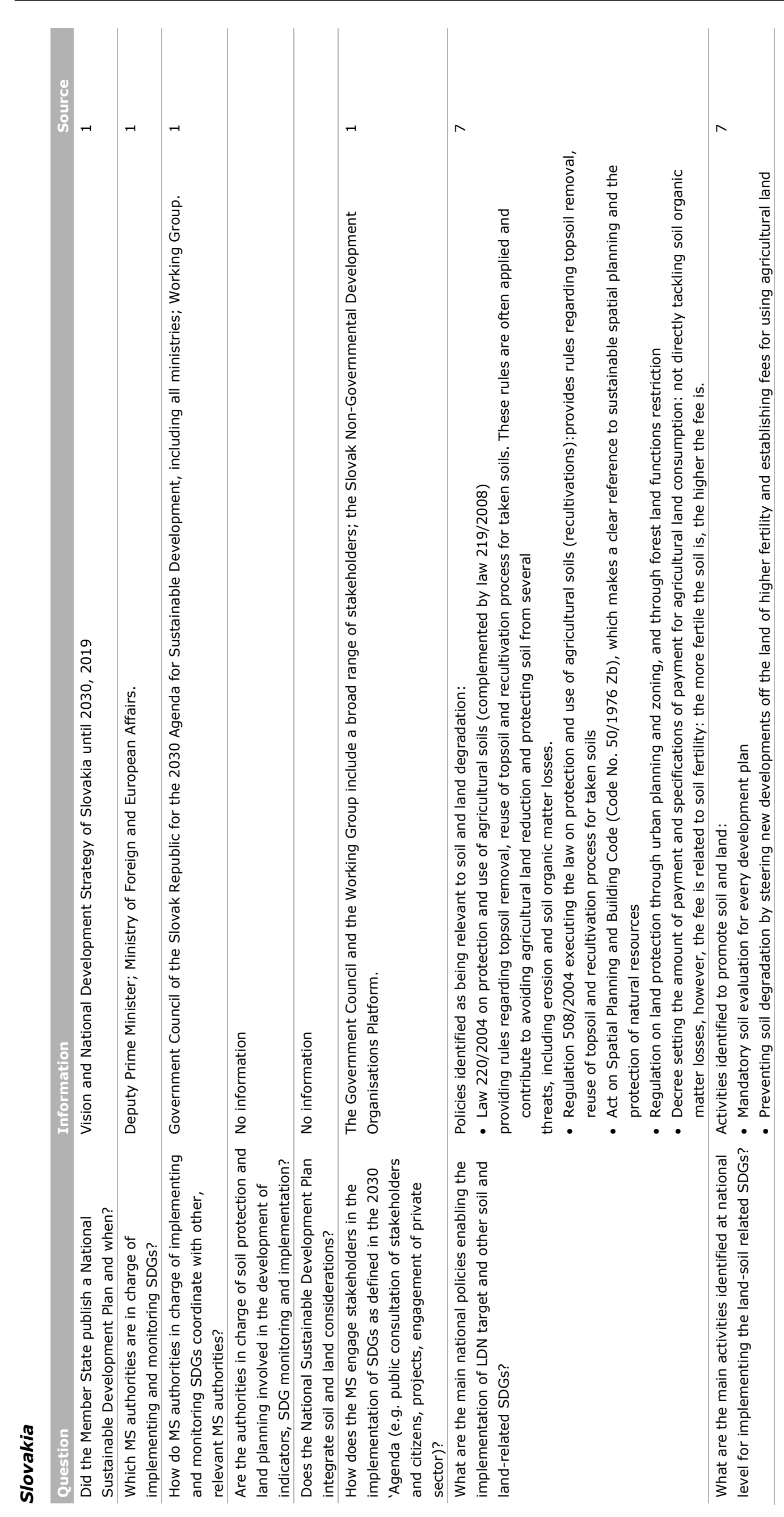



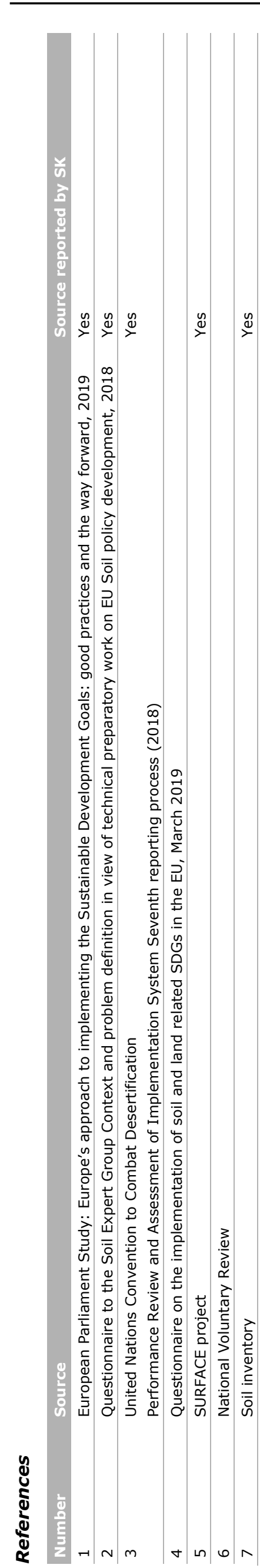


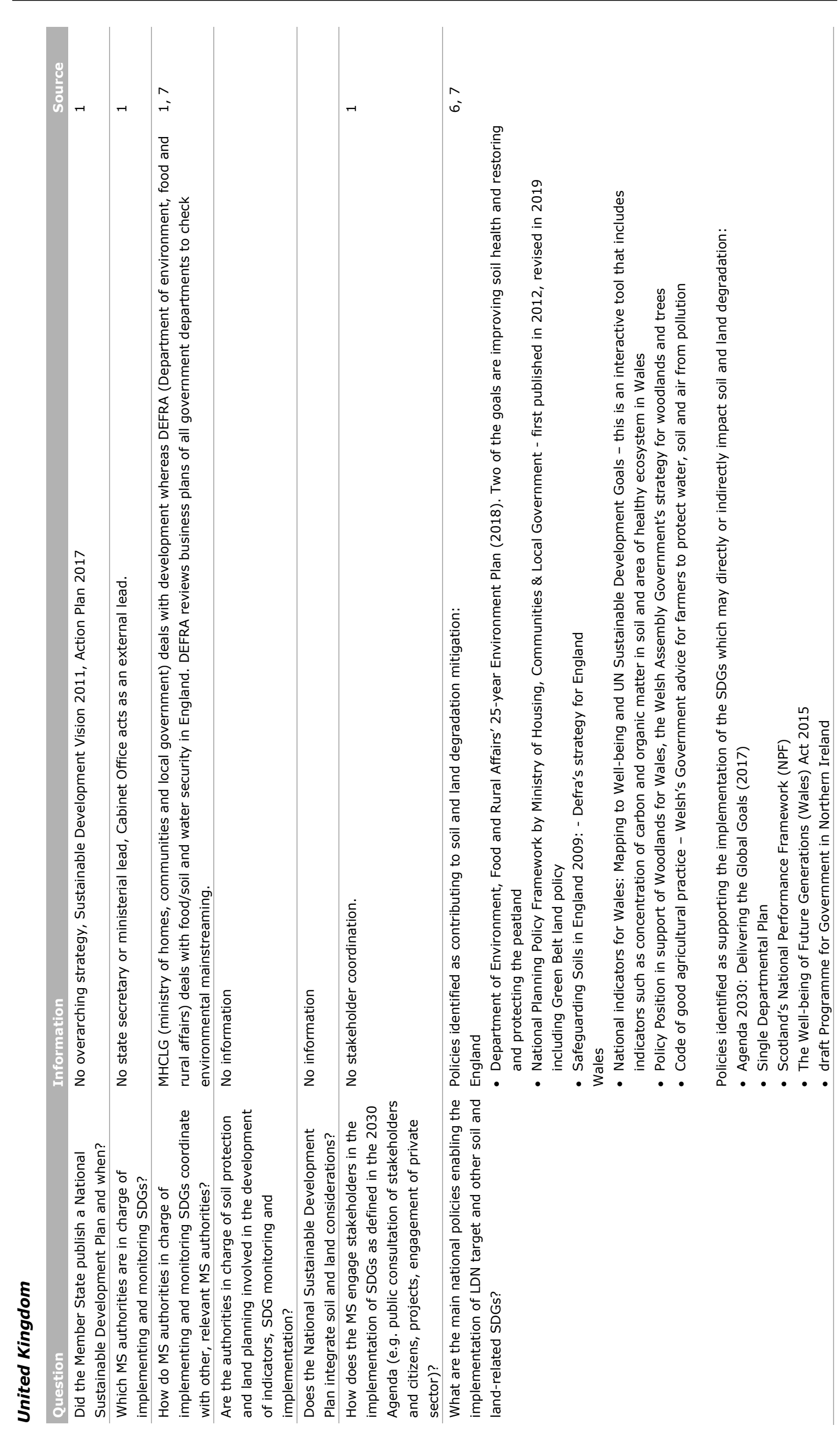




\section{ํํㅁ}

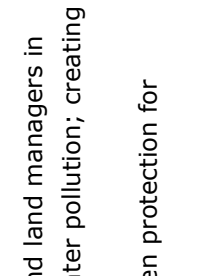

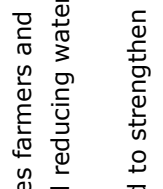

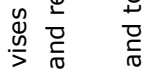

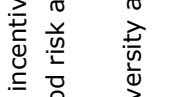

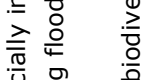

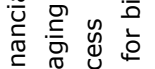

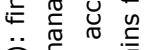

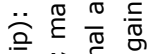

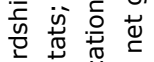

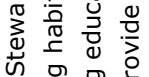

ज药

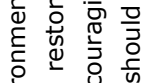

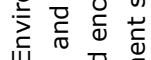

岃

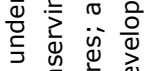

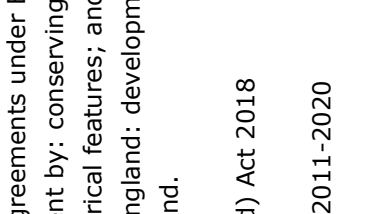

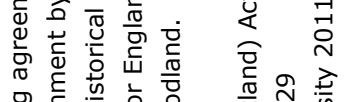

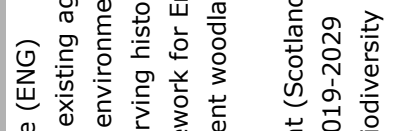

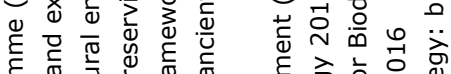

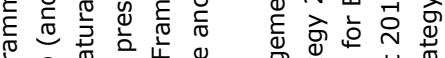

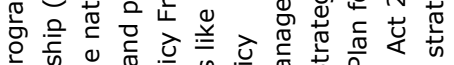

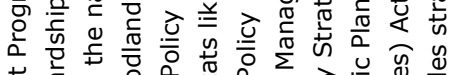

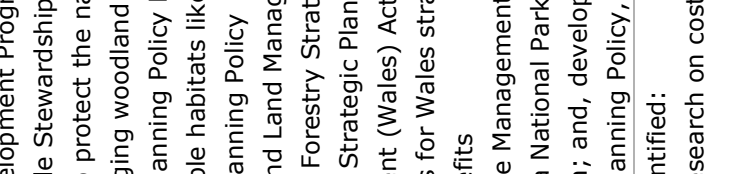

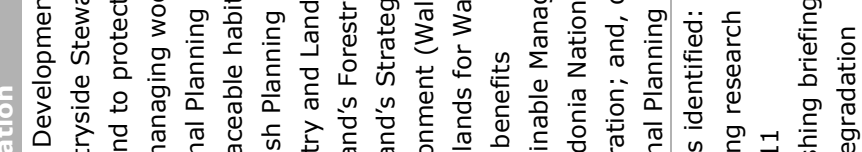

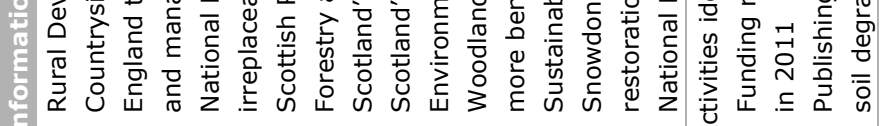

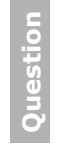

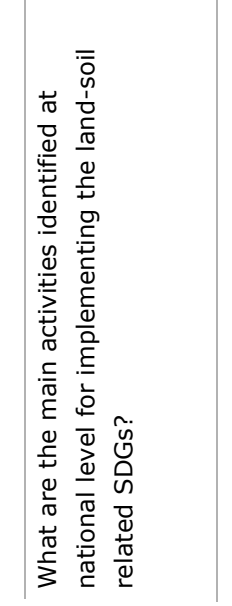

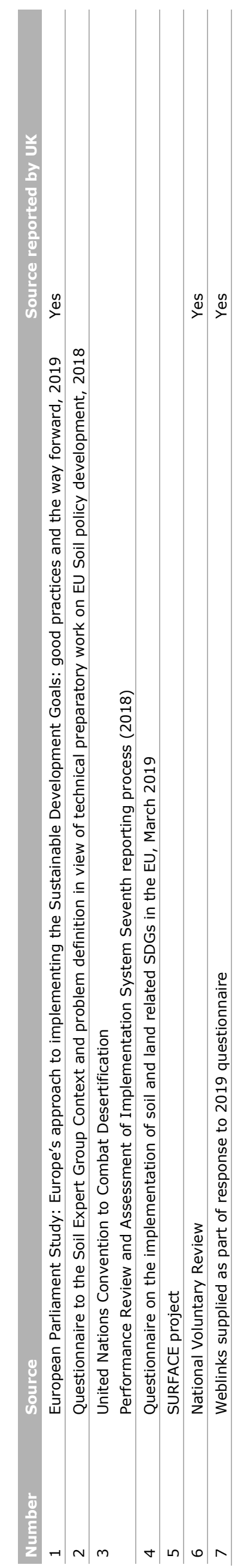




\section{Annex 6 Examples of good practices/initiatives to achieve soil and land-related SDGs}

List of Initiatives starting from Soil Sustainable Management

- Good practice name: UNCCD Science-Policy Interface (SPI)

- Good practice name: UNCCD and WOCAT cooperation Country: Global

- Good practice name: UNCCD Drought Initiative Country: Global

- Good practice name: 4 per 1000 Country: France-global

- Good practice name: Climate smart farming Country: Finland

- Good practice name: Soil monitoring Country: Italy

- Good practice name: Global Long-Term Agricultural Experiment Country: global

- Good practice name: Voluntary Guidelines for Sustainable Soil Management (VGSSM) Country: Global

- Good practice name: SoilCare Country: EU

- Good practice name: RECARE Country: EU

- Good practice name: EJP SOIL Country: EU

- Good practice name: LANDSUPPORT Country: EU

- Good practice name: CIRCASA Country: EU

- Good practice name: LANDMARK Country: EU

- Good practice name: Life AMDRY 4 Country: Mediterranean area

- Good practice name: land stewardship and soil stewardship scenarios OVAM Country: Belgium

- Good practice name: Guidelines on best practice to limit, mitigate or compensate soil sealing Country: EU

- Good practice name: SOS4Soil Country: Italy

- Good practice name: 0.666 Circular ideas (OVAM) Country: Belgium

Initiatives starting from LDN / combating LD

- Good practice name: LDN action UNCCD /LDN target setting Country: Global

- Good practice name: LDN Fund Country: Global

- Good practice name: World Atlas of Desertification Country: Global

- Good practice name: Land Degradation Neutrality: Italy Country: Italy

- Good practice name: JustDigIt Country: Africa

- Good practice name: MFA subsidies / Great green wall Country: Africa

- Good practice name: European Environment - State and Outlook (SOER) Country: EU

- Good practice name: Initiative on Sustainability, Stability and Security (3S) Country: Africa

Initiatives starting from SDGs

- Good practice name: Land and soil related SDG project Country: EU

- Good practice name: UNCCD Peace Forest Initiative Country: Global

- Good practice name: Nicole network discussion on SDGs Country: Europe

- Good practice name: IPBES-Food Country: EU

Initiatives starting from Soil Sustainable Management 


\section{Good practice name: UNCCD Science-Policy Interface (SPI)}

$\begin{array}{ll}\text { Good practice name: } & \text { UNCCD Science-Policy Interface } \\ & (\text { SPI) } \\ \text { Type of initiative: } & \text { 冈 Policy } \\ & \text { 冈 Practice } \\ & \square \text { Network } \\ & \text { 囚 Research } \\ & \square \text { Tool / Instrument } \\ & \square \text { Methodology } \\ & \square \text { Pilot } \\ & \square \text { Other (please specify) }\end{array}$

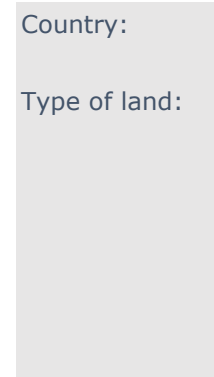

Global

Agricultural

叉 Forest

$\square$ Nature

$\square$ Industrial

$\square$ Urban

$\square$ Derelict/unused

Context. What is the background of the project/initiative?

An EC contract with the UNCCD provided partial funding for this work.

What is the main purpose/objective of the initiative?

To develop scientifically grounded policy proposals for consideration of the signatory Parties of the UNCCD.

Short description if the initiative/project/network

The UNCCD Science-Policy Interface (SPI) conducted a comprehensive scientific assessment and produced the technical report 'Realising the Carbon Benefits of Sustainable Land Management Practices: Guidelines for Estimation of Soil Organic Carbon in the Context of Land Degradation' provides decision guidance for the estimation of soil organic carbon (SOC) in support of appropriate deployment of sustainable land management (SLM) technologies, in order to maintain or increase carbon in the soil and contribute to the achievement of land degradation neutrality (LDN).

What are the main outputs and outcomes (take-home messages)?

See UNCCD global policy decision 16/COP.14. See pages 46-49:

https://www.unccd.int/sites/default/files/sessions/documents/2019-12/ICCD_COP\%2814\%29_23_Add.1-1918355E.pdf Soil threats addressed:

SDGs addressed:

凶 Soil erosion

$\square$ 1. No poverty

囚 Soil sealing

$\square$ 2. Zero hunger

\Soil contamination

$\square$ 3. Good health and well-being

凶 Decline in soil organic matter (SOM)

$\square$ 4. Quality education

凶Soil compaction

$\square$ 5. Gender equality

凶 Desertification

$\square$ 6. Clean water and sanitation

冈 Flooding

$\square$ 7. Affordable and clean energy

\Soil salinisation

$\square$ 8. Decent work and economic growth

Droughts

凶 Landslides

$\square$ 9. Industry, innovation and infrastructure

$\square$ 10. Reduce inequalities

区utrophication

$\square$ 11. Sustainable cities and communities

$\otimes$ Soil biodiversity

$\square$ 12. Responsible consumption and production

叉 Forest fires

$\square$ 13. Climate action

$凶$ Soil acidification

$\square$ 14. Life below water

$\square$ Other (please specify)

$\otimes 15$. Life on land

$\square$ 16. Peace, justice and strong institutions

$\square$ 17. Partnerships for the goals

References/Links/More info:

https://knowledge.unccd.int/publication/Idn-scientific-conceptual-framework-land-degradation-neutrality-report-sciencepolicy 


\section{Good practice name: UNCCD and WOCAT cooperation Country: Global}

$\begin{array}{ll}\text { Good practice name: } & \text { UNCCD and WOCAT cooperation } \\ \text { Type of initiative: } & \square \text { Policy } \\ & \square \text { Practice } \\ & \text { 囚 Network } \\ & \text { 囚 Research } \\ & \text { 囚 Tool / Instrument } \\ & \square \text { Methodology } \\ & \square \text { Pilot } \\ & \square \text { Other (please specify) }\end{array}$

\begin{tabular}{|c|c|}
\hline $\begin{array}{l}\text { Country: } \\
\text { Type of land: }\end{array}$ & $\begin{array}{l}\text { Global } \\
\bigotimes \text { Agricultural } \\
\otimes \text { Forest } \\
\text { 冈 Nature } \\
\square \text { Industrial } \\
\square \text { Urban } \\
\square \text { Derelict/unused }\end{array}$ \\
\hline
\end{tabular}

Context. What is the background of the project/initiative?

UNCCD and WOCAT cooperation

What is the main purpose/objective of the initiative?

In the area of SLM, WOCAT focuses mainly on preventing and reducing land degradation through Soil and Water

Conservation technologies and the implementation approaches. The aim of WOCAT is to increase the awareness and motivation of planners and decision makers, as well as land users and agricultural advisors. WOCAT hopes to reduce investment failures by providing knowledge support on advantages and disadvantages of available alternatives, based on a wide range of experience in the field.

Short description if the initiative/project/network

For UNCCD stakeholders the World Overview of Conservation Approaches and Technologies (WOCAT) is the primary recommended database for best practices on 'sustainable land management (SLM) technologies, including adaptation'. WOCAT was established in 1992 as a global network of Sustainable Land Management (SLM) specialists and has more than 2000 registered users, over 60 participating institutions, and around 30 national and regional initiatives. It connects SLM specialists with experts that provide tools and methods for identifying fields of action and enables users to share knowledge of landresource management. An agreement between UNCCD and WOCAT was signed on 15 April 2014. UNCCD identified WOCAT as a primary recommended database for best practices on SLM technologies. The official recognition of UNCCD gives WOCAT a mandate to support the 194 signatory countries in recording their SLM best practices and using the SLM knowledge of stakeholders worldwide - from land users to decision-makers - to improve local land management.

The cooperation between UNCCD and WOCAT focusses on the dissemination of practices, techniques and experiences with implementing SLM. UNCCD stakeholders are encouraged to share their SLM experiences through the WOCAT database (in a structured way) and to use the WOCAT database and associated knowledge and decision support tools in their planning processes.

What are the main outputs and outcomes (take-home messages)?

Together with the WOCAT Consortium partners the UNCCD intends to continue offering support and SLM knowledge through the WOCAT 2020+ strategy. The proposed WOCAT 2020+ initiative, developed by WOCAT Consortium Partners and long-term partners from 19 countries, will build on the WOCAT tools, database and networks to stimulate the uptake of SLM around the world through a strengthened global partnership. The WOCAT global network will commit to achieving key targets of the 2030 Agenda: promoting land-based solutions to reach zero hunger (SDG 2), clean water and sanitation (SDG 6), supporting life on land (SDG 15) - particularly land degradation neutrality - promoting climate action (SDG 13), and reducing poverty (SDG 1). Achieving these targets will not be possible without focusing on interlinked targets such as governance (SDG 16) and sustainable production and consumption (SDG 12). As a global platform, it will unite partners for transformative actions towards a future with greener land and bluer water.

Soil threats addressed:

凶 Soil erosion

$凶$ Soil sealing

凶 Soil contamination

囚 Decline in soil organic matter (SOM)

囚 Soil compaction

囚 Desertification

凶 Flooding

$凶$ Soil salinisation

凶 Droughts

凶 Landslides

凶 Eutrophication

囚 Soil biodiversity

ॠ Forest fires

凶 Soil acidification

$\square$ Other (please specify)

\section{SDGs addressed:}

$\square 1$. No poverty

$\square$ 2. Zero hunger

$\square$ 3. Good health and well-being

$\square$ 4. Quality education

$\square$ 5. Gender equality

$\square$ 6. Clean water and sanitation

$\square$ 7. Affordable and clean energy

$\square$ 8. Decent work and economic growth

$\square$ 9. Industry, innovation and infrastructure

$\square$ 10. Reduce inequalities

$\square$ 11. Sustainable cities and communities

$\square$ 12. Responsible consumption and production

$\square$ 13. Climate action

$\square$ 14. Life below water

$\otimes 15$. Life on land

$\square$ 16. Peace, justice and strong institutions

$\square$ 17. Partnerships for the goals

\section{References/Links/More info:}

On Best practices in sustainable land management, see: https://knowledge.unccd.int/knowledge-products-and-pillars/bestpractices-sustainable-land-management On the UNCCD and WOCAT, see: https://knowledge.unccd.int/knowledgeproducts-and-pillars/best-practices-sustainable-land-management/about-unccd-wocat The WOCAT database also contains detailed descriptions of best practices from various countries in Europe. 


\section{Good practice name: UNCCD Drought Initiative \\ Country: Global}

$\begin{array}{ll}\text { Good practice name: } & \text { UNCCD Drought Initiative } \\ \text { Type of initiative: } & \text { 冈 Policy } \\ & \square \text { Practice } \\ & \square \text { Network } \\ & \square \text { Research } \\ & \bigotimes \text { Tool / Instrument } \\ & \bigotimes \text { Methodology } \\ & \text { 冈 Pilot } \\ & \square \text { Other (please specify) }\end{array}$

$\begin{array}{ll}\text { Country: } & \text { Global } \\ \text { Type of land: } & \text { \ Agricultural } \\ & \text { \ Forest } \\ & \text { \ Nature } \\ & \square \text { Industrial } \\ & \square \text { Urban } \\ & \square \text { Derelict/unused }\end{array}$

Context. What is the background of the project/initiative?

UNCCD Drought Initiative

What is the main purpose/objective of the initiative?

To help countries build drought resilience, the Parties at COP 13 requested the UNCCD secretariat to implement a drought initiative (2018-2019). It will support concrete action on drought preparedness systems to boost the resilience of people, communities and ecosystems. Most countries already have some elements in place on how to respond to a drought. But, in general, approaches are not comprehensive and mostly reactive. The elements tend not to function well together.

72 countries are participating

Short description if the initiative/project/network

The UNCCD Drought Initiative was adopted at COP 13 where the Parties requested the secretariat and appropriate UNCCD institutions and bodies, including the Science-Policy Interface, within their respective mandates to: (a) Implement the drought initiative for the biennium 2018-2019 (later extended to 2020-2021) which proposes action on: (i) drought preparedness systems; (ii) regional efforts to reduce drought vulnerability and risk; and (iii) a toolbox to boost the resilience of people and ecosystems to drought;

What are the main outputs and outcomes (take-home messages)?

- We need to move away from 'reactive' to 'proactive' approaches to drought management. That means we need to treat the 'symptoms' not the 'causes'.

- Drought should be treated as a 'risk' and not 'crisis'.

- We need to move away from 'uncoordinated and piece meal approach' to a more coordinated approach and integrated approach to drought management. So, intersectoral coordination should be strengthened to tackle drought in a more sustainable way.

- $\quad$ Early warning systems, vulnerability assessment and risk mitigation measures are the three key pillars for a proactive to drought management.

Soil threats addressed:

\section{SDGs addressed:}

$\square$ Soil erosion

$\square$ Soil sealing

$\square$ Soil contamination

$\square$ Decline in soil organic matter (SOM)

$\square$ Soil compaction

$\square$ Desertification

$\square$ Flooding

$\square$ Soil salinisation

Droughts

$\square$ Landslides

$\square$ Eutrophication

$\square$ Soil biodiversity

$\square$ Forest fires

$\square$ Soil acidification

$\square$ Other (please specify) $\square 1$. No poverty

$\square$ 2. Zero hunger

$\square$ 3. Good health and well-being

$\square$ 4. Quality education

$\square$ 5. Gender equality

$\square$ 6. Clean water and sanitation

$\square$ 7. Affordable and clean energy

$\square$ 8. Decent work and economic growth

$\square$ 9. Industry, innovation and infrastructure

$\square$ 10. Reduce inequalities

$\square$ 11. Sustainable cities and communities

$\square$ 12. Responsible consumption and production

$\square$ 13. Climate action

$\square$ 14. Life below water

$\otimes 15$. Life on land

$\square$ 16. Peace, justice and strong institutions

$\square$ 17. Partnerships for the goals

References/Links/More info: 
Good practice name: 4 per 1000

\section{Country: France-global}

\begin{tabular}{|c|c|c|c|}
\hline $\begin{array}{l}\text { Good practice name: } \\
\text { Type of initiative: }\end{array}$ & $\begin{array}{l}4 \text { per } 1000 \\
\text { 冈 Policy } \\
\square \text { Practice } \\
\square \text { Network } \\
\square \text { Research } \\
\square \text { Tool / Instrument } \\
\square \text { Methodology } \\
\square \text { Pilot } \\
\square \text { Other (please specify) }\end{array}$ & $\begin{array}{l}\text { Country: } \\
\text { Type of land: }\end{array}$ & $\begin{array}{l}\text { France-global } \\
\bigotimes \text { Agricultural } \\
\bigotimes \text { Forest } \\
\square \text { Nature } \\
\square \text { Industrial } \\
\square \text { Urban } \\
\square \text { Derelict/unused }\end{array}$ \\
\hline
\end{tabular}

Context. What is the background of the project/initiative?

Own initiative

What is the main purpose/objective of the initiative?

The international initiative ' 4 per 1000', launched by France on 1 December 2015 at the COP 21, consists of federating all voluntary stakeholders of the public and private sectors (national governments, local and regional governments, companies, trade organisations, NGOs, research facilities, etc.) under the framework of the Lima-Paris Action Plan (LPAP). The aim of the initiative is to demonstrate that agriculture, and in particular agricultural soils can play a crucial role where food security and climate change are concerned.

Short description if the initiative/project/network on soil carbon storage and the type of practices to achieve this (e.g. agroecology, agroforestry, conservation agriculture, landscape management, etc.). The ambition of the initiative is to encourage stakeholders to transition towards a productive, highly resilient agriculture, based on the appropriate management of lands and soils, creating jobs and incomes hence ensuring sustainable development. The Executive Secretariat of the ' 4 per 1000 ' initiative is hosted by the CGIAR System Organization, an international organization based in Montpellier.

What are the main outputs and outcomes (take-home messages)?

Primarily composed of carbon, the organic matter in soils plays a role in four important ecosystem services: resistance to soil erosion, soil water retention, soil fertility for plants and soil biodiversity. Even small changes in the soil carbon pool have large-scale effects both on agricultural productivity and on greenhouse gas balance. Maintaining organic carbon-rich soils, restoring and improving degraded agricultural lands and, more generally, increasing soil carbon, play an important role in addressing the three-fold challenge of food security, adaptation of food systems and people to climate change, and mitigation of anthropogenic emissions.

\author{
Soil threats addressed: \\ 凶Soil erosion \\ $\square$ Soil sealing \\ $\square$ Soil contamination \\ 囚ecline in soil organic matter (SOM) \\ 囚 Soil compaction \\ 囚 Desertification \\ $\square$ Flooding \\ $\square$ Soil salinisation \\ $\square$ Droughts \\ $\square$ Landslides \\ $\square$ Eutrophication \\ $凶$ Soil biodiversity \\ $\square$ Forest fires \\ $\square$ Soil acidification \\ $\square$ Other (please specify)
}

\author{
SDGs addressed: \\ $\square$ 1. No poverty \\ $凶$ 2. Zero hunger \\ $\square$ 3. Good health and well-being \\ $\square$ 4. Quality education \\ $\square$ 5. Gender equality \\ $\square$ 6. Clean water and sanitation \\ $\square$ 7. Affordable and clean energy \\ $\square$ 8. Decent work and economic growth \\ $\square$ 9. Industry, innovation and infrastructure \\ $\square$ 10. Reduce inequalities \\ $\square$ 11. Sustainable cities and communities \\ $\square$ 12. Responsible consumption and production \\ $\otimes$ 13. Climate action \\ $\square$ 14. Life below water \\ $\otimes 15$. Life on land \\ $\square$ 16. Peace, justice and strong institutions \\ $\square$ 17. Partnerships for the goals
}

References/Links/More info:

https://www.4p1000.org/ 


\section{Good practice name: Climate smart farming}

\section{Country: Finland}

$\begin{array}{ll}\text { Good practice name: } & \text { Climate smart farming } \\ \text { Type of initiative: } & \square \text { Policy } \\ & \square \text { Practice } \\ & \bigotimes \text { Network } \\ & \square \text { Research } \\ & \square \text { Tool / Instrument } \\ & \square \text { Methodology } \\ & \square \text { Pilot } \\ & \square \text { Other (please specify) }\end{array}$

$\begin{array}{ll}\text { Country: } & \text { Finland } \\ \text { Type of land: } & \bigotimes \text { Agricultural } \\ & \square \text { Forest } \\ & \square \text { Nature } \\ & \square \text { Industrial } \\ & \square \text { Urban } \\ & \square \text { Derelict/unused }\end{array}$

Context. What is the background of the project/initiative?

Own initiative

What is the main purpose/objective of the initiative?

To give practical solution to combate climate change

Short description if the initiative/project/network

Communication network and action for soil productivity and climate friendly use with farmers organization (Central Union of Agricultural Producers and Forest Owners in Finland MTK) and advisory organization ProAgria. The booklet 'Climatesmart farm' was published September 2019 and the communication to disseminate the messages and content of the book written by many experts from Research Institutes and Universities)

What are the main outputs and outcomes (take-home messages)?

Communication plan and common main messages for climate smart farming.

The climate smart farm use healthy and productive soils, plants and animals and strive for resource efficiency also in energy options and nutrient use.

\author{
Soil threats addressed: \\ 囚 Soil erosion \\ $\square$ Soil sealing \\ $\square$ Soil contamination \\ 囚 Decline in soil organic matter (SOM) \\ 凶 Soil compaction \\ $\square$ Desertification \\ 凶 Flooding \\ $\square$ Soil salinisation \\ 凶 Droughts \\ $\square$ Landslides \\ 凶 Eutrophication \\ $凶$ Soil biodiversity \\ $\square$ Forest fires \\ 囚 Soil acidification \\ $\square$ Other (please specify)
}

\section{SDGs addressed:}

$\square 1$. No poverty

$\otimes 2$. Zero hunger

\3. Good health and well-being

$\square$ 4. Quality education

$\square$ 5. Gender equality

$凶$ 6. Clean water and sanitation

$\otimes 7$. Affordable and clean energy

8. Decent work and economic growth

$\square$ 9. Industry, innovation and infrastructure

$\square$ 10. Reduce inequalities

$\square$ 11. Sustainable cities and communities

$凶 12$. Responsible consumption and production

$凶$ 13. Climate action

$\otimes 14$. Life below water

$\otimes 15$. Life on land

$\square$ 16. Peace, justice and strong institutions

$\square$ 17. Partnerships for the goals

References/Links/More info:

https://www.mtk.fi/fi/web/en 
Good practice name: Soil monitoring

\section{Country: Italy}

$\begin{array}{ll}\text { Good practice name: } & \text { Soil monitoring } \\ \text { Type of initiative: } & \text { \Policy } \\ & \text { \ Practice } \\ & \square \text { Network } \\ & \square \text { Research } \\ & \square \text { Tool / Instrument } \\ & \square \text { Methodology } \\ & \square \text { Pilot } \\ & \square \text { Other (please specify) }\end{array}$

Context. What is the background of the project/initiative?

$\begin{array}{ll}\text { Country: } & \text { Italy } \\ \text { Type of land: } & \bigotimes \text { Agricultural } \\ & \square \text { Forest } \\ & \square \text { Nature } \\ & \square \text { Industrial } \\ & \square \text { Urban } \\ & \square \text { Derelict/unused }\end{array}$

EU's Common Agricultural Policy (CAP 2014-2020) and the Rural Development Programme (RDP)

What is the main purpose/objective of the initiative?

a soil regional monitoring network to assess soil quality and the impact of agricultural management

Short description if the initiative/project/network

Monitoring of representative soil and land use sites with soil sampling and analysis of chemical physical and biological parameters. The soil management is also detected.

What are the main outputs and outcomes (take-home messages)?

Assessment of soil quality in relationship with land management and evaluation of the RDP effectiveness

Soil threats addressed:

SDGs addressed:

$\otimes$ Soil erosion

$\square$ Soil sealing

$\otimes$ Soil contamination

$\otimes$ Decline in soil organic matter (SOM)

$\otimes$ Soil compaction

$\otimes$ Desertification

$\square$ Flooding

\Soil salinisation

$\square$ Droughts

$\square$ Landslides

$\square$ Eutrophication

$\otimes$ Soil biodiversity

$\square$ Forest fires

$\square$ Soil acidification

$\square$ Other (please specify) $\square$ 1. No poverty

$\square$ 2. Zero hunger

$\square$ 3. Good health and well-being

$\square$ 4. Quality education

$\square$ 5. Gender equality

$\square$ 6. Clean water and sanitation

$\square$ 7. Affordable and clean energy

$\square$ 8. Decent work and economic growth

$\square$ 9. Industry, innovation and infrastructure

$\square$ 10. Reduce inequalities

$\square$ 11. Sustainable cities and communities

$\square$ 12. Responsible consumption and production

$\square$ 13. Climate action

$\square$ 14. Life below water

$\otimes 15$. Life on land

$\square$ 16. Peace, justice and strong institutions

$\square$ 17. Partnerships for the goals

References/Links/More info:

https://ambiente.regione.emilia-romagna.it/it/geologia/suoli/proprieta-e-qualita-dei-suoli/monitoraggio-delle-

caratteristiche-chimico-fisiche-e-biologiche-dei-suoli-agricoli 


\section{Good practice name: Global Long-Term Agricultural Experiment}

\section{Country: Global}

$\begin{array}{ll}\text { Good practice name: } & \text { Global Long-Term Agricultural } \\ & \text { Experiment } \\ \text { Type of initiative: } & \square \text { Policy } \\ & \square \text { Practice } \\ & \text { 冈 Network } \\ & \text { Q Research } \\ & \square \text { Tool / Instrument } \\ & \bigotimes \text { Methodology } \\ & \square \text { Pilot } \\ & \square \text { Other (please specify) }\end{array}$

$\begin{array}{ll}\text { Country: } & \text { global } \\ \text { Type of land: } & \\ & \bigotimes \text { Agricultural } \\ & \square \text { Forest } \\ & \square \text { Nature } \\ & \square \text { Industrial } \\ & \square \text { Urban } \\ & \square \text { Derelict/unused }\end{array}$

Context. What is the background of the project/initiative?

International Project supported by Charity Trust Fund and Research Institute.

What is the main purpose/objective of the initiative?

The identification, data Harmonisation and accessibility of Long-term experiments worldwide. The GLTEN aim to establish and support collaborative network within the agricultural science community carrying out research through LTEs. Short description if the initiative/project/network

The Global Long-Term Agricultural Experiment Network was launched in May 2018. The GLTEN is a network of long-term agricultural experiments and associated researchers spanning six continents and representing a range of climates, environments, crop systems and farming practices.

What are the main outputs and outcomes (take-home messages)?

In progress

Soil threats addressed:

SDGs addressed:

$\otimes$ Soil erosion

$凶 1$. No poverty

$\square$ Soil sealing

$\otimes 2$. Zero hunger

$凶$ Soil contamination

$凶$ 3. Good health and well-being

$凶$ Decline in soil organic matter (SOM)

$\square$ 4. Quality education

\Soil compaction

$\square$ 5. Gender equality

$\square$ Desertification

$\square$ 6. Clean water and sanitation

$\square$ Flooding

$\square$ 7. Affordable and clean energy

$\otimes$ Soil salinisation

$\square$ Droughts

$\square$ 8. Decent work and economic growth

$\square$ Landslides

$\square$ 9. Industry, innovation and infrastructure

$\otimes$ Eutrophication

$\square$ 10. Reduce inequalities

\ Soil biodiversity

$凶$ 11. Sustainable cities and communities

$\square$ Forest fires

$\square$ 12. Responsible consumption and production

$\otimes$ Soil acidification

$\square$ Other (please specify)

$\square$ 13. Climate action

$\square$ 14. Life below water

$\otimes 15$. Life on land

$\square$ 16. Peace, justice and strong institutions

$\otimes 17$. Partnerships for the goals

References/Links/More info:

www.glten.org/

https://www.rothamsted.ac.uk/glten-global-long-term-agricultural-experiment-network

https://www.rothamsted.ac.uk/news/wltm-176-year-old-seeking-significant-other-long-term\%E2\%80\%A6experiment

https://www.rothamsted.ac.uk/events/future-long-term-experiments-agricultural-science\#DOWNLOADS-2 
Good practice name: Voluntary Guidelines for Sustainable Soil Management (VGSSM) Country: Global

\begin{tabular}{|c|c|c|c|}
\hline Good practice name: & $\begin{array}{l}\text { Voluntary Guidelines for Sustainable } \\
\text { Soil Management (VGSSM) }\end{array}$ & Country: & Global \\
\hline Type of initiative: & $\begin{array}{l}\square \text { Policy } \\
\text { 冈 Practice } \\
\text { 冈 Network } \\
\square \text { Research } \\
\square \text { Tool / Instrument } \\
\square \text { Methodology } \\
\square \text { Pilot } \\
\square \text { Other (please specify) }\end{array}$ & Type of land: & $\begin{array}{l}\text { 囚 Agricultural } \\
\text { 冈 Forest } \\
\square \text { Nature } \\
\square \text { Industrial } \\
\square \text { Urban } \\
\square \text { Derelict/unused }\end{array}$ \\
\hline \multicolumn{4}{|c|}{ Context. What is the background of the project/initiative? } \\
\hline \multicolumn{4}{|l|}{ GSP initiative } \\
\hline \multicolumn{4}{|c|}{ What is the main purpose/objective of the initiative? } \\
\hline \multicolumn{4}{|c|}{ What are the main outputs and outcomes (take-home messages)? } \\
\hline \multicolumn{4}{|c|}{ Practical guidelines } \\
\hline \multicolumn{2}{|l|}{ Soil threats addressed: } & \multicolumn{2}{|c|}{ SDGs addressed: } \\
\hline \multicolumn{2}{|l|}{ 凶 Soil erosion } & \multicolumn{2}{|c|}{$\square$ 1. No poverty } \\
\hline \multicolumn{2}{|l|}{ 凶 Soil sealing } & \multicolumn{2}{|c|}{ 凶2. Zero hunger } \\
\hline \multicolumn{2}{|l|}{ 凶 Soil contamination } & \multicolumn{2}{|c|}{$\square$ 3. Good health and well-being } \\
\hline \multicolumn{2}{|c|}{ 凶 Decline in soil organic matter (SOM) } & \multicolumn{2}{|c|}{$\square$ 4. Quality education } \\
\hline \multicolumn{2}{|l|}{ 凶 Soil compaction } & \multicolumn{2}{|c|}{$\square$ 5. Gender equality } \\
\hline \multicolumn{2}{|l|}{$\square$ Desertification } & \multicolumn{2}{|c|}{$\square$ 6. Clean water and sanitation } \\
\hline$\square$ Forest fires & & $\square$ 13. Climate & \\
\hline$\otimes$ Soil acidification & & $\square$ 14. Life bel & ater \\
\hline 凶 Other (please spec & & 凶15. Life on & \\
\hline & & $\square$ 16. Peace, & e and strong institutions \\
\hline & & $\square$ 17. Partner & for the goals \\
\hline
\end{tabular}




\section{Good practice name: SoilCare}

\section{Country: EU}

\begin{tabular}{|c|c|c|c|}
\hline $\begin{array}{l}\text { Good practice name: } \\
\text { Type of initiative: }\end{array}$ & $\begin{array}{l}\text { SoilCare } \\
\square \text { Policy } \\
\square \text { Practice } \\
\square \text { Network } \\
\bigotimes \text { Research } \\
\square \text { Tool / Instrument } \\
\square \text { Methodology } \\
\square \text { Pilot } \\
\square \text { Other (please specify) }\end{array}$ & $\begin{array}{l}\text { Country: } \\
\text { Type of land: }\end{array}$ & $\begin{array}{l}\text { EU } \\
\bigotimes \text { Agricultural } \\
\square \text { Forest } \\
\square \text { Nature } \\
\square \text { Industrial } \\
\square \text { Urban } \\
\square \text { Derelict/unused }\end{array}$ \\
\hline \multicolumn{4}{|c|}{ Context. What is the background of the project/initiative? } \\
\hline \multicolumn{4}{|c|}{ European research project } \\
\hline \multicolumn{4}{|c|}{ What is the main purpose/objective of the initiative? } \\
\hline \multicolumn{4}{|c|}{$\begin{array}{l}\text { To test and promote soil-improving cropping systems (SICS) which ensure productivity while reducing environmental } \\
\text { impacts }\end{array}$} \\
\hline \multicolumn{4}{|c|}{ Short description if the initiative/project/network } \\
\hline \multicolumn{4}{|c|}{ A review of soil- improving cropping systems is made in a report } \\
\hline \multicolumn{4}{|c|}{ What are the main outputs and outcomes (take-home messages)? } \\
\hline \multicolumn{4}{|c|}{$\begin{array}{l}\text { This project is ongoing and will provide insights into the environmental and economic benefits of various SICS tested across } \\
16 \text { European study sites. }\end{array}$} \\
\hline \multicolumn{2}{|l|}{ Soil threats addressed: } & \multicolumn{2}{|c|}{ SDGs addressed: } \\
\hline \multicolumn{2}{|l|}{$\otimes$ Soil erosion } & \multicolumn{2}{|c|}{$\square$ 1. No poverty } \\
\hline \multicolumn{2}{|l|}{ 囚 Soil sealing } & \multicolumn{2}{|c|}{$\unrhd 2$. Zero hunger } \\
\hline \multicolumn{2}{|l|}{$\otimes$ Soil contamination } & \multicolumn{2}{|c|}{$\square$ 3. Good health and well-being } \\
\hline \multicolumn{2}{|c|}{$凶$ Decline in soil organic matter (SOM) } & \multicolumn{2}{|c|}{$\square$ 4. Quality education } \\
\hline \multicolumn{2}{|l|}{ 凶 Soil compaction } & \multicolumn{2}{|c|}{$\square$ 5. Gender equality } \\
\hline \multicolumn{2}{|l|}{$\otimes$ Desertification } & \multicolumn{2}{|c|}{$\square$ 6. Clean water and sanitation } \\
\hline \multicolumn{2}{|l|}{$\otimes$ Flooding } & \multicolumn{2}{|c|}{$\square$ 7. Affordable and clean energy } \\
\hline \multicolumn{2}{|l|}{ 囚 Soil salinisation } & \multicolumn{2}{|c|}{$\square$ 8. Decent work and economic growth } \\
\hline \multicolumn{2}{|l|}{$\otimes$ Droughts } & \multicolumn{2}{|c|}{$\square 9$. Industry, innovation and infrastructure } \\
\hline \multicolumn{2}{|l|}{ 凶 Landslides } & \multicolumn{2}{|c|}{$\square$ 10. Reduce inequalities } \\
\hline \multicolumn{2}{|l|}{$凶$ Eutrophication } & \multicolumn{2}{|c|}{$\square$ 11. Sustainable cities and communities } \\
\hline \multicolumn{2}{|l|}{$\otimes$ Soil biodiversity } & $\square$ 12. Respon & consumption and production \\
\hline$\otimes$ Forest fires & & $\square$ 13. Climate & \\
\hline 凶Soil acidification & & $\square$ 14. Life be & ater \\
\hline$\square$ Other (please speci & & $\otimes 15$. Life on & \\
\hline & & $\square$ 16. Peace, & e and strong institutions \\
\hline & & $\square$ 17. Partner & for the goals \\
\hline
\end{tabular}

References/Links/More info:

https://www.soilcare-project.eu/en/ 


\section{Good practice name: RECARE}

\section{Country: $\quad E U$}

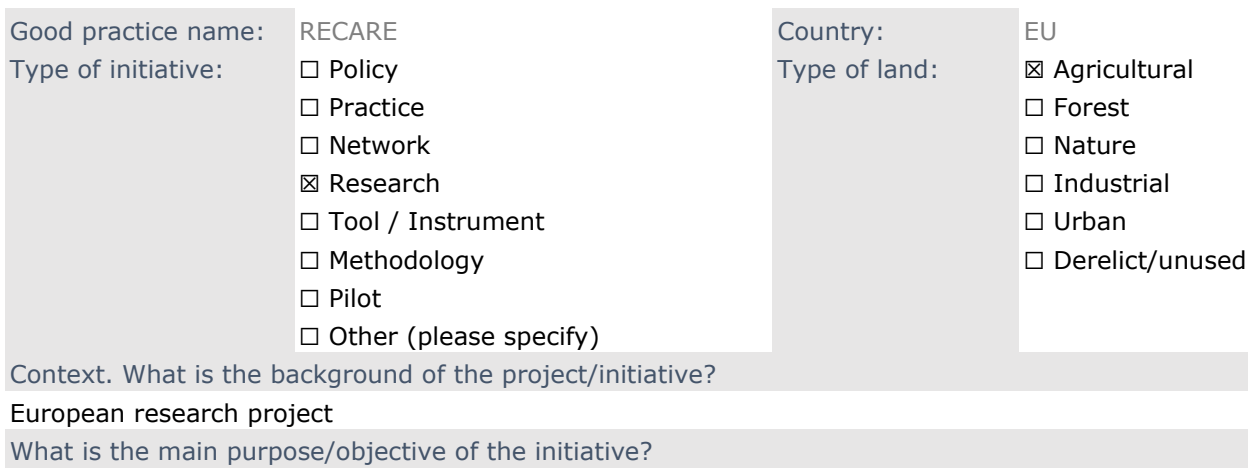

Short description if the initiative/project/network

research project to ensure implementation of the available suite of practical management responses that address the soil threats.

What are the main outputs and outcomes (take-home messages)?

Finding and sharing solutions to protect our soils Soil threats addressed:

SDGs addressed:

$\square$ 1. No poverty

$凶$ Soil sealing

$\square$ 2. Zero hunger

$凶$ Soil contamination

$\square$ 3. Good health and well-being

$\otimes$ Decline in soil organic matter (SOM)

$\square$ 4. Quality education

$\otimes$ Soil compaction

$\square$ 5. Gender equality

$凶$ Desertification

$\square$ 6. Clean water and sanitation

\ Flooding

$\square$ 7. Affordable and clean energy

$\otimes$ Soil salinisation

$\otimes$ Droughts

$\square$ 8. Decent work and economic growth

\ Landslides

9. Industry, innovation and infrastructure

$\otimes$ Eutrophication

$\square$ 10. Reduce inequalities

$\otimes$ Soil biodiversity

$\square$ 11. Sustainable cities and communities

\ Forest fires

$\square$ 12. Responsible consumption and production

$凶$ Soil acidification

$\square$ 13. Climate action

$\square$ Other (please specify)

$\square$ 14. Life below water

$\square$ 15. Life on land

$\square$ 16. Peace, justice and strong institutions

$\square$ 17. Partnerships for the goals

References/Links/More info:

https://www.recare-project.eu/downloads-by-category/project-deliverables-2/441-recare-final-publishable-report-finalaug2019/file 


\section{Good practice name: EJP SOIL}

\section{Country: EU}

\begin{tabular}{|c|c|c|c|}
\hline $\begin{array}{l}\text { Good practice name: } \\
\text { Type of initiative: }\end{array}$ & $\begin{array}{l}\text { EJP SOIL } \\
\bigotimes \text { Policy } \\
\bigotimes \text { Practice } \\
\bigotimes \text { Network } \\
\text { 冈 Research } \\
\square \text { Tool / Instrument } \\
\square \text { Methodology } \\
\square \text { Pilot } \\
\square \text { Other (please specify) }\end{array}$ & $\begin{array}{l}\text { Country: } \\
\text { Type of land: }\end{array}$ & $\begin{array}{l}\text { EU } \\
\bigotimes \text { Agricultural } \\
\square \text { Forest } \\
\text { 冈 Nature } \\
\square \text { Industrial } \\
\square \text { Urban } \\
\square \text { Derelict/unused }\end{array}$ \\
\hline \multicolumn{4}{|c|}{ Context. What is the background of the project/initiative? } \\
\hline \multicolumn{4}{|l|}{ programme of EU } \\
\hline \multicolumn{4}{|c|}{ What is the main purpose/objective of the initiative? } \\
\hline \multicolumn{4}{|c|}{ climate smart sustainable agricultural soil management } \\
\hline \multicolumn{4}{|c|}{ Short description if the initiative/project/network } \\
\hline \multicolumn{4}{|c|}{ programme in which project will be developed } \\
\hline \multicolumn{4}{|c|}{ What are the main outputs and outcomes (take-home messages)? } \\
\hline \multicolumn{4}{|l|}{ just started } \\
\hline \multicolumn{2}{|l|}{ Soil threats addressed: } & \multicolumn{2}{|c|}{ SDGs addressed: } \\
\hline \multicolumn{2}{|l|}{ 囚 Soil erosion } & \multicolumn{2}{|c|}{$\square$ 1. No poverty } \\
\hline \multicolumn{2}{|l|}{$\otimes$ Soil sealing } & \multicolumn{2}{|c|}{$\square$ 2. Zero hunger } \\
\hline \multicolumn{2}{|l|}{$\otimes$ Soil contamination } & \multicolumn{2}{|c|}{ \3. Good health and well-being } \\
\hline \multicolumn{2}{|c|}{$凶$ Decline in soil organic matter (SOM) } & \multicolumn{2}{|c|}{$\square$ 4. Quality education } \\
\hline \multicolumn{2}{|l|}{$\otimes$ Soil compaction } & \multicolumn{2}{|c|}{$\square$ 5. Gender equality } \\
\hline \multicolumn{2}{|l|}{$凶$ Desertification } & \multicolumn{2}{|c|}{ 冈 6. Clean water and sanitation } \\
\hline \multicolumn{2}{|l|}{$\square$ Flooding } & \multicolumn{2}{|c|}{$\square$ 7. Affordable and clean energy } \\
\hline \multicolumn{2}{|l|}{$\otimes$ Soil salinisation } & \multicolumn{2}{|c|}{$\otimes$ 8. Decent work and economic growth } \\
\hline \multicolumn{2}{|l|}{$\otimes$ Droughts } & \multicolumn{2}{|c|}{$\square$ 9. Industry, innovation and infrastructure } \\
\hline \multicolumn{2}{|l|}{$\square$ Landslides } & \multicolumn{2}{|c|}{$\square$ 10. Reduce inequalities } \\
\hline \multicolumn{2}{|l|}{$凶$ Eutrophication } & \multicolumn{2}{|c|}{$\square$ 11. Sustainable cities and communities } \\
\hline \multicolumn{2}{|l|}{$\otimes$ Soil biodiversity } & \multicolumn{2}{|c|}{$\otimes 12$. Responsible consumption and production } \\
\hline$\square$ Forest fires & & 凶 13. Climate & \\
\hline$\otimes$ Soil acidification & & $\square$ 14. Life bel & ater \\
\hline$\square$ Other (please speci & & $\otimes 15$. Life on & \\
\hline & & $\square$ 16. Peace, & e and strong institutions \\
\hline & & 冈 17. Partner & for the goals \\
\hline
\end{tabular}

References/Links/More info:

https://projects.au.dk/ejpsoil/ 


\section{Good practice name: LANDSUPPORT}

\section{Country: EU}

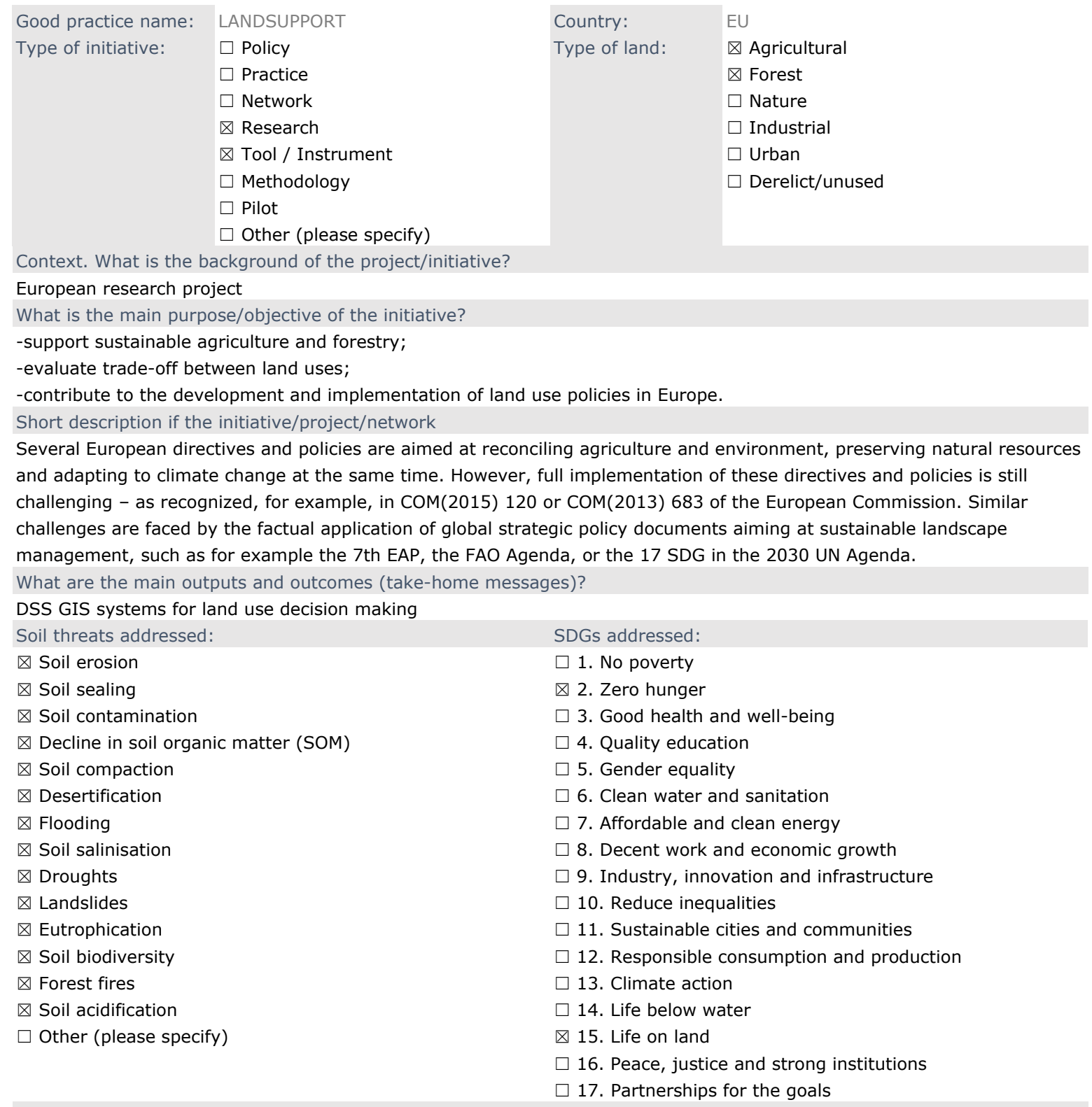

References/Links/More info:

https://www.landsupport.eu/

https://www.youtube.com/watch?v=zqfSS2puu4E

https://www.youtube. com/watch?v=wCKC5IBLbbI 


\section{Good practice name: CIRCASA}

\section{Country: EU}

\begin{tabular}{|c|c|c|c|}
\hline $\begin{array}{l}\text { Good practice name: } \\
\text { Type of initiative: }\end{array}$ & $\begin{array}{l}\text { CIRCASA } \\
\square \text { Policy } \\
\square \text { Practice } \\
\square \text { Network } \\
\text { 冈 Research } \\
\square \text { Tool / Instrument } \\
\square \text { Methodology } \\
\square \text { Pilot } \\
\square \text { Other (please specify) }\end{array}$ & $\begin{array}{l}\text { Country: } \\
\text { Type of land: }\end{array}$ & $\begin{array}{l}\text { EU } \\
\bigotimes \text { Agricultural } \\
\square \text { Forest } \\
\square \text { Nature } \\
\square \text { Industrial } \\
\square \text { Urban } \\
\square \text { Derelict/unused }\end{array}$ \\
\hline \multicolumn{4}{|c|}{ Context. What is the background of the project/initiative? } \\
\hline \multicolumn{4}{|c|}{ European research project } \\
\hline \multicolumn{4}{|c|}{ What is the main purpose/objective of the initiative? } \\
\hline \multicolumn{4}{|c|}{$\begin{array}{l}\text { CIRCASA (Coordination of International Research Cooperation on Soil Carbon Sequestration in Agriculture) aims to develop } \\
\text { international synergies concerning research and knowledge exchange in the field of carbon sequestration in agricultural } \\
\text { soils at European Union and global levels, with the active engagement of all relevant stakeholders. }\end{array}$} \\
\hline \multicolumn{4}{|c|}{ Short description if the initiative/project/network } \\
\hline \multicolumn{4}{|c|}{$\begin{array}{l}\text { The CIRCASA project is at its 3rd year (in 2020). At this stage, we are preparing a 2020-2022 implementation plan for the } \\
\text { International Research Consortium (IRC) on soil carbon. Current work on a Strategic Research Agenda co-designed with } \\
\text { stakeholders, grounded on scientific evidence and stakeholders' knowledge demands will support the alignment of research } \\
\text { for this IRC. }\end{array}$} \\
\hline \multicolumn{4}{|c|}{ What are the main outputs and outcomes (take-home messages)? } \\
\hline \multicolumn{4}{|c|}{ Strategic Research Agenda at EU and global levels } \\
\hline \multicolumn{2}{|l|}{ Soil threats addressed: } & \multicolumn{2}{|c|}{ SDGs addressed: } \\
\hline \multicolumn{2}{|l|}{$\square$ Soil erosion } & \multicolumn{2}{|c|}{$\square$ 1. No poverty } \\
\hline \multicolumn{2}{|l|}{$\square$ Soil sealing } & \multicolumn{2}{|c|}{$\otimes 2$. Zero hunger } \\
\hline \multicolumn{2}{|l|}{$\square$ Soil contamination } & \multicolumn{2}{|c|}{$\square$ 3. Good health and well-being } \\
\hline \multicolumn{2}{|c|}{ Decline in soil organic matter (SOM) } & \multicolumn{2}{|c|}{$\square$ 4. Quality education } \\
\hline \multicolumn{2}{|l|}{$\square$ Soil compaction } & \multicolumn{2}{|c|}{$\square$ 5. Gender equality } \\
\hline \multicolumn{2}{|l|}{$\square$ Desertification } & \multicolumn{2}{|c|}{$\square 6$. Clean water and sanitation } \\
\hline \multicolumn{2}{|l|}{$\square$ Flooding } & \multicolumn{2}{|c|}{$\square$ 7. Affordable and clean energy } \\
\hline \multicolumn{2}{|l|}{$\square$ Soil salinisation } & \multicolumn{2}{|c|}{$\square$ 8. Decent work and economic growth } \\
\hline \multicolumn{2}{|l|}{$\square$ Droughts } & \multicolumn{2}{|c|}{$\square$ 9. Industry, innovation and infrastructure } \\
\hline \multicolumn{2}{|l|}{$\square$ Landslides } & \multicolumn{2}{|c|}{$\square$ 10. Reduce inequalities } \\
\hline \multicolumn{2}{|l|}{$\square$ Eutrophication } & \multicolumn{2}{|c|}{$\square$ 11. Sustainable cities and communities } \\
\hline \multicolumn{2}{|l|}{$\square$ Soil biodiversity } & \multicolumn{2}{|c|}{$\square$ 12. Responsible consumption and production } \\
\hline$\square$ Forest fires & & 凶 13. Climate & \\
\hline$\square$ Soil acidification & & $\square$ 14. Life belc & later \\
\hline$\square$ Other (please speci & & $\otimes 15$. Life on & \\
\hline & & $\square$ 16. Peace, $j$ & ce and strong institutions \\
\hline & & $\square$ 17. Partners & for the goals \\
\hline
\end{tabular}




\section{Good practice name: LANDMARK}

\section{Country: EU}

$\begin{array}{ll}\text { Good practice name: } & \text { LANDMARK } \\ \text { Type of initiative: } & \bigotimes \text { Policy } \\ & \square \text { Practice } \\ & \square \text { Network } \\ & \bigotimes \text { Research } \\ & \bigotimes \text { Tool / Instrument } \\ & \square \text { Methodology } \\ & \square \text { Pilot } \\ & \square \text { Other (please specify) }\end{array}$

Context. What is the background of the project/initiative?

$\begin{array}{ll}\text { Country: } & \text { EU } \\ \text { Type of land: } & \square \text { Agricultural } \\ & \square \text { Forest } \\ & \square \text { Nature } \\ & \square \text { Industrial } \\ & \square \text { Urban } \\ & \square \text { Derelict/unused }\end{array}$

European Research Project

What is the main purpose/objective of the initiative?

Comprehensively quantify the current and potential supply of soil functions across the EU, as determined by soil properties

(soil diagnostic criteria), land use (arable, grassland, forestry) and soil management practices.

Short description if the initiative/project/network

LANDMARK is a European Research Project on the sustainable management of land and soil in Europe. The questions that

LANDMARK aims to address are: "How can we make the most of our land? How can we ensure that our soils deliver on the many expectations we have of our land?". These expectations (or 'demands') include:

- $\quad$ Primary productivity (agriculture and forestry)

- Water purification and regulation

- Carbon sequestration, cycling and regulation

- Provision of functional and intrinsic biodiversity

- Provision and cycling of nutrients.

What are the main outputs and outcomes (take-home messages)?

- $\quad$ For farmers \& advisors - a Soil Navigator that provides advice on the sustainable management of soils on ' $m y$ farm'. This agricultural Decision Support Tool (DST) will be developed for soil management that optimises soil functions, both from an agronomic perspective (optimising yields) and an ecosystem function perspective (enhanced environmental performance), and that sustains soil functions by mitigating threats to soil quality;

- $\quad$ For legislators - a framework for monitoring of soil quality and soil functions that is applicable across Europe. The monitoring scheme designed will be applicable at regional scale, for a range of soil types, land uses and pedo-climatic zones;

- For policy makers - an assessment of policies that can ensure that we 'make the most of our land', from both an agronomic and environmental point of view. The policy framework developed for 'Functional Land Management' at European scale will optimise the sustainable use of Europe's soil resource across all major land uses: grassland, arable and forestry.

Soil threats addressed:

SDGs addressed:

$\otimes$ Soil erosion

$\square$ 1. No poverty

$\otimes$ Soil sealing

$凶$ Soil contamination

$\otimes 2$. Zero hunger

$\square$ 3. Good health and well-being

$凶$ Decline in soil organic matter (SOM)

$\square$ 4. Quality education

$凶$ Soil compaction

$\square$ 5. Gender equality

$\otimes$ Desertification

$\square$ 6. Clean water and sanitation

$\square$ Flooding

$\square$ 7. Affordable and clean energy

$凶$ Soil salinisation

$\square$ 8. Decent work and economic growth

$\otimes$ Droughts

$\square$ Landslides

$\square$ 9. Industry, innovation and infrastructure

$\square$ 10. Reduce inequalities

$\otimes$ Eutrophication

$\square$ 11. Sustainable cities and communities

$\otimes$ Soil biodiversity

$\square$ 12. Responsible consumption and production

$\square$ Forest fires

$\square$ 13. Climate action

$\otimes$ Soil acidification

$\square$ 14. Life below water

$\square$ Other (please specify)

$\otimes 15$. Life on land

$\square$ 16. Peace, justice and strong institutions

$\square$ 17. Partnerships for the goals

References/Links/More info

http://landmark2020.eu/ 
Good practice name: Life AMDRY 4

\section{Country: Mediterranean area}

\begin{tabular}{|c|c|c|c|}
\hline $\begin{array}{l}\text { Good practice name: } \\
\text { Type of initiative: }\end{array}$ & $\begin{array}{l}\text { Life AMDRY } 4 \\
\square \text { Policy } \\
\text { 冈 Practice } \\
\square \text { Network } \\
\text { 囚 Research } \\
\square \text { Tool / Instrument } \\
\square \text { Methodology } \\
\square \text { Pilot } \\
\square \text { Other (please specify) }\end{array}$ & $\begin{array}{l}\text { Country: } \\
\text { Type of land: }\end{array}$ & $\begin{array}{l}\text { Mediterranean area } \\
\bigotimes \text { Agricultural } \\
\square \text { Forest } \\
\square \text { Nature } \\
\square \text { Industrial } \\
\square \text { Urban } \\
\square \text { Derelict/unused }\end{array}$ \\
\hline \multicolumn{4}{|c|}{ Context. What is the background of the project/initiative? } \\
\hline \multicolumn{4}{|l|}{ LIFE project } \\
\hline \multicolumn{4}{|c|}{ What is the main purpose/objective of the initiative? } \\
\hline \multicolumn{4}{|c|}{ To promote resilience in Mediterranean agricultural areas } \\
\hline \multicolumn{4}{|c|}{ Short description if the initiative/project/network } \\
\hline \multicolumn{4}{|c|}{$\begin{array}{l}\text { Project AMDRY4(Life) Adaptation to Climate Change of Agricultures in the Mediterranean Area. It focuses on the promotion } \\
\text { of resilience in Mediterranean agricultural areas, along with its sustainable management. It also promotes ecosystem-based } \\
\text { adaptation }\end{array}$} \\
\hline \multicolumn{4}{|c|}{ What are the main outputs and outcomes (take-home messages)? } \\
\hline \multicolumn{4}{|c|}{$\begin{array}{l}\text { Agriculture and biodiversity can survive together, they are not enemies but complementary in the adaptation to climate } \\
\text { change }\end{array}$} \\
\hline \multicolumn{2}{|l|}{ Soil threats addressed: } & \multicolumn{2}{|c|}{ SDGs addressed: } \\
\hline \multicolumn{2}{|l|}{$\square$ Soil erosion } & \multicolumn{2}{|c|}{$\square$ 1. No poverty } \\
\hline \multicolumn{2}{|l|}{$\square$ Soil sealing } & \multicolumn{2}{|c|}{$凶 2$. Zero hunger } \\
\hline \multicolumn{2}{|l|}{$\square$ Soil contamination } & \multicolumn{2}{|c|}{$\square$ 3. Good health and well-being } \\
\hline \multicolumn{2}{|c|}{$凶$ Decline in soil organic matter (SOM) } & \multicolumn{2}{|c|}{$\square$ 4. Quality education } \\
\hline \multicolumn{2}{|l|}{$\square$ Soil compaction } & \multicolumn{2}{|c|}{$\square$ 5. Gender equality } \\
\hline \multicolumn{2}{|l|}{$\square$ Desertification } & \multicolumn{2}{|c|}{$\square$ 6. Clean water and sanitation } \\
\hline \multicolumn{2}{|l|}{$\square$ Flooding } & \multicolumn{2}{|c|}{$\square$ 7. Affordable and clean energy } \\
\hline \multicolumn{2}{|l|}{$\square$ Soil salinisation } & \multicolumn{2}{|c|}{$\square$ 8. Decent work and economic growth } \\
\hline \multicolumn{2}{|l|}{$\square$ Droughts } & \multicolumn{2}{|c|}{$\square$ 9. Industry, innovation and infrastructure } \\
\hline \multicolumn{2}{|l|}{$\square$ Landslides } & \multicolumn{2}{|c|}{$\square$ 10. Reduce inequalities } \\
\hline \multicolumn{2}{|l|}{$\square$ Eutrophication } & \multicolumn{2}{|c|}{$\square$ 11. Sustainable cities and communities } \\
\hline \multicolumn{2}{|l|}{$凶$ Soil biodiversity } & $\square$ 12. Respons & consumption and production \\
\hline$\square$ Forest fires & & $\square$ 13. Climate & \\
\hline$\square$ Soil acidification & & $\square$ 14. Life belc & vater \\
\hline$\square$ Other (please speci & & 冈 15. Life on I & \\
\hline & & $\square$ 16. Peace, $j$ & and strong institutions \\
\hline
\end{tabular}

References/Links/More info:

http://lifeamdryc4.eu/en/ 


\section{Good practice name: land stewardship and soil stewardship scenarios OVAM Country: Belgium}

$\begin{array}{ll}\text { Good practice name: } & \text { land stewardship and soil } \\ & \text { stewardship scenarios OVAM } \\ \text { Type of initiative: } & \text { \Policy } \\ & \square \text { Practice } \\ & \square \text { Network } \\ & \square \text { Research } \\ & \text { 冈 Tool / Instrument } \\ & \text { 冈 Methodology } \\ & \square \text { Pilot } \\ & \square \text { Other (please specify) }\end{array}$

\begin{tabular}{|c|c|}
\hline Country: & Belgium \\
\hline Type of land: & 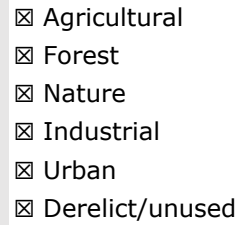 \\
\hline
\end{tabular}

Context. What is the background of the project/initiative?

own initiative:

OVAM, the Flemish Waste Management Agency, has initiated a program to explore novel policy approaches to dealing with soil care and new challenges on soil contamination such as diffuse pollution and emerging contaminants. One of the key elements in this program for more soil care is a strategy based on soil and land stewardship.

With the Soil Remediation and Protection Decree, there is already an important instrument in the realization of the Flemish soil policy: it provides for a thorough curative approach to soil contamination with, in addition, an important prevention component (e.g. stricter regulation of the remediation obligation and liability for new soil contamination; sustainable management of soil materials) through the regulation on excavated soil; a general framework for soil protection). Other (new) challenges, such as the policy on emerging substances and diffuse contamination, the strengthening of the ambitions of sustainable circular land use (such as brownfields and landfill sites), the further prevention of pollution, the integration of care for soil ecosystem services and soil biodiversity, ... require new solution pathways that are currently in an exploratory phase.

What is the main purpose/objective of the initiative?

OVAM considers stewardship as a potential lever for activating everyone in order to take responsibility for soil care (including the listed challenges ${ }^{82}$ ) and put it into practice. To achieve this, it is necessary that 1 ) we strengthen the insight of the importance of a healthy soil and the sense of urgency for soil care through soil awareness, 2) that we offer the necessary regulatory frameworks and knowledge to be able to apply this soil care in such a way that this leads to 3) more soil care (and therefore more soil care workers or soil stewards) in practice, and this within different contexts, for different target groups and in different spatial scales: from micro to meso to macro scales.

Short description if the initiative/project/network

Within each of the 3 above mentioned layers, we work on various actions:

- creating support and awareness, and expanding knowledge through workshops on international forums

- developing future scenarios within an international stakeholder group

-exploring the legal possibilities for stewardship and soil care in regulations

- building of stewardship communities

- encouraging good practices tailormade for each target group: eg via guidelines for the management of contaminated soil within un-sealing processes,..

What are the main outputs and outcomes (take-home messages)?

1. Align policy on soil

2. Centralize and exchange knowledge in order to provide tools for soil care

3. Build communities

4. Integrate policy-knowledge-practice

5. Build inspiring future scenarios

Policy tools, regulations, guidelines, community of good practices, scenarios, ...

Soil threats addressed:

\section{$\otimes$ Soil erosion}

Soil sealing

$凶$ Soil contamination

冈 Decline in soil organic matter (SOM)

$凶$ Soil compaction

$\otimes$ Desertification

$凶$ Flooding

$凶$ Soil salinisation

$\otimes$ Droughts

凶 Landslides

Eutrophication

$\otimes$ Soil biodiversity
SDGs addressed:

$\square$ 1. No poverty

$\otimes 2$. Zero hunger

$\otimes 3$. Good health and well-being

$凶$ 4. Quality education

$\square$ 5. Gender equality

$凶$ 6. Clean water and sanitation

$\square$ 7. Affordable and clean energy

$\otimes 8$. Decent work and economic growth

$\otimes 9$. Industry, innovation and infrastructure

$\square$ 10. Reduce inequalities

$\otimes 11$. Sustainable cities and communities

$\otimes 12$. Responsible consumption and production

${ }^{82}$ Such as the policy on emerging substances and diffuse pollution, the strengthening of the ambitions of sustainable circular land use (such as brownfields and landfill sites), the further prevention of pollution, the integration of care for soil ecosystem services and soil biodiversity, ... 
ॠ Forest fires

$凶$ Soil acidification

$\square$ Other (please specify)

References/Links/More info:

Not ready yet
囚 13. Climate action

$\square$ 14. Life below water

$\otimes 15$. Life on land

$\square$ 16. Peace, justice and strong institutions

$\otimes$ 17. Partnerships for the goals 
Good practice name: Guidelines on best practice to limit, mitigate or compensate soil sealing Country: EU

$\begin{array}{ll}\text { Good practice name: } & \text { Guidelines on best practice to limit, } \\ & \text { mitigate or compensate soil sealing } \\ & \square \text { Policy } \\ & \text { \Practice } \\ & \bigotimes \text { Network } \\ & \square \text { Research } \\ & \square \text { Tool / Instrument } \\ & \square \text { Methodology } \\ & \square \text { Pilot } \\ & \square \text { Other (please specify) }\end{array}$

\begin{tabular}{|c|c|}
\hline Country: & EU \\
\hline Type of land: & 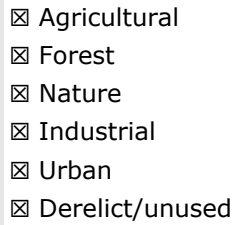 \\
\hline
\end{tabular}

Context. What is the background of the project/initiative?

EC initiative

What is the main purpose/objective of the initiative?

Main goals are to provide information on the magnitude of soil sealing in the European Union (EU), its impacts and examples of best practice.

Short description if the initiative/project/network

This Commission Staff Working Document describes approaches based on limiting, mitigating and compensating for the effects of soil sealing which have been implemented in the Member States. Limiting soil sealing means preventing the conversion of green areas and the subsequent sealing of (part of) their surface. The re-use of already built-up areas, e.g. brownfield sites, can also be included in this concept. Targets have been used as a tool for monitoring as well as spurring progress. Where soil sealing occurs, appropriate mitigation measures have been taken in order to maintain some of the soil functions and to reduce any significant direct or indirect negative effects on the environment and human well-being. Where on-site mitigation measures are regarded as insufficient, compensation measures have been considered, bearing in mind, however, that sealing cannot be exactly compensated for. The objective has rather been to sustain or restore the overall capacity of soils in a certain area to fulfil (most of) their functions. Existing best practices designed to limit, mitigate and compensate soil sealing show that sound spatial planning follows an integrated approach, requiring the full commitment of all relevant public authorities (and not only planning and environmental departments), in particular those governance entities (e.g. municipalities, counties and regions) which are normally responsible for the management of land. A second common element is that specific regional approaches are developed, taking into account unused resources at local level, for example a particularly large number of empty buildings or brownfield sites. Finally, existing funding policies for infrastructure development have been carefully reviewed, leading to a reduction of those subsidies that act as drivers for unsustainable land take and soil sealing; the scope for lowering the share of urbanisation fees in municipal budgets is also sometimes considered.

What are the main outputs and outcomes (take-home messages)?

Practical guidelines

Soil threats addressed:

SDGs addressed:

$\square$ Soil erosion

\Soil sealing

$\square$ Soil contamination

$\square$ Decline in soil organic matter (SOM)

$\square$ 1. No poverty

$\square$ 2. Zero hunger

$\square$ 3. Good health and well-being

$\square$ Soil compaction

$\square$ 4. Quality education

$\square$ Desertification

$\square$ 5. Gender equality

$\square$ Flooding

$\square$ 6. Clean water and sanitation

$\square$ 7. Affordable and clean energy

$\square$ Soil salinisation

$\square$ 8. Decent work and economic growth

$\square$ Droughts

$\square$ Landslides

$\square$ 9. Industry, innovation and infrastructure

$\square$ Eutrophicatio

$\square$ 10. Reduce inequalities

$\square$ Soil biodiversity

$\otimes 11$. Sustainable cities and communities

$\square$ Forest fires

$\square$ 12. Responsible consumption and production

$\square$ Soil acidification

$\square$ 13. Climate action

$\square$ Other (please specify)

$\square$ 14. Life below water

$\otimes 15$. Life on land

$\square$ 16. Peace, justice and strong institutions

$\square$ 17. Partnerships for the goals

References/Links/More info:

https://ec.europa.eu/environment/soil/pdf/soil_sealing_guidelines_en.pdf 


\section{Good practice name: SOS4Soil}

\section{Country: Italy}

$\begin{array}{ll}\text { Good practice name: } & \text { SOS4Soil } \\ \text { Type of initiative: } & \square \text { Policy } \\ & \text { \Practice } \\ & \square \text { Network } \\ & \square \text { Research } \\ & \text { \ Tool / Instrument } \\ & \square \text { Methodology } \\ & \text { 冈 Pilot } \\ & \square \text { Other (please specify) }\end{array}$

$\begin{array}{ll}\text { Country: } & \text { Italy } \\ \text { Type of land: } & \square \text { Agricultural } \\ & \square \text { Forest } \\ & \square \text { Nature } \\ & \square \text { Industrial } \\ & \bigotimes \text { Urban } \\ & \square \text { Derelict/unused }\end{array}$

Context. What is the background of the project/initiative?

SOS4Soil LIFEENV/IT/000225

What is the main purpose/objective of the initiative?

SOS4LIFE aims to contribute to the enforcement at the municipal scale of European orientations about soil protection and urban regeneration, with particular preference to the Guidelines on best practices to reduce, mitigate and compensate soil sealing $[(\operatorname{SWD}(2012) 101]$

Short description if the initiative/project/network

Evaluation of ecosystems services provided by urban soils; regulation framework and operational tools at municipal level to achieve the 'no net landtake' target;

What are the main outputs and outcomes (take-home messages)?

desealing interventions to promote urban regeneration; operational tools at municipal level; Urban and Soil Decision Support System adopted by municipal and regions for monitoring land use change, urban regeneration processes and ecosystem services

Soil threats addressed:

SDGs addressed:

$\square$ Soil erosion

$\square$ 1. No poverty

\ Soil sealing

$\square$ 2. Zero hunger

$\square$ Soil contamination

$\square$ 3. Good health and well-being

\. Decline in soil organic matter (SOM)

$\square$ 4. Quality education

$\square$ Soil compaction

$\square$ 5. Gender equality

$\square$ Desertification

$\square$ 6. Clean water and sanitation

Flooding

$\square$ 7. Affordable and clean energy

$\square$ Soil salinisation

$\square$ 8. Decent work and economic growth

$\square$ Droughts

$\square$ 9. Industry, innovation and infrastructure

$\square$ Landslides

$\square$ 10. Reduce inequalities

$\square$ Eutrophication

冈11. Sustainable cities and communities

$\otimes$ Soil biodiversity

$\square$ 12. Responsible consumption and production

$\square$ Forest fires

$\square$ Soil acidification

$\square$ 13. Climate action

$\square$ Other (please specify)

$\square$ 14. Life below water

$\square$ 15. Life on land

$\square$ 16. Peace, justice and strong institutions

$\square$ 17. Partnerships for the goals

References/Links/More info:

www.sos4life.it

https://ambiente.regione.emilia-romagna.it/en/geologia/temi/suoli?set_language=en 
Good practice name: 0.666 Circular ideas (OVAM)

\section{Country: Belgium}

$\begin{array}{ll}\text { Good practice name: } & \text { O.666 Circular ideas (OVAM) } \\ \text { Type of initiative: } & \square \text { Policy } \\ & \text { 冈 Practice } \\ & \square \text { Network } \\ & \square \text { Research } \\ & \square \text { Tool / Instrument } \\ & \square \text { Methodology } \\ & \square \text { Pilot } \\ & \square \text { Other (please specify) }\end{array}$

$\begin{array}{ll}\text { Country: } & \text { Belgium } \\ \text { Type of land: } & \square \text { Agricultural } \\ & \square \text { Forest } \\ & \square \text { Nature } \\ & \text { 囚 Industrial } \\ & \text { 冈 Urban } \\ & \text { 冈 Derelict/unused }\end{array}$

Context. What is the background of the project/initiative?

\section{What is the main purpose/objective of the initiative?}

\section{Short description if the initiative/project/network}

Due to the 'Protocol Trusty', the OVAM (public waste agency of Flanders) was able to acquire a property located at the harbor of Ostend (Belgium), for one symbolic euro. For years, the firm 'The North Sea Bunkers' was a deposit for fuels. The legacy of this activity was a severe contamination of petroleum in soil and groundwater. The previous owner was bankrupt and therefore not able to pay for the soil remediation. Moreover, the estimated remediation costs were far above the sales value of the site.

The site has a unique location on shore. It lies on the border of two areas with on the one hand the redevelopment to residential area and on the other hand the existing port area. The port area has a fall back in terms of economic growth, such as many other port areas. Due to its specific position, the site has a strong potential for the launch of new dynamics on the Eastern Shore.

Considering the remediation of the groundwater on the site is a long-term project, making the space unavailable for further development, OVAM allowed temporary use for local stakeholders who were willing to invest into activities with circular ideas. Now they are a well organises group and called themselves ' $O .666$ '. They considered themselves to be a testing ground for circular economy, social and corporate social responsibility. It is focused on a close connection and dialogue with the neighborhood and the city of Oostende, giving meaning back to the site. They stand for public partnerships, participation and education in the form of open workshops, forums, presentations and events What are the main outputs and outcomes (take-home messages)?

It is necessary to do a tailor-made approach with goal setting to redevelop specific contaminated spaces toward meaningful places. Focussing on local societal challenges and collaborating with the local authority and committed stakeholders is key for success

\author{
Soil threats addressed: \\ $\square$ Soil erosion \\ $\square$ Soil sealing \\ Q Soil contamination \\ $\square$ Decline in soil organic matter (SOM) \\ $\square$ Soil compaction \\ $\square$ Desertification \\ $\square$ Flooding \\ $\square$ Soil salinisation \\ $\square$ Droughts \\ $\square$ Landslides \\ $\square$ Eutrophication \\ $\square$ Soil biodiversity \\ $\square$ Forest fires \\ $\square$ Soil acidification \\ $\square$ Other (please specify)
}

SDGs addressed:

\section{$\square$ 1. No poverty}

$\square$ 2. Zero hunger

$\square$ 3. Good health and well-being

$\square$ 4. Quality education

$\square$ 5. Gender equality

$\square$ 6. Clean water and sanitation

$\square$ 7. Affordable and clean energy

$\square$ 8. Decent work and economic growth

$\square$ 9. Industry, innovation and infrastructure

$\square$ 10. Reduce inequalities

$\square$ 11. Sustainable cities and communities

$\square$ 12. Responsible consumption and production

$\square$ 13. Climate action

$\square$ 14. Life below water

$\otimes$ 15. Life on land

$\square$ 16. Peace, justice and strong institutions

$\square$ 17. Partnerships for the goals

References/Links/More info: 


\section{Initiatives starting from LDN / combating LD}

\section{Good practice name: LDN action UNCCD / LDN target setting Country: Global}

$\begin{array}{ll}\text { Good practice name: } & \text { LDN action UNCCD /LDN target } \\ & \text { setting } \\ \text { Type of initiative: } & \text { 冈 Policy } \\ & \text { 冈 Practice } \\ & \square \text { Network } \\ & \square \text { Research } \\ & \square \text { Tool / Instrument } \\ & \square \text { Methodology } \\ & \square \text { Pilot } \\ & \square \text { Other (please specify) }\end{array}$

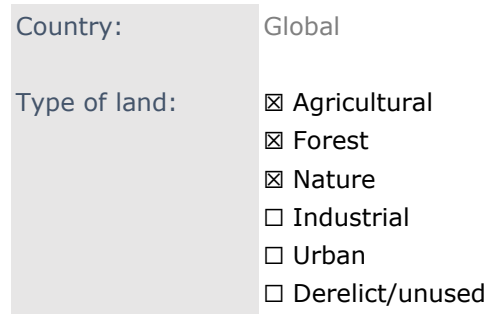

Context. What is the background of the project/initiative?

LDN initiative UNCCD

What is the main purpose/objective of the initiative?

The new UNCCD 2018-2030 Strategic Framework is the most comprehensive global commitment to achieve Land

Degradation Neutrality (LDN) in order to restore the productivity of vast expanses of degraded land, improve the livelihoods of more than 1.3 billion people, and reduce the impacts of drought on vulnerable populations to build a future that avoids, minimizes, and reverses desertification/land degradation and mitigates the effects of drought in affected areas at all levels. To achieve a land degradation-neutral world consistent with the 2030 Agenda for Sustainable Development Short description if the initiative/project/network

Different action programmes have been set to provide policy-relevant information and further guidance, awareness -raising and advocacy on LDN, for UNCCD country parties, key decision- and policy-makers, national and international development partners.

one of the actions is the Land Degradation Neutrality Target Setting, aimed at operationalisation of LDN and transform it into an implementable approach that enables countries to make progress towards achieving SDG target 15.3 and the objectives of the UNCCD.

A policy brief has been made containing on four main building blocks: (1) leveraging LDN, (2) assessing LDN, (3) setting LDN targets and measures, and (4) achieving LDN.

As of today, 123 countries have committed to set LDN targets

What are the main outputs and outcomes (take-home messages)?

consult the knowledge hub on https://knowledge.unccd.int/

Soil threats addressed:

SDGs addressed:

\Soil erosion

$\otimes 1$. No poverty

囚 Soil sealing

$凶$ 2. Zero hunger

\ Soil contamination

$\square$ 3. Good health and well-being

凶 Decline in soil organic matter (SOM)

$\square$ 4. Quality education

\Soil compaction

冈 Desertification

\5. Gender equality

凶 6. Clean water and sanitation

凶 Flooding

$\square$ 7. Affordable and clean energy

$\otimes$ Soil salinisation

$\square$ 8. Decent work and economic growth

冈 Droughts

$\square$ 9. Industry, innovation and infrastructure

凶 Landslides

$凶$ 10. Reduce inequalities

छutrophication

$\otimes$ Soil biodiversity

$\square$ 11. Sustainable cities and communities

$凶$ Forest fires

$\square$ 12. Responsible consumption and production

$凶$ Soil acidification

$\square$ Other (please specify)

$\otimes$ 13. Climate action

$\square$ 14. Life below water

$凶 15$. Life on land

$\square$ 16. Peace, justice and strong institutions

$\square$ 17. Partnerships for the goals

References/Links/More info:

http://catalogue.unccd.int/1217_UNCCD_GM_Report_18_V2_2019.pdf 


\section{Good practice name: LDN Fund \\ Country: Global}

$\begin{array}{ll}\text { Good practice name: } & \text { LDN Fund } \\ \text { Type of initiative: } & \square \text { Policy } \\ & \text { 冈 Practice } \\ & \square \text { Network } \\ & \square \text { Research } \\ & \square \text { Tool / Instrument } \\ & \square \text { Methodology } \\ & \square \text { Pilot } \\ & \square \text { Other (please specify) }\end{array}$

$\begin{array}{ll}\text { Country: } & \text { Global } \\ \text { Type of land: } & \text { Agricultural } \\ & \text { 冈 Forest } \\ & \text { 冈 Nature } \\ & \square \text { Industrial } \\ & \square \text { Urban } \\ & \square \text { Derelict/unused }\end{array}$

Context. What is the background of the project/initiative?

LDN initiative UNCCD

What is the main purpose/objective of the initiative?

To establish an innovative finance instrument (managed and operated independently by a private sector fund manager) that combines private and public resources to invest in financially viable projects that contribute to achieving LDN.

Short description if the initiative/project/network

The Land Degradation Neutrality Fund is an innovative fund that combines public and private resources to finance a range of financially viable investments - from sustainable agriculture projects that benefit small landowners or rural cooperatives to large agroforestry projects for rehabilitating vast tracts of land - in application of the LDN response hierarchy of avoiding, reducing, and reversing land degradation. The LDN Fund was conceived in recognition of rapidly growing interest from individual investors, savers, and pensioners who wish their money to have a positive impact on many environmental challenges beyond a financial return. The LDN Fund aims to play a catalytic role by supporting productive and conservation activities that contribute to both achieving LDN and creating decent jobs and livelihoods for the most vulnerable people and countries. The LDN Fund initiative is part of a broader framework of Land Degradation Neutrality under the UNCCD, noting that the Fund is independently managed and the Global Mechanism of the UNCCD spearheaded the development of the Fund.

What are the main outputs and outcomes (take-home messages)?

The main take-home message is: the LDN Fund initiative is an exemplary case that is creating an impact by leveraging innovatively substantial private-sector capital, thereby contributing to the achieving LDN at a global level.

\author{
Soil threats addressed: \\ 凶 Soil erosion \\ 囚 Soil sealing \\ 凶Soil contamination \\ 囚 Decline in soil organic matter (SOM) \\ 凶 Soil compaction \\ 囚 Desertification \\ 凶 Flooding \\ 囚 Soil salinisation \\ Droughts \\ 凶 Landslides \\ 区utrophication \\ 凶Soil biodiversity \\ ₹ Forest fires \\ 囚 Soil acidification \\ $\square$ Other (please specify)
}

SDGs addressed:

$凶 1$. No poverty

$\otimes 2$. Zero hunger

$\square$ 3. Good health and well-being

$\square$ 4. Quality education

$凶 5$. Gender equality

囚. Clean water and sanitation

$\square$ 7. Affordable and clean energy

$\square$ 8. Decent work and economic growth

$\square$ 9. Industry, innovation and infrastructure

$\otimes 10$. Reduce inequalities

$\square$ 11. Sustainable cities and communities

$\square$ 12. Responsible consumption and production

$\otimes 13$. Climate action

$\square$ 14. Life below water

$\otimes 15$. Life on land

$\square$ 16. Peace, justice and strong institutions

$\square$ 17. Partnerships for the goals

References/Links/More info:

https://www.unccd.int/actions/impact-investment-fund-land-degradation-neutrality

https://www.mirova.com/en/invest/natural-capital 


\section{Good practice name: World Atlas of Desertification}

\section{Country: Global}

$\begin{array}{ll}\text { Good practice name: } & \text { World Atlas of Desertification } \\ \text { Type of initiative: } & \square \text { Policy } \\ & \square \text { Practice } \\ & \square \text { Network } \\ & \bigotimes \text { Research } \\ & \text { \ool / Instrument } \\ & \square \text { Methodology } \\ & \square \text { Pilot } \\ & \square \text { Other (please specify) }\end{array}$

\begin{tabular}{|c|c|}
\hline $\begin{array}{l}\text { Country: } \\
\text { Type of land: }\end{array}$ & 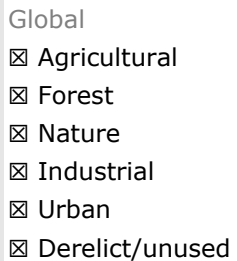 \\
\hline
\end{tabular}

Context. What is the background of the project/initiative?

UNCCD / JRC initiative

What is the main purpose/objective of the initiative?

To analyse the causes and impacts of desertification, and their impact of land degradation

Short description if the initiative/project/network

Overview and analysis of the different aspects that relate to desertification and then land degradation, such as aridity, pollution, biodiversity, fire regimes, nutrients, mining, biodiversity, etc.

What are the main outputs and outcomes (take-home messages)?

Land degradation happens locally but has repercussions at global scale. Human activities drive change, with land degradation one unfortunate result.

\author{
Soil threats addressed: \\ $\square$ Soil erosion \\ $\square$ Soil sealing \\ $\square$ Soil contamination \\ $\square$ Decline in soil organic matter (SOM) \\ $\square$ Soil compaction \\ $\otimes$ Desertification \\ $\square$ Flooding \\ $\square$ Soil salinisation \\ $\square$ Droughts \\ $\square$ Landslides \\ $\square$ Eutrophication \\ $\square$ Soil biodiversity \\ $\square$ Forest fires \\ $\square$ Soil acidification \\ $\square$ Other (please specify)
}
SDGs addressed:
$\square$ 1. No poverty
$\otimes 2$. Zero hunger
$\square$ 3. Good health and well-being
$\square$ 4. Quality education
$\square$ 5. Gender equality
$\square$ 6. Clean water and sanitation
$\square$ 7. Affordable and clean energy
$\square$ 8. Decent work and economic growth
$\square$ 9. Industry, innovation and infrastructure
$\square$ 10. Reduce inequalities
$\square$ 11. Sustainable cities and communities
$凶 12$. Responsible consumption and production
$\square$ 13. Climate action
$\square$ 14. Life below water
$\otimes$ 15. Life on land
$\square$ 16. Peace, justice and strong institutions
$\square$ 17. Partnerships for the goals 


\section{Good practice name: Land Degradation Neutrality: Italy \\ Country: Italy}

\begin{tabular}{|c|c|c|c|}
\hline $\begin{array}{l}\text { Good practice name: } \\
\text { Type of initiative: }\end{array}$ & $\begin{array}{l}\text { Land Degradation Neutrality: Italy } \\
\bigotimes \text { Policy } \\
\square \text { Practice } \\
\square \text { Network } \\
\square \text { Research } \\
\square \text { Tool / Instrument } \\
\square \text { Methodology } \\
\square \text { Pilot } \\
\square \text { Other (please specify) }\end{array}$ & $\begin{array}{l}\text { Country: } \\
\text { Type of land: }\end{array}$ & $\begin{array}{l}\text { Italy } \\
\bigotimes \text { Agricultural } \\
\bigotimes \text { Forest } \\
\bigotimes \text { Nature } \\
\square \text { Industrial } \\
\square \text { Urban } \\
\square \text { Derelict/unused }\end{array}$ \\
\hline \multicolumn{4}{|c|}{ Context. What is the background of the project/initiative? } \\
\hline \multicolumn{4}{|l|}{ LDN initiative UNCCD } \\
\hline \multicolumn{4}{|c|}{ What is the main purpose/objective of the initiative? } \\
\hline implementing LDN in & & & \\
\hline
\end{tabular}

The Italian National Institute for Environmental Protection and Research (ISPRA) participated in the project 'Towards achieving land degradation neutrality: turning the concept into practice. Pilot country: Italy'. The project was carried out by a working group of experts from the main national research institutions under the supervision of the Ministry of Environment and the UNCCD Focal Point in the Ministry of Foreign Affairs.

A project that addressed land cover, land productivity and soil organic carbon, in order to be consistent with the LDN indicator proposed by UNCCD and adopted by UN Statistical Commission and an extensive analysis of available data was carried out, using data, including CORINE Land Cover Project of the European Environmental Agency and the national contribution to the Global Soil Organic Carbon Map (GSOC map). The Environmental Quality Index was also used, encompassing soil quality, climate, vegetation and land use, showing that $10 \%$ of soils turned out to be very vulnerable, while $49.2 \%$ have average vulnerability and $26 \%$ have low vulnerability. Sicily is the most vulnerable region. What are the main outputs and outcomes (take-home messages)?

- It is necessary to utilise/develop national/local data - global databases are not sufficient;

- Better understanding of the driving forces behind degradation processes is needed for the identification of policies and actions;

- Involvement of stakeholders is necessary at all levels to validate the assessment;

- $\quad$ Other SDG indicators should be integrated in order to build an effective policy framework;

- $\quad$ A long-term strategy should be considered, since land and soil degradation are slow processes, as are restoration activities;

- $\quad$ All land components should be taken into consideration alongside all related factors. Built infrastructure and cultural heritage, for example, should be included and their individual values maintained.

- Global databases must be integrated with national/local data for validation and to increase spatial and temporal resolution in order to develop national LDN strategies;

- A benchmark system should be built for each indicator;

- Integration with other indicators (e.g. climate change impact and adaptation, biodiversity loss) is necessary;

- Indicators for restoration activities should be developed.

Soil threats addressed:

SDGs addressed:

凶 Soil erosion

$凶 1$. No poverty

$凶$ Soil sealing

囚 Soil contamination

$\otimes 2$. Zero hunger

$\square$ 3. Good health and well-being

凶Decline in soil organic matter (SOM)

$\square$ 4. Quality education

\Soil compaction

冈 Desertification

\5. Gender equality

凶 6. Clean water and sanitation

$\otimes$ Flooding

$\square$ 7. Affordable and clean energy

囚 Soil salinisation

$\square$ 8. Decent work and economic growth

凶 Droughts

$\square$ 9. Industry, innovation and infrastructure

凶 Landslides

$\otimes 10$. Reduce inequalities

区utrophication

凶 Soil biodiversity

$\square$ 11. Sustainable cities and communities

凶 Forest fires

$\square$ 12. Responsible consumption and production

$凶$ Soil acidification

$\otimes$ 13. Climate action

$\square$ 14. Life below water

$\square$ Other (please specify)

冈 15. Life on land

$\square$ 16. Peace, justice and strong institutions

$\square$ 17. Partnerships for the goals

References/Links/More info:

http://www.isprambiente.gov.it/en/archive/news-and-other-events/ispra-news/2016/11/monitoring-and-assessment-of-

land-for-to-climate-change-mitigation-and-adaptation 
Good practice name: JustDigIt

Country: Africa

\begin{tabular}{|c|c|c|c|}
\hline $\begin{array}{l}\text { Good practice name: } \\
\text { Type of initiative: }\end{array}$ & $\begin{array}{l}\text { JustDigIt } \\
\square \text { Policy } \\
\text { 冈 Practice } \\
\otimes \text { Network } \\
\square \text { Research } \\
\square \text { Tool / Instrument } \\
\square \text { Methodology } \\
\square \text { Pilot } \\
\square \text { Other (please specify) }\end{array}$ & $\begin{array}{l}\text { Country: } \\
\text { Type of land: }\end{array}$ & $\begin{array}{l}\text { Africa } \\
\otimes \text { Agricultural } \\
\square \text { Forest } \\
\square \text { Nature } \\
\square \text { Industrial } \\
\square \text { Urban } \\
\otimes \text { Derelict/unused }\end{array}$ \\
\hline \multicolumn{4}{|c|}{ Context. What is the background of the project/initiative? } \\
\hline \multicolumn{4}{|c|}{ NGO - UN funding and donations } \\
\hline \multicolumn{4}{|c|}{ What is the main purpose/objective of the initiative? } \\
\hline \multicolumn{4}{|c|}{ Landscape restauration } \\
\hline \multicolumn{4}{|c|}{ Short description if the initiative/project/network } \\
\hline \multicolumn{4}{|c|}{$\begin{array}{l}\text { Justdiggit applies rain harvesting techniques to restore African landscape in collaboration with local partners and organizes } \\
\text { training and community building for local farmers }\end{array}$} \\
\hline \multicolumn{4}{|c|}{ What are the main outputs and outcomes (take-home messages)? } \\
\hline \multicolumn{4}{|c|}{ We can slow down climate change, make our soil more productive and our society more inclusive at the same time } \\
\hline \multicolumn{2}{|c|}{ Soil threats addressed: } & \multicolumn{2}{|c|}{ SDGs addressed: } \\
\hline \multicolumn{2}{|l|}{$凶$ Soil erosion } & \multicolumn{2}{|c|}{$凶 1$. No poverty } \\
\hline \multicolumn{2}{|l|}{$\square$ Soil sealing } & \multicolumn{2}{|c|}{$\otimes 2$. Zero hunger } \\
\hline \multicolumn{2}{|l|}{$\square$ Soil contamination } & \multicolumn{2}{|c|}{$\square$ 3. Good health and well-being } \\
\hline \multicolumn{2}{|c|}{$凶$ Decline in soil organic matter (SOM) } & \multicolumn{2}{|c|}{$\square$ 4. Quality education } \\
\hline \multicolumn{2}{|l|}{$\square$ Soil compaction } & \multicolumn{2}{|c|}{$\otimes 5$. Gender equality } \\
\hline \multicolumn{2}{|l|}{$\otimes$ Desertification } & \multicolumn{2}{|c|}{$凶$ 6. Clean water and sanitation } \\
\hline \multicolumn{2}{|l|}{$\square$ Flooding } & \multicolumn{2}{|c|}{$\square$ 7. Affordable and clean energy } \\
\hline \multicolumn{2}{|l|}{$\square$ Soil salinisation } & \multicolumn{2}{|c|}{$凶$ 8. Decent work and economic growth } \\
\hline \multicolumn{2}{|l|}{$\otimes$ Droughts } & \multicolumn{2}{|c|}{$\square$ 9. Industry, innovation and infrastructure } \\
\hline \multicolumn{2}{|l|}{$\square$ Landslides } & \multicolumn{2}{|c|}{$\square$ 10. Reduce inequalities } \\
\hline \multicolumn{2}{|l|}{$\square$ Eutrophication } & \multicolumn{2}{|c|}{$\square$ 11. Sustainable cities and communities } \\
\hline \multicolumn{2}{|l|}{$\otimes$ Soil biodiversity } & \multicolumn{2}{|c|}{$\square$ 12. Responsible consumption and production } \\
\hline$\square$ Forest fires & & 囚 13. Climate & \\
\hline$\square$ Soil acidification & & $\square$ 14. Life belc & ater \\
\hline$\square$ Other (please speci & & $凶 15$. Life on & \\
\hline & & $\square$ 16. Peace, j & and strong institutions \\
\hline & & 冈 17. Partner & for the goals \\
\hline
\end{tabular}

References/Links/More info:

justdiggit.org 
Good practice name: MFA subsidies / Great green wall

\section{Country: Africa}

\begin{tabular}{|c|c|c|c|}
\hline $\begin{array}{l}\text { Good practice name: } \\
\text { Type of initiative: }\end{array}$ & $\begin{array}{l}\text { Great green wall } \\
\square \text { Policy } \\
\text { 冈 Practice } \\
\text { 冈 Network } \\
\square \text { Research } \\
\square \text { Tool / Instrument } \\
\square \text { Methodology } \\
\square \text { Pilot } \\
\square \text { Other (please specify) }\end{array}$ & $\begin{array}{l}\text { Country: } \\
\text { Type of land: }\end{array}$ & $\begin{array}{l}\text { Africa } \\
\bigotimes \text { Agricultural } \\
凶 \text { Forest } \\
\bigotimes \text { Nature } \\
\bigotimes \text { Industrial } \\
\bigotimes \text { Urban } \\
\bigotimes \text { Derelict/unused }\end{array}$ \\
\hline
\end{tabular}

What is the main purpose/objective of the initiative?

Short description if the initiative/project/network

Great Green Wall:

The Great Green Wall is an African-led movement with an epic ambition to grow an 8,000km natural wonder of the world across the entire width of Africa.

A decade in and roughly $15 \%$ underway, the initiative is already bringing life back to Africa's degraded landscapes at an unprecedented scale, providing food security, jobs and a reason to stay for the millions who live along its path.

The Wall promises to be a compelling solution to the many urgent threats not only facing the African Continent, but the global community as a whole - notably climate change, drought, famine, conflict and migration. What are the main outputs and outcomes (take-home messages)?

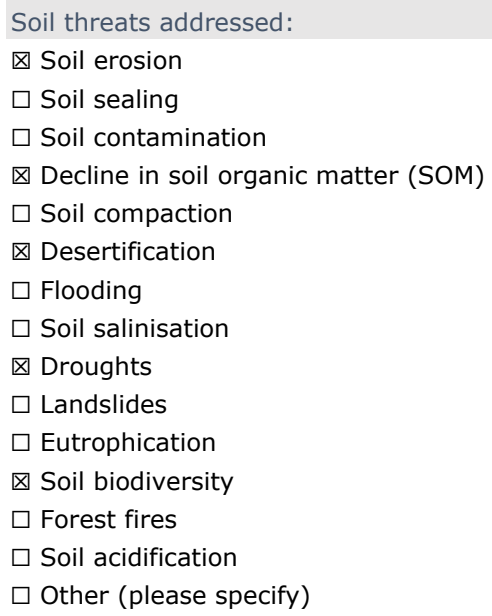

\section{SDGs addressed:}

$\otimes 1$. No poverty

$\otimes 2$. Zero hunger

$\square$ 3. Good health and well-being

$\square$ 4. Quality education

$\otimes 5$. Gender equality

$\otimes$ 6. Clean water and sanitation

$\square$ 7. Affordable and clean energy

$\otimes 8$. Decent work and economic growth

$\square$ 9. Industry, innovation and infrastructure

$\square$ 10. Reduce inequalities

$\square$ 11. Sustainable cities and communities

$\square$ 12. Responsible consumption and production

$\otimes$ 13. Climate action

$\square$ 14. Life below water

$\otimes 15$. Life on land

$\square$ 16. Peace, justice and strong institutions

$\otimes 17$. Partnerships for the goals

References/Links/More info: 
Good practice name: European Environment - State and Outlook (SOER)

Country: EU

\begin{tabular}{|c|c|c|c|}
\hline Good practice name: & $\begin{array}{l}\text { European Environment - State and } \\
\text { Outlook (SOER) }\end{array}$ & Country: & EU \\
\hline Type of initiative: & $\begin{array}{l}\square \text { Policy } \\
\square \text { Practice } \\
\square \text { Network } \\
\bigotimes \text { Research } \\
\bigotimes \text { Tool / Instrument } \\
\square \text { Methodology } \\
\square \text { Pilot } \\
\square \text { Other (please specify) }\end{array}$ & Type of land: & $\begin{array}{l}\bigotimes \text { Agricultural } \\
\bigotimes \text { Forest } \\
\bigotimes \text { Nature } \\
\square \text { Industrial } \\
\square \text { Urban } \\
\square \text { Derelict/unused }\end{array}$ \\
\hline
\end{tabular}

What is the main purpose/objective of the initiative?

The European Environment Agency's (EEA) 'State of the Environment' reports assess Europe's environmental challenges Short description if the initiative/project/network

The European environment - state and outlook 2020 (SOER 2020) comes at a crucial time of urgent sustainability challenges that require urgent systemic solutions. The overarching challenge of this century is how we achieve development across the world that balances societal, economic and environmental considerations. Sustainability needs to become the guiding principle for ambitious and coherent policies and actions across society.

What are the main outputs and outcomes (take-home messages)?

Europe will not achieve its 2030 goals without urgent action during the next 10 years to address the alarming rate of biodiversity loss, increasing impacts of climate change and the overconsumption of natural resources. The European Environment Agency's (EEA) latest 'State of the Environment' report states that Europe faces environmental challenges of unprecedented scale and urgency.

\author{
Soil threats addressed: \\ \Soil erosion \\ $凶$ Soil sealing \\ $凶$ Soil contamination \\ Decline in soil organic matter (SOM) \\ $\otimes$ Soil compaction \\ $\otimes$ Desertification \\ 囚 Flooding \\ $\otimes$ Soil salinisation \\ $\otimes$ Droughts \\ 凶 Landslides \\ $\otimes$ Eutrophication \\ $\otimes$ Soil biodiversity \\ $\square$ Forest fires \\ $\otimes$ Soil acidification \\ $\square$ Other (please specify)
}

\section{SDGs addressed:}

$\square$ 1. No poverty

$\otimes 2$. Zero hunger

$\otimes 3$. Good health and well-being

$\square$ 4. Quality education

$\square$ 5. Gender equality

$\otimes$ 6. Clean water and sanitation

$\square$ 7. Affordable and clean energy

$\square$ 8. Decent work and economic growth

$\square$ 9. Industry, innovation and infrastructure

$\square$ 10. Reduce inequalities

$\square$ 11. Sustainable cities and communities

$\square$ 12. Responsible consumption and production

$\otimes$ 13. Climate action

$\square$ 14. Life below water

$\otimes 15$. Life on land

$\square$ 16. Peace, justice and strong institutions

$\square$ 17. Partnerships for the goals

References/Links/More info:

https://www.eea.europa.eu/soer-2020 
Good practice name: Initiative on Sustainability, Stability and Security (3S)

\section{Country: Africa}

$\begin{aligned} \text { Good practice name: } & \text { Initiative on Sustainability, Stability } \\ & \text { and Security (3S) } \\ \text { Type of initiative: } & \text { 叉Policy } \\ & \text { 冈 Practice } \\ & \text { 冈 Network } \\ & \square \text { Research } \\ & \square \text { Tool / Instrument } \\ & \square \text { Methodology } \\ & \square \text { Pilot } \\ & \square \text { Other (please specify) }\end{aligned}$

$\begin{array}{ll}\text { Country: } & \text { Africa } \\ \text { Type of land: } & \\ & \bigotimes \text { Agricultural } \\ & \bigotimes \text { Forest } \\ & \bigotimes \text { Nature } \\ & \square \text { Industrial } \\ & \square \text { Urban } \\ & \square \text { Derelict/unused }\end{array}$

Context. What is the background of the project/initiative?

Development partnership (African governments and UNCCD)

What is the main purpose/objective of the initiative?

The Initiative on Sustainability, Stability and Security (3S) aims to improve stability in Africa by promoting sustainable land management and offering economic opportunity in rural areas, thereby reducing incentives for migration within and from the continent.

Short description if the initiative/project/network

Within 5 years of Program implementation, the Program aims to restore 10 million hectares of degraded cropland, primarily in the Sahel zone of sub-Saharan Africa, through investment, policy reforms and technical and financial innovation. This physical output will have the economic impact of sustaining and creating employment opportunities in the form of 2 million land-based jobs - both existing ones at peril of getting lost due to climate change and new ones being created as a result of stopping and reversing land degradation. The final outcome will be reduced migration from rural areas as populations chose to remain on their cropland instead of moving away for economic reasons. Achieving the restoration of 10 million hectares of land will benefit nearly $10 \%$ of the total cropland currently affected by land degradation, desertification and drought in all of Africa. The land area to be restored also corresponds to nearly $5 \%$ of all cropland on the African continent. While this will be a modest impact for Africa in the aggregate, the relative impact in the specific countries participating in the Program will be considerably higher. Safeguarding or newly creating 2 million rural jobs over the Program duration will be equivalent to nearly one quarter of the job gap in Africa arising in one single year. These 2 million jobs also represent $5 \%$ of the about 40 million international migrants living within and outside of Africa. These are modest impact numbers in a continental perspective, yet the relative impact of the Program in participating African countries will be substantially larger. Under the leadership of Morocco and Senegal much preparatory work has been undertaken by African governments including the development of coordination frameworks, national roadmaps and proof-of-concept projects. The United Nations Convention to Combat Desertification (UNCCD) is entrusted with the Secretariat of the Initiative and is coordinating its launch planned for late 2020 on the basis of a development partnership involving African nations, ODA donors and multilateral lenders. This development partnership to implement the 35 Initiative is named 'Resilient Africa Program (RAP): Program on Climate Resilience, Employment and Migration' ('the Program'). The Initiative links the issue of youth unemployment to the availability of and access to natural resources as the majority of jobs in Africa are based on the utilization of land. The 3S Initiative has so far been African-led with 14 countries from the continent joining to date, including Benin, Burkina Faso, Central African Republic, Chad, Gambia, Ghana, Mali, Morocco, Niger, Nigeria, Rwanda, Senegal, Zambia and Zimbabwe. Selected official development assistance (ODA) donors, including the EU through the DG DEV and EU DEL in Morocco, are providing seed funding and the International Organization for Migration (IOM) provides technical advice.

What are the main outputs and outcomes (take-home messages)?

If goals are achieved, the initiative will have the economic impact of creating employment opportunities in the form of 2 million jobs. The final outcome will be reduced migration from rural areas as populations chose to remain on their croplands instead of moving away or risking to become prays of radicalized groups. The total program cost is estimated at USD 5.0 billion. This indicative figure rests on an expected average cost of restoring degraded land of USD 500 per hectare. The expected 2 million rural jobs to be sustained or created imply cost of USD 2,500 per employment, which is also comparable with similar initiatives. The financing plan includes USD 4 billion of private resources and USD 1 billion of public resources. Public resources will be composed of USD 900 million in funding from ODA donors, other donors such as NGOs and foundations, multilateral finance. USD 100 million will be made available from budgetary contributions by participating African countries; some of these will be in-kind, for instance through the provision of land access rights which will be assessed at their market value. Private resources will come from domestic and foreign investors in agriculture, agroindustry and forestry. These will provide equity capital, loans and guarantees. The Program will also promote innovation in providing incentives to harness the potential of remittances and diaspora investments.
Soil threats addressed:
SDGs addressed:
$凶$ Soil erosion
$\square$ Soil sealing
$凶 1$. No poverty
$\checkmark$ Soil sealing
$\square$ 2. Zero hunger
$\square$ Decline in soil organic matter (SOM)
$\square$ 3. Good health and well-being
$\square$ Soil compaction
$\square$ 4. Quality education
$\otimes$ Desertification
$\square$ 5. Gender equality
$\square$ Flooding
$\square$ 6. Clean water and sanitation
$\square$ Soil salinisation
$\square$ 7. Affordable and clean energy
Droughts
$\otimes$ 8. Decent work and economic growth
$\square$ 9. Industry, innovation and infrastructure 


\section{$\square$ Landslides}

$\square$ Eutrophication

$凶$ Soil biodiversity

$\square$ Forest fires

$\square$ Soil acidification

$\square$ Other (please specify) $\square$ 10. Reduce inequalities

$\square$ 11. Sustainable cities and communities

$\square$ 12. Responsible consumption and production

$\otimes$ 13. Climate action

$\square$ 14. Life below water

$₫$ 15. Life on land

$\square$ 16. Peace, justice and strong institutions

$\square$ 17. Partnerships for the goals

References/Links/More info:

https://3s-initiative.org/ 


\section{Initiatives starting from SDGs}

\section{Good practice name: UNCCD Peace Forest Initiative \\ Country: Global}

\begin{tabular}{|c|c|}
\hline $\begin{array}{l}\text { Good practice name: } \\
\text { Type of initiative: }\end{array}$ & $\begin{array}{l}\text { UNCCD Peace Forest Initiative } \\
\text { 冈 Policy } \\
\text { 囚 Practice } \\
\text { 囚 Network } \\
\square \text { Research } \\
\square \text { Tool / Instrument } \\
\square \text { Methodology } \\
\text { Pilot } \\
\square \text { Other (please specify) }\end{array}$ \\
\hline
\end{tabular}

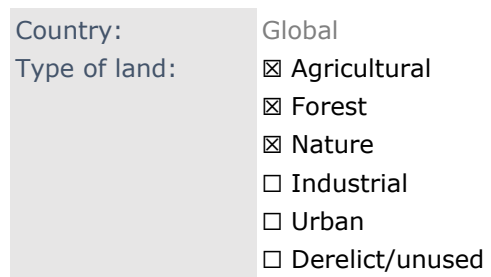

Context. What is the background of the project/initiative?

Own initiative

What is the main purpose/objective of the initiative?

The Peace Forest Initiative is to facilitate the implementation of the Land Degradation Neutrality in fragile and post-conflict situation. Ultimate goal of the Initiative is to enhance trust and peace through cooperation on land and forest management while contributing to multiple SDGs.

Short description if the initiative/project/network

The Peace Forest Initiative is designed to provide a practical platform to forge a partnership in the implementation of LDN focusing on the post-conflict situations. Rehabilitation of degraded land and forest is one of urgent challenges faced by conflict-affected community. Joint effort and joint management of natural resources would help build confidence and lasting peace, while strengthening positive relationship and benefiting local communities.

What are the main outputs and outcomes (take-home messages)?

Sustainable management of land and forest. Concrete actions on ground with mobilization of multi partners engagement can contribute to resilience building and permanent peace.

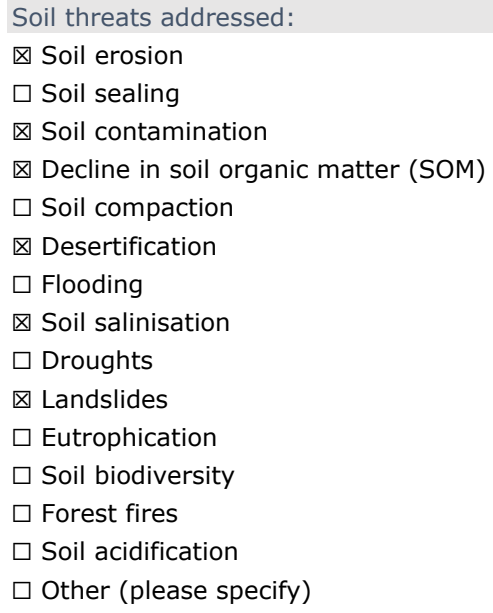

\section{SDGs addressed:}

\begin{abstract}
冈1. No poverty
\end{abstract}
$\otimes 2$. Zero hunger

\. Good health and well-being

$\square$ 4. Quality education

$凶$ 5. Gender equality

$凶$ 6. Clean water and sanitation

$\square$ 7. Affordable and clean energy

$凶$ 8. Decent work and economic growth

$\square$ 9. Industry, innovation and infrastructure

囚10. Reduce inequalities

$\square$ 11. Sustainable cities and communities

$\square$ 12. Responsible consumption and production

$\otimes$ 13. Climate action

$\square$ 14. Life below water

$\otimes 15$. Life on land

$凶$ 16. Peace, justice and strong institutions

$\otimes$ 17. Partnerships for the goals

References/Links/More info: 
Good practice name: Nicole network discussion on SDGs

\section{Country: Europe}

\begin{tabular}{|c|c|c|c|}
\hline $\begin{array}{l}\text { Good practice name: } \\
\text { Type of initiative: }\end{array}$ & 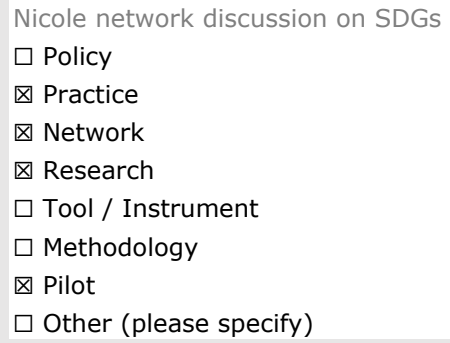 & $\begin{array}{l}\text { Country: } \\
\text { Type of land: }\end{array}$ & 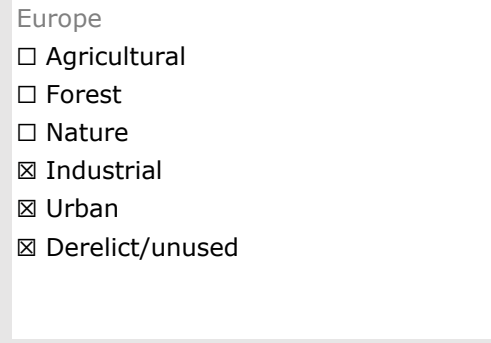 \\
\hline \multicolumn{4}{|c|}{ Context. What is the background of the project/initiative? } \\
\hline \multicolumn{4}{|c|}{ Nicole network comprising over 100 organisations. } \\
\hline \multicolumn{4}{|c|}{ What is the main purpose/objective of the initiative? } \\
\hline \multicolumn{4}{|c|}{ Promote sustainable land management across Europe. } \\
\hline \multicolumn{4}{|c|}{ Short description if the initiative/project/network } \\
\hline \multicolumn{4}{|c|}{ Nicole members discussing how best to implement the SDGs in land management. } \\
\hline \multicolumn{4}{|c|}{ What are the main outputs and outcomes (take-home messages)? } \\
\hline \multicolumn{4}{|c|}{ Much interest however frameworks need to be further developed to capture the SDGs into sustainable land management. } \\
\hline \multicolumn{2}{|l|}{ Soil threats addressed: } & \multicolumn{2}{|c|}{ SDGs addressed: } \\
\hline \multicolumn{2}{|l|}{$凶$ Soil erosion } & \multicolumn{2}{|c|}{$\square$ 1. No poverty } \\
\hline \multicolumn{2}{|l|}{$凶$ Soil sealing } & \multicolumn{2}{|c|}{$\square$ 2. Zero hunger } \\
\hline \multicolumn{2}{|l|}{$凶$ Soil contamination } & \multicolumn{2}{|c|}{$\square$ 3. Good health and well-being } \\
\hline \multicolumn{2}{|c|}{$\square$ Decline in soil organic matter (SOM) } & \multicolumn{2}{|c|}{$\square$ 4. Quality education } \\
\hline \multicolumn{2}{|l|}{$\square$ Soil compaction } & \multicolumn{2}{|c|}{$\square 5$. Gender equality } \\
\hline \multicolumn{2}{|l|}{$\square$ Desertification } & \multicolumn{2}{|c|}{$\square 6$. Clean water and sanitation } \\
\hline \multicolumn{2}{|l|}{$\square$ Flooding } & \multicolumn{2}{|c|}{$\square$ 7. Affordable and clean energy } \\
\hline \multicolumn{2}{|l|}{$\square$ Soil salinisation } & \multicolumn{2}{|c|}{$\square$ 8. Decent work and economic growth } \\
\hline \multicolumn{2}{|l|}{$\square$ Droughts } & \multicolumn{2}{|c|}{ ๑. Industry, innovation and infrastructure } \\
\hline \multicolumn{2}{|l|}{$\square$ Landslides } & \multicolumn{2}{|c|}{$\square$ 10. Reduce inequalities } \\
\hline \multicolumn{2}{|l|}{$\square$ Eutrophication } & \multicolumn{2}{|c|}{$\otimes 11$. Sustainable cities and communities } \\
\hline \multicolumn{2}{|l|}{$\square$ Soil biodiversity } & $\square$ 12. Respons & consumption and production \\
\hline$\square$ Forest fires & & $\square$ 13. Climate & \\
\hline$\square$ Soil acidification & & $\square$ 14. Life belc & ater \\
\hline$\square$ Other (please speci & & $凶 15$. Life on & \\
\hline & & $\square$ 16. Peace, j & e and strong institutions \\
\hline & & $\square$ 17. Partners & for the goals \\
\hline
\end{tabular}

References/Links/More info: 


\section{Good practice name: IPBES-Food}

\section{Country: $E U$}

$\begin{array}{ll}\text { Good practice name: } & \text { IPBES-Food } \\ \text { Type of initiative: } & \text { 冈 Policy } \\ & \square \text { Practice } \\ & \square \text { Network } \\ & \square \text { Research } \\ & \square \text { Tool / Instrument } \\ & \square \text { Methodology } \\ & \square \text { Pilot } \\ & \square \text { Other (please specify) }\end{array}$

$\begin{array}{ll}\text { Country: } & \text { EU } \\ \text { Type of land: } & \bigotimes \text { Agricultural } \\ & \square \text { Forest } \\ & \square \text { Nature } \\ & \square \text { Industrial } \\ & \square \text { Urban } \\ & \square \text { Derelict/unused }\end{array}$

Context. What is the background of the project/initiative?

IPBES food together with farmers, food entrepreneurs, civil society activists, scientists and policymakers.

What is the main purpose/objective of the initiative?

To develop a common food policy for the European Union

Short description if the initiative/project/network

Flagship initiative of the International Panel of Experts on Sustainable Food Systems (IPES-Food) that proposes a common policy based on Cross-sectoral (ensuring adequate synergies and avoiding inconsistencies between different policy areas);

- Informed by best practices found in cities and Member States;

- $\quad$ Long-term, with indicators allowing to monitor progress towards time-bound objectives;

- $\quad$ Supporting local and regional initiatives;

- Improving legitimacy and accountability in food systems, including calling for EU food policy council.

What are the main outputs and outcomes (take-home messages)?

Policy inconsistencies that hinder the development of more sustainable food policy, and misplaced incentives should be incorporated in the development of policy.

Key challenges for land in the EU include reduction of utilised agricultural area, increased concentration of land and inflation of land prices, unsustainable agricultural practices leading to various threats to soil health and pressure on water resources from nitrogen run-off and eutrophication.

\begin{tabular}{|c|c|}
\hline Soil threats addressed: & SDGs addressed: \\
\hline 凶Soil erosion & $\square$ 1. No poverty \\
\hline$\square$ Soil sealing & $凶$ 2. Zero hunger \\
\hline$凶$ Soil contamination & $\square$ 3. Good health and well-being \\
\hline$\square$ Decline in soil organic matter (SOM) & $\square$ 4. Quality education \\
\hline$\square$ Soil compaction & $\square$ 5. Gender equality \\
\hline$\square$ Desertification & $\square 6$. Clean water and sanitation \\
\hline$\square$ Flooding & $\square$ 7. Affordable and clean energy \\
\hline$\square$ Soil salinisation & $\square$ 8. Decent work and economic growth \\
\hline$\square$ Droughts & $\square 9$. Industry, innovation and infrastructure \\
\hline$\square$ Landslides & $\square$ 10. Reduce inequalities \\
\hline 凶 Eutrophication & $\square$ 11. Sustainable cities and communities \\
\hline$\otimes$ Soil biodiversity & $\square$ 12. Responsible consumption and production \\
\hline$\square$ Forest fires & $\square$ 13. Climate action \\
\hline$\square$ Soil acidification & $\square$ 14. Life below water \\
\hline \multirow{3}{*}{$\square$ Other (please specify) } & $凶 15$. Life on land \\
\hline & $\square$ 16. Peace, justice and strong institutions \\
\hline & $\square$ 17. Partnerships for the goals \\
\hline
\end{tabular}

References/Links/More info: 
Wageningen Environmental Research P.O. Box 47

6700 AA Wageningen

The Netherlands

$\mathrm{T}+31(0) 317480700$

www.wur. nl/environmental-research

Wageningen Environmental Research Report 3032

ISSN 1566-7197
The mission of Wageningen University \& Research is "To explore the potential of nature to improve the quality of life". Under the banner Wageningen University \& Research, Wageningen University and the specialised research institutes of the Wageningen Research Foundation have joined forces in contributing to finding solutions to important questions in the domain of healthy food and living environment. With its roughly 30 branches, 6,500 employees (5,500 fte) and 12,500 students, Wageningen University \& Research is one of the leading organisations in its domain. The unique Wageningen approach lies in its integrated approach to issues and the collaboration between different disciplines.

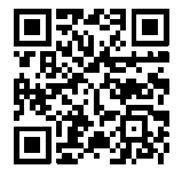





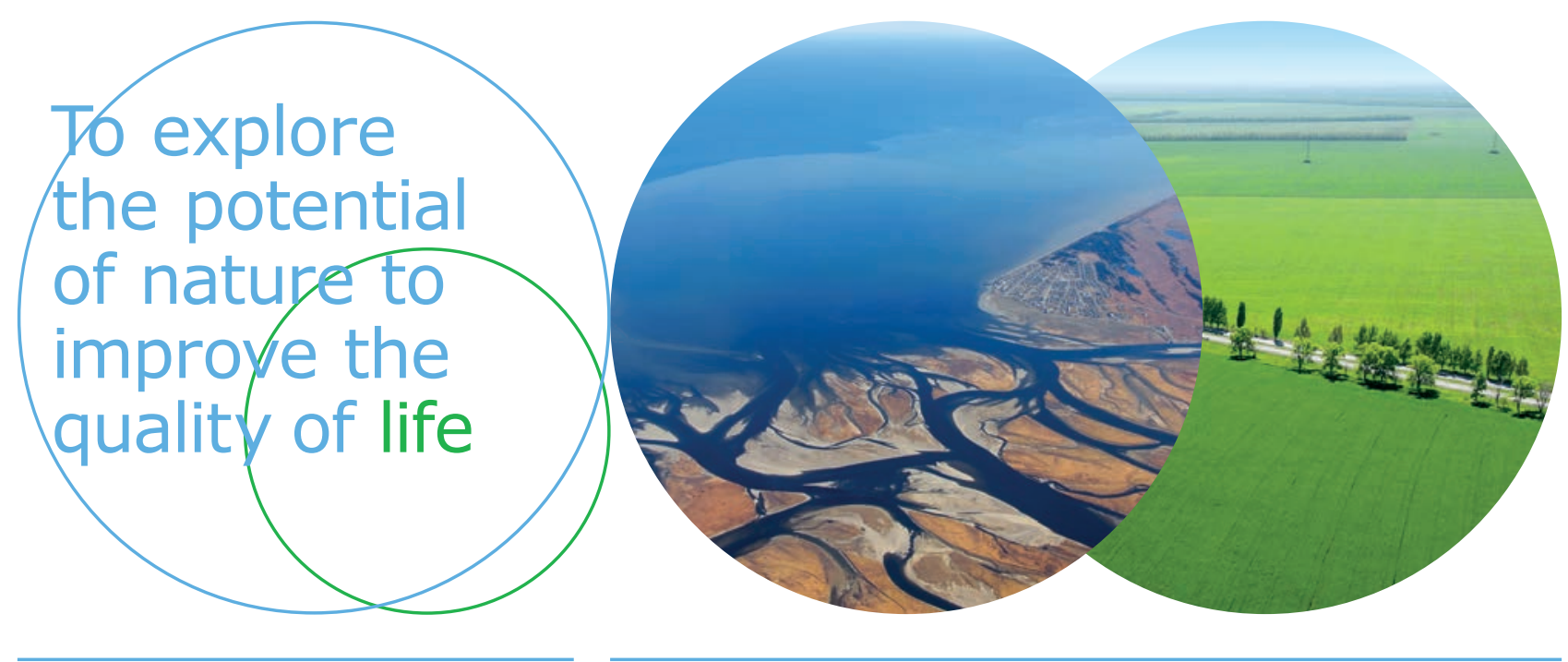

Wageningen Environmental Research P.O. Box 47

$6700 \mathrm{AB}$ Wageningen

The Netherlands

$T+31(0) 317480700$

www.wur.eu/environmental-research

Report 3032

ISSN 1566-7197
The mission of Wageningen University \& Research is "To explore the potential of nature to improve the quality of life". Under the banner Wageningen University \& Research, Wageningen University and the specialised research institutes of the Wageningen Research Foundation have joined forces in contributing to inding solutions to important questions in the domain of healthy food and living environment. With its roughly 30 branches, 6,500 employees (5,500 fte) and 12,500 students, Wageningen University \& Research is one of the leading organisations in its domain. The unique Wageningen approach lies in its integrated approach to issues and the collaboration between different disciplines. 